\title{
Cultural Resource Management Plan for Brookhaven National Laboratory
}

March - 2005

prepared by

Mark C. Davis

Environmental and Waste Management Services Division

Brookhaven National Laboratory

Operated by

Brookhaven Science Associates

Upton, NY 11973-5000 


\section{DISCLAIMER}

This report was prepared as an account of work sponsored by an agency of the United States Government. Neither the United States Government nor any agency thereof, nor any of their employees, nor any of their contractors, subcontractors or their employees, make any warranty, express or implied, or assumes any legal liability or responsibility for the accuracy, completeness, or any third party's use or the results of such use of any information, apparatus, product, or process disclosed, or represents that its use would not infringe privately owned rights.

Reference herein to any specific commercial product, process, or service by trade name, trademark, manufacturer, or otherwise, does not necessarily constitute or imply its endorsement, recommendation, or favoring by the United States Government or any agency thereof or its contractors or subcontractors. The views and opinions of authors expressed herein do not necessarily reflect those of the United States Government or any agency thereof. 


\title{
Acronyms and Abbreviations
}

\author{
ACHP Advisory Council on Historic Preservation \\ ADS Activity Data Sheet system \\ AGS Alternating Gradient Synchrotron \\ AIRFA American Indian Religious Freedom Act \\ ARPA Archeological Resource Protection Act \\ BGRR Brookhaven Graphite Research Reactor \\ BMRR Brookhaven Medical Research Reactor \\ BNL Brookhaven National Laboratory (also, "Laboratory”) \\ BSA Brookhaven Science Associates \\ CEGPA Community Education Government and Public Affairs division \\ CERCLA Comprehensive Environmental Response, Compensation and Liability Act \\ CR Cultural Resources \\ CRC Cultural Resources Coordinator \\ CRM Cultural Resource Management \\ CRMP Cultural Resource Management Plan \\ CURL Current Unfunded Requirements List \\ D\&D decontamination and decommissioning \\ DOE Department of Energy \\ DOE-BHSO Department of Energy Brookhaven Site Office \\ EIMS Environmental Information Management System \\ EMS Environmental Management System \\ ESH\&Q Environmental Safety Health and Quality Directorate \\ FY fiscal year \\ GIS Geographic Information System \\ HFBR High Flux Beam Reactor \\ ILIA Institute for Long Island Archeology \\ ISABELLE Intersecting Storage Accelerator (+ BELLE for "beauty") \\ ISO International Organization for Standardization \\ LIHJ Long Island Historic Journal \\ NAGPRA Native Americans Graves Protection and Repatriation Act \\ NFPA National Fire Protection Act \\ NHPA National Historic Preservation Act \\ NRHP National Register of Historic Places (also, "National Resister”) \\ NYAC New York Archaeological Council \\ NYSDEC New York Sate Department of Environmental Conservation \\ NYSHPO New York State Historic Preservation Officer (also, “SHPO”) \\ PAL Public Archaeology Laboratory, Inc \\ SER Site Environmental Report \\ SOP standard operating procedure \\ SPLIA Society for the Preservation of Long Island Antiquities \\ STP shovel test pit
}




\section{Contents}

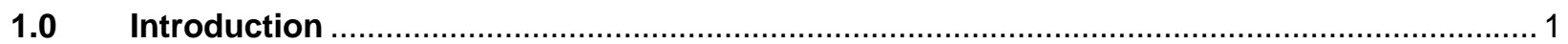

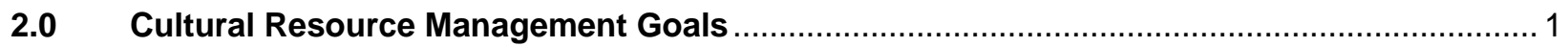

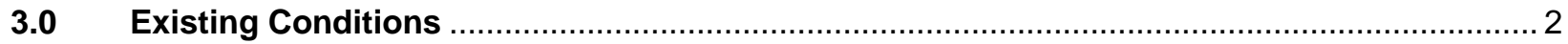

3.1 Facility and Cultural Resource Program Descriptions ............................................. 2

3.1.1 Current Physical Setting ...................................................................... 2

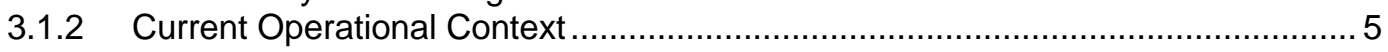

3.1.3 Potential Impacts to Cultural Resources....................................................... 6

3.1.4 Summary of Current CRM Program................................................................ 10

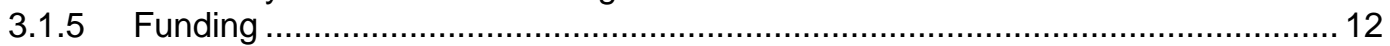

3.2 Cultural and Historic Setting (Introduction of Historic Eras)...................................... 12

3.2.1 Historic and Prehistoric Natural Environment .............................................

3.2.2 Prehistory and History.................................................................. Appendix $A$

3.2.3 Traditional Lands and Resource Uses.............................................Appendix A

3.2.4 Treaties, Executive Orders, and Land Grants ..................................Appendix A

3.2.5 Recent Scientific Significance ................................................................. 13

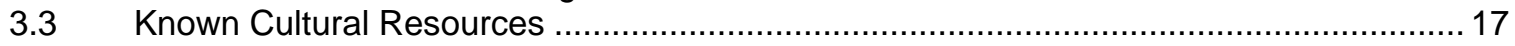

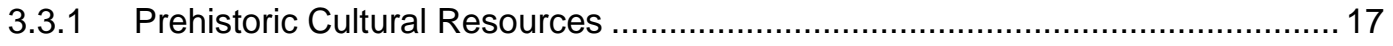

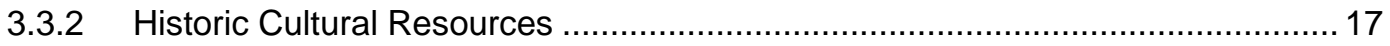

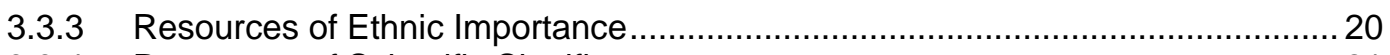

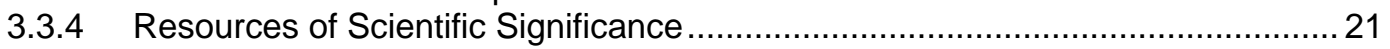

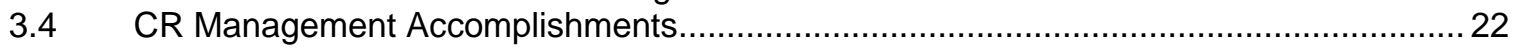

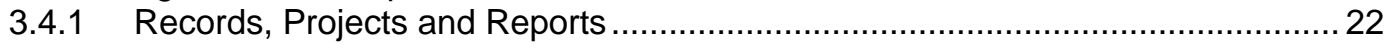

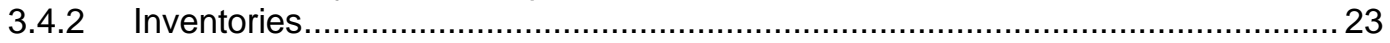

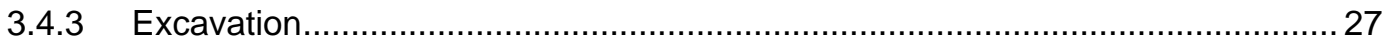

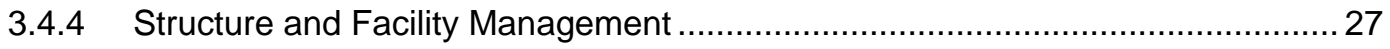

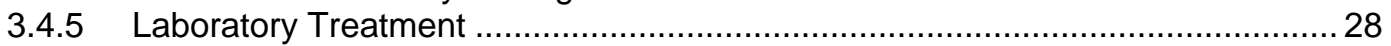

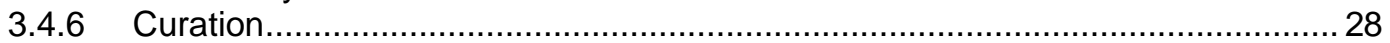

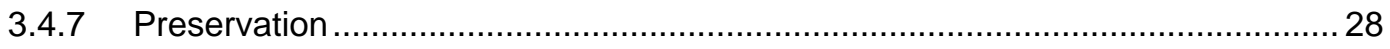

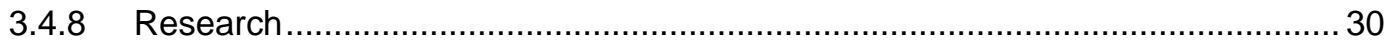

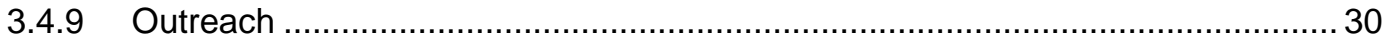

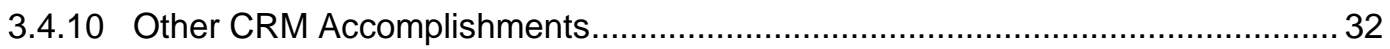

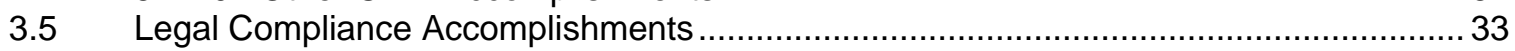

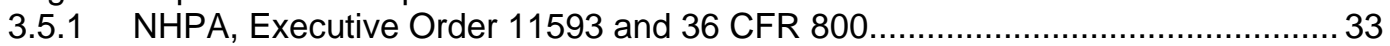

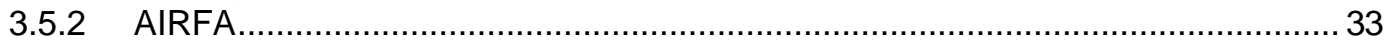

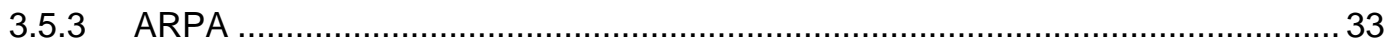

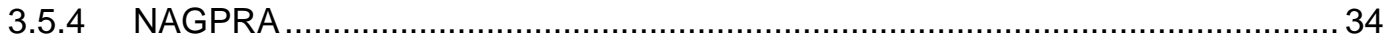

3.5.5 Curation of Federally Owned and Administered Archeological

Collections (36 CFR Part 79) ................................................................... 34

3.5.6 Executive Order 13287 Preserve America ........................................................ 36

3.5.7 Other Regulatory or Reporting Requirements ............................................ 36

4.0 Cultural Resource Management Strategies and Methods .............................................. 37

4.1 CR Management Strategies $\quad 37$

4.1.1 Management Strategy Forms …......................................................... 37

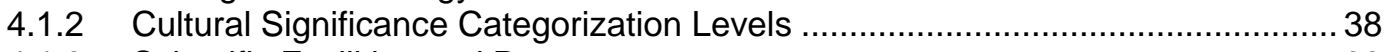

4.1.3 Scientific Facilities and Programs ................................................................ 38

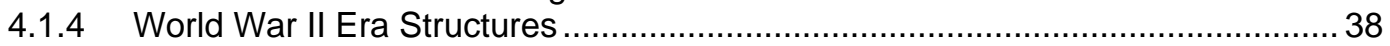

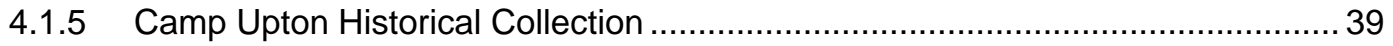

4.1.6 Document, Audio, Video and Photographic Archives ...................................... 40

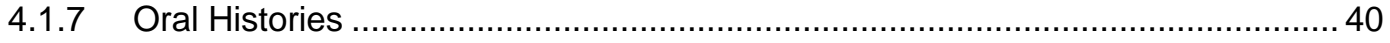

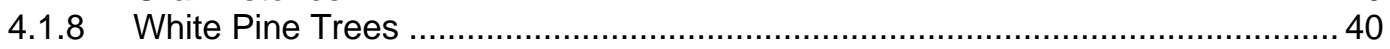

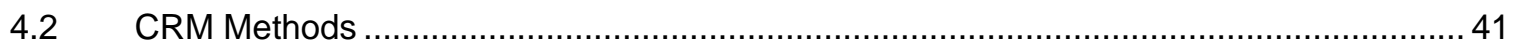

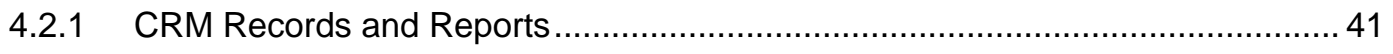


4.2.2 NHPA Section 106 Reviews …................................................................ 43

4.2.3 Process for Listing Properties on the National Register of Historic Places ................................... 43

4.2.4 Archeological Methods............................................................................ 43

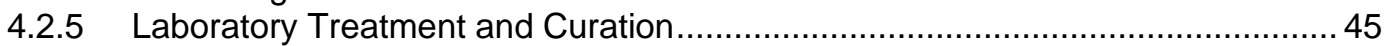

$5.0 \quad$ CR Management Procedures and Administration ........................................................... 46

$5.1 \quad$ NHPA Compliance Procedures........................................................................... 46

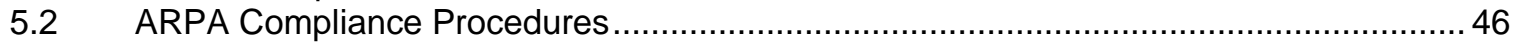

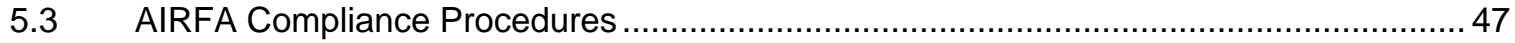

5.4 Collections Management (36 CFR Part 79) Procedures .......................................... 47

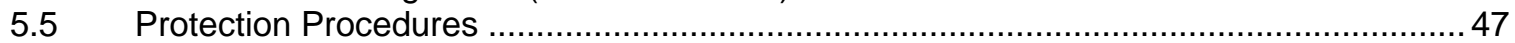

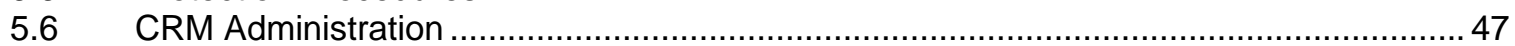

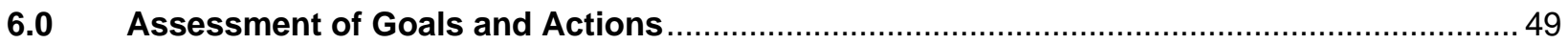

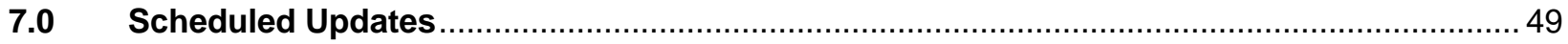

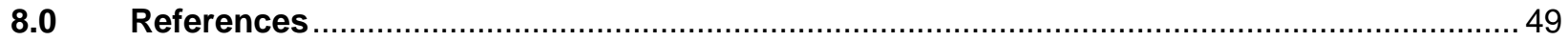

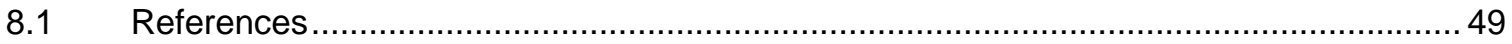

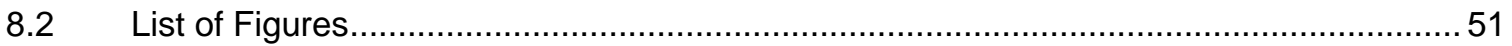

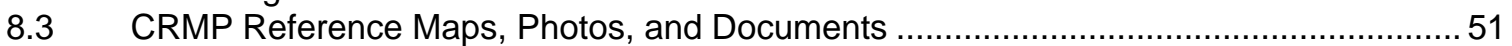

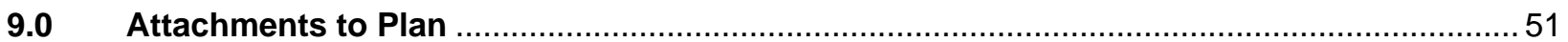

Attachment 1: Map of WW I Camp Upton

Attachment 2: Camp Upton Site Land Purchase and Lease Map (1917)

Attachment 3: WW II Camp Upton Map

Attachment 4: BNL Vegetation Map

Attachment 5: BNL Site Map Building and Roads

Attachment 6: Planned Ground Disturbing Activities

Attachment 7: Known Cultural Resources

Attachment 8: Map of Cultural Resource Areas, Structures, Sites, and Buildings (Limited

Distribution)

Attachment 9: Cultural Resource Projects

Attachment 10: NHPA Section 106 Reviews - performed after 2003

Attachment 11: Location of Buildings Reviewed Under NHPA Section 106

Attachment 12: Archeological Survey Areas

Attachment 13: Cultural Resource Outreach Activities

Attachment 14: CR Management Strategy Form

Attachment 15: Cultural Resource Management Strategy Groups

Attachment 16: Archeological Site Numbers

Attachment 17: New York State Prehistoric Archeological Site Inventory Form

Attachment 18: New York State Historic Archeological Site Inventory Form

Attachment 19: BNL Trench Feature Inventory Form

Attachment 20: BNL Foundation Feature Inventory Form

Attachment 21: Cultural Resources Accession Receiving Report Forms

Attachment 22: Camp Upton Historical Collection - Accession Record Form

Attachment 23: Camp Upton Historical Collection - Cataloging Worksheet Form

Attachment 24: Shovel Test Pit Record

Attachment 25: Excavation Records Form

Attachment 26: Feature Record Form

Attachment 27: BNL SBMS subject area National Environmental Policy Act (NEPA) and Cultural Resource Reviews

Attachment 28: RC-SOP-501 Project Reviews For Potential Impact to Cultural Resources

Attachment 29: RC-SOP-500 BNL Historical Resource Identification Tag Program

Attachment 30: Application for a Federal Permit under the Archeological Resources Protection Act

Attachment 31: Division Organization Chart 
Attachment 32: Resume and R2A2 for the Natural and Cultural Resources Manager

Attachment 33: Resume and R2A2 for the Cultural Resources Coordinator

Attachment 34: Archeologically Sensitive Areas

Attachment 35: Oral History Interviews

Attachment 36: BNL Oral History Program - Overview and Planning Document

Attachment 37: Memorandum of Agreement (MOA) - Brookhaven Graphite Research Reactor

\subsection{Appendices}

A Cultural Resources Inventory Including Archival Search, Prehistoric and Historic Period Contexts, and Archeology Sensitivity Assessment ...

B Cultural Significance Categories Table

C Cultural Resource Management Strategy Forms

D $\quad$ CRMP - Action Items

\section{List of Figures}

Figure 3.1-1 BNL Site Map indicating Upton Ecological and Research Reserve ........................... 3

Figure 3.1-2 Major BNL Scientific Facilities......................................................................... 7

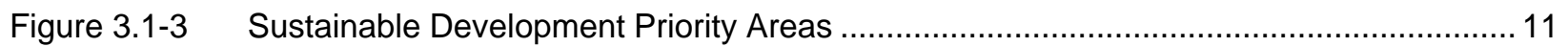

Figure 3.3-1 Stone Foundation Wall, Weeks Campbell .............................................................. 18

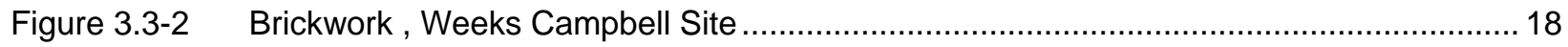

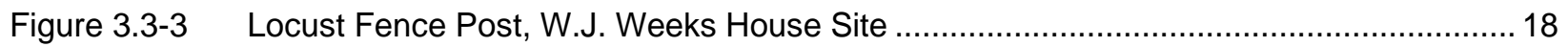

Figure 3.3-4 Foundation Stones, W.J. Weeks House Site .............................................................. 18

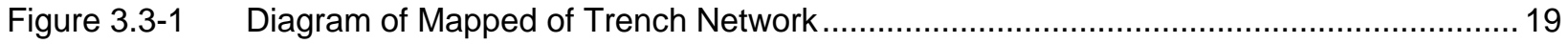

Figure 3.3-2 Photo of an Extant WW I Training Trench (2002) .................................................. 19

Figure 4.2-1 Areas of Substantial Ground Disturbance ................................................................ 45 


\section{$1.0 \quad$ INTRODUCTION}

The Cultural Resource Management Plan (CRMP) for Brookhaven National Laboratory (BNL) provides an organized guide that describes or references all facets and interrelationships of cultural resources at BNL. This document specifically follows, where applicable, the format of the U.S. Department of Energy (DOE) Environmental Guidelines for Development of Cultural Resource Management Plans, DOE G 450.1-3 (9-22-04[m1]).

Management strategies included within this CRMP are designed to adequately identify the cultural resources that BNL and DOE consider significant and to acknowledge associated management actions. A principal objective of the CRMP is to reduce the need for additional regulatory documents and to serve as the basis for a formal agreement between the DOE and the New York State Historic Preservation Officer (NYSHPO).

The BNL CRMP is designed to be a "living document." Each section includes identified gaps in the management plan, with proposed goals and actions for addressing each gap. The plan will be periodically revised to incorporate new documentation.

Historically, Brookhaven National Laboratory had little need for cultural resource management because many of its buildings were less than 50 years old. Most of the features that are potentially eligible for inclusion in the National Register of Historic Places were protected simply by avoiding the features. Compliance with cultural resource laws and regulations has included archeological surveys, such as those associated with the 1977 Final Environmental Impact Statement for Brookhaven National Laboratory and the 1978 Final Environmental Impact Statement for the Proton-Proton Storage Accelerator Facility (ISABELLE). In 1979, World War I trenches associated with the former Camp Upton and located near ISABELLE were determined to be eligible for inclusion in the National Register of Historic Places; however, many of these trenches had been destroyed by construction work. In 1991, the NYSHPO provided BNL with a letter indicating that only three structures and features were likely to be eligible for inclusion in the National Register of Historic Places. Between 1991 and 1999, little work associated with cultural resource management was accomplished. Beginning in 1999, awareness for the need of a program to manage cultural resources grew out of the realization that over half of the buildings at BNL were either 50 years old or were reaching that age and were, therefore, subject to the requirements in Section 106 of the National Historic Preservation Act. This fact, concomitant with the decontamination and decommissioning of the Brookhaven Graphite Research Reactor (BGRR) and the subsequent determination of BGRR's eligibility for listing as an historical site, fueled the need for developing and implementing a more structured program for managing cultural resources at BNL.

\subsection{CULTURAL RESOURCE MANAGEMENT GOALS}

The BNL Cultural Resource Management Program is being developed to achieve the following goals:

- Maintain regulatory compliance.

- Identify and document all facets of BNL's cultural resources.

- Ensure that stewardship responsibilities are met.

- Increase recognition and availability for public and research interpretation.

One of the major goals of the CRM program is to fully assess both known and potential cultural resources. The range of BNL cultural resources includes buildings and structures, WW I earthwork features, the Camp Upton Historical Collection, scientific equipment, photo archives, and institutional 
records (plan drawings, public relations archives, etc.). Everything will be assessed, from potential prehistoric and historic Native American sites, through the site's development during the twentieth century. Identifying cultural resources associated with each of these eras is essential to ensure that the history of BNL and the BNL site is complete and available for future interpretation.

As various cultural resources are identified, plans for their long-term stewardship will be developed and implemented. Responsibility for stewardship includes maintenance, mitigation, preservation, and protection issues. Stewardship actions may include: formally identifying artifacts; documenting and designating responsibility for historical assets such as documents, photos, and tapes; protecting items ranging from earthwork features, to scientific equipment; maintaining significant building features; and curating historical collections.

Few individuals working at BNL, or local community members, are fully aware of the history of the BNL site. Another primary goal of the CRM program is to present opportunities to inform both the internal and external communities. Potential avenues for new outreach include, but are not limited to: establishing a cultural resources website, developing historic features tours, pamphlets, and videos, and making presentations to various community gatherings.

Achieving these goals will ensure that the contributions BNL science and the BNL site have made to our history and culture are documented and available for interpretation. The information presented in the subsequent sections of the Cultural Resource Management Plan provides the roadmap toward achieving these goals.

\subsection{EXISTING CONDITIONS}

This section of the CRMP contains an overview of BNL's past accomplishments and existing conditions related to cultural resources. Descriptions of the facility's natural setting and operational context are provided, along with the cultural/historical context and known cultural resources. Programmatic and regulatory aspects are also addressed. The objective of this section is to present details of BNL's history, current operations, management, and compliance programs, in order to provide an accurate perspective on how cultural resource management issues have evolved.

\subsection{FACILITY AND CULTURAL RESOURCE PROGRAM DESCRIPTIONS}

Note: The information presented in Sections 3.1.1 and 3.1.2 was extracted from the 2003 BNL Site Environmental Report (BNL 2004). The SER contains maps, photos, and the original references used to develop this information.

\subsubsection{Current Physical Setting}

Brookhaven National Laboratory is located near the geographical center of Suffolk County, Long Island, New York. BNL is in Brookhaven Township, about 60 miles east of New York City. Most of BNL's principle facilities are located near the center of the 5,265-acre (8.23 square mile) site. The developed area encompasses approximately 1,650 acres, consisting of:

- 500 acres originally developed by the Army (as part of WW II Camp Upton) and still used for offices and other operational buildings.

- 200 acres occupied by large, specialized research facilities.

- 550 acres occupied by outlying facilities, such as the Sewage Treatment Plant, research agricultural fields, housing facilities, and fire breaks.

- 400 acres of roads, parking lots, and connecting areas.

The balance of the site, approximately 3,600 acres, is largely wooded and represents a native pine barrens ecosystem. In November 2000, DOE set aside 530 acres of the undeveloped land at BNL as the Upton 
Ecological and Research Reserve (see Figure 3.1-1). The Upton Reserve preserves this portion of the pine barrens ecosystem and provides an area for ecological research and education activities. Note: The white areas within Figure 3.1-1 map indicate developed or cleared areas of the BNL site.

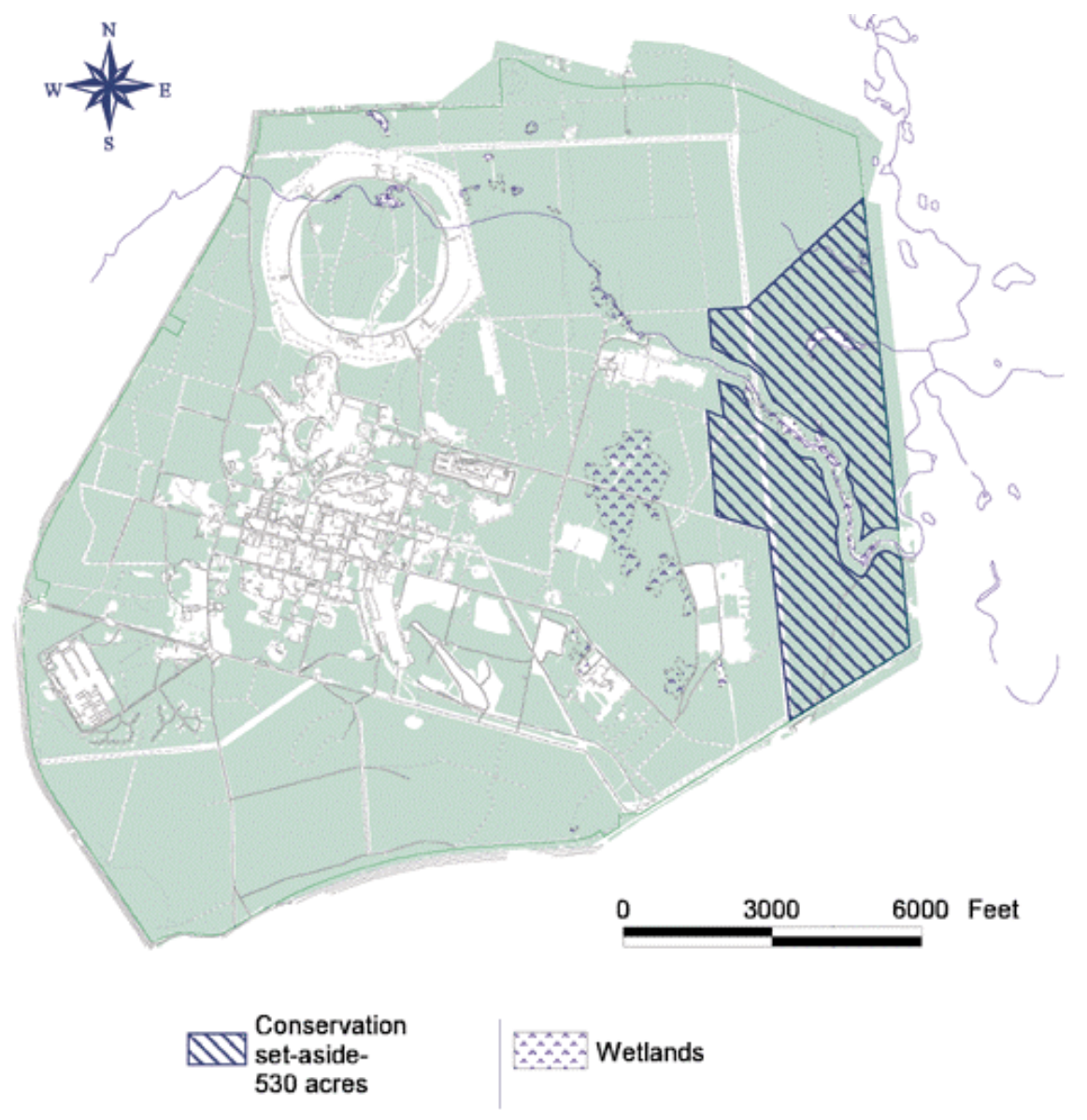

Figure 3.1-1 Map of the Reserve Area

3.1.1.1 Geology and Hydrology\{tc "1.5 Geology and Hydrology "\}. BNL lies on the western rim of the shallow Peconic River watershed. The marshy areas in the northern and eastern sections of the site are part of the headwaters of the Peconic River. Depending on the position of the water table relative to the base of the riverbed, the Peconic River both recharges to, and receives water from, the sole source aquifer system below Long Island. In times of sustained drought, the river water typically recharges to the groundwater. When precipitation is normal to above normal, the river receives water from the groundwater.

In general, the terrain of the site is gently rolling, with elevations varying between 44 and 120 feet above sea level. Depth to groundwater from the surface of the land ranges from 5 feet near the Peconic River to about 80 feet in the higher areas in the central and western portions of the site. Studies of Long Island hydrology and geology in the vicinity of the Laboratory indicate that the uppermost Pleistocene deposits, composed of highly permeable glacial sands and gravel, are between 120 and 250 feet thick (BNL 2004). Water penetrates these deposits readily and there is little direct runoff into surface streams unless precipitation is intense. These sandy deposits store large quantities of water called the Upper Glacial Aquifer. On average, about half of the annual precipitation is lost to the atmosphere through evapotranspiration, and the other half percolates through the soil to recharge the groundwater (BNL 2004). The area has a high recharge rate (22 inches per year) that varies seasonally. Groundwater flow direction across the BNL site is influenced by natural drainage systems moving eastward along the 
Peconic River, southeast toward the Forge River, and south toward the Carmans River. Pumping from onsite water supply wells impacts the direction and speed of groundwater flow, especially in the central, developed areas of the site. Two natural groundwater divides have been identified near BNL (BNL 2004). One divide is located approximately one-half mile north of BNL and a second divide transects portions of the site when the water table is high and the aquifer flows into the streambed of the Peconic River. These divides define the boundaries of the area contributing groundwater to the Peconic River watershed. In most areas at BNL, the horizontal velocity of groundwater is approximately 0.75 to 1.2 feet per day (BNL 2004). In general terms, groundwater takes approximately 20 to 22 years to travel from the central, developed area of the site to the BNL southern boundary.

3.1.1.2 Climatic Data. The Meteorological Group at Brookhaven National Laboratory has collected meteorological data on site since 1949. The Site Environmental Report(BNL 2004) contains figures such as the annual wind rose for BNL and graphs comparing annual precipitation and temperature data with additional historic climatic data.

The prevailing ground-level winds at BNL are from the southwest during the summer, from the northwest during the winter, and about equally from these two directions during the spring and fall (BNL 2004).

The average annual precipitation for BNL is approximately 48.36 inches. Although the summer of 2002 was mostly dry, the total precipitation of 52.07 inches was above average, due to more rainfall than usual from September through December. The overall average temperature on site over the past 50 years is $50.1^{\circ} \mathrm{F} .(\mathrm{BNL} 2004)$

3.1.1.3 Ecological Resources\{tc "1.7 Ecological Resources"\}. BNL is located in the oak/chestnut forest region of the Coastal Plain. BNL property constitutes about 5 percent of the 100,000-acre New York State designated region known as the Central Pine Barrens. Additionally, the Peconic River running through BNL's property was designated "scenic" by the New York State Wild, Scenic, and Recreational River System Act. As noted before, because of the general topography and porous soil, the land is very well drained and generally there is little surface runoff or open standing water. However, depressions form small pocket wetlands with standing water on a seasonal basis (vernal pools), and there are six significant regulated wetlands on site. Thus, a mosaic of wet and dry areas on the site correlates with variations in topography and depth to the water table. Vegetation onsite is in various stages of succession, which reflects a history of disturbances to the area. The past disturbances with the most impact were tree clearcutting (the land was cleared extensively prior to 1947 when the site was Camp Upton), fire, local flooding, and draining.

More than 230 plant species have been identified on site. The 15 mammal species endemic to the site include species common to mixed hardwood forests and open grassland habitats. The white-tailed deer density is upwards of 250 per square mile. This compares to the 100 per square mile estimated in 1992. At least 85 species of birds are known to nest at BNL, and an additional 130 species have been documented as "visiting" the site. These numbers are a result of BNL's location within the Atlantic Flyway and the scrub/shrub habitats that offer food and rest to migratory songbirds. Open fields bordered by hardwood forests at the recreation complex are excellent hunting areas for hawks. Permanently flooded retention basins and other watercourses support amphibians and aquatic reptiles. Nine amphibian and ten reptile species have been identified, as well as nine species of fish.

Ecological studies at the BNL site have confirmed 14 breeding sites for the New York State endangered eastern tiger salamander (Ambystoma tigrinum tigrinum) in vernal pools and some recharge basins. The New York Sate Department of Environmental Conservation (NYSDEC) listed the banded sunfish (Eanneacanthus obesus) as a state threatened species in 1999. It lives solely within the Peconic River system, including backwater areas of the river onsite (Scheibel 1990). In 2000, the New York Statethreatened swamp darter (Etheostoma fusiforme) was located in one of the larger ponds associated with the Peconic River. One New York State threatened plant is found on site: the stiff goldenrod (Solidago rigida). 
As mentioned earlier, the Upton Ecological and Research Reserve was established to preserve a section of the Central Pine Barrens, a unique ecosystem of forests and wetlands on Long Island. At 530 acres, the Upton Ecological and Research Reserve sets aside 10 percent of BNL property for conservation and ecological research. This area provides habitat for approximately 27 endangered, threatened, or species of special concern, including the endangered eastern tiger salamander and the state-threatened banded sunfish and swamp darter. Other wildlife species of interest that inhabit this area include the wild turkey, red fox, eastern box turtle, and the red-tailed hawk. More information about the Reserve and the plants and animals it protects can be found in Chapter 6 of the 2003 SER (BNL 2004) or the Reserve website, accessible from the BNL website www.bnl.gov.

\subsubsection{Current Operational Context}

Brookhaven Science Associates, LLC (BSA) operates BNL for the Department of Energy. BSA is a notfor-profit partnership of the Battelle Memorial Institute and the Research Foundation of the State University of New York on behalf of the State University of New York at Stony Brook. BSA began operating the Laboratory on March 1, 1998 through an agreement with DOE (Contract No. DE-AC0298CH10886). Approximately 2,700 resident scientists and support staff work at BNL. In addition, more than 4,000 academic and industrial researchers from all over the world visit the site each year to participate in scientific collaborations.

BNL's broad mission is to produce excellent science and advanced technology in a safe, environmentally responsible manner with the cooperation, support, and appropriate involvement of the community. Specifically, the elements of the BNL mission are to:

- Conceive, design, construct, and operate complex, leading-edge, user-oriented facilities in a safe and environmentally benign manner that is responsive not only to DOE, but also to the needs of the users.

- Carry out basic and applied research in long-term programs at the frontier of science that supports DOE missions and the needs of the Laboratory's user community.

- Develop advanced technologies that address national needs, and initiate their transfer to other organizations and to the commercial sector.

- Disseminate technical knowledge to educate new generations of scientists and engineers, to maintain technical currency in the nation's workforce, and to encourage scientific awareness in the general public.

BNL's early research focused on advanced physics, specifically nuclear research in the fields of medicine, biology, chemistry, physics, and nuclear engineering; but it has since expanded into chemistry, materials science, biology, medicine, and environmental research. The Laboratory's large and unique scientific user facilities make this research possible, providing the tools for BNL scientists and visiting researchers to extend the boundaries of knowledge and technology. Brookhaven's newest accelerator facility, the Relativistic Heavy Ion Collider (RHIC) began operations in 2000. The RHIC is designed to recreate a state of matter that scientists believe existed moments after the universe was formed.

Unfortunately, historical operations and waste management practices at the Laboratory led to releases of chemicals and radioactive materials that resulted in soil and groundwater contamination. In 1989, BNL was added to the National Priorities List of environmentally contaminated sites established by the federal Comprehensive Environmental Response, Compensation and Liability Act (CERCLA), and was identified for priority cleanup. BNL has made significant progress toward improving environmental operations and remediation of past contamination. In 2001, BNL's Environmental Management System (EMS) was registered by an independent, accredited organization to the International Organization for Standardization (ISO) 14001 environmental management standard. BNL's Environmental Stewardship Policy can be reviewed at the following website link:

http://www.bnl.gov/bnlweb/stewardship.htm 
The major scientific facilities at BNL are shown and briefly described in Figure 3.1-2. In addition to the scientific facilities, the location of other facilities supporting BNL's science and technology mission are identified in the Site Environmental Report.

\subsubsection{Potential Impacts to Cultural Resources}

3.1.3.1 Past Practices. Although the property was essentially undeveloped before 1918, the BNL site has experienced numerous ground-disturbing and building demolition events since its initial development by the U.S. Army in 1917 as Camp Upton.

Pre-Camp Upton. Prior to the establishment of Camp Upton, the land was used as source of wood for the local cordwood industry. A small section, located in the southeast part of the property, was also farmed in the 1800s, and included at least two houses.

Camp Upton 1917 -1919. The initial construction of Camp Upton required the clearing of approximately 1,400 acres of pine and oak forest. Roads were established and railroad spurs into the site were developed along the south boundary. Additional excavation actions included establishing water supply and wastewater conveyance piping, a sewage treatment plant, a landfill, target shooting ranges, several areas of warfare training trenches, and a network of ditches to drain the wetland areas as a means of mosquito control. More than 1,700 buildings were constructed as part of the Army camp (see Attachment $1-1917$ Map of WW I Camp Upton). Following the government's decision to abandon the camp, all of the transportable items, including lumber from buildings, planks that lined the training trenches, and (in some cases) entire buildings, were sold at auction in 1921 and removed from the site (Army 1921). Attachment 2 provides land purchase and lease information from 1917.

Civilian Conservation Corps (CCC) 1934 - 1939. Although few details of CCC activities are known at this time, it is understood that their projects involved constructing two separate groupings of buildings, foresting many areas on site by planting eastern white pines, and establishing fire breaks, most of which remain today. The following aerial photographs and map provide information on the CCC's impact on the BNL site.

- CRMP Reference Document \#1 - Site Aerial Photograph Post WW I Pre-Fire Breaks (circa 1932)

- CRMP Reference Document \#2 - Site Aerial Photograph Showing Fire Breaks (circa 1938)

- CRMP Reference Document \#7 -- CCC Plantings Map of Camp Upton Site (1934)

Note: The reference documents identified above are not included within this Plan, but are available through the Cultural Resource Coordinator.

Camp Upton 1940-1946. Reestablishing Camp Upton for WW II involved clearing many of the CCC tree plantings. Construction for the developed portion of the camp would likely have destroyed ground-based feature remnants from the main WW I camp area. However, because the WW II camp served as an induction and rehabilitation center, the footprint of development was somewhat less than during WW I Camp Upton. Some foundations and other evidence of WW I Camp Upton, therefore, have remained. Along with building and road construction activities, excavation actions undertaken during the WW II period included trenching for water and sewer piping, and establishing a landfill (see Reference Attachment 3 - 1944 WW II Camp Upton Map).

BNL 1947-present. Brookhaven National Laboratory has utilized many of the original WW II Camp Upton buildings and other facilities, including roads, railroad lines, firebreaks, and landfills. Several buildings were relocated and/or joined together to form larger structures. While many WW II-era structures have been replaced as part of ongoing development at BNL, more than 50 of the original camp buildings are still in use today. Major ground disturbing actions have included construction of the major science and support facilities described in Section 3.1.2, and associated utility (water, electric, communications, etc.) 


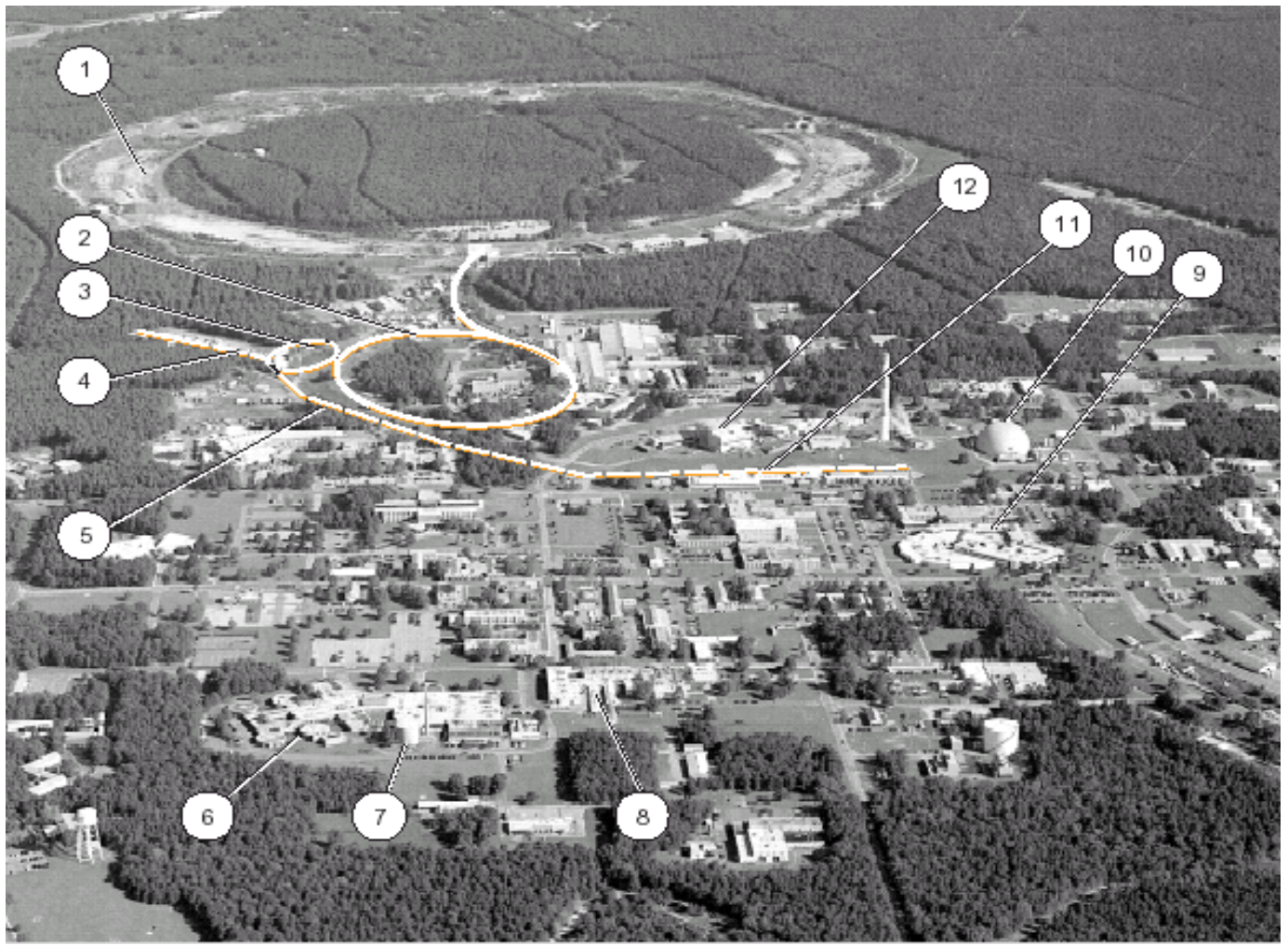

Figure 3.1-2 Major BNL Science Facilities

1. Relativistic Heavy lon Collider (RHIC) RHIC is one of the world's largest and most powerful accelerators. RHIC's main physics mission is to study particles smaller than atoms.

2. Alternating Gradient Synchrotron (AGS) The AGS is used for high-energy physics research. It accelerates protons to energies up to $30 \mathrm{GeV}$, and heavy-ion beams to $15 \mathrm{GeV}$.

3. AGS Booster The AGS Booster is a circular accelerator, 200 meters in circumference, that receives either a proton beam from the Linac, or heavy ions from the Tandem Ban de Graaff. The AGS Booster accelerates proton particles and heavy ions before injecting them into the AGS ring. This facility became operational in 1992.

4. Linear Accelerator (LINAC) and Brookhaven Linac Isotope Producer (BLIP) The Linac provides beams of polarized protons for the AGS and for the RHIC. BLIP utilizes the excess beam capacity of the Linac to produce radioisotopes used in research and medical imaging. It is one of the key production facilities in the nation for radioisotopes, which are crucial to clinical nuclear medicine. It also supports research on new diagnostic and therapeutic radiopharmaceuticals.

5. Heavy Ion Transfer Line (HITL) The HITL connects the Tandem Van de Graaff and the AGS Booster. This interconnection permits ions of intermediate mass to be injected into the AGS, where they can be accelerated to an energy of 15 $\mathrm{GeV}$. These ions then are extracted and sent to the AGS experimental area for physics research.

6. Radiation Therapy Facility (RTF) Part of the Medical Research Center, the RTF is a high-energy dual x-ray mode linear accelerator for radiation therapy of cancer patients. This accelerator delivers therapeutically useful beams of $x$-rays and electrons for advanced medical radiotherapy techniques.
7. Brookhaven Medical Research Reactor (BMRR) The BMRR was the world's first nuclear reactor built exclusively for medical research and therapy. It produced neutrons for experimental treatment of a brain cancer known as glioblastoma multiforme. This reactor stopped operating in December 2000.

\section{Scanning Transmission Electron Microscope (STEM)} This facility includes two microscopes that are used for biological research. Both devices allow scientists to see the intricate details of living things, from bacteria to human tissue.

9. National Synchrotron Light Source (NSLS) The NSLS has two electron storage rings which operate at energies of 750 $\mathrm{MeV}$ vacuum ultraviolet (VUV) and $2.5 \mathrm{GeV}$ (x-ray). The synchrotron radiation produced by the stored electrons is used for VUV spectroscopy and x-ray diffraction studies.

10. High Flux Beam Reactor (HFBR) The HFBR was one of the premier neutron physics research facilities in the world. Neutron beams produced at the HFBR were used to investigate the molecular structure of materials, which aided in pharmaceutical design and materials development as well as expanded the knowledge base of physics, chemistry, and biology. A leak in the fuel storage pool was discovered in 1997. The HFBR was permanently shut down in November 1999.

\section{Tandem Van de Graaff and Cyclotron These two} facilities are used in medium-energy physics investigations and for producing special nuclides. The heavy ions from the Tandem Van de Graaf also can be injected into the AGS Booster for physics experiments.

12. Brookhaven Graphite Research Reactor (BGRR) No longer in operation, the BGRR was used for scientific exploration in the fields of medicine, biology, chemistry, physics, and nuclear engineering. 
infrastructure. Additional actions include the development of an additional landfill, and environmental remediation activities such as access ways, well drilling, and soil removal. Although some Camp Upton artifacts have been recovered during excavation activities, the highly developed areas of BNL are unlikely to yield any substantial below-ground cultural resources.

Construction of the Proton-Proton Storage Accelerator Facility (ISABELLE) in 1979 (now the site of the RHIC) destroyed some Camp Upton WW II trenches and features. The trenches were determined to be eligible for inclusion in the National Register of Historic Places.

3.1.3.2 Information Management Tools. The following systems/tools are used to document and track land use activities.

Environmental Information Management System. The Environmental Information Management System (EIMS) maintains a Geographic Information System (GIS) website for internet mapping tools. The GIS tools support BNL environmental programs by creating and maintaining geospatial information about BNL and its environmental surveillance, compliance, and remediation efforts. The following tools are available through the intranet to assist internal personnel in these efforts: Well Logs Tool; Buildings and Roads Map; Download Shapefiles; and Map Request Form. Detailed descriptions of these tools are available on the EIMS GIS Tools website http://eimsdev.oer.bnl.gov/gis/index.htm

Environmental Remediation mapping website. This website (http://www.bnl.gov/erd/general/maps.html) contains several maps identifying specific areas where environmental restoration activities are in progress.

Historical Site Review Report (1993). This report describes records (drawings, photos, files, interviews) that were reviewed to identify areas with the potential to become areas of environmental concern. Tables identifying historical ground disturbances are provided, along with their locations on BNL site grid maps.

Plant Engineering Job Database. The Plant Engineering Division maintains a database of all their work activities by building number and job number.

Plant Engineering Microfilm Index. The Plant Engineering Division maintains a microfilm index of more than 15,000 facility engineering drawings organized by building number, job number, title, and date. The types of drawings included in the index are plot plans, site plans, floor plans, and Utilities, Details and General Construction plans.

Camp Upton Drawings (microfilm and hardcopy). The Plant Engineering Division maintains an inventory of more than 200 microfilmed and hardcopy drawings from WW II Camp Upton.

Plant Engineering Active Drawings. The types of drawings include: plot plans, site plans, floor plans, and Utilities, Details, and General Construction plans. These drawings are stored electronically (Autocad) and are available in categorical layers (examples: individual mechanical utilities, buildings, roadways, etc.).

Miscellaneous drawings, maps, photos. The following items are also useful in identifying past and current land use actions:

- BNL Vegetation Map (Attachment \#4). This map is based on examination of a spring 2001 aerial photograph, and follows the National Vegetation Standard. Produced for BNL, the map is color coded to indicate the various types of vegetation currently found around the BNL site and is especially useful for identifying areas containing white pines. The map also indicates land uses such as buildings, parking lots, roads, disturbed areas, and grass.

- BNL Site Map Building and Roads (Attachment \#5). This map identifies all existing buildings, structures, and roads.

- World War I Camp Upton Map Overlaying Current BNL Site Map (CRMP Ref. Doc. \#3). The WW I map was geo-referenced to create an electronic map layer. The WW I layer was electronically superimposed over the current BNL site buildings and roads map. The extent of the WW I Camp footprint can now be easily compared with specific locations. 
- World War II Camp Upton Map Overlaying Current BNL Site Map (CRMP Ref. Doc. \#4). The WW II camp map was geo-referenced to create a separate electronic map layer. The WW II layer was electronically superimposed over the current BNL site buildings and roads map. The extent of the WW II Camp footprint can now be easily compared with specific locations.

- WW I Camp Upton Map Overlaying 2001 Aerial Photo of BNL Site (CRMP Ref. Doc. \#5).

- WW I Camp Upton Map Overlaying 1934 Aerial Photo of BNL Site (CRMP Ref. Doc. \#6)

- Civilian Conservation Corp Plantings Map of Camp Upton Site (1934) - (CRMP Ref. Doc. \#7)

Goal. Continue to develop geo-referenced map layers of pre-BNL photos and maps (nineteenth-century map layers, WW I Camp Upton, CCC, WW II Camp Upton), and other historic aerial photos, as necessary. These layers can then be used to identify and compare land use actions on specific areas, and track changes over time.

3.1.3.3 Planned Ground-Disturbing Activities. The following documents and tools describe BNL's planned ground-disturbing activities.

Site Master Plan 2000. The Site Master Plan (available at the following web address:

http://epweb.pe.bnl.gov/infrastructure/masterplan/index.htm), issued in September 2000, provides a template for near (5-year) and long-term (10- and 20-year) decisions needed to address site and facilities issues. The plan includes proposed land uses on a broad scale, as well as plans for specific facilities. A hardcopy of this document is available to the CR Coordinator. Figure 3.1-3, Sustainable Development Priority Areas (obtained from the Site Master Plan), identifies prioritized development zones for the BNL site.

The BNL Institutional Plan. Each year BNL develops an Institutional Plan describing planned actions for the next 5 years. These documents are available at the following website address:

http://www.bnl.gov/bnlweb/Admin/instplan.html.

The ESHI Management Plan. The Environment Safety Health and Infrastructure Management Plan, developed by the Plant Engineering (PE) Infrastructure Group, identifies prioritized projects and programs that BNL would like to accomplish. From this plan the Current Unfunded Requirements List (CURL) is produced and available on the PE Infrastructure Group's web page. Shaded sections of the CURL table indicate those projects that are currently funded. The CR Coordinator receives copies of the following documents that identify funded projects for the current year. These documents will remain available for reference with the CR Coordinator. Examples of FY Project Funding Tables and Documents:

- FY GPP Construction Program Funding Authorization Sheet

- FY Operating Funded (Special Maintenance) Program Funding Authorization Sheet

- ES\&H Commitment Affirmation Letter (Dir. Office to DOE-BHSO)

NEPA Database. The NEPA and Cultural Resources Coordinator maintains a Microsoft Access database of all projects submitted for NEPA (National Environmental Policy Act) review. This database presents a list of the most current items planned for near term implementation.

Based on the planning documents identified above and project NEPA reviews performed by the NEPA/Cultural Resources Coordinator, Attachment 6 summarizes planned ground disturbing activities. This attachment will be revised and replaced each year, with obsolete copies filed by the CRC.

3.1.3.4 Integration with Natural Resource Management Plan. The BNL Natural Resources Management Plan addresses issues having the potential to affect cultural resources, such as: prescribed fire, fire suppression, and forest thinning (white pines). Therefore, cultural resource considerations must be integrated into the planning of these natural resources management actions.

Goal. Fully integrate knowledge about cultural resources into natural resource planning through the use of GIS and other documentation of the locations of cultural resources. 
Actions

- Develop GIS layers for cultural resources. The Natural and Cultural Resources Manager will utilize these layers and other pertinent documentation in the planning of natural resource management actions.

- Include planning of pre- and post-cultural resource surveys in prescribed fire areas.

\subsubsection{Summary of Current CRM Program}

BNL established a formal Cultural Resource Management program in 1999, under the responsibility of the Environmental Services program. Cultural resource management staff consists of two individuals, a Cultural Resource Manager and a Cultural Resource Coordinator. These individuals devote approximately one-third of their duties to cultural resource management.

The primary function of the CRM staff is to identify applicable regulatory requirements, develop appropriate plans and procedures, and integrate these into applicable BNL processes. The program is designed to interact with all aspects of the Laboratory that have the potential to affect cultural resources.

BNL Standards Based Management System procedure "NEPA and Cultural Resource Evaluations” is the primary means of initiating CRM reviews of BNL projects. This procedure describes the protocol requiring formal evaluation of projects for environmental and cultural resource concerns. When a project/proposal is received for review under NEPA, the NEPA/Cultural Resources Coordinator evaluates the action for potential cultural resource implications. Additional procedures and methods utilized in the CRM program, including the Section 106 Review process, are identified and described in Sections 4.0 and 5.0 of this plan.

In addition to NEPA reviews, cultural resource aspects are also considered when environmental personnel review Digging Permits for Endangered Species concerns (the Digging Permit cultural resource review process requires additional formalization).

Along with development of the CRMP, recent cultural resource management activities have focused on mitigation activities associated with one of BNL's research reactors in the process of being decommissioned, and evaluation of other on-site buildings identified for demolition.

While the environmental services program is responsible for the BNL Cultural Resource Management Program, the CR program overlaps and is complemented by two other BNL functions.

BNL Historian. The Director's Office has provided funding for the BNL Historian, Robert Crease. Robert Crease is a professor in the Philosophy Department at Stony Brook University and performs research/documentation on BNL science and administrative history on a contract basis. The BNL Historian's activities have included conducting "living histories" through audio and video-interviews of individuals significant to the founding of BNL and its science programs, authoring a book on the history of BNL 1946-1972 (Crease 1999), writing numerous articles and presenting lectures related to the science history of the Laboratory.

Camp Upton Historical Collection Coordinator. The BNL Community, Education, Government and Public Affairs (CEGPA) Division oversees operation of the Camp Upton Historical Collection. Within CEGPA, a portion of one individual's responsibility is to oversee the Camp Upton Historical 


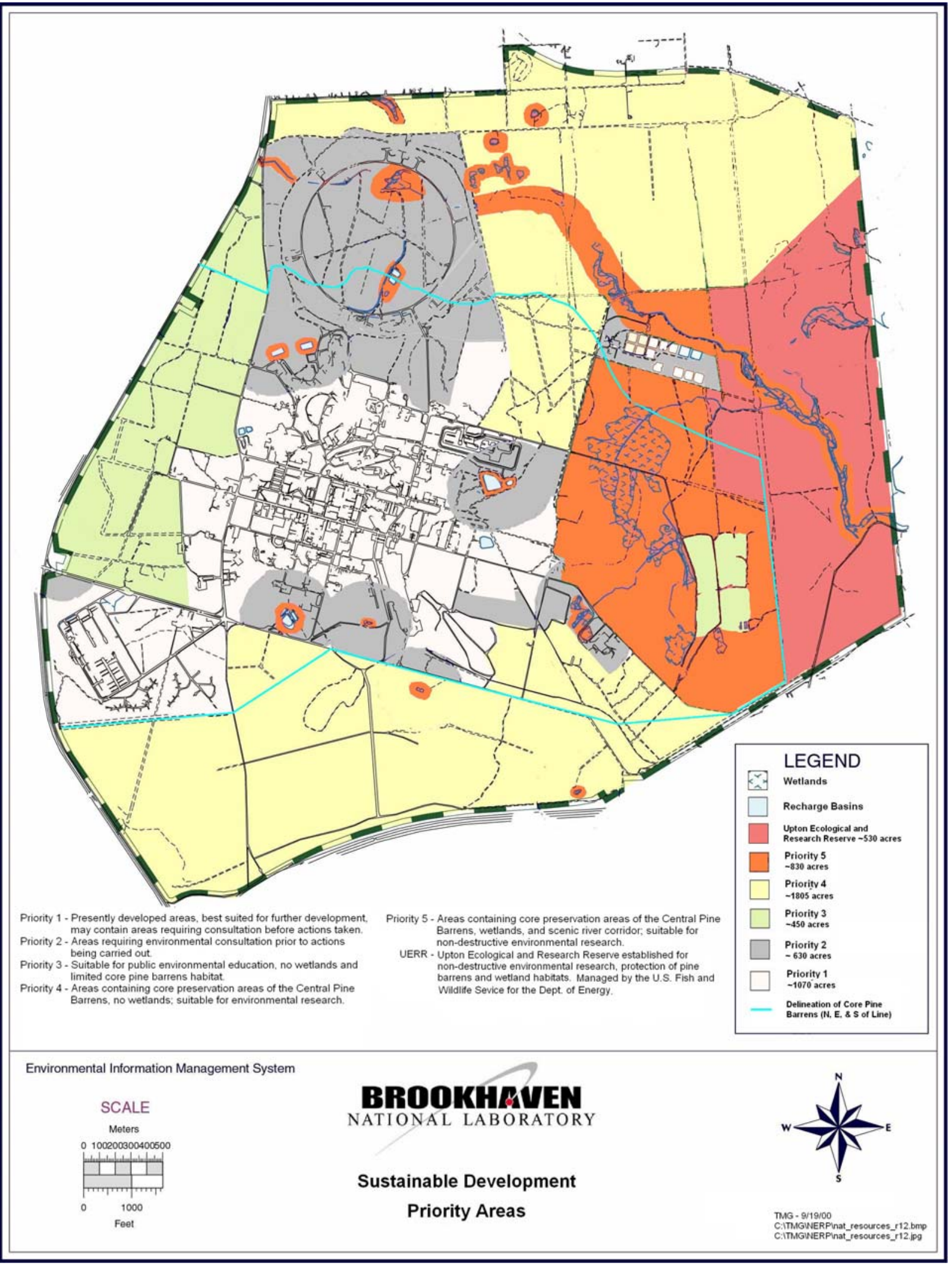

Figure 3.1-3 Sustainable Development Priority Areas 
Collection and develop related outreach programs. This individual was a certified history teacher prior to employment at BNL.

The CR Coordinator has developed a close working relationship with each of these individuals in order to ensure that their programs are aligned with the CRMP. Additional information related to the CRM staff can be found in Section 5.6, CRM Administration.

\subsubsection{Funding}

The two individuals responsible for the CR program are funded through the environmental program staff budget. The environmental program budget addresses the cost of the personnel salaries, professional development training/travel, and small operational administrative needs.

Funding for development of the CRMP has been designated through the BNL Activity Data Sheet (ADS) system. Environment, Safety and Health ADS \#AAOD0071 was funded, starting in Fiscal Year (FY) 2001. These funds are being used to contract external vendors to develop and implement discrete tasks associated with the CRMP.

Oversight and management of the Camp Upton Historical Collection is funded through the CEGPA division's budget process. CEGPA supplies funding for a portion of one employees time, space charges for housing the collection, and miscellaneous supplies to support outreach activities.

The BNL Historian is funded through the Director's Office on a contract basis.

\subsection{CULTURAL AND HISTORIC SETTING}

Five distinct periods are associated with the history of the BNL site. Each of these eras is briefly introduced below.

Pre-Camp Upton (pre-1917). The current site of what is now Brookhaven National Laboratory once consisted of hardwood forests, pine barrens, and wetlands. While there is no evidence of Native American community settlements on BNL property, they may have performed hunting/gathering activities in the area. Early European settlers in the surrounding areas cut hardwood trees on site as part of the local cordwood industry. Two circa-1850s house sites have been identified on BNL property (Reference BNL CR Project \# CRP2004-02 for additional details).

World War I Camp Upton (1917-1921). The federal government acquired 15 square miles of central Long Island woodlands in June 1917 in order to establish a training cantonment. Approximately 1,400 acres were cleared for construction and operation of the main camp area, which ultimately consisted of 1,719 buildings. By October 1917, 30,000 soldiers were being trained at Camp Upton. Renowned composer Irving Berlin was stationed at Camp Upton, where he wrote and performed in the musical Yip, Yip Yaphank, made famous by the song Oh How I Hate to Get Up in The Morning. Berlin's initial draft of God Bless America was also composed while he was stationed at Camp Upton. Following the end of WW I, the government ordered the camp to be closed. The camp was completely dismantled and sold at public auction in August 1921.

Civilian Conservation Corps (CCC) (mid 1930s). During the mid-1930s, the CCC stationed four work camps at the Camp Upton site, known then as the Upton National Forest. More than 800 workers were primarily involved with constructing firebreaks and trails, digging water holes to aid in fighting forest fires, and reforestation. The firebreaks remain today, along with stands of the white pine trees planted by the CCC.

World War II Camp Upton (1940-1946). In 1940, Camp Upton was rebuilt and functioned as an induction center for thousands of WW II recruits. In 1944, the camp was converted to a rehabilitation hospital for wounded soldiers. One section of the property functioned as a prisoner of war compound that housed 
German POWs. Following WW II, Camp Upton was not dismantled but was transformed into the site of a new government laboratory.

Brookhaven National Laboratory (1947-present). On January 1, 1947, the War Department transferred the Camp Upton property from the Army to the Atomic Energy Commission and Brookhaven National Laboratory, under the management of Associated Universities Incorporated, was officially established to form a peacetime atomic research facility. The BNL site has steadily evolved over the years, with the development of several major research machines. A few of the buildings and structures from WW II Camp Upton remain in use today.

\subsection{1 - 3.2.4 (Covered in Appendix A)}

The Cultural Resources Inventory Including Archival Search, Prehistoric and Historic Period Contexts, and Archeology Sensitivity Assessment of the Brookhaven National Laboratory was developed in 2001 for BNL by the Institute for Long Island Archeology (ILIA), which is associated with the Department of Anthropology, State University of New York (SUNY) at Stony Brook. This document is presented in its entirety as Appendix A, and represents the following sections of the BNL Cultural Resource Management Plan:

3.2.1 Historic and Prehistoric Natural Environments

3.2.2 Prehistory and History

3.2.3 Traditional Lands and Resource Uses

3.2.4 Treaties, Executive Orders, and Land Grants

\subsubsection{Recent Scientific Significance}

Brookhaven National Laboratory was established as the nation's first peacetime (non weapons) nuclear research facility and was conceived to promote basic research in the physical, chemical, biological, and engineering aspects of the atomic sciences. The concept behind establishing a national laboratory in the northeast was to design, construct, and operate large scientific machines that individual institutions (universities and corporations) could not afford to develop on their own.

3.2.5.1 Research Reactors. The first big machine constructed at BNL was the 10-megawatt Brookhaven Graphite Research Reactor (BGRR). Operating from 1950 to 1969, the BGRR was the first reactor built for civilian research into peaceful uses of the atom. Its sole purpose was to create vast quantities of neutrons, which made it an extremely versatile scientific instrument. Researchers used the BGRR's neutrons as tools for studying atomic nuclei and the structure of solids, and to investigate many physical, chemical, and biological systems. The American Nuclear Society declared the BGRR a Nuclear Historic Landmark in 1988.

The Laboratory's second-generation research reactor, the High Flux Beam Reactor (HFBR) began operations in October 1965. The HFBR operated at power levels of 30, 40, and 60 megawatts until 1996. During 31 years of operation the reactor, which was cooled and moderated by heavy water, provided scientists with beams of neutrons for basic and applied research studies in physics, chemistry, materials sciences, biology, medical, and forefront technologies. Discovery of radioactively contaminated water leaking from the facility’s spent fuel storage pool ultimately resulted in its permanent closure in 1999.

Section 3.3.4 contains additional information on the BGRR and HFBR. Examples of contributions to science and society made possible by research at the BGRR and HFBR are available at the following websites:

http://www.bnl.gov/bnlweb/history/BGRR.htm and http://www.bnl.gov/bnlweb/history/HFBR_main.htm

3.2.5.2 Cosmotron. The second "Big Machine" for Brookhaven was the Cosmotron; a 3 billion electron volt $(\mathrm{GeV})$ proton accelerator used in high-energy physics studies. The Cosmotron consisted of $288 \mathrm{C}$-shaped magnet blocks, each weighing 6 tons, arranged like beads around a 75-foot diameter necklace. After one second of acceleration in the Cosmotron, the protons had traveled 135,000 miles and had reached an energy 
of about $3 \mathrm{GeV}$. At that energy, the protons were allowed to strike a target. The fragments of the nuclear collisions were observed using a variety of detectors, including photographs of the telltale trails they left in cloud chambers. These observations proved to be tremendously important for a better understanding of the complex nature of many subatomic particles. The Cosmotron operated from 1952 to1966 and was the first accelerator to achieve $1 \mathrm{GeV}$ (also known as a BeV). It was also the first accelerator to provide an external beam of particles for experimentation outside the accelerator itself. The Cosmotron established BNL as a leader in the physics community and led to the development of the "Strong-Focusing Principle" that would soon become the basis of all large accelerators. After its shutdown, the Cosmotron was completely disassembled. Section 3.3.4 contains information on existing Cosmotron-related assets.

3.2.5.3 Alternating Gradient Synchrotron (AGS). The next generation of particle accelerator took a dramatic step forward, because it could no longer be housed within its own building. The Alternating Gradient Synchrotron (AGS), which came on line in July 1960, required construction of a half-mile long trench, with a 260-foot radius. Its main ring is housed in an underground tunnel $18 \mathrm{ft}$ x $18 \mathrm{ft}$ in cross section. At $33 \mathrm{GeV}$, the particles are accelerated in a vacuum chamber and maintained in orbit by 240 bending-focusing magnets, each 39 x 33 inches in lateral dimensions. The AGS proton beam is used directly in experiments or to produce a variety of secondary beams that supply an array of experimental installations. Until 1968, the AGS was the highest energy accelerator in the world. The AGS is still serving the science community as an accelerator facility and as an injector for BNL's newest accelerator facility, the Relativistic Heavy Ion Collider (RHIC).

3.2.5.4 Medical and Biological Research Programs. Medical research at BNL began in 1950 with the opening of one of the first hospitals devoted to nuclear medicine. The Medicine Department was initially housed in Camp Upton's rehabilitation hospital, located in the present-day apartment area. The Life Sciences Program at BNL expanded in the late 1950s with construction of the Brookhaven Medical Research Center in 1958 and the 3-megawatt Brookhaven Medical Research Reactor (BMRR), which operated from 1959 to 2000.

A unique asset of the cultural resource program is the Gamma Forest, the site of a Biology Department research project that operated from 1961 to 1979. Refer to Section 3.3.4 for additional information on the Gamma Forest.

3.2.5.5 Additional Facilities (After 1970). Information in this section comes from the BNL website: http://www.bnl.gov/bnlweb/history.html.

Tandem Van de Graaff. The world's largest electrostatic accelerator (at that time), the 30-million eV (3 MeV) Tandem Van de Graaff, became operational in 1970. It supported the continuing work of the Physics Department as they investigated the structure of nuclei and atomic reactions.

The National Synchrotron Light Source. The NSLS began operations in 1982. Located near the center of the developed portion of the site, the NSLS operates two electron storage rings: an X-Ray Ring and a Vacuum Ultra Violet (VUV) Ring. Both rings provide intense, focused light spanning the electromagnetic spectrum, from the infrared through x-rays. The properties of this light and the experimental stations ("beamlines") allow scientists to study the properties of matter such as crystal structure, bonding energies of molecules, details of chemical and physical phase transformations, electronic structure, and magnetic properties.

The Relativistic Heavy Ion Collider. In designing and building the RHIC, BNL took advantage of the AGS's injection capability and a circular tunnel (15 ft wide by $11 \mathrm{ft}$ high, 2.5 miles in circumference) from an abandoned project (ISABELLE). The RHIC, which began operations in 2000, drives two intersecting beams of gold ions head-on to create subatomic collisions. Designed for scientists to study what may have occurred moments after the universe was created, RHIC's two concentric rings are made up of 1,740 superconducting magnets, strung end-to-end like beads on a necklace. RHIC is powered by over 1,600 miles of superconducting niobium titanium wire, wrapped around the RHIC magnets. The facility contains four beam-intersecting regions, where the experimental halls are positioned. RHIC's two largest detectors, STAR and PHENIX, are larger than typical houses. PHENIX weighs 3,000 tons and STAR weighs 1,200 tons. 
3.2.5.6 Nobel Prizes. Six Nobel Prizes have been awarded to individuals whose work was closely associated with BNL. Over a period of 35 years, particle physics studies performed at the Cosmotron and AGS facilities have resulted in four Nobel Prizes in Physics. Most recently, in 2002, a retired BNL chemist received the Nobel Prize in physics for his accomplishment in the study of neutrinos, and in 2003, a visiting scientist shared the Nobel Prize in Chemistry for explaining how a class of proteins helps to generate nerve impulses.

Parity violation, 1957. In 1957, two scientists who had worked as guest scientists at Brookhaven during the summer of 1956 received the Nobel Prize in physics for radically questioning one of physics' basic tenets. T. D. Lee, of Columbia University, and C. N. Yang, then of BNL, interpreted results of particle decay experiments at Brookhaven's Cosmotron particle accelerator and discovered that the fundamental and supposedly absolute law of parity conservation had been violated.

Their studies concerned two particles, the tau and the theta, which had the same masses, lifetimes, and scattering behaviors, but which decayed differently in experiments at the Cosmotron. Because of this, the law of parity conservation required that these otherwise similar particles be considered different from one another. Lee and Yang suggested experiments that showed that the weak interaction of radioactive decay could indeed violate parity conservation. When the experiments were later successfully completed, the puzzle of the two particles was solved - they could be the same.

The J/psi particle, 1976. The 1976 Nobel Prize in physics was shared by a Massachusetts Institute of Technology researcher who used Brookhaven's Alternating Gradient Synchrotron (AGS) to discover a new particle and confirm the existence of the charmed quark. Samuel C.C. Ting was credited for finding what he called the "J" particle, the same particle as the "psi" found at nearly the same time at the Stanford Linear Accelerator Center by a group led by Burton Richter. The particle is now known as the J/psi. Ting's experiment at the AGS took advantage of high-intensity proton beams, which bombarded a stationary target to produce showers of particles that could be detected by complex detectors. A strong peak in electron and positron production at an energy of $3.1 \mathrm{GeV}$ led Ting to suspect the presence of a new particle, the same one found by Richter. Their discoveries not only won the Nobel Prize; they also helped confirm the existence of the charmed quark — the $\mathrm{J} / \mathrm{psi}$ is composed of a charmed quark bound to its antiquark.

CP violation, 1980. Just four years after Ting and Richter received their prize, the 1980 Nobel Prize in physics was awarded to two researchers whose discovery at Brookhaven's AGS was the opposite of what they had expected to find when they began their experiment in 1963. James W. Cronin and Val L. Fitch, both then of Princeton University, proposed using Brookhaven's AGS to verify a fundamental tenet of physics known as CP symmetry, by showing that two different particles did not decay into the same products. They picked as their example neutral $\mathrm{K}$ mesons, which are routinely produced in collisions between a proton beam and a stationary metal target.

The experiment set out to show that in millions of collisions, the short-lived variety of $\mathrm{K}$ meson always decayed into two pi mesons, while the long-lived variety never did. But to their surprise, a "suspiciouslooking hump" in the data showed an unexpected result that years of subsequent experimentation and theory have been unable to explain: occasionally, the long-lived neutral K meson does decay into two pi mesons. Cronin and Fitch had found an example of CP violation. The discovery's ramifications stretched far beyond the neutral K mesons; Cronin and Fitch had discovered a flaw in physicists' central belief that the universe is symmetrical.

Discovery of the muon-neutrino, 1988. BNL's next Nobel Prize came in 1988, when a trio of physics researchers were honored for their 1962 discovery of the muon-neutrino. Leon Lederman, Melvin Schwartz, and Jack Steinberger, at the time all of Columbia University, made their discovery at the brand-new AGS. At that time, only the electron-neutrino was known, and the scientists wondered if they could find more types of these ghostlike particles that pass through everything. The AGS, then the most powerful accelerator in the world, was capable of producing the beam needed.

The experiment used a beam of the AGS's energetic protons to produce a shower of pi mesons, which traveled 70 feet toward a 5,000-ton steel wall made of old battleship plates. On the way, the pi mesons decayed into muons and neutrinos, but only the latter particles could pass through the wall into a neon-filled 
detector called a spark chamber. There, the impact of neutrinos on aluminum plates produced muon spark trails that could be detected and photographed-proving the existence of muon-neutrinos. The experiment's use of the first-ever neutrino beam paved the way for scientists to use these particles in research at the AGS and around the world.

Detection of cosmic neutrinos, 2002. In 2002, Raymond Davis, Jr. was awarded the Nobel Prize for first detecting solar neutrinos, ghostlike particles produced in nuclear fusion reactions occurring in the core of the sun. Davis devised a method to detect solar neutrinos based on the theory that the elusive particles produce radioactive argon when they interact with a chlorine nucleus. He constructed his first solar neutrino detector in 1961, 2,300 feet below ground in a limestone mine in Ohio. Building on this experience, he mounted a full-scale experiment 4,800 feet underground in the Homestake Gold Mine in South Dakota. In research that spanned from 1967 to 1985, Davis consistently found only one-third of the neutrinos that standard theories predicted. His results threw the field of astrophysics into an uproar, and for nearly three decades physicists tried to resolve the so-called "solar neutrino puzzle.” Davis's lower-than-expected neutrino detection rate is now accepted by the international science community as evidence that neutrinos have the ability to change from one of the three known neutrino forms into another. This characteristic, called neutrino oscillation, implies that the neutrino has mass, a property that is not included in the current standard model of elementary particles (in contrast, particles of light, called photons, have zero mass). Davis's detector was sensitive to only one form of the neutrino, so he observed less than the expected number of solar neutrinos.

Class of proteins that helps to generate nerve impulses, 2003. In 2003, Roderick MacKinnon, M.D., a visiting researcher at BNL's National Synchrotron Light Source, was one of two recipients of the Nobel Prize in Chemistry for work explaining how a class of proteins helps to generate nerve impulses - the electrical activity that underlies all movement, sensation, and perhaps even thought. The work leading to the prize was done partly at BNL’s NSLS and partly at the Cornell High Energy Synchrotron Source.

3.2.5.7 Additional Discoveries. Other significant scientific discoveries made at BNL include those listed below, with additional information available at the BNL website http://www.bnl.gov/bnlweb/history/

- L-dopa, used to treat Parkinson's disease

- Magnetically-levitated (maglev) trains

- Pioneering work using X-rays and neutrons to study biological specimens, leading to the modern science of structural biology

- The radionuclide thallium-201, now used in millions of heart stress-tests each year

- The radionuclide technetium-99m, now used to diagnose heart disease and other ailments in more than 11 million Americans each year

- X-ray angiography for non-invasive heart imaging

- The strong focusing principle, crucial to the function of all modern particle accelerators

- The first video game

\subsection{KNOWN CULTURAL RESOURCES}

This section presents the identified cultural resources associated with BNL, grouped into the following main categories: Prehistoric, Historic, Ethnic, and Scientifically Significant. Attachment 7 presents a tabular listing of each known cultural resource and will be updated as new resources are identified. The table includes the following information for each identified resource:

- BNL CR ID \#. A number assigned to uniquely identify each cultural resource

- Type. Resources are identified as properties (buildings, structures, sites, districts), objects, or "other."

- Period. Prehistoric, Historic, Ethnic, and Scientifically Significant

- Name. Common name assigned to the resource

- Description. Short description of the resource 
- NRHP. Identifies the resource's National Register status as either: U- undetermined; Y-Determined to be NRHP eligible; L - Listed on the NRHP; N - Determined not to be NRHP eligible.

Included with traditional cultural resources (buildings, sites, etc.) are items that may be considered more as supporting assets. These items are identified in order to acknowledge their contribution and vital role in the CRM program and to ensure they are managed in the appropriate manner. In some cases a single listing in the table may represent a group of items; for example, the Camp Upton Historical Collection. Such a group may include many items that are identified individually in a separate database or inventory. In these situations, the associated inventory or database is identified in the Attachment 7 table.

\subsubsection{Prehistoric Cultural Resources}

Resources in this category pertain to the period of time before the advent of written history, generally, prior to the arrival of Europeans to the region. To date, prehistoric cultural resources have not been identified at the BNL site. According to the Institute for Long Island Archeology, "areas of the BNL property within or adjacent to wetlands and other fresh water sources have a high sensitivity for the presence of prehistoric deposits. Sections of BNL property not adjacent to fresh water resources have a low to moderate potential for prehistoric archeological sites. Areas thoroughly disturbed by twentieth century land use activities have a very low sensitivity for the presence of intact archeological deposits.” Refer to the Archeology Sensitivity section of Appendix A for additional details.

\subsubsection{Historic Cultural Resources}

Resources in this category pertain to the period of time after the advent of written history, generally following the arrival of Europeans to the region. While the majority of these resources are associated with the twentieth-century developed site, specifically World War I Camp Upton through World War II Camp Upton, a few resources related to pre-twentieth century land use are identified. Refer to the Archeology Sensitivity section of Appendix A for additional details. Attachment 8 identifies the location of cultural resource areas, sites, and buildings, including sensitive cultural resource areas, primarily the WW I trenches and foundations. (Note: This map is considered Sensitive Information - Limited Distribution Only). Brief descriptions of these historic resources are provided below.

(Weeks Campbell Site) (BNL-CR-1). The site of a house/farm, whose main period of occupation was the late nineteenth-early twentieth century, has been identified on BNL property (Merwin, Manfra 2005). An archeological site evaluation of this property was performed in 2004 (Reference CR Project \#CRP-200402). This site may be National Register eligible. Figures 3.3-1 and 3.3-2 present photos of the stone wall/foundation and brickwork identified at the site.

Wheel and Hub (BNL-CR-02). A steel rim and hub, likely from a wagon or carriage-type of vehicle, were found on site.

W. $\boldsymbol{J}$. Weeks Site (BNL-CR-32). The site of a house whose main period of occupation was the mid- to late nineteenth century was identified on BNL property. An archeological site evaluation of the house site was performed in 2004 (Reference CR Project \#CRP-2004-03). Potential research topics associated with this site may include: lifeways of otherwise "undocumented" people, (i.e. tenant woodchoppers); socio-economic issues of non-landholding lower class in nineteenth century rural setting (Merwin, Manfra 2005). This site is National Register eligible, but has not been formally submitted to SHPO for official determination. Figures 3.3-3 and 3.3-4 present photos of the locust fence post and stone foundation wall. 


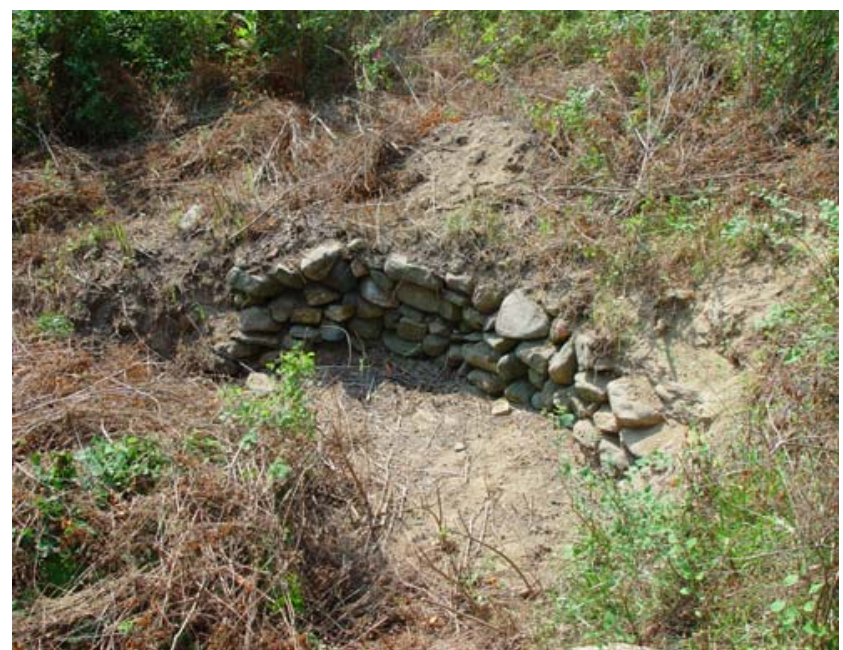

Figure 3.3-1 Stone Foundation Wall, Weeks Campbell Site

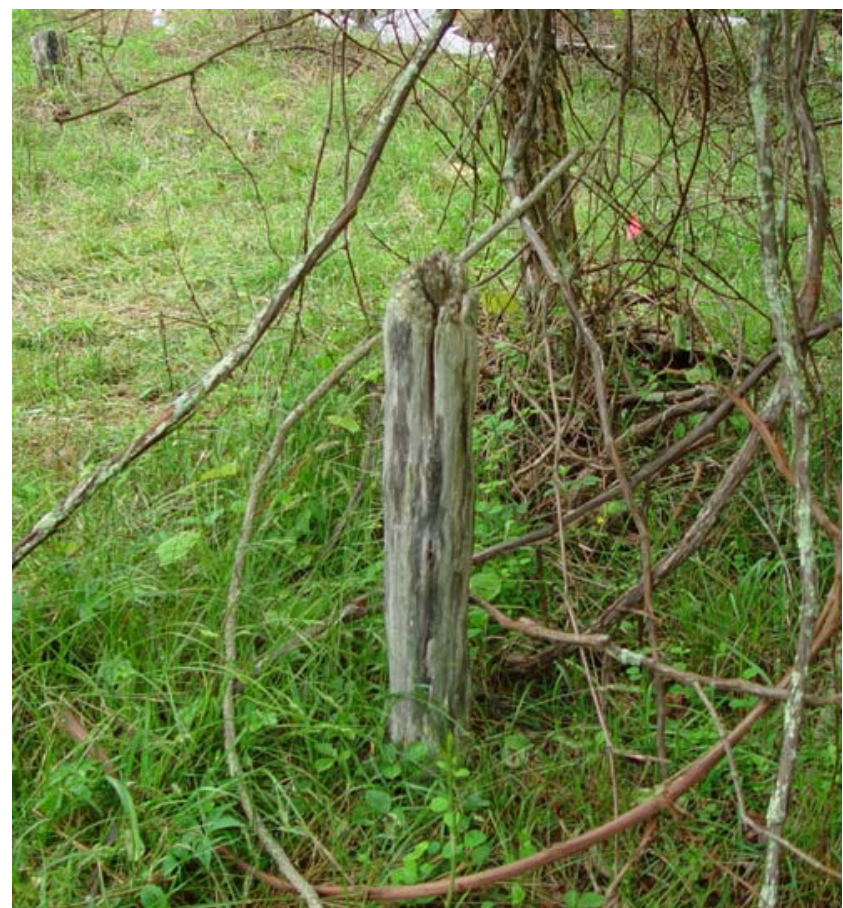

Figure 3.3-3 Locust Fence Post, W.J. Weeks House Site

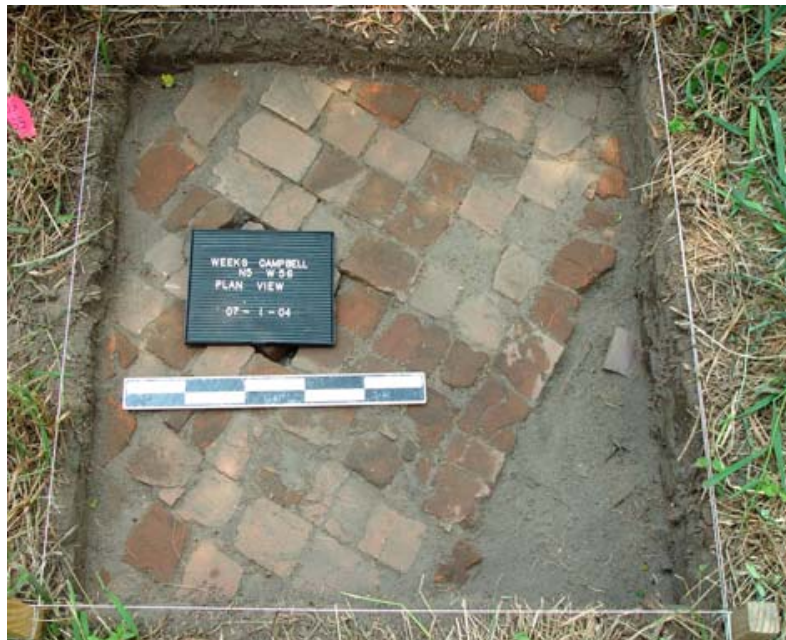

Figure 3.3-2 Brickwork, Weeks Campbell Site

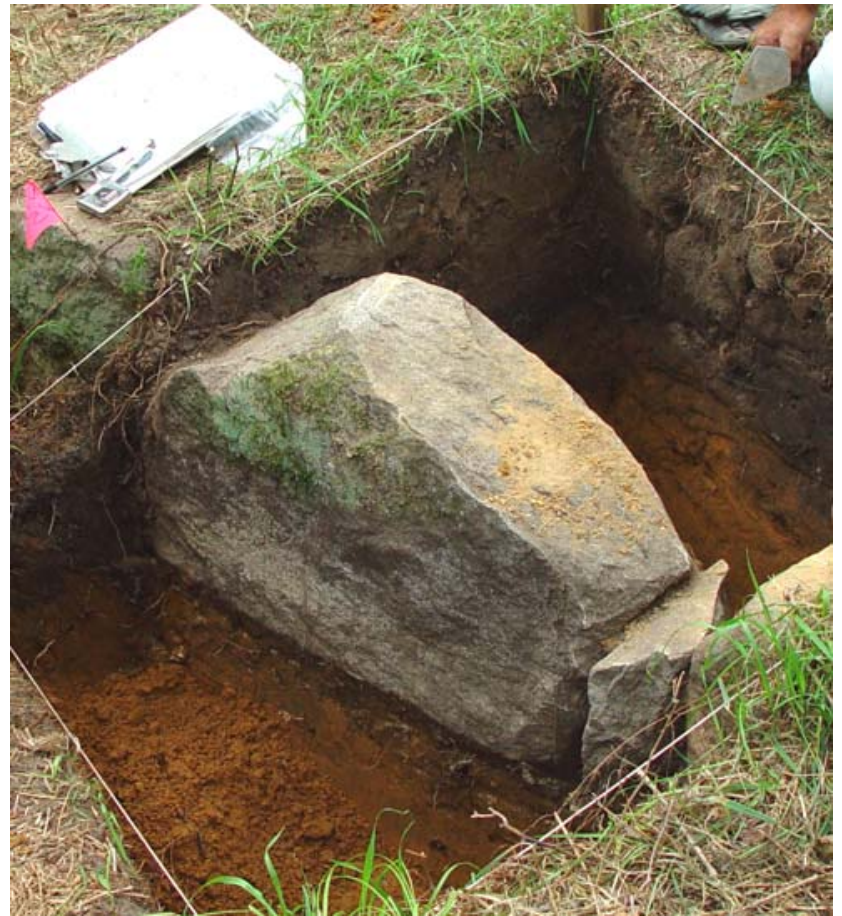

Figure 3.3-4 Foundation Stones, W.J. Weeks House Site

World War I Training Trenches (BNL-CR-4). Within the BNL property, ten separate areas of trench warfare training trenches dating back to World War I Camp Upton have been identified (Merwin and Lam 2002). Each of the ten trench areas varies in the degree of complexity; one area may encompass a single trench, while other areas may include a network of interconnecting trenches. These features are likely the only surviving WW I trenches in the United States. Their presence and high degree of preservation may provide opportunities for documenting construction techniques and training methods, which is significant for both American and international military engineering and history. The BNL training trenches were determined to be eligible for listing on the National Register of Historic Places in 1979. Each trench was surveyed and mapped as part of CR Project No. CRP-2002-02, thus providing an overview of the complexity of each network. Figure 3.3-5 shows the result of mapping the most intricate network of the BNL trenches. Figure 3.3-6 is a photo of one of the trenches as it appears today. 


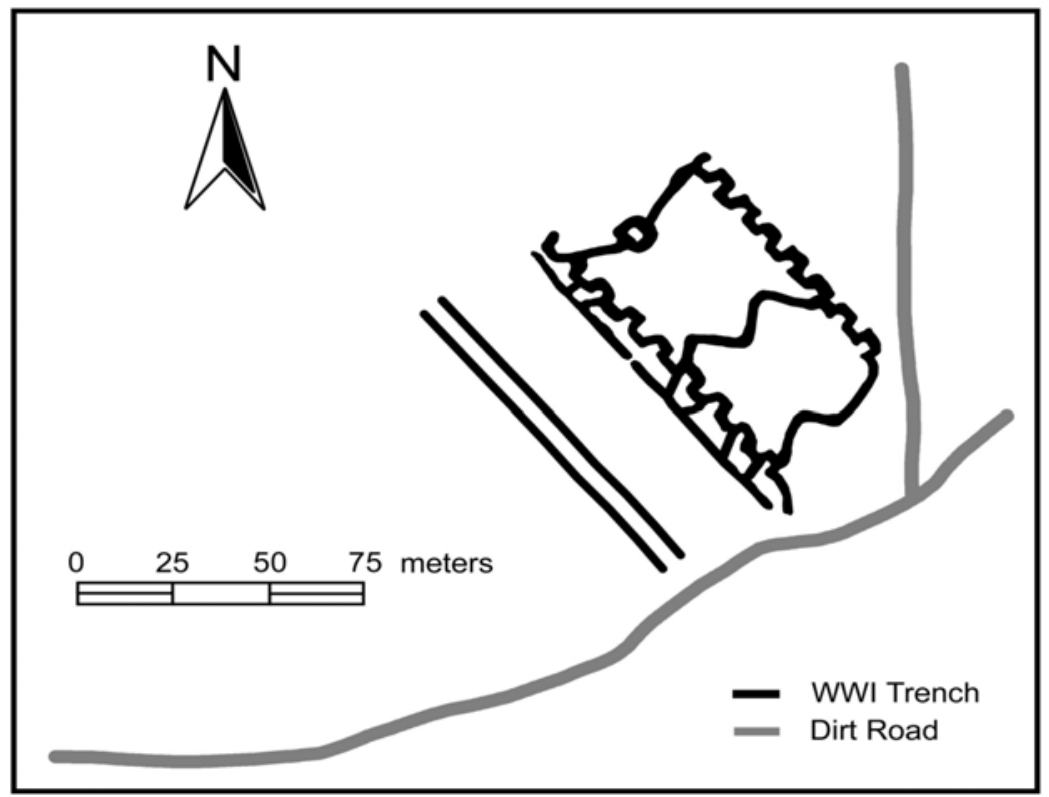

Figure 3.3-5 Diagram of Mapped Trench Network

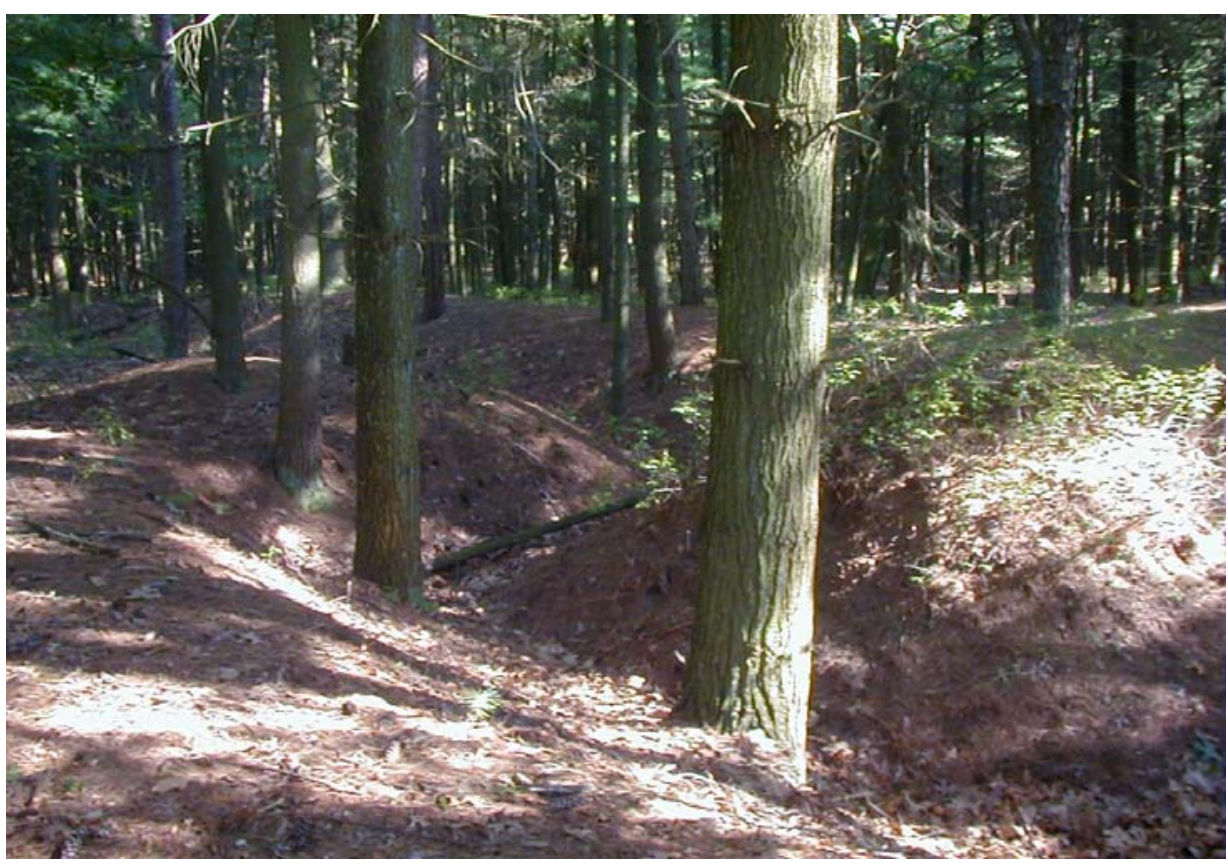

Figure 3.3-6 Extant WW I Training Trench

World War I Foundations and Features (BNL-CR-5). In addition to the trenches, remnants of WW I Camp Upton are also present on site in the form of building foundations and structural features such as concrete railroad loading platforms, brick buildings, wells, and sewers. Two areas contain concentrations of the majority of the foundations, although additional foundations have been identified in outlying areas of the site. Surveying and mapping these areas, as part of CR Project No. CRP-2002-02, revealed that the foundations do conform to building locations identified on maps of WW I Camp Upton (Reference Attachment 1: Map of WW I Camp Upton).

Camp Upton Historical Collection (BNL-CR-3). The collection contains more than 2,000 items related to the U.S. Army's occupation of the property as Camp Upton during both World War I and II, including both 
donated articles and those recovered on site. Examples of collection items include uniforms, metals, weaponry, original camp newspapers and original period newspapers, and $77^{\text {th }}$ Division, and "Lost Battalion" items. In addition to military items, the collection houses memorabilia related to the famous composer Irving Berlin and his days at Camp Upton. Refer to Section 3.4.9, Outreach, for additional information on the collection.

Grain Silo Bases (BNL-CR-6). Building 482 is comprised of the two concrete bases from the original grain silos from WW I Camp Upton. New roofs and ventilation hardware have been installed, along with other modifications. The structures are currently used as storage facilities.

Building 455 (BNL-CR-7). This small brick building is one of the few extant structures remaining from WW I Camp Upton. The building has been modified with new framing and roofing, and is currently used for storage.

White Pine Trees (BNL-CR-8). Several stands of white pines can be found throughout the BNL site. These trees were planted by the Civilian Conservation Corps (CCC) in the 1930s as part a reforestation project that followed the closing and dismantling of Camp Upton after the end of World War I.

Building 30 (BNL-CR-9). The center section of Building 30 was constructed in 1934 when the CCC occupied the site. As part of WW II Camp Upton, the building served as an officers' club.

Building 120 (BNL-CR-10). Building 120 is the only two-story barracks building remaining from WW II Camp Upton which has not had its exterior significantly renovated. The building was moved from its original location in the late 1940s and the interior has been modified to accommodate offices.

WW II Mural (BNL-CR-23). A small portion of a mural painted on the wall of what was once the WW II noncommissioned officers' club is visible above the ceiling level in Building 197. The mural depicts a map of WW II Camp Upton. While the mural once encompassed the entire wall of the building, most of the mural appears to have been destroyed by renovations over time.

BNL Photo Negative Archives (BNL-CR-21). Photographic negatives from the inception of BNL in 1947 to the present day are stored on site. These archives document the facilities, personnel, and science that have taken place at BNL. A bound index listing each negative is available.

BNL Bulletin and Press Release Archives (BNL-CR-22). Archives of BNL press releases and newsletters (The Brookhaven Bulletin and Isotopics) are stored on site. These archives document the scientific, occupational, and social activities at BNL through the years.

Actions

- Develop a map layer indicating the location of extant WW I trenches and structures (foundations, silo bases, loading platforms, etc.).

- Determine if BNL press release and newsletter archives are properly stored, and initiate corrective actions as needed.

\subsubsection{Resources of Ethnic Importance}

Resources in this category include those of religious value or other cultural significance to Native Americans or other ethnic groups.

To date, resources of ethnic importance, such as sacred sites, traditional-use resources, and Native American cultural items, have not been identified on the BNL site. If such items are identified in the future, appropriate consultation with Native American tribes and the NY State SHPO will be initiated. Refer to the Archeology Sensitivity section of Appendix A for additional details. 


\subsubsection{Resources of Scientific Significance}

Resources in this category may include buildings, structures, objects, programs, or properties associated with scientific, engineering, or technical themes of historic significance.

Cultural resources of scientific significance that are identified in Attachment 7 include buildings, sites, and scientific equipment artifacts, as well as supporting assets such as scale models of facilities. Resources that can potentially help to document BNL's scientifically significant activities, such as photograph negative archives and public relations files, also are included. Brief descriptions of some of the scientifically significant resources are provided below.

Brookhaven Graphite Research Reactor (BGRR) Complex (BNL-CR-11), model (BNL-CR-20), archives (BNL-CR24), and History Video (BNL-CR-25). The BGRR is considered a "core" facility—a building that uniquely characterizes BNL's scientific significance as well as its reason for existence. In addition to the Reactor Building (Building 701) and Reactor Pile (Bldg. 702), the BGRR complex encompasses buildings that were constructed to support the BGRR or that were directly supported by it. Included in this category are the Reactor Laboratory (Bldg. 703), the Fan House (Bldg. 704), the Pile Stack (Bldg. 705), the Instrument House (Bldg. 708), the Canal House (Bldg. 709), the Water Treatment Facility (Bldg. 709A), and the Hot Laboratory (Bldg. 801). The complex is currently undergoing decontamination and decommissioning (D\&D), with the final end state currently undefined. The BGRR Complex was determined to be eligible for listing on the National Register of Historic Places in 2000 (Desmarais 2000). Additional information on the BGRR is available at the following website:

http://www.bnl.gov/bnlweb/history.html

A scale model of the BGRR exists and is currently in use for D\&D planning and implementation at the facility. Documents related to the design, construction, operations, and maintenance of the facility have been professionally inventoried and archived. A Microsoft Excel database of all records was developed and keyword descriptors were established. A list of records and photographs contained in the BGRR files was also produced. A video history of the BGRR was produced and distributed in September 2003. The video presents the BGRR through the recollections of key individuals who contributed to its success as a premier research tool throughout its 18-year operating history, (1950-1968). BNL Historian Robert Crease narrates the design, construction, operation, scientific research, and shutdown of America's first nuclear reactor designed for peacetime civilian applications.

High Flux Beam Reactor (HFBR) Complex (BNL-CR-12) and scale models (BNL-CR-17, 18, and 19). The HFBR, which operated from 1965 to 1996, was one of the first research reactors designed to be optimized for a specific function - neutron beam experimentation. Its breakthrough design allowed the population of neutrons to peak at the outside edge of the reactor core, thus providing maximum access for scientific experimentation. The basic research conducted at the HFBR provided a better understanding of the mechanisms and processes that make materials, matter, and pharmaceuticals unique and effective. The HFBR complex is comprised of the easily recognizable dome-shaped reactor building (Building 750), the Cold Neutron Compressor Building (Bldg. 751), the Pump House (Buildings 707 and 707A), the Water Treatment House (Bldg. 707B), as well as support buildings shared with the BGRR Complex (Buildings 704 and 705). The HFBR Complex was determined to be eligible for listing on the National Register of Historic Places in 2001 (Warren 2001). The complex is currently undergoing D\&D planning, with the final end state currently undefined. Additional information on the HFBR is available at the following website:

http://www.bnl.gov/bnlweb/history.html

Three scale models of the HFBR (the HFBR building, its biological shield and vessel, and a mock-up of the fuel element) are available for interpretation.

Gamma Forest Site (BNL-CR-13). From 1961 to 1979, the Biology Department operated the Gamma Forest as a long-term research experiment designed to yield information on the sensitivity of plants to ionizing 
radiation and other biological interactions. This facility consisted of a fenced, 50 -acre forested tract in the northeast area of the site where a large cesium-137 gamma source was exposed for 20 hours each day. The program was discontinued and the source was removed in 1979. The effects on the study area's ability to regenerate vegetation can still be observed, along with remnants of the program's operational hardware and control shack.

Cosmotron Site (BNL-CR-14), C-Magnet (BNL-CR-15), and Model. Refer to Section 3.2.5 for a description of the Cosmotron's scientific significance. All that remains of the facility is a slightly raised circle of concrete on the floor of Building 902, indicating the outline of the Cosmotron ring. However, one of the Cosmotron C-magnets is displayed outside Building 911, and the Smithsonian Institution added several to their historical collection. Scale models of the Cosmotron are displayed in Building 438.

Goal. Continue to research the significance of the identified resources and other potentially scientifically significant resources and supporting assets.

Actions

- Develop brief descriptions of additional CR assets listed in Attachment 7.

- Confirm that Smithsonian Institute has one or more BNL 'C'-magnets in their collection.

\subsection{CULTURAL RESOURCE MANAGEMENT ACCOMPLISHMENTS}

This section of the CRMP addresses past accomplishments in the management of cultural resources at BNL. Included are descriptions of accomplishments for CR records, project reports, inventories, surveys, excavations, structure management, laboratory treatment, curation, protection, and outreach. The Introduction to the CRMP (Section 1.0) explains the history of cultural resource management at BNL and therefore is not repeated here. Until the development of this management plan, BNL did not have standardized systems related to most aspects of cultural resource management, including archeological site records, reports, and so forth. Systems established during development of the CRMP are described in Section 4.2, CRM Methods.

\subsubsection{Records, Projects, and Reports}

Records. Records related to CRM are filed according to departmental file codes. Past and current file codes related to CRM documents are identified in Section 4.2, CRM Methods.

Projects. CR projects preformed or initiated to date are identified in Attachment 9. The table presents the following information related to each project: Project \#, Name, Description, Performed By, and Comments. Note: Assigning specific CRM project numbers was initiated in October 2002, and only projects performed in or after 1999 have been listed. CRM projects performed to date either utilized existing BNL numbering schemes (such as the BNL building numbers) or have established an identification system unique to the specific project or report.

CR Library. A system for acquiring, storing and accessing originals or copies of reports, documents, and other written materials dealing with BNL cultural resources has not been established to date.

Goal. Develop new, and refine existing, systems for managing CRM documents.

Actions

- Develop a searchable bibliographic database of current BNL cultural resource-related documents.

- Develop a system for acquiring, storing, and accessing originals or copies of reports, documents, and other written materials that concern BNL cultural resources (i.e., develop the CR Library). 


\subsubsection{Inventory}

\subsubsection{Archival Searches.}

BGRR Records. An archival search was performed for the Brookhaven Graphite Research Reactor (BGRR) Records Project (CRP-2000-02). As part of the Memorandum of Agreement between DOE and the NYSHPO on mitigating the decommissioning of the BGRR, BNL contracted with an outside vendor to inventory and appraise records relating to the BGRR design, construction, operations, and maintenance. The records were assigned to series and retention recommendations were made for all items. A Microsoft Excel database of all records was developed and key-word descriptors were established. A listing of records and photographs contained in the BGRR files was produced. All records and photographs are currently retained on site at Brookhaven National Laboratory. This project was performed from August 11, 2000 to August 31, 2001. Refer to CRP-2000-02 for additional details.

W. J. Weeks House Site and Weeks Cambell Site. Archival research was also conducted as part of the archeological evaluations of the two nineteenth century sites. Refer to CRP-2004-02 (Merwin and Manfra 2004) for additional details.

3.4.2.2. Ethnographic Fieldwork. Not anticipated to be necessary at BNL.

3.4.2.3 Structure and Facility Surveys. The following structure/facility surveys have been performed to date:

June 1981 Historic and Natural Districts Inventory Form. A New York State Parks and Recreation Historic and Natural Districts Inventory Form was completed by the Town of Brookhaven and the Society for the Preservation for Long Island Antiquities (SPLIA 1981).

Architectural Inventory of BNL. In 2000, BNL contracted with the Institute for Long Island Archeology (ILIA) to evaluate BNL buildings and structures for National Register of Historic Places (NRHP) eligibility potential in accordance with the National Historic Preservation Act (NHPA) Section 110. The study was performed from July through September 2000 and evaluated 448 structures, essentially all of BNL's standing structures(Bernstein 2001a). See CRP-2000-01 for additional details.

Architectural Evaluations - Chemistry Building, Berkner Hall, and other Historically Significant Structures. In 2004, BNL contracted with Public Archeology Laboratory, (PAL) of Rhode Island to perform a survey and evaluation of the architectural significance of Berkner Hall (Building 488) and the Chemistry Building (Building 555). The project also included the inspection of the following historically significant structures: to identify their key architectural features and assist BNL in the development of management strategies for their future treatment: Brookhaven Center (Building 30), Reactor Division Building (Building 120), Brookhaven Graphite Research Reactor and Laboratory (Buildings 701-703), High Flux Beam Reactor (Building 750), and the Medical Hot Laboratory (Building 801), (PAL 2004).

NHPA Section 106 Reviews. The following Section 106 Reviews were performed for individual or small groups of buildings. The date the review was performed and the resulting determination are also presented:

- Brookhaven Graphite Research Reactor (BGRR) Complex - 1999. Determined to be eligible for listing in the National Register of Historic Places (NRHP eligible).

- Storage Building 577 - 1999. Determined to be ineligible.

- High Flux Beam Reactor (HFBR) - 2001. Determined to be NRHP eligible.

- 2002 Building Demolition Project Section 106 packages:

- Buildings 89, 90, and 91 (warehouses). Determined to be ineligible.

- Buildings 93 and 168 (well houses). Determined to be ineligible.

- Buildings 194 (warehouse/offices). Determined to be ineligible.

- Building 318 (Oceanography Dept.). Determined to be ineligible.

- Building 324 (apartment \#9). Determined to be ineligible.

Cultural Resource Management Plan 
- Building 426 (labs/offices). Determined to be ineligible.

- $\quad$ Building 428 (trash incinerator). Determined to be ineligible.

- 2003 Building Demolition Project Section 106 packages:

- Buildings 118, 184, 185, 206, 207, 208, 209, 457, 458, and 459. All determined to be ineligible.

- FY2005 Building Demolition Project Section 106 packages:

- Buildings 193 (Credit Union), and 527. Determined to be ineligible.

Section 106 Reviews performed after 2005 will be listed in Attachment 10. Attachment 11 identifies the location of buildings and structures reviewed under NHPA Section 106. Note: In 2003, Section 106 Reviews were also submitted to SHPO for a new railroad spur project (Refer to section 3.4.2.5 Archeological Surveys) and the project evaluating the World War I training trenches (Refer to CRP-2002-02).

3.4.2.4 Structure and Facility Survey Status. The surveys described in the previous subsection (3.4.2.3) encompass evaluations performed by several different individuals or organizations, considering both historic and recent scientific significance. Information provided by these surveys is being used as the basis to formulate the BNL's approach to cultural resources management. Future surveys and evaluations under consideration include an evaluation of architectural features and an evaluation of scientifically significant assets.

Action(s)

- Have an assessment performed to evaluate BNL's scientifically significant facilities (pending available funding).

3.4.2.5 Archeological Surveys. This section identifies archeological surveys performed to date. Attachment 12 identifies the location of these archeological survey areas (Note: This map is considered Sensitive Information - Limited Distribution Only):

- 1974 - Archeological Site Survey Report of BNL. Performed by the Incorporated Long Island Chapter of the New York State Archeological Association, Edward Johannemann, Field Director (Johannemann 1974).

Purpose. To ascertain the existence of cultural material indicating a historic, and or prehistoric occupation within the BNL property. This survey did not include the investigation of structures or material relating to World War I and the Post World War I-era.

Area Surveyed. The following five areas were surveyed (see Attachment 12):

Area A - Periphery of the 5.6-acre Zeek’s Pond

Area B - East and west sides of the smaller 2-acre pond $~ 1,000 \mathrm{ft}$ north of Zeek's Pond

Area C - Streambed of the Peconic River

Area D - Approximately 20 acres, bounded on the south by a line $300 \mathrm{ft}$ north of and parallel to Fifth Avenue. Bounded on the west by a firebreak parallel to Upton Road, distant 1,600 ft west.

Area E - Half Moon Pond, 1 acre in size.

Results. All areas tested proved to be devoid of cultural resource materials.

1977 - Cultural Resource Inventory - Part I - BNL ISABELLE Project. Performed by the Long Island Archeological Project, SUNY Stony Brook - Edward J. Johannemann (Johannemann 1977).

Purpose. To determine the presence or absence of prehistoric and/or historic evidence on the proposed work site for the ISABELLE Project.

Area Surveyed. The survey focused on six specific areas within the $\sim 450$ acre area impacted by the ISABELLE project (see Attachment 12). 
Results. Fourteen specific cultural resource areas were located, mapped, and investigated. These sites consisted primarily of World War I warfare training trenches and depressions. A small amount of WW I-era midden (nails, buttons, wire, etc.) was recovered from two of the areas. No evidence of prehistoric or Native American artifacts was recovered.

1978 - Cultural Resource Inventory - Part II - BNL - ISABELLE Project. Performed by the Long Island Archeological Project, SUNY Stony Brook - Edward J. Johannemann (Johannemann 1978).

Purpose. Focus on surveying three specific areas of the proposed ISABELLE project to determine the presence or absence of prehistoric or historic evidence. The project also included archival research of the World War II-era and additional World War I documentation.

Area Surveyed. The survey focused on three specific areas within the $\sim 450$-acre area impacted by the ISABELLE project (see Attachment 12).

Results. Six specific cultural resource sites were located, mapped and investigated. These sites consisted primarily of World War I warfare training trenches and World War II-era encampments. No cultural resource materials were recovered from these areas.

2001 - Islander East Pipeline Project (Non-BNL Sponsored). Performed by Public Archaeology Laboratory, Inc. (PAL) based in Pawtucket, Rhode Island.

Purpose. To conduct an archeological survey in advance of a proposed gas pipeline.

Area Surveyed. PAL excavated 89 shovel test pits (50 x 50 centimeters) along eight transects. The transects ran along the eastern side of William Floyd Parkway at the far western end of the BNL campus (see Attachment 12).

Results. Only two artifacts were reported (an isolated quartz flake and a single piece of historic period ceramic), along with one Camp Upton foundation feature (Public Archaeology Laboratory 2002).

2001 - Eastern Long Island Extension (Non-BNL Sponsored). The DOE issued a Federal Archeological Permit to R. Christopher Goodwin and Associates, Inc.

Purpose. To conduct an archeological survey for the Iroquois Gas Transmission System's proposed pipeline.

Area Surveyed. Surface reconnaissance and shovel testing along a 200-ft-wide corridor where the west side of the BNL property borders the William Floyd Parkway (see Attachment 12).

Results. No prehistoric materials were identified, but four features likely dating to the World War I and World II eras were reported (Maymon et al. 2003).

2003 - Stage 1B Archeological Survey for BNL Railway Extension. Performed by the Institute for Long Island Archeology.

Purpose. A small-scale archeological survey was conducted in advance of construction of a railroad spur (approximately a half-mile long). The area was known to contain concrete features from the WW I Camp Upton era (two building foundations, two square pillars, and four concrete pads).

Area Surveyed. The project area is located in the southeast portion of the Laboratory property. The area surveyed was approximately $100 \mathrm{ft}$ wide and a half-mile long. The process consisted of field inspection and surface survey, followed by excavating a total of 35 shovel test pits. 
Results. No prehistoric materials or features were encountered. A small complex of WW I Camp Upton era concrete remnants were identified, along with a light density of cultural material. The study concluded that no further archeological investigations would be necessary in the project area (Bernstein and Merwin 2003).

2004 - Archeological Evaluations of the W.J. Weeks House Site and the Weeks Campbell Site. Performed by the Institute for Long Island Archeology.

Purpose. Archeological evaluations of two sites were performed to delineate the horizontal and vertical boundaries of cultural deposits, and to obtain information on the structure, function, cultural/historical context, significance, and integrity of each site. This information was used to evaluate the sites' potential eligibility for the National Register of Historic Places and includes recommendations for site protection. The evaluations consisted of archival research and field investigations.

Area Surveyed. Both project areas are located in the southeast portion of the Laboratory property. The W.J. Weeks house site evaluation encompassed $\sim 1$ acre, and the Weeks Campbell site evaluation encompassed $\sim 2$ acres. Fieldwork entailed surface inspection along with the excavation of shovel test pits to define spatial boundaries and artifact distribution patterns, and excavation squares ( $3.3 \times 3.3$ foot) to assess subsurface integrity and site function, and create larger exposures to search for buried features.

Results.

W.J. Weeks House site: The main occupation of the W.J. Weeks House site is mid nineteenth century. The age, density and diversity of artifacts, along with intact subsurface features suggest high research potential. Despite earlier looting/disturbance, the site is National Register eligible. Potential research topics related to this site may include: lifeways of otherwise "undocumented" people, in this case, tenant woodchoppers; socio-economic issues of non-land holding lower class in nineteenth century rural setting. (Merwin and Manfra 2005).

Weeks Campbell site: The main occupation of the Weeks Campbell site is late nineteenth-early twentieth century. The site has a relatively high degree of integrity, with several surface and subsurface features (agricultural landscape markers, the brick walkway, and most importantly, the foundation/cellar hole). The Weeks Campbell site appears to be National Register eligible. Possible research topics may include: late nineteenth century rural domestic lifeways of what was likely an agrarian family; also, the site yielded evidence of military occupation, probably World War I era, so might be important as a "satellite" site (even if not used for an official Army function) of Camp Upton. (Merwin and Manfra 2005)

3.4.2.6 Archeological Survey Status. A large majority of the BNL site has not been surveyed. While test excavations have revealed virtually no evidence of prehistoric and little evidence of historic cultural resources, additional testing and investigation has been recommended. In the 1974 report, Johannemann recommended that any areas proposed for construction or terrain alteration and not already surveyed, should require investigation (Johannemann 1974). Bernstein concluded that the BNL site might contain significant archeological resources, especially those related to the historic period after 1900 (Bernstein 2001b). Recently, the New York SHPO recommended that more in-depth archeological surveys, including fieldtesting where determined necessary, be conducted wherever ground-disturbing activities may be planned. An assessment of BNL's archeological field survey requirements was performed in 2003 (CRP-1003-01). Output from this report, including areas recommended for future archeological surveys, has been incorporated into BNL procedure RC-SOP-103 Project Reviews for Potential Impact to Cultural Resource." Refer to Section 4.2.2 Archeological Methods for descriptions of area field survey requirements.

3.4.2.7 Other Inventory/Assessment Activities. Activities that do not fall into either the archeological or structure/facility survey categories are presented below: 
- Cultural Resources Inventory of BNL. In 2001, BNL contracted with ILIA to document the prehistoric and historic period contexts for the property and to determine the probability of the presence of previously unknown cultural resources (Bernstein October 2001b). See CRP-2001-01 for additional details.

- Evaluation of Work War I Features. In 2002, BNL contracted with ILIA to document the location, extent, and nature of WW I period-features at BNL. This study also assessed whether the determination of National Register of Historic Places eligibility for WW I trenches on the property, made during the mid1970s, applied to other trenches on the BNL property (Merwin and Lam 2002). See CRP-2002-02 for additional details.

- Camp Upton Historical Collection Inventory. In 2002, cultural resource project CRP-2002-03 consisted of inventorying and cataloging the entire Camp Upton Historical Collection. The scope of the project included developing accession and collection record systems and database tables, and digitally photographing each item in the collection.

- Historic Firm Reels. In 2000, a collection of historic 16-mm film reels was converted on to high quality Betacam SP-BCT-90M tapes. A listing of the 19 tapes is available on the Cultural Resources website: http://www.bnl.gov/esd/cresource/historic_inventory.htm. Segments from these video tapes are being linked to the BNL homepage website feature "BNL: Now \& Then..."

\subsubsection{Excavation}

Test excavations were performed as part of each of the archeological surveys identified above. No largescale excavations have been performed or planned to date.

A large portion of the developed areas on the BNL site has experienced major ground-disturbing activity since the inception of BNL in 1947. Therefore, the potential for cultural resource artifacts in these areas is relatively low. Areas that have been identified as containing earthworks (training trenches) and foundations dating from World War I have remained relatively undisturbed. Areas in the immediate vicinity of historic sources of fresh water such as ponds and the Peconic River were identified as having the potential for prehistoric/historic Native American cultural resources. There are currently no defined plans for large-scale archeological excavations.

\subsubsection{Structure and Facility Management}

Specific CR management strategies have been, or are in the process of being, developed for the buildings or structures identified in Appendix B, “Cultural Significance Categories Table," as Category I or II facilities or programs. Appendix C contains the individual strategy forms. Some strategies may call for the development of specific architectural management plans or guidance documents to further describe specific requirements for the building. CRM concerns are being integrated into existing project review and building maintenance planning mechanisms. To date, the following mitigation efforts have been initiated.

Brookhaven Graphite Research Reactor (BGRR). As part of the Memorandum of Agreement between DOE and the NYSHPO on mitigating the decommissioning of the BGRR, the following projects have been initiated to date (Reference Attachment 37, MOA for BGRR).

- BNL contracted to inventory and appraise records relating to the BGRR's design, construction, operation, and maintenance. The records were assigned to series and retention recommendations were made for all items. A Microsoft Excel database of all records was developed and key-word descriptors were established. A list of all records and photographs in the BGRR files was produced. All records and photographs are currently retained on site at BNL. This project was performed from August 2000 to August 2001. (See CRP-2000-02).

- A video history of the BGRR was completed and distributed in September 2003. This project includes video interviews of several individuals directly involved with the BGRR including designers, project engineers, and scientists, and incorporates numerous photographs of the BGRR from construction and throughout its operation. See CRP-2000-03 for additional information.

- Development of a Researcher's Guide identifying specific information and documentation resources associated with the BGRR. This project is approximately 70 percent complete. 
- Additional BGRR mitigation actions include an assessment and curation of BGRR related tools and equipment.

World War II-Era Building Demolition Mitigation Packages. While the WW II-era buildings on site have been determined not to be eligible for listing on the National Register, they do represent a unique era in the history of the BNL site and are, therefore, considered items of "cultural interest.” The objective of these mitigation packages is to ensure that information related to the site's appearance and utilization throughout the different periods is retained. Mitigation packages, consisting primarily of photos and plan drawings (earliest available and current), were developed and submitted to the NYSHPO for the following buildings or types of buildings identified for demolition:

- Warehouse Buildings 89, 90, 91, 158, 209, 207, 208, and 209

- Buildings: 118, 184, 193, 194, 426, and 459

Actions.

- Complete BGRR mitigation actions identified in the MOA as financial resources permit (Researchers Guide and tools/equipment evaluation/curation).

- Integrate CR management strategy into BNL planning and maintenance programs.

\subsubsection{Laboratory Treatment}

Any laboratory treatment (processing, analysis, or special studies) of cultural resource materials, recovered as part of formal surveys, would have been performed by the professionally trained and qualified organizations that conducted the survey. At this time, minor cleaning actions are the only treatment method believed to have been performed. This process will be followed for future surveys. If the need for specific treatment actions were identified, BNL would consult with knowledgeable and qualified resources to determine the appropriate course of action.

\subsubsection{Curation}

The Camp Upton Historical Collection has been a part of the Laboratory since approximately the late1970s, and includes items found on site, as well as numerous donations. During CRP-2002-03, qualified personnel performed a complete inventory of the collection, including digitally photographing each item. Each item was then identified and stored in accordance with professional curation standards. A formal accessioning and cataloging system was established, and recommendations have been made with regard to future curation issues. This accessioning and cataloging system will be utilized for future collection management actions.

3.4.6.1 Curation Status. BNL currently does not have a formal program addressing curation of CR materials found as part of cultural survey or excavation actions, or items recovered onsite by employees. Over the years, BNL employees and contractors have recovered items on site, both surface finds and those as a result of construction project excavations. Due to the lack of a formal cultural resource program, many of these items were, and currently are, retained in the possession of individuals.

Action. Develop a curation/treatment program procedure addressing items recovered during formal surveys, old “finds" retained by individuals, and new discoveries.

\subsubsection{Preservation}

BNL currently does not have a formal program addressing preservation of cultural resources. Activities related to preservation are described below, and actions that must be evaluated for possible implementation are presented as goals/actions.

3.4.7.1 Protection from Natural Forces. At this time, this type of activity primarily applies to two categories of resources, World War I features, and scientific equipment. Other cultural resources, (buildings, and artifacts contained within) are protected by the Laboratory's overall fire protection program and wildfire management plan. 
World War I Features (training trenches and foundations). In CRM Project \#CRM-2002-02, the consultants recommend a preferred treatment of these features by preserving an adequate wooded buffer to minimize potential damage from construction or erosion (Merwin, et al. 2002). They also stated that erosion or other natural forces do not appear likely to immediately threaten most of these features. They recommended that a program be developed to periodically evaluate the extent and rate of erosion by performing sample measurements and comparing them to those documented during the 2002 and 1970s surveys, where possible. Attachment 8 identifies the location of these resources.

Equipment related to programs/facilities of recent scientific significance. One of the strategies associated with managing BNL facilities and programs of recent scientific significance is to maintain select pieces of equipment available for interpretation. Some of these items were set aside 10 to 40 years ago, and are now showing signs of deterioration from exposure to the elements. Protection or maintenance plans need to be developed for these types of items.

Actions

- Develop a monitoring plan for the WW I trenches.

- Develop evaluation/protection/maintenance plans for the scientifically significant display equipment.

- Develop map layer identifying location of equipment related to programs/facilities of recent scientific significance.

- Evaluate the potential effects of wildland fires on cultural resource areas and develop appropriate documentation (Section 106, Procedure(s), MOA, etc.) to address issues identified in DOE G 450-1.4 Wildland Fire Management Program.

3.4.7.2 Protection from Human Forces. The BNL NEPA program reviews projects for their potential environmental impacts, and includes cultural resource aspects in the review process. In addition, BNL's Digging and Trenching Permit process includes a review and signature by environmental program personnel knowledgeable in cultural resources. CRM concerns are being integrated into existing project review and building maintenance planning mechanisms to ensure significant features, sites and structures are not inadvertently damaged. A BNL site map identifying known cultural resource areas, sites, and buildings has been developed (Attachment 8, limited distribution only). This map will be used by the CRC in reviewing projects and to inform affected personnel/groups involved in project planning actions.

A similar map was distributed to the BNL Fire Group in order to minimize the potential for disturbing cultural resource areas in the event of a brush fire. The Natural/Cultural Resource Manager has also briefed the Fire Group on this issue

Protection of cultural resource areas from illegal actions is performed indirectly in that the entire BNL site is a posted and restricted area that is patrolled by security personnel.

In 2004, as a result of evidence of recent "pot hunting” and disturbance prior to the archeological evaluation, protective fencing was erected and warning signs posed around a 0.4 acre area encompassing the W.J. Weeks House Site. The site is located away from routine security patrol areas, and will be monitored periodically by cultural resource personnel (Reference CRP-2004-03).

Direct measures to protect other cultural resources have not been evaluated or developed.

Actions

- Develop cultural resource training; target specific groups such as Plant Engineering supervisors and engineers, security, fire, EM engineers, work control planners, etc.

- Develop a periodic surveillance process to monitor specific cultural resources as determined appropriate

- Develop communications methods discouraging BNL employees from collecting artifacts (include in CR subject area, general employee training, the Bulletin, Monday Memo, etc) 


\subsubsection{Research}

There have been no research efforts to date. Potential topics for research include, but are not limited to:

- WW I Trench Warfare Training Trenches - construction techniques (experimental vs. field manual)

- WW I Camp Upton grave relocation

- Existence of Native American sites around fresh water areas

- Nineteenth-century house sites (refer to section 3.4.2.5 Archeological Surveys for addition details)

- Historic trails and roads within the BNL site

- Scientifically significant facilities, and their contributions

\subsubsection{Outreach}

While the Environmental Compliance staff is responsible for the BNL Cultural Resource Management Program, the program is complemented by other BNL organizations, including the Director's Office (BNL Historian), and the Community Involvement Office, which oversees the Camp Upton Historical Collection. This section describes current outreach activities performed by these groups, along with past outreach accomplishments.

\subsubsection{Activities on the DOE Site.}

Camp Upton Historical Collection - Since the 1970s, BNL has maintained a collection of items related to the U.S. Army's occupation of the property as Camp Upton during both World War I and II (Reference section 3.3.2 for additional information on the collection). In the past, displays have been established and the collection had been opened to the public during BNL "open house” tours and through scheduled appointments. Most recently, portions of the collection were temporarily displayed in the lobby of the cafeteria/lecture hall as part of BNL's Summer Sundays open house days. The Community Involvement Office oversees the collection including funding a portion of an FTE (full time employee) who is responsible for overall collection management including, but not limited to, outreach, and curation issues.

Current Status. In 2003, the collection was relocated to a building having a climate-controlled environment (air conditioned/heated). While a majority of the collection is currently not on display, the new storage arrangement provides access to the collection for inventory, and selection of items for development of smallscale temporary displays. Reference CRP-2002-03 for details on the inventory and catalog project.

Camp Upton Historical Collection Website. The following website, managed by the Community Involvement Office, presents photos and information pertaining to Camp Upton and the collection: http://www.bnl.gov/community/campupton1.htm.

Camp Upton Related Publications. Over the years BNL has published several articles related to Camp Upton history in its weekly employee newsletter, the Brookhaven Bulletin. Other promotional type publications have included postcards of Camp Upton photos, flyers, etc.

Camp Upton Video. A 12-minute video on the history of Camp Upton was produced by BNL in 1985 . The video has been shown as part of the collection tour, during open houses, and as part of off-site presentations. The video can also be viewed from the internal BNL network at the following website:

http://intranet.bnl.gov/video/main_i.htm.

BNL History Website. The following website, managed by CEGPA, presents photos and information pertaining to the scientific history of BNL, including major facilities, discoveries and Nobel Prize awards: http://www.bnl.gov/bnlweb/history.html. The homepage of the BNL website also contains the feature "BNL: Now \& Then...” which presents a new historic BNL photograph each day, along with a descriptive caption, and a link to a web-video obtain from historic film reels. 
Cultural Resources Website. The following website, developed in 2002 and managed by the Cultural Resource Coordinator, presents information related to the cultural resource management program, and links to the related websites identified above: http://www.bnl.gov/esd/cresource/home.htm.

BGRR History Video. This 64-minute video presents a history of the BGRR through the recollections of key individuals that contributed to its success as a premier research tool, throughout its 18-year operating history, (1950-1968). BNL Historian Robert Crease narrates the design, construction, operation, scientific research and shutdown of America's first nuclear reactor designed for peacetime civilian applications. Physicists, engineers, and scientists describe the challenges and rewards of their accomplishments, along with the experiences of everyday life associated with the BGRR. This video was completed and distributed in September 2003.

Partnership with Longwood Public Library. In 2005, BNL agreed to partner with the Longwood Public Library in grant application related to a World War I video review/discussion series. As part of the partnership, BNL would work to arrange public tours of the WWI Trenches. While the library was not awarded the grant, BNL will work to assist Longwood in establishing a WWI program.

Publications. BNL Historian, Robert Crease has published articles on Brookhaven programs in prominent history of science journals and elsewhere. Listed below are some of those titles.

"Fallout: Issues in the Study, Treatment, and Reparations of Exposed Marshall Islanders" [this involved a BNL program], in Exploring Diversity in the Philosophy of Science and Technology, ed. by Robert Figueroa and Sandra Harding, Routledge, 2003, pp. 106-125.

“Anxious History: The High Flux Beam Reactor and Brookhaven National Laboratory,” Historical Studies in the Physical Sciences 32, Part 1, 2001, pp. 41-56.

“Conflicting Interpretations of Risk: The Case of Brookhaven’s Spent Fuel Rods.” Technology: A Journal of Science Serving Legislative, Regulatory, and Judicial Systems, V 6 (1999): 495-500.

"The History of Brookhaven National Laboratory Part Six: The Lab and the Long Island Community, 19471972.” Long Island Historical Journal (LIHJ), 9:1 (Fall, 1996): 4-24.

“The History of Brookhaven National Laboratory Part Five”, LIHJ 4:2 (Spring 1995).

“The History of Brookhaven National Laboratory Part Four: Problems of Transition,” LIHJ 7:1 (Fall 1994): 22-41.

“The National Laboratories and Their Future,” Forum, Winter, 1993.

“The History of Brookhaven National Laboratory Part Three,” LIJH 6:1 (Fall, 1993).

“The History of Brookhaven National Laboratory Part Two: The Haworth Years,” LIHJ 4:2 (Spring 1992).

“The History of Brookhaven National Laboratory Part One: the Graphite Reactor and the Cosmotron,” LIJH 3:2 (Spring 1991): 167-188.

Lectures. BNL Historian Robert Crease has presented eight BNL lectures related to the history of BNL's development, its scientific achievements and facilities.

3.4.9.2 Activities Not on the DOE Site. Activities not carried out at the BNL site are listed below. 
Making Physics - A Biography of BNL, 1946-1972. Written by BNL Historian Robert Crease, this book describes the history of BNL from the Laboratory's inception in 1946 until 1972 and provides a unique view of the people, instruments, science, and politics of BNL history (Crease 1999).

Professional History of Science Meetings. Robert Crease founded the Laboratory History conference series that meets approximately every two years. The first such conference was held at Stony Brook University and BNL in 1998. He actively participates in other professional history of science meetings.

Presentations to Off-Site Organizations. Over the years, many presentations related to Camp Upton have been given to off-site organizations such as local civic associations, historical societies, and community groups. Details of presentations performed prior to 2000 are not available. Those performed after 2000 are listed in Attachment 13, which will be updated periodically. Note: The Community Involvement Office maintains reports that document each outreach activity performed by their group.

Off-Site Displays. Display booths presenting information on the history of BNL and/or Camp Upton are occasionally setup at local events such as the Brookhaven Town Country Fair at Longwood Estate, Wading River Duck Pond Day, and so on. These events are also listed in Attachment 13.

Brookhaven Town $350^{\text {th }}$ Anniversary. In 2004, BNL established a committee, made up of individuals from CEGPA and the CRC, to work with the Brookhaven Town $350^{\text {th }}$ Anniversary Committee. BNL provided the Town Anniversary Committee with written information on the Laboratory and site history, for a book they are developing, and also developed a poster designed for the Town's traveling display.

3.4.9.3 Outreach Status. Community outreach activities to date have tended to focus on one aspect of BNL cultural resources: Camp Upton and the associated historical collection. Although this is a major part of the program, additional areas should be conveyed such as science history and overall site history (Pre-WW I, CCC, etc.). In 2001, the BNL Cultural Resources Coordinator drafted a video script on the history of the BNL site and identified historical photos for potential inclusion in the video. The project lost funding at the end of the fiscal year, but can be resurrected once funding is established. The CRC and the BNL Tour Coordinator have preliminarily identified a proposed CR tour route. Talking points for a tour program and visual aids require additional development and refinement.

Actions

- Increase interactions with local historical societies and other internal/external outreach opportunities, offering presentations on BNL history and the BNL Cultural Resources Management Plan.

- Develop a cultural resource tour program, including talking-points script and visuals.

- Develop CR presentation and display materials.

- Continue expansion of the cultural resource website.

- Work with CEGPA to develop a communications plan associated with the CRMP, considering Bulletin and Monday Memo articles, presentations to the BNL community, the Community Advisory Counsel, and the Brookhaven Executive Roundtable, as appropriate.

\subsubsection{Other CRM Accomplishments}

In November 2000, the conceptual project for establishing a Camp Upton Historical Museum Complex (CUHMC) was designated an Official Project of Save America's Treasures. Save America's Treasures is a partnership between the White House Millennium Council and the National Trust for Historic Preservation. The concept for the CUHMC was to establish a historical setting of Camp Upton on the BNL site, designed to provide the appropriate atmosphere for public interpretation and education with regard to the contributions the BNL site has made in our military history. The CUHMC would include: WW II-era buildings relocated from other areas on the BNL site and restored to their original presentation, expanded space for the Camp Upton Collection and associated programs, and establishing access to the WW I Training Trenches. 
Status. This concept of establishing a historical setting has not been further developed, primarily due to the cost of relocating buildings and re-routing utilities. Plans for improving access to the WW I training trenches and developing a tour program are being pursued. A management strategy has been developed for Building 120, essentially the only two-story, WW II-era barracks-style building that has not had major exterior renovation. The strategy maintains the building's exterior presentation so it can serve as an example of these once-ubiquitous WW II structures.

\subsection{LEGAL COMPLIANCE ACCOMPLISHMENTS}

\subsubsection{National Historic Preservation Act 1966 (NHPA), Executive Order 11593, and 36 CFR 800}

All BNL projects are reviewed for their potential impacts on the site's historic resources as part of BNL's formal NEPA program. The BNL Standards Based Management System (SBMS) contains the subject area "NEPA and Cultural Resource Evaluations" describing the review process. Section 4.2.2 of this CRMP, NHPA Section 106 Reviews, describes the Section 106 process employed by BNL.

The BNL Cultural Resource Management Program actively promotes efforts to identify properties eligible for listing on the National Register of Historic Places. Cultural Resource Project No. CRP-2000-01 evaluated all BNL buildings and structures for National Register eligibility. Since the BNL cultural resource program has become more focused, starting in 1999, two additional properties have been determined eligible for listing; the Brookhaven Graphite Research Reactor (BGRR) and the High Flux Beam Reactor (HFBR). In 2002, the 1979 determination of eligibility for the World War I training trenches in the ISABELLE project area of impact was evaluated and considered to extend to the other trenches and WW I features extant on the BNL property (Merwin et al. 2002). Sections 3.3.2 and 3.3.4 of this CRMP provide descriptions of these eligible resources. Section 4.0 includes specific strategies for managing each identified cultural resource, including nominating certain properties for actual listing on the National Register.

\subsubsection{American Indian Religious Freedom Act (AIRFA) \& E.0 13007}

To date, resources important to Native Americans, such as sacred sites, traditional-use resources, and Native American cultural items, have not been identified on the BNL site. No local Native American group has indicated that such sites may be present on BNL property. If such items are identified in the future, BNL will initiate appropriate consultation with Native American tribes and the NY State SHPO, and the requirements associated with AIRFA and Executive Order 13007, Indian Sacred Sites, dated 5/24/96, will be implemented. Refer to the Archeology Sensitivity section of Appendix A for additional details.

The Shinnecock tribe, a New York State recognized tribe located on Suffolk County, is currently seeking federal recognition.

\subsubsection{Archeological Resources Protection Act (ARPA) - 1979, Amended 1988}

Much of the material contained in this section is based on Bernstein and colleagues (2003). ARPA regulations apply to remains of past human activities or lifeways that are at least 100 years old. Currently, two sites located on BNL property fall under the purview of ARPA: the W.J. Weeks House Site, and the Weeks Campbell Site. In addition, as the 100-year anniversary of the formation of Camp Upton approaches in 2017, the BNL CRM program will need to ensure that any ARPA issues are addressed.

3.5.3.1 Archeological Permits. ARPA requires issuance of a permit prior to the excavation of archeological resources (at least 100 years old) on federal property. DOE has issued one federal archeological permit to date for an action on the BNL site (see Section 3.4.2.5, Archeological Surveys, for additional details). A permit is not currently required for excavation of World War I-, CCC-, or World War II-era sites, however, as a best management practice, the permit process would be instituted for non-BNL sponsored actions.

3.5.3.2 Archeological Protection. The BNL site is a relatively secure area. Unauthorized individuals are not permitted on the BNL site and identification badges are required to be worn by all employees and guests. Although the property is posted and BNL security forces regularly patrol the property, it is not fenced and 
unauthorized access is possible. Reference section 3.4.7.2 for details on specific protective measures that have been implemented.

3.5.3.3 ARPA, Section 10c. Section 3.4.9 of this CRMP identifies outreach activities associated with BNL cultural resources, including program goals.

3.5.3.4 ARPA, Section 14. Sections 3.4.2.5 and 3.4.2.6 of this CRMP identify archeological surveys performed to date, along with the status and goals for future surveys.

\subsubsection{Native American Graves Protection and Repatriation Act (NAGPRA)}

To date, no artifacts requiring invocation of NAGPRA regulations have been identified on the BNL site. If such items are identified in the future, appropriate consultation with Native American tribes and the NY State SHPO will be initiated and the requirements associated with NAGPRA will be implemented. Refer to the Archeology Sensitivity section of Appendix A for additional details.

\subsubsection{Curation of Federally-Owned and Administered Archeological Collections (36 CFR Part 79)} Curation of Federally Owned and Administered Archeological Collections (36 CFR Part 79) addresses requirements that "generally include those that are the result of a prehistoric or historic survey, excavation or other study conducted in connection with a Federal action, assistance, license or permit” (Bernstein et al. 2003). "This means that materials collected by other means (e.g., donation, field finds) are not specifically covered under CFR Part 79” (Bernstein et al. 2003). The Camp Upton Historical Collection contains items found on site by individuals, as well as those obtained through donation. Regardless of whether the stated requirement is directly applicable, BNL is committed to managing the collection in accordance with established museum standards, to the extent that resources permit. See Section 4.2.4 for additional information on curation methods.

Materials that are classified as federal archeological items are to be treated and curated in accordance with 36 CFR Part 79 requirements. The following pre-existing collections may fall under the purview of the requirements:

1. Items from “A Stage 1B Archeological Survey for the Proposed Railway Extension at BNL” include artifacts. According to the original report and field records, those artifacts include nails, two coins, and pieces of bottle glass, window glass, coal, brick, porcelain, insulator, mortar, and concrete.

2. A small number of items collected on the surface of a WW II-era midden during the course of the trenchmapping project (CRP-2002-02).

3. Artifacts from the Islander East Pipeline Project, including one piece of "fire-charred whiteware and one piece of quartz chipping debris" and associated records.

4. A small collection of twentieth-century material and associated records from the Eastern Long Island Extension Project.

5. Artifacts from the W.J. Weeks House site and the Weeks Campbell site.

3.5.5.1 Assessment of BNL Compliance to 36 CFR Part 79. The following summary highlights a rough assessment of the CR program's compliance with 36 CFR Part 79, Curation of Federally Owned and Administered Archeological Collections. Note: Areas requiring development are identified in Section 3.5.5.2.

Standards for determining if a repository possesses capability to provide long-term curational services:

Requirement: Able to accession, label, catalog and store using professional museum and archival practices. Assessment: CR Project \# CRP-2002-03 inventoried all items in the Camp Upton Collection, and developed a catalog/accession/labeling system. Future additions to the collection will utilize these established protocols.

The processes outlined in Section 4.2.1, CRM Records and Reports, will be used when BNL staff encounter previously undocumented artifacts or records and when BNL accepts materials and records collected or produced during compliance or research projects. These items will be stored in accordance with professional museum and 
archival practices by either integrating them into the Camp Upton Collection, establishing a separate CRM collection at BNL, or arranging to curate items and records with a qualified organization off site. These items may not always be accessioned into the Camp Upton Collection.

Requirement: Able to maintain records related to the collection such as description, location, accession, approved loans/other uses, field notes, inspection and environmental monitoring records, deaccessions, etc. Assessment: The systems identified above (CR Project \# CRP-2002-03, and CRMP Section 4.2.1) provide a solid foundation for these records.

Requirement: Maintain dedicated facilities and equipment to store, study and conserve the collection ....and keep under physically secure conditions, including the following:

- Facility meets fire, building and safety codes. Assessment: The storage facility meets all BNL fire and safety codes. However, the facility does not meet the National Fire Protection Association (NFPA) Standard on Cultural Resources, NFPA 909. NFPA 909 includes requirements for firewalls separating storage areas and smoke detectors protecting storage rooms, both of which are lacking in the BNL facility.

- Appropriate fire detection and suppression system. Assessment: Fire detection and suppression systems are present in the storage area. See above assessment.

- Appropriate intrusion detection and deterrent system. Assessment: Facility does not have an intrusion detection and deterrent system. However, building key distribution is limited, the BNL site is routinely patrolled, and gate access is controlled.

- Adequate emergency management plans for responding to fires, floods, etc. Assessment: BNL's emergency response and Building Manager systems adequately address this issue.

- Additional security for fragile or valuable items. Assessment: Collection items are stored in locked cabinets or display cases.

- Limiting and controlling access to keys. Assessment: BNL maintains a key control system that minimizes the distribution of building keys, and keys for collection cabinets are on a very limited availability (one or two individuals).

- Inspections for security and environmental controls. Assessment/goal: A program for conducting regular inspections needs to be developed and implemented.

Requirement: Require staff and consultant to be qualified museum professionals. Assessment: Current staff is not qualified museum professionals; however, consultants hired to perform CRM projects are qualified and experienced.

Requirement: Handle, store, conserve, and exhibit collection in a manner that protects items from adverse temperatures, relative humidity, visible light, ultraviolet radiation, mold, insects, etc.

Assessment: The Camp Upton Collection is stored in a climate-controlled building, and environmental monitoring devices have been purchased. The CRC has attended training on basic conservation and storage/display methods. Reference materials provided during this training and those identified in CRMP Section 4.2.3, Laboratory Treatment and Curation, are available and should be utilized as primary guidance for these types of activities.

Requirement: Store site forms, records, inventories, computer disks, reports, etc. in a manner to protect them from theft and fire, such as:

- Storing in properly insulated, fire resistant, locking cabinets or in a location with a fire suppression system. Assessment. Records are stored in metal cabinets in buildings that have fire detection and suppression systems.

- Storing a duplicate set of records in a separate location, or ensuring records are maintained by another party such as SHPO, university, etc. Assessment. Copies of CR reports are provided to the onsite DOE Office as well as the NYSHPO. The author maintains bNL-generated documents, with a separate copy filed in the departmental records file system. Copies of the Camp Upton Collection inventory and accession files are maintained in separate locations. Digital records are stored in a CEGPA office, the CRC office, and on a password-protected BNL network server. Print copies of these records are also maintained with the collection.

Requirement. Periodically conduct inspections and inventory for security and environmental controls, including:

- Assessing condition of collection, signs of deterioration/damage

- Inventories to verify location of material remains and records 
- Have qualified museum professionals conduct inspections and inventories.

Assessment. A program for conducting regular inspections and inventories that satisfies the above requirements needs to be developed and implemented.

3.5.5.2 Areas Needing Action. The following actions are required to ensure that all CR-related activities are maintained in compliance with applicable regulations and best management practices.

Actions

- Formalize Camp Upton Collection catalog/accession/labeling/storage system by incorporating it directly into a BNL procedure, or by reference.

- Evaluate the appropriate means of establishing a catalog/accession/labeling/storage system for general CR materials and records such as integrating them with the Camp Upton Collection, establishing a separate CRM collection at BNL, or arranging to keep the curated items and records with a qualified offsite organization.

- Incorporate site forms and numbering system into one or more ESH\&Q SOPs.

- Contact organizations currently possessing materials and records identified in this section for a complete accounting and copies of records, requesting that items be returned to BNL/DOE as determined appropriate.

- Develop procedures to address the approval process for loaning or using collection items, based on 36 CFR Part 79 Appendix C.

- Evaluate options related to improving fire code-related issues and fire detection/suppression systems.

- Evaluate the need for, and extent of, intrusion detection/deterrent system and consider tightening building access in the collection storage areas.

- Develop a program for periodic security and environmental monitoring and inspection.

\subsubsection{Executive Order 13287, Preserve America}

Executive Order 13287, Preserve America, requires each federal agency to ensure that the management of historic properties in its ownership is conducted in a manner that promotes the long-term preservation and use of those properties as federal assets, and (where consistent with agency missions and governing law) that the nature of the properties contributes to the local community and its economy. The BNL CRMP meets the intent of this policy by formally documenting BNL's historic resources and associated management strategies. Cooperation with programs that contribute to the local community and its economy is encouraged and will be supported, provided the necessary resources are available.

The Order also requires federal agencies to prepare specific cultural resource assessments/reports. Upon request, BNL will work with DOE to prepare and/or provide the necessary information for the applicable actions. Most of the information will likely be taken from various sections of the CRMP.

\subsubsection{Other Regulatory or Reporting Requirements}

Each February or March, the DOE requests BNL to provide information related to cultural resource management and archeological activities for use in completing a questionnaire "Department of Interior Questionnaire On Fiscal Year Federal Archaeology Activities.” The BNL Cultural Resources Coordinator prepares the necessary information, which is then formally submitted by the Division Manger to DOE's Brookhaven Site Office (DOE-BHSO). 


\subsection{CULTURAL RESOURCE MANAGEMENT STRATEGIES AND METHODS}

This section describes management strategies associated with either individual resources or groups of resources, and the methods and protocols utilized in their management. Programs/systems requiring development are also identified. Applicable portions of this section will be revised as these new systems are developed and implemented.

\subsection{CR Management Strategies}

Overview: In developing an overall strategy for managing BNL’s culturally significant resources, information from the following sources was used to identify those assets that should be appropriately recognized, documented, and made available for research, interpretation, and appreciation: institutional knowledge, contractor evaluations, and NYSHPO input (including building significance rankings). Approximately 13 principle cultural assets were identified and categorized (ranked) according the significance levels outlined in Section 4.1.2. These principle assets can be grouped into four types of resources:

- Historic or Unique Sites. Includes sites and earthwork features related to WW I Camp Upton, nineteenth-century house sites, and a unique area that encompasses scientific, cultural, and natural resource aspects

- Scientific Achievement and Engineering Design. Includes facilities and programs related to BNL scientific achievements and design

- Architecturally Significant. Buildings designed by famous architects

- Period Representation. Buildings not NRHP eligible, but representative of two periods in the site's history (the 1930s Civilian Conservation Corp and 1940s Camp Upton).

Note: Attachment 35 lists the principle resources within their respective types. Management Strategy Forms were developed for each individual resource, taking into account BNL's planned uses for the structure or area, interpretive options, contractor recommendations, and realistic funding and resource expectations (see Section 4.1.1 below and Appendix C). Strategies associated with additional resources and those that may be considered supporting assets are describing within this section of the CRMP.

\subsubsection{Management Strategy Forms}

A Cultural Resource Management Strategy Form (Attachment 14) is to be developed for each major resource in order to describe how it will be managed in a consistent and concise manner. Each section of the form is to be completed to the extent that a strategy has been formulated. Two sections of the form, "Plans for Bldg. or Site" and "Treatment / Mitigation Plans," are designed to serve as the principle guide and agreement for managing the resource. Two "levels" of Treatment/Mitigation Plans are also presented that identify more specific types: Level A lists activities that have already been achieved, are in progress, or are considered relatively achievable. Level B lists activities that would likely require considerably greater resources (funding, manpower, etc.) and would only be performed if those resources could be allocated. Revisions that change the scope or intent of these sections require BNL/DOE review and approval, and must be submitted to NYSHPO. Other sections that provide background and supporting information may be revised informally. Once a form has been developed, and upon major revision, the BNL CR Coordinator has the responsibility to:

- Obtain concurrence from BNL management

- Obtain concurrence from DOE-BHSO

- Ensure DOE-BHSO submits document to SHPO for review and 30-day comment period

- Incorporate forms into Appendix C of the CRMP.

Each Strategy Form shall include a Revision Number and Issue Date, so that individual forms may be revised/added without having to update the entire CRMP. The forms will serve as the summary document outlining the strategy by which the associated resource will be managed. In some cases, more detailed 
treatment or mitigation plans and procedures may be required to address specific issues. These plans are to be referenced on the Strategy Form.

Appendix C, Cultural Resource Management Strategy Forms, contains the detailed strategy forms developed to date.

\subsubsection{Cultural Significance Categorization Levels}

Three categories defining levels of potential historic significance are described below, along with general treatment and/or mitigation strategies. Appendix B, the Cultural Significance Categories Table, identifies specific buildings, sites, or programs included within each category.

4.1.2.1 Cultural Significance Category Descriptions. The three categories for cultural significance are described below, along with the treatment or mitigation options.

Category I. A building, site or program determined to be historically significant due to historic context; architecture, engineering and design, direct association with important personages, or scientific achievement. The resource(s) may be individually eligible for listing on the National Register; however, eligibility is not a requirement.

Treatment and/or mitigation: Some degree of treatment and/or mitigation is necessary to ensure that cultural significance is retained and available for interpretation. Examples include, but are not limited to:

- Specific treatment or architectural management plan, if architecturally significant

- Documentation of engineering and design, and scientific achievements (photos, scale models, document archives, etc.)

- Development of a Researcher's Guide

- Preservation/display of associated equipment.

Category II. A building, facility, or site that directly supported a significant BNL program, or uniquely represents a specific period in the evolution of BNL's site history and has had little alteration.

Treatment and/or mitigation:

- For support buildings, as-built drawings and photos; documented description of structure's role (may be included in existing facility description documents).

- For period structures: treatment plans to minimize further alteration of specifically identified aspects (implementation is funding dependent). Mitigation would entail documentation of as-built drawings and photos.

Category III. Buildings or structures that supported lab-wide programs and may be representative of the evolution of government use of the site. Buildings in this category include the World War II-era buildings. During a site visit (January 3, 2003), NYSHPO agreed that these structures would not be considered eligible for the National Register. However, since these types of structures do represent a distinct period in the site and BNL history, the following means may be used to document their association.

Treatment and/or mitigation. Document the development and evolution of the site by archiving engineering and plan drawings of site layout, building plans and photos for select structures, and aerial photos.

\subsubsection{Scientific Facilities and Programs}

General management strategies associated with groups of resources, and those not described on Strategy Forms, are presented in this section.

Most of BNL's scientifically significant historic resources are associated with large scientific facilities that are currently operating, structures modified over the years for alternative uses, and those contaminated or undergoing decommissioning actions. Other aspects pertain more to scientific programs and 
accomplishments, rather than buildings and structures. The general approach for managing historic resources associated with BNL scientific facilities and programs is to emphasize the significance of the scientific achievements and their contributions to society, rather than focusing solely on buildings or structures. Engineering and design aspects of buildings or facilities will be documented and maintained available for interpretation through the use of scale models, equipment artifacts and displays, and archived engineering drawings and photographs. When buildings or structures are expected to remain in place, architectural guidelines and management plans may be developed to identify specific architectural or functional aspects associated with a structure. These structures may also be included as part of cultural resource tours.

\subsubsection{World War II-Era Structures}

Many structures on the BNL site were constructed in the 1940s as part of World War II Camp Upton. Most of these buildings have been altered to improve their energy and space efficiency and appearance. Typical renovations include vinyl siding, replacement windows, reconfiguration of interior space for office modernization, and so on. Based on correspondence with representatives from NYSHPO, and confirmed by a visit to the BNL site in January 2003, the NYSHPO has indicated that BNL's World War II-era structures do not retain enough integrity to convey their historic function and are therefore not considered eligible for listing on the National Register of Historic Places.

Although these structures are not eligible for listing, they do represent a specific time period in the history of the BNL site. The Cultural Resource Program will use the following means to ensure that this period remains available for interpretation:

- Retain or archive original plan drawings

- Develop an overlay map depicting WW II Camp Upton overlaying existing BNL site.

- Develop documentation packages as select WW II-era structures are demolished. Packages will contain earliest available photo(s), current photos, references to available architectural drawings, and description of various building uses.

- Maintain and augment (as possible) the Camp Upton Historical Collection.

- Maintain the two-story barracks-style Building 120 as a "representative structure" from the WW II era. (Refer to associated CRM Strategy Form for additional details.)

By documenting (in this CRMP) the ineligibility of the WW II-era buildings for listing on the National Register, BNL acknowledges that any future actions involving these structures would not require the development of a Section 106 Review package.

\subsubsection{Camp Upton Historical Collection}

The Camp Upton Historical Collection is one of the unique historical resources present at BNL. It assists in interpretation of the site's history through historic photographs and donated documents and artifacts (refer to Section 3.3.2 for additional descriptive information on the collection). The strategy associated with this resource is one of continued cooperation between two BNL organizations, Community Education, Government and Public Affairs (CEGPA) and Environmental Compliance.

The Camp Upton Historical Collection is managed and funded through CEGPA. An individual from CEGPA has the responsibility to oversee the Camp Upton Historical Collection and to develop and implement related outreach programs. The collection is only a portion of this individual's overall roles and responsibilities.

The Cultural Resource Coordinator (CRC) coordinates with CEGPA on issues related to compliance with historic and cultural resource laws and regulations, as they are determined to apply to the collection. Areas of interaction include identifying regulatory requirements, assessing compliance, informing CEGPA of existing or potential compliance related deficiencies, and providing recommendations for best management practices. The CRC also periodically assists with outreach activities.

Current expectations are to continue to house the collection at BNL. The collection is currently considered "in storage" and is not on display. The collection is stored according to an inventoried management system, 
and items are easily accessible to permit establishing temporary displays. Near-term plans ( $3-5$ years) include maintaining the collection in its present environmentally controlled (e.g., air conditioned/heated) storage facility. Temporary displays will be established periodically for events such as BNL Summer Sunday open house days.

Goal. Maintain the Camp Upton Historical Collection at BNL, and develop ways to increase its availability for interpretation.

Actions

1. Evaluate the potential for establishing a more permanent area for rotating display themes of Camp Upton Collection items.

2. Develop a formal Collections Management Policy to guide future decisions on the collection, including what the collection will contain, processes for accepting items into the collection, loans, deaccessioning, and so forth.

3. See additional actions identified in Section 3.5.5.

\subsubsection{Document, Audio, Video, and Photographic Archives}

BNL maintains documents (architectural and plan drawings, BNL newsletters, etc.), audio-video, and photographic archives in several locations around the BNL complex. Many of these are associated with the early development and operations of BNL, or unique scientific programs.

Goal. Ensure these document collections are maintained as supporting assets to the Laboratory's cultural resource program.

\section{Actions}

1. Identify location and content of the potential significant document resources.

2. Develop methods to identify these as historic or supporting resources, verify/assign responsible personnel/organizations/points of contact, and assure proper storage/archiving.

\subsubsection{Oral Histories}

BNL possesses audio and videotape interviews with BNL founders, research leaders and administrators. These interviews were performed by different individuals over the years and consist of the following general groupings:

BNL Oral Interviews. Video interviews, conducted in the mid-1980s, of 30 individuals involved in the founding of BNL. Conducted by Lou Harson, BNL's principle architect (1976-1986) and an amateur historian. These interviews were also transcribed.

Crease Audio Interviews. BNL Historian Robert Crease conducted approximately 100 oral interviews of BNL founders, research leaders, and administrators.

BGRR History Interviews. Fifteen video interviews associated with the BGRR History video were conducted by Robert Crease in 2000.

Cosmotron Interviews. Robert Crease conducted interviews of three individuals associated with the Cosmotron

Chemistry Department Interviews. Robert Cease conducted video interviews associated with the Chemistry Department, Ray Davis (Nobel Prize winner), and G. Friedlander.

NSLS History. R. Crease conducted three video interviews, associated with the design and development of the National Synchrotron Light Source, in 2004. 
Attachment 35, Oral History Interviews, presents a more detailed listing of these resources and will be periodically revised as additional information is identified.

Attachment 36, BNL Oral History Program - Overview and Planning Document, presents the current strategy for managing this program.

Goal. Establish a more formal program for conducting oral histories based on National Park Service guidelines.

\section{Actions}

1. Identify location and content of the oral histories.

2. Develop methods to identify these as historic or supporting resources, verify or assign responsible personnel, organizations, or points of contact, and assure proper storage or archiving.

3. Evaluate the possibility of incorporating the BNL Historian's role as part of the CRM program.

4. Develop a list of key figures in BNL's scientific history for interview.

5. Develop a procedure for triggering and conducting oral histories of employees retiring with [some number to be determined] years of service.

\subsubsection{White Pine Trees}

Some of the few remaining vestiges of the Civilian Conservation Corp's presence on the BNL site are the groves of white pine trees. These trees were planted as part of the CCC's reforestation project in the 1930s. While the Laboratory currently makes every effort to remove as few trees as possible (of any species) during any maintenance or construction action, potential impacts to the white pines will receive additional evaluation and consideration. The additional scrutiny will ensure that the white pines remain as an example of a specific and unique era in the site's history. The white pines will also be managed under and integrated with the BNL Natural Resource Management Plan.

\subsection{CRM METHODS}

\subsubsection{Cultural Resource Management Records and Reports}

This section is intended to be practical in nature and identifies the basic procedures and protocols BNL intends to follow for managing collections and records. These protocols conform to those in use throughout the United States, with New York State requirements specified wherever appropriate. Much of the information presented in this section was derived from Bernstein (2003a), developed for Cultural Resource Project \#CRP-2003-01.

Existing record systems related to cultural resource management are identified and described as follows:

4.2.1.1 File Codes. The following file codes have been assigned to records related to the Cultural Resource Management Program in accordance with the BNL Records Management System. The XX at the end of the file code corresponds to the last two digits of the year the document was generated. (For example, ESDEC130ER.02 is for a letter generated in 2002.)

$\begin{array}{ll}\text { CRMP general correspondence } & \text { EC130ER.XX } \\ \text { NHPA Section 106 Reviews } & \text { EC131ER.XX } \\ \text { SHPO } & \text { EC132ER.XX } \\ \text { Accessions } & \text { EC133ER.XX } \\ \text { Sites } & \text { EC134ER.XX } \\ \text { Projects } & \text { EC135ER.XX }\end{array}$

The appropriate file code is to appear on the record, and the record is placed in the designated file. Two to three years' worth of records are filed in a central file room of the Environmental Compliance group. After that time, the records are transferred to the BNL Records Holding area. The Cultural Resources Coordinator also maintains "working copies" of these files, records, and reports. Records determined to be sensitive with respect to the location of cultural resources are filed in locked cabinets. 
Prior years' CRM records may be identified with the following file codes:

2002 (Jan-Sept)

2000-2001 NEPA Compliance

Pre-2000
ESD-EC54, 55, or 56, ER.02

ESD EC50ER.XX

Designated Safety and Environmental Protection (SEP)

Division files

4.2.1.2 Projects. CRM projects initiated in 1999 or later are assigned a unique number as follows:

$$
\text { CRP - year initiated - sequential number }
$$

For example, CRP-2002-01 would correspond to the first project initiated in year 2002. Attachment 9 presents a database/list identifying projects performed or initiated to date.

4.2.1.3 Archeological Site Form and Numbering System. A separate site form is to be completed for every archeological site (prehistoric and historic) on BNL property. If both prehistoric and historic sites are identified at the same location, then separate forms are to be completed for each of the two components. A unique site number, obtained by contacting a representative of the New York State Historic Preservation Officer, is to be assigned to each identified site. Note: Only the NYSHPO numbering system should be used for newly discovered sites. Attachment 16, Archeological Site Numbers, identifies sites that have been assigned official NYSHPO numbers to date. Attachment 17, New York State Prehistoric Archeological Site Inventory Form, and Attachment 18, New York State Historic Archeological Site Inventory Form, are copies of the forms to be used by BNL.

4.2.1.4 Trench and Foundation Feature Inventory and Forms. The numbering scheme and forms developed during the 2002-2003 evaluation of the World War I-era features at BNL are to be utilized to record information on newly discovered trenches and foundations (see Cultural Resource Project \#CRP-2002-02). Attachment 19, BNL Trench Feature Inventory Form, and Attachment 20, BNL Foundation Feature Inventory Form, present examples of these forms.

4.2.1.5 Cultural Resources Accession Receiving Report Form. Attachment 21 presents a copy of the blank form that is to be used when BNL staff encounters previously undocumented artifacts or records, and when BNL accepts materials and records collected or produced during compliance or research projects.

4.2.1.6 Camp Upton Historical Collection. Cultural resource project \#CRP-2002-03 consisted of inventorying and cataloging the entire Camp Upton Historical Collection. The scope of the project also included the development of accession and collection record systems and database tables. The BNL Camp Upton Cataloging Project - Completion Report, March - September 2002, and Addendum to Completion Report, February 2003 (Czarniecki et al. 2002, 2003) presently serve as the process for cataloging the collection. These documents describe the accession and cataloging system and database established for the collection. This system is to be utilized for future additions to the collection. Attachments 22 and 23 present blank copies of the Accession Record Form and the Cataloging Worksheet.

4.2.1.7 Duplicate Copies. Duplicate copies of all CRM documents and records are to be maintained in separate locations, whenever practical. This may be accomplished through either of the following means:

- Copies of BNL-generated documents provided to DOE and NYSHPO, as appropriate.

- Copies of BNL-generated documents filed in author's office, electronically, and in official department record files.

- Contractor-generated documents filed by contractor, BNL, DOE, and NYSHPO, as appropriate.

- Camp Upton Collection database information stored on BNL server, on CD, and print copy. 
Goal. Utilize the identified systems and records to properly document existing and future cultural resource management activities.

\section{Actions}

1. Obtain official site number for WW I Camp Upton Features from NYSHPO.

2. Complete site forms for other BNL sites as appropriate.

3. Incorporate site forms and numbering system into an ESH\&Q SOP.

\subsubsection{NHPA Section 106 Reviews}

When a review process identifies that a project has the potential to impact either a formally identified or potential historic resource, the BNL Cultural Resource Coordinator initiates a Section 106 Review. The Section 106 Review process includes a determination of the eligibility along with a determination of effects and any proposed mitigating actions. The determination of eligibility is based on surveys and evaluations performed by qualified individuals or organizations. Photographs, maps, and engineering drawings are included as determined necessary. Once the Section 106 Review documentation package is developed by the $\mathrm{CRC}$, it is then forwarded to DOE-BHSO for review, and concurrence. If the Review is acceptable, DOE submits the package to the New York State Historic Preservation Officer, who has 30 business days, from the date of receipt, to review and comment. The requirements and guidance specified in the following references are utilized as the Section 106 process for BNL: ACHP and UN Reno 2000, Bernstein et al. 2003, and 36 CFR Part 800.

Section 106 review packages performed to date are identified in Section 3.4.2.3, Structure and Facility Surveys. See Section 4.1.4 for information regarding WW II-era structures and Section 106 reviews. Attachment 11 identifies the location of buildings reviewed under NHPA Section 106.

Should this CRMP become the basis for a formal agreement between DOE and NYSHPO, the processes described within the Plan (Strategy Forms, etc.), and any future additions or revisions would eliminate the need for the development of separate Section 106 review packages.

\subsubsection{Process for Listing Properties on the National Register of Historic Places}

In the absence of an established process, the following approach should be followed to formally nominate a property for listing on the National Register of Historic Places,

Develop a draft nomination form using the National Register Bulletin Guidelines for Completing National Register of Historic Places Forms (NPS 1997)

Obtain BNL management and DOE-BHSO concurrence to proceed.

Coordinate with the local DOE office to determine the proper protocol (e.g., either submission of the nomination package through the DOE Federal Preservation Officer or through the SHPO), and next steps in the process.

\subsubsection{Archeological Methods}

The information presented in this section is derived from CRM projects CRM-2003-01 (Bernstein et al. 2003), and CRM-2003-2 (Merwin 2003). These two reports were developed to serve as guidance documents and references for BNL’s Cultural Resource Management Program.

4.2.4.1 Archeological Field Survey Requirements. In 2001, a general assessment of the sensitivity for the presence of prehistoric and historic period archeological sites at BNL was performed by the Institute for Long Island Archeology at SUNY Stony Brook University (Bernstein and Merwin 2001). In 2003, an assessment of BNL's archeological field survey requirements was performed. Based on these reports, 
archeological surveys are recommended prior to initiating excavation actions if ground-disturbing activities are planned for the following areas:

A. Areas in the immediate vicinity of fresh water sources at BNL (property within or adjacent to wetlands and other fresh water sources, especially near the Peconic River). These areas are identified in Attachment 34, Archeologically Sensitive Areas (Merwin 2003).

B. Areas within the footprint of World War I-era Camp Upton, the Civilian Conservation Corps period, and World War II-era Camp Upton that have not had major disturbance. These areas are identified in Attachment 34, Archeologically Sensitive Areas (Merwin 2003).

C. Areas in the vicinity of nineteenth-century house sites. These areas are also identified within Attachment 34.

Large portions of the BNL property have been thoroughly disturbed by post-1946 building demolition and construction, excavation for below-ground utilities and facilities, and other earth-moving activities. Disturbed areas have a very low sensitivity for the presence of intact archeological deposits. Therefore, actions planned in the areas identified in Figure 4.2-1, Areas of Substantial Ground Disturbance, do not require an archeological survey (Merwin 2003).

4.2.4.1 Archeological Field Survey Methods. When it is necessary to conduct an archeological field survey, the standards developed by the New York Archeological Council (NYAC) are to be followed whenever practical (NYAC 2000). These standards are summarized below.

Phase I Survey: The primary goal of a Phase I archeological survey is to locate all prehistoric or historic period sites within a project area. The initial part of a Phase I survey involves a literature search and sensitivity assessment to evaluate the overall potential of the project area for the presence of cultural resources. Bernstein and colleagues (2003) provide specific examples of typical activities involved in this stage of investigation. Field methods used to identify sites include surface survey, subsurface testing, and remote sensing. Shovel test pits (STP) are the most common technique used for initial subsurface testing. Merwin (2003) describes specific spacing guidelines for performing STP based on the archeological sensitivity of the area.

Phase II Survey. The purpose of a Phase II evaluation is to obtain detailed information on integrity, limits, structure, function, and the cultural and historical context of an archeological site in order to determine if it is eligible for listing on the National Register of Historic Places. Typically, a Phase II survey involves excavating a series of closely spaced shovel test pits to precisely define the extent and limits of the site, and a number of larger units ( 1 x 1 meter or larger) to ascertain the contents and integrity of the site. Merwin (2003) presents additional detail with regard to conducting Phase II surveys. Attachments 24, 25, and 26 are copies of Archeological Field Forms that are to be used to record information obtained.

Phase III Data Recovery. Phase III data recovery is required when an archeological site that is listed on, or eligible for, the National Register is slated for impact from the proposed project and avoidance is not possible. The goal of a data recovery is to mitigate the direct impact of proposed construction by intensive excavation in the portion of the site that will be destroyed. A research design (data recovery plan) must be approved by the New York State Historic Preservation Officer and other involved agencies (i.e., the Department of Energy and/or the Advisory Council on Historic Preservation) prior to any Phase III items, "a detailed discussion of the research topics and questions to be addressed; the types of data that must be gathered in order to address these questions" and "strategies and methodology for recovery of the necessary data.” Fieldwork and excavation procedures are generally the same as those outlined for Phase I and II investigations (Merwin 2003).

If Phase II and Phase III investigations do not reveal physical evidence believed to exist at a site, then archeological monitoring should be performed during the initial stages of construction. If human remains are encountered, archeological excavation and/or construction work is stopped, the site is secured, and appropriate local and state agencies are contacted immediately. In cases where cultural resources that are not 
eligible for listing on the state or national register are slated to be destroyed by construction, BNL staff may remove objects from the site just prior to demolition. Although some objects may not have archeological significance, they may have value for display or teaching (Merwin 2003)

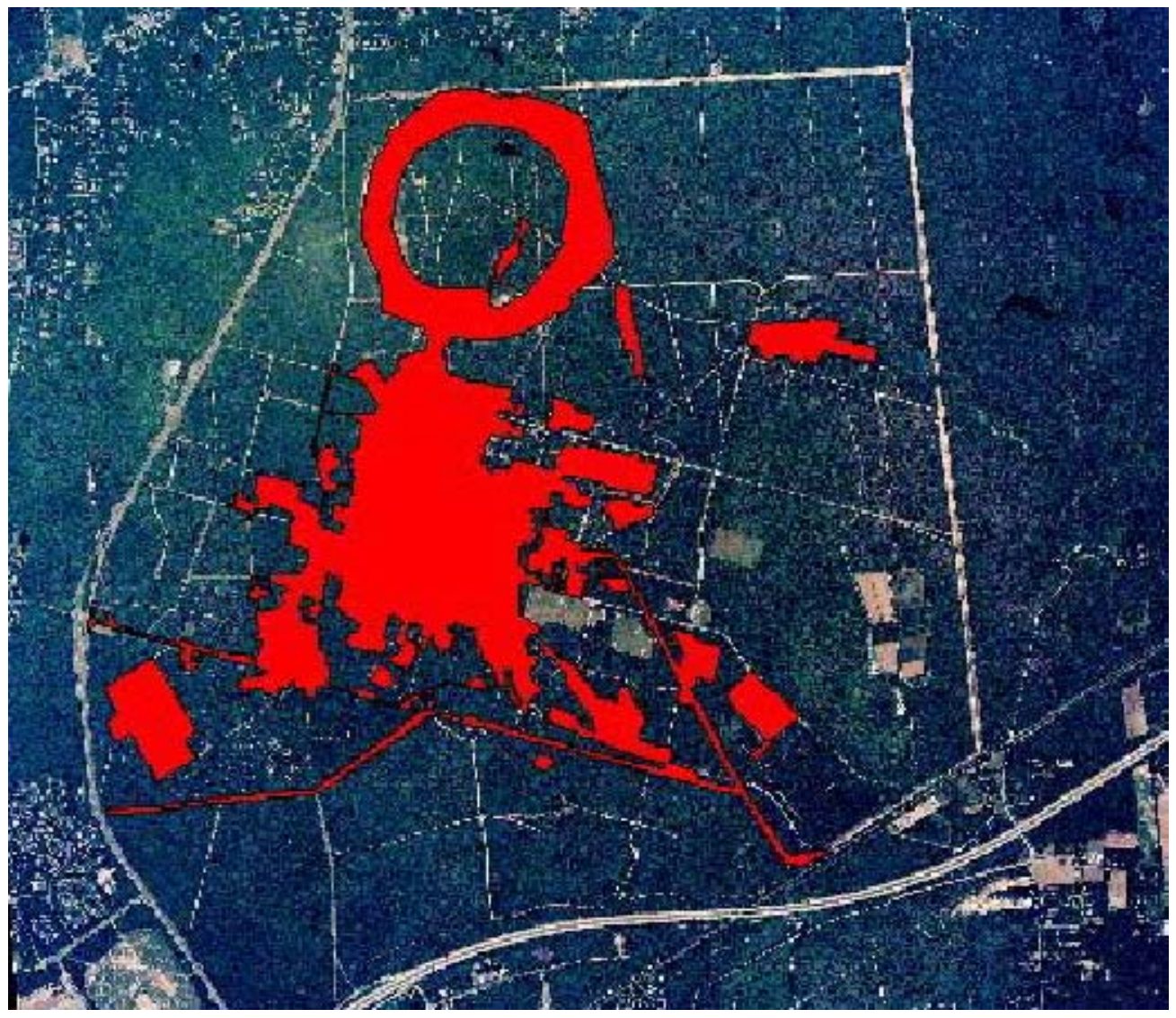

Figure 4.2-1 Areas of Substantial Ground Disturbance

\subsubsection{Laboratory Treatment and Curation}

Based on CRP-2003-01, "there does not appear to be a need for BNL to establish its own laboratory for the treatment and study of cultural materials”(Bernstein et al. 2003). To date, artifacts collected during CRM studies have been treated by organizations qualified to perform these actions - the same organization that performed the study. This practice is expected to continue. Before conducting any future treatment or study activities, BNL would seek direction from a qualified organization.

Curation management of the Camp Upton Historical Collection will follow the systems established during CRP-2002-03 (Czarniecki et al. 2002, 2003).

The curation standards found in the New York Archeological Council Standards for Cultural Resource Investigations and the Curation of Archeological Collections in New York State will be followed to the extent practical, resources permitting. The following document includes basic information on conservation techniques, identifies additional information resources, and may be used as a technical reference:

Conservation Basics for the $4^{\text {th }}$ Conference on Partnership Opportunities for Federally Associated Collections [Canada] (FSRAAC 2002). In addition, BNL will seek outside technical guidance on collections management issues from qualified sources such as the Suffolk County Historical Society and the Long Island Institute for Archaeology. 
Materials that can be classified as federal archeological items are to be treated and curated in accordance with 36 CFR Part 79 requirements.

Action. Evaluate the need to establish a contract or MOA with a qualified institution for curation of materials, and periodic assessment of curation methods at BNL, or the value in becoming a designated repository.

\subsection{CULTURAL RESOURCES MANAGEMENT PROCEDURES AND ADMINISTRATION}

\section{$5.1 \quad$ NHPA COMPLIANCE PROCEDURES}

The following procedures relate to project reviews, the NHPA Section 106 process, resource identification, and the cultural resource management program. The most current copies of these procedures are provided as attachments to this plan.

BNL SBMS subject area: NEPA and Cultural Resource Reviews. This web-based procedure describes when a review under NEPA is required, how it is initiated and processed, and includes links to the NEPA form and the designated point of contact. Reviews for potential impacts to cultural resources are incorporated into the NEPA review process. The process associated with performing an NHPA Section 106 review is described in Section 4.2.2 of this plan.

RC-SOP-103. Project Reviews For Potential Impact to Cultural Resources. This procedure describes the processes followed to review BNL projects in order to assess their potential to impact on-site cultural resources. The scope includes descriptions of the mechanisms used to initiate the reviews, cultural resource aspects to be considered, and management tools used to assist these evaluations.

RC-SOP-104. BNL Historical Resource Identification Tag Program. This procedure describes implementation of the BNL Historical Resource Identification Tag system. The scope includes identification, application, tracking, and expectations associated with the program. Historical resources encompassed by this tagging program primarily include items that could be physically relocated. Very large items, buildings, and sites may be tracked through other means identified in the BNL Cultural Resource Management Plan (for example, by listing in the CRMP). The primary reasons for tagging these items are to identify them as significant or supporting resources, acknowledge responsibility, and prevent inadvertent loss or disposal.

\subsection{ARPA COMPLIANCE PROCEDURES}

Specific procedures applicable to requirements of the Archaeological Resource Protection Act have not been developed. When the need for an archeological permit is identified (i.e., excavation of resources $>100$ years old requested by or performed for non-BNL/DOE organizations), environmental programs personnel coordinate directly with the DOE-BHSO to issue the permit. Attachment 32, Application for a Federal Permit under the Archeological Resources Protection Act, is a copy of the form that may be used to initiate the archeological permit process.

Goals. Formalize CRMP procedures on a lab-wide basis, as appropriate. Integrate CRM project reviews, flags, and hold points into established Laboratory-wide and departmental project initiation and review processes.

Actions. Include the following topics in development of a Cultural Resources Management subject area:

1. Archeological Permit requirements. Also, evaluate the value in requiring an Archeological Permit for survey and excavation of twentieth-century sites less than 100 years old (e.g., World War I and II Camp Upton, and CCC era). 
2. Archeological Site Protection. Include wording on the programmatic and illegal aspects associated with unauthorized excavation and collecting under ARPA. Consider establishing a BNL Policy discouraging collecting twentieth-century materials. Include a description of the proper steps in reporting and responding to field finds.

3. Incorporate RC-SOP-103 and RC-SOP-104.

4. Coordinate with Plant Engineering and Environmental Restoration personnel to identify appropriate CR review flags and checks and incorporate them into existing programs and procedures such as the ESH500 form, Digging Permit, maintenance management system, and so on.

\subsection{AIRFA, NAGPRA AND TREATY COMPLIANCE PROCEDURES}

None required to date (see Section 3.5 Legal Compliance).

\subsection{CFR PART 79 COMPLIANCE PROCEDURES (COLLECTIONS MANAGEMENT)}

Section 4.2, CRM Methods, and Appendix B describe the processes or references BNL will utilize with regard to collections management.

\subsection{PROTECTION PROCEDURES}

Formal procedures related to monitoring and inspections have not been developed to date. Project screening processes are outlined in proceeding sections.

Action. Develop procedure(s) to address periodic monitoring and inspection of cultural resources to identify potential damage due to natural, unauthorized, or illegal actions.

\subsection{CRM ADMINISTRATION}

\subsubsection{Staffing and Contracting}

The environmental services program is responsible for developing and implementing the BNL Cultural Resource Management Program. Two individuals, a Natural/Cultural Resource Manager and a Cultural Resource Coordinator, are responsible for implementing all aspects associated with the Cultural Resource Management Program. Approximately one-quarter to one-third of their total employment responsibilities relate to cultural resource management. These CR management-related responsibilities, defined in official BNL documents known as “R2A2s - Roles Responsibilities Accountabilities and Authorities,” are detailed in Attachments 32 and 33, together with resumes for the current Natural/Cultural Resources Manager and Cultural Resource Coordinator.

The primary function of the CRM staff is to identify applicable regulatory requirements, develop appropriate plans and procedures, and integrate these into applicable BNL processes. Because the CRM staff does not have formal education in the history/archeological field, they rely on the use of qualified contract organizations and personnel to provide the required expertise. Plans and procedures are then developed based on the resulting input. The following is an example of contractor qualification language typically contained in statements of work:

\section{Contractor Qualifications}

The contractor would be expected to possess or have available personnel with the following qualifications:

- Strong background in historic and cultural resource reviews

- Strong background in WW I and WW II military history

- Demonstrated ability to research cultural and/or historic issues at an identified location

- Experience with cultural and/or historical issues at DOE facilities

- Demonstrated familiarity, or ability to become familiar, with Long Island history. 
In addition to contracts, the CRM staff has developed working relationships and will consult the following qualified organizations for input and guidance on CRM issues:

\begin{tabular}{|c|c|c|}
\hline $\begin{array}{l}\text { NY State SHPO's office } \\
\text { James Warren } \\
\text { SHPO L.I. Regional Coordinator } \\
\text { NY State Historic Preservation Office } \\
\text { Field Services Bureau, Peebles Island } \\
\quad \text { State Park } \\
\text { P.O. Box } 189 \\
\text { Waterford, NY } 12188 \\
\text { (518) 237-8643 } \\
\text { James.Warren@OPRHP.State.NY.US }\end{array}$ & $\begin{array}{l}\text { Suffolk County Historical Society } \\
\text { Wallace Broege } \\
\text { Director, Suffolk County } \\
\quad \text { Historical Society } \\
\text { Riverhead, NY } \\
\text { (631) } 727-2881\end{array}$ & $\begin{array}{l}\frac{\text { DOE-Chicago }}{\text { Cultural Resource POC }} \\
\text { Debra Marcantonio } \\
\text { (630) } 252-2154 \\
\text { Debra.Marcantonio@CH.DOE.GOV }\end{array}$ \\
\hline $\begin{array}{l}\text { Institute for Long Island Archeology } \\
\text { Dr. David Bernstein, Director } \\
\text { Stony Brook University Dept. of } \\
\quad \text { Anthropology } \\
\text { SBS Building, Room S-549 } \\
\text { Stony Brook, NY 11794-4364 } \\
\text { (631) 632-7615 }\end{array}$ & & \\
\hline
\end{tabular}

5.6.1.2 Related Positions. Although the environmental services program is responsible for the BNL Cultural Resource Management Program, the CR program overlaps and is complemented by two other BNL departments that are identified in Section 3.1.4.

\subsubsection{Training}

Both BNL and the environmental services program strongly encourage staff to identify needed training and professional development opportunities. This level of commitment to training is demonstrated and documented in each individual's R2A2 and in the division's Self-Assessment Plan. Annual Performance Evaluations also include the identification of training and professional development opportunities as a goal.

\subsubsection{Quality Assurance}

BNL maintains a Quality Management Office, and an individual from this program is matrixed to assist the environmental program areas. Assessments of environmental programs are typically identified in the division's annual Self-Assessment Plan. Examples of recent division-wide assessments include Records Management and Contracts Administration. In addition to division assessments, DOE-BHSO or the BNL Independent Oversight Office can schedule audits.

Goal. Integrate aspects of cultural resource management into the environmental program self-assessment plan.

Action. Evaluate the potential to have assessments performed by qualified outside organizations via contract or cooperative agreement.

\subsection{ASSESSMENT OF GOALS AND ACTIONS}

An annual review will be performed to determine progress on actions items listed in Appendix D, Cultural Resources Management Plan - Action Items. The CR Coordinator and Manager will review prioritizations and identify possible financial needs. Actions will be scheduled based on anticipated funding levels, BNL programmatic requirements, mitigation or protection priorities, and CRMP prioritization levels. Note: The 
prioritization levels $\mathrm{A}-\mathrm{C}$ found in Appendix $\mathrm{D}$ are designed to provide a relative ranking to the items $(\mathrm{A}=$ highest priority) and are not discretely defined. Although the action items in Appendix D are currently grouped by prioritization level, they have not been prioritized with each grouping level.

\subsection{SCHEDULED UPDATES}

Major updates to the CRMP will be done every 5 years. Minor revisions may be necessary after annual assessment of the action items, and will be documented in the annual report and action items.

\subsection{REFERENCES}

\subsection{References Cited}

ACHP (Advisory Council on Historic Preservation and University of Nevada, Reno. 2000. "Introduction to Section 106 Review - Participant’s Course Handbook.” ACHP, Washington DC. 2000.

Army. 1921. "Public Auction at Camp Upton, LI, NY August 15, 1921.” U.S. Department of the Army, General Quarter Master. 1921.

Bernstein, D. 2001a. "The Architectural Inventory of the Brookhaven National Laboratory.” The Institute for Long Island Archeology, Department of Anthropology, State University of New York at Stony Brook. February 2001.

Bernstein, D. 2001b. “Cultural Resources Inventory of the Brookhaven National Laboratory.” The Institute for Long Island Archeology, Department of Anthropology, State University of New York at Stony Brook. October 2001.

Bernstein, D. and Merwin, D. 2003. “A Stage IB Archeological Survey for the Proposed Railway Extension at BNL.” The Institute for Long Island Archeology, Department of Anthropology, State University of New York at Stony Brook. May 2003.

Bernstein, D., Merwin, D., and Morrison, M. 2003. "Cultural Resources Methods and Procedures for Brookhaven National Laboratory.” The Institute for Long Island Archeology, Department of Anthropology, State University of New York at Stony Brook. September 2003.

BNL. 2000. “BNL Site Mater Plan 2000.” Brookhaven National Laboratory, Upton, NY, Draft September 2000.

BNL. 2004. “2003 Site Environmental Report.” BNL-73160-2004. Brookhaven National Laboratory, Upton, NY, October 2004.

Crease, Robert P. 1999. Making Physics, A Biography of Brookhaven National Laboratory, 1946-1972. University of Chicago Press, Chicago, IL.

Czarniecki, S., Stone, G., and Vogt, R. BNL Camp Upton Cataloging Project - Completion Report, MarchSeptember 2002 and Addendum to Completion Report, February 2003.

Desmarais, R. 2000. "MOA Between BHG and New York State Historic Preservation Office Concerning Decommissioning Project.” DOE letter to E.A. Zimmerman, BNL. May 3, 2000.

DOE. 2004. “Environmental Guidelines for Development of Cultural Resource Management Plans. Update.” DOE G 450.1-3 9-22-04. U.S. Department of Energy, Washington DC.

FSRAAC (Fraser Spafford Ricci Art and Archival Conservation, Inc.). 2003. "Conservation Basics for the $4^{\text {th }}$ Conference on Partnership Opportunities for Federally Associated Collections.” SO. Surry, BC Canada. 
Johannemann, Edward J. 1974. “Archaeology Site Report, Brookhaven National Laboratory, Yapank N.Y.” Report prepared for the Untied Sates Department of Energy by the Incorporated Long Island Chapter of the New York State Archaeology Association.

Johannemann, Edward J. and Schroeder, Laurie. 1977. “Cultural Resource Inventory, Part I, Brookhaven National Laboratory, Upton, New York.” Report prepared for the United Sates Department of Energy by the Long Island Archaeology Project, State University of New York at Stony Brook.

Johannemann, Edward J. and Schroeder, Laurie. 1978. "Cultural Resource Inventory, Part II, Brookhaven National Laboratory, Upton, New York.” Report prepared for the United Sates Department of Energy by the Long Island Archaeology Project, State University of New York at Stony Brook.

Goodwin and Associates. 2003. "Interim Report on Cultural Resource Survey for the Proposed Eastern Long Island Extension Pipeline, New Haven County, Connecticut and Suffolk County, New York.” Report prepared by R. Christopher Goodwin and Associates, Inc. for ENSR International, Willington, Connecticut. Authors: Maymon, Jeffrey H., Jean B. Pelletier, Samuel P. Turner, Martha Williams, Daniel Grose, Nathaniel Workman, Emmett Brown, and Joel Evans, with contributions by David J. Bernstein and Daria E. Merwin.

Merwin, D., Lam, Y., Abe, Y. 2002. "Evaluation of World War I Training Trenches and Other Features at Brookhaven National Laboratory.” The Institute for Long Island Archeology, Department of Anthropology, State University of New York at Stony Brook. October 2002.

Merwin, D. 2003. “Archeological Field Survey Requirements for the Brookhaven National Laboratory.” The Institute for Long Island Archeology, Department of Anthropology, State University of New York at Stony Brook. October 2003.

Merwin, D., Manfra A. 2005. “Archeological Evaluations of the W.J. Weeks House Site and the Weeks Campbell Site at Brookhaven National Laboratory.” The Institute for Long Island Archeology, Department of Anthropology, State University of New York at Stony Brook. March 2005.

NPS. 1997. National Register Bulletin - Guidelines for Completing National Register of Historic Places Forms, Part A, How To Complete The National Registration Form. U.S. Department of Interior, National Park Service. 1997.

NYAC. 2000. Cultural Resource Standards Handbook. The New York Archeological Council. October 2000.

PAL (Public Archaeology Laboratory, Inc.). 2001. 2001. “Islander East Pipeline Project, Cultural Resource Report.” Report prepared for the Islander East Pipeline Company, Branford, Connecticut, by the Public Archaeology Laboratory, Pawtucket, Rhode Island. Authors: Pasquariello, Raymond D., Steve Willan, Anna K. Graves, David J. Bernstein, and Daria E. Merwin.

PAL. 2002. “Islander East Pipeline Project, Cultural Resources -New York.” Supplemental report to June 2001 resource report filing. Report prepared for Islander East Pipeline Company by the Public Archaeology Laboratory, Inc., Pawtucket, Rhode Island.

PAL. 2004. "Technical Report - Architectural Survey and Evaluation: Berkner Hall (Building 488) and Chemistry Building (Building 555)”. Author: S. Olausen. August 2004.

Scheibel, M.S. 1990. "Review of New York state Endangered Species Potentially Impacted by Construction of the RHIC at Brookhaven National Laboratory.” Letter to Gerald C. Kinne, September 24, 1990.

SPLIA. 1981. New York State Parks and Recreation Historic and Natural Districts Inventory Form. June 1981.

Warren, J. 2001. “HFBR Determination of Eligibility.” New York State Historic Preservation Officer letter to M. Davis (BNL). October 4, 2001. 


\subsection{List of Figures}

Figure 3.1-1 BNL Site Map indicating Upton Ecological and Research Reserve

Figure 3.1-2 Major BNL Scientific Facilities

Figure 3.1-3 Sustainable Development Priority Areas

Figure 3.3-1 Stone Foundation Wall, Weeks Campbell Site

Figure 3.3-2 Brickwork, Weeks Campbell Site

Figure 3.3-3 Locust Fence Post, W.J. Weeks House Site

Figure 3.3-4 Foundation Stones, W.J. Weeks House Site

Figure 3.3-5 Diagram of Mapped of Trench Network

Figure 3.3-6 Photo of an Extant WW I Training Trench (2002)

Figure 4.2-1 Areas of Substantial Ground Disturbance

\subsection{CRMP Reference Maps, Photos, and Documents}

Note: CRMP reference documents include documents that require limited or restricted distribution and some that are not practical to copy. These documents are available through the CR Coordinator.

CRMP Ref. Doc. \#1: Site Arial Photograph Post WW I / Pre-Fire Breaks (circa 1932)

CRMP Ref. Doc. \#2: Site Arial Photograph Showing Fire Breaks (circa 1938)

CRMP Ref. Doc. \#3: World War I Camp Upton Map Overlaying Current BNL Site Map

CRMP Ref. Doc. \#4: World War I Camp Upton Map Overlaying Current BNL Site Map

CRMP Ref. Doc. \#5: WW I Camp Upton Map Overlaying 2001 Aerial Photo of BNL Site

CRMP Ref. Doc. \#6: WW I Camp Upton Map Overlaying 1934 Aerial Photo of BNL Site

CRMP Ref. Doc. \#7: Civilian Conservation Corp Plantings Map of Camp Upton Site (1934)

\subsection{ATTACHMENTS}

Refer to Table of Contents for a complete listing of attachments.

Note: Reduced-size maps are presented as examples. The Cultural Resource Coordinator maintains or has access to larger versions. 


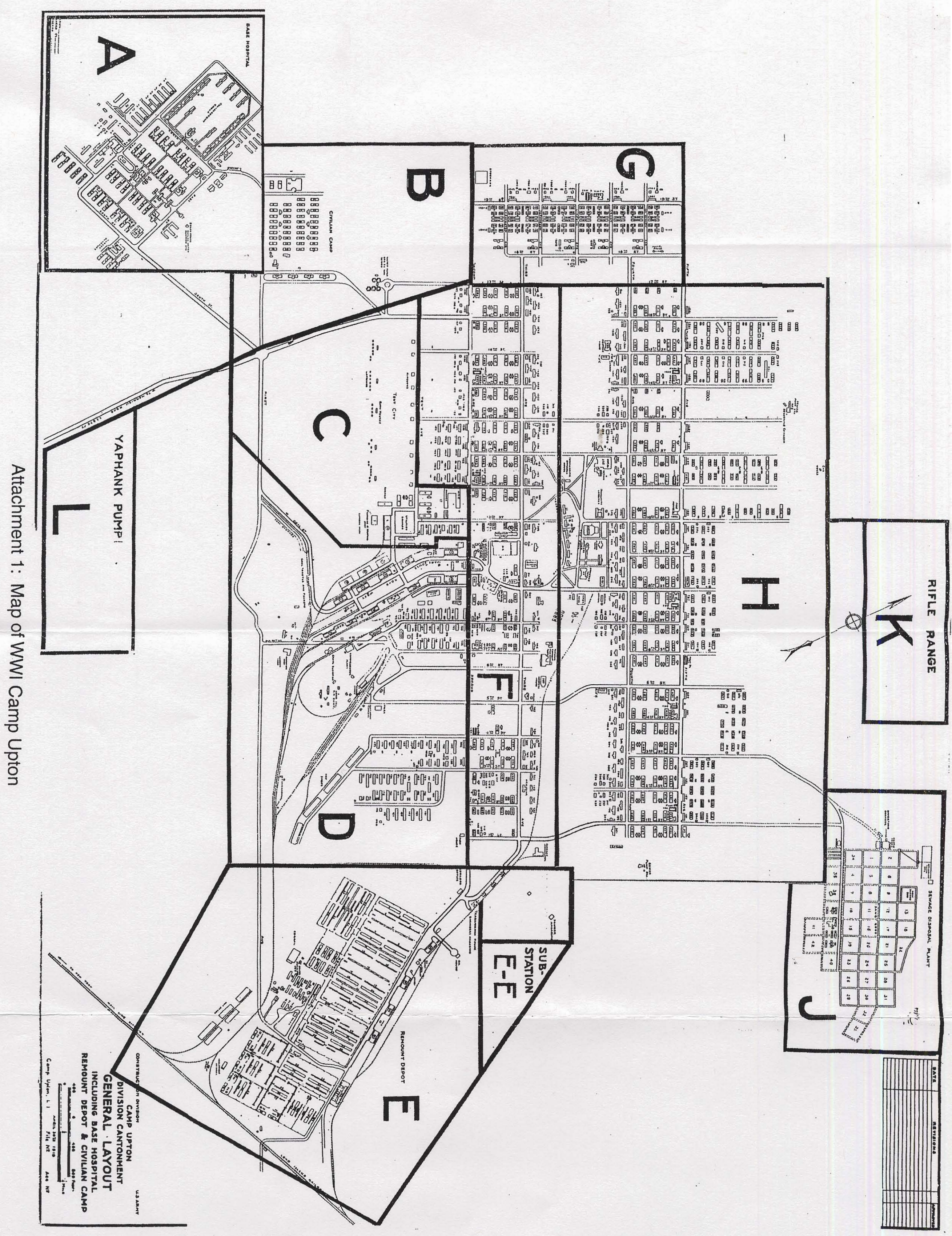




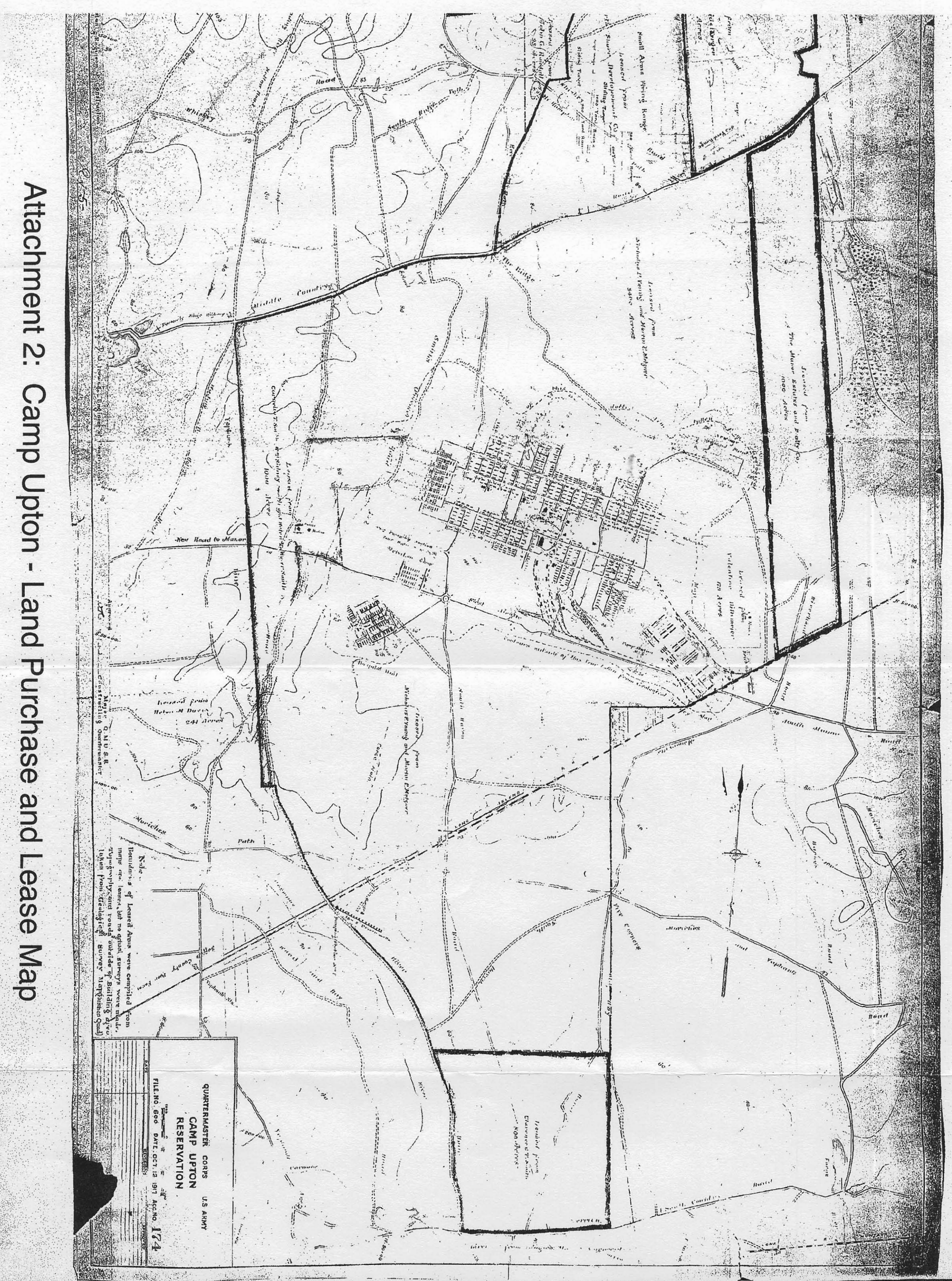









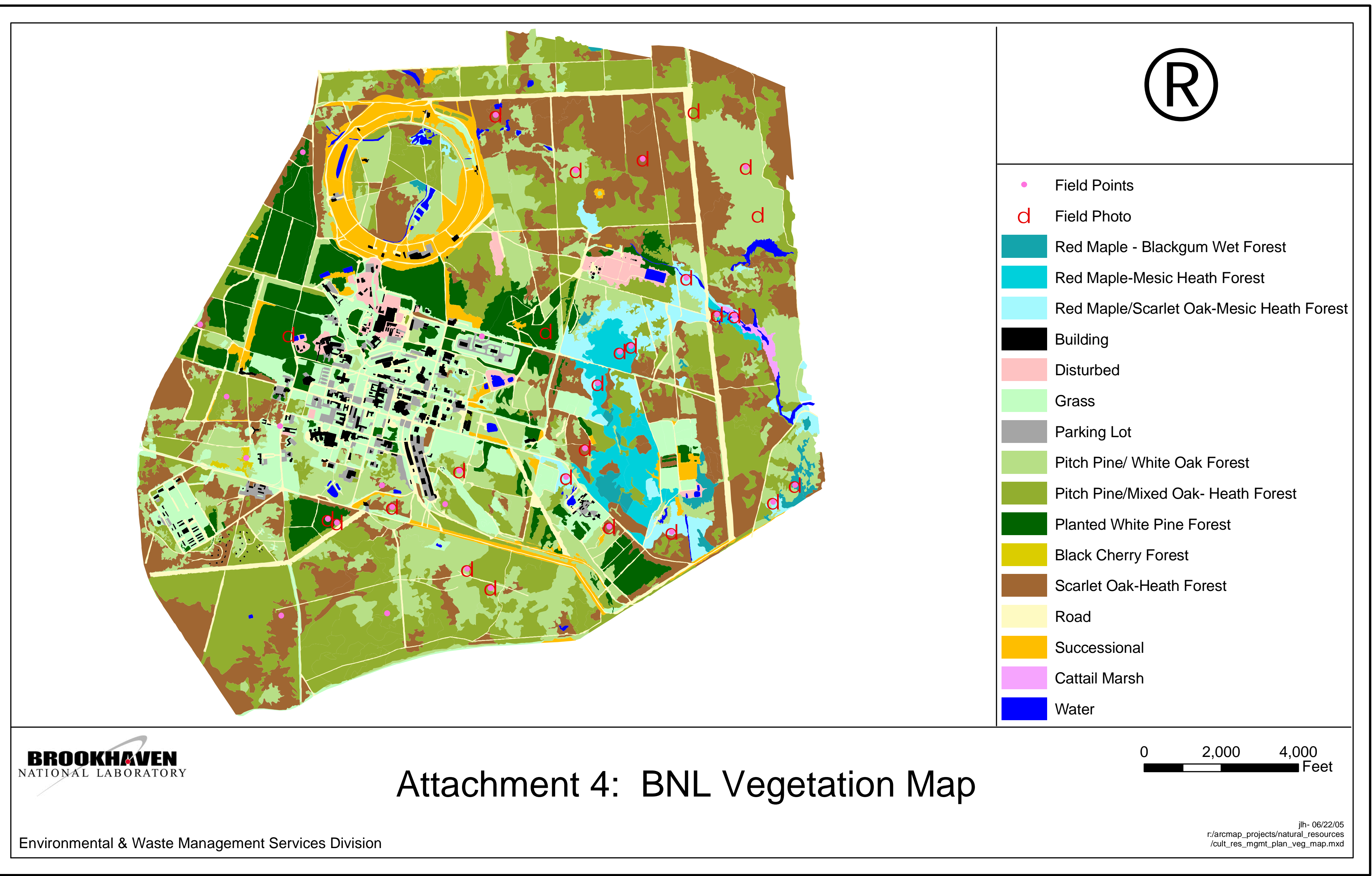




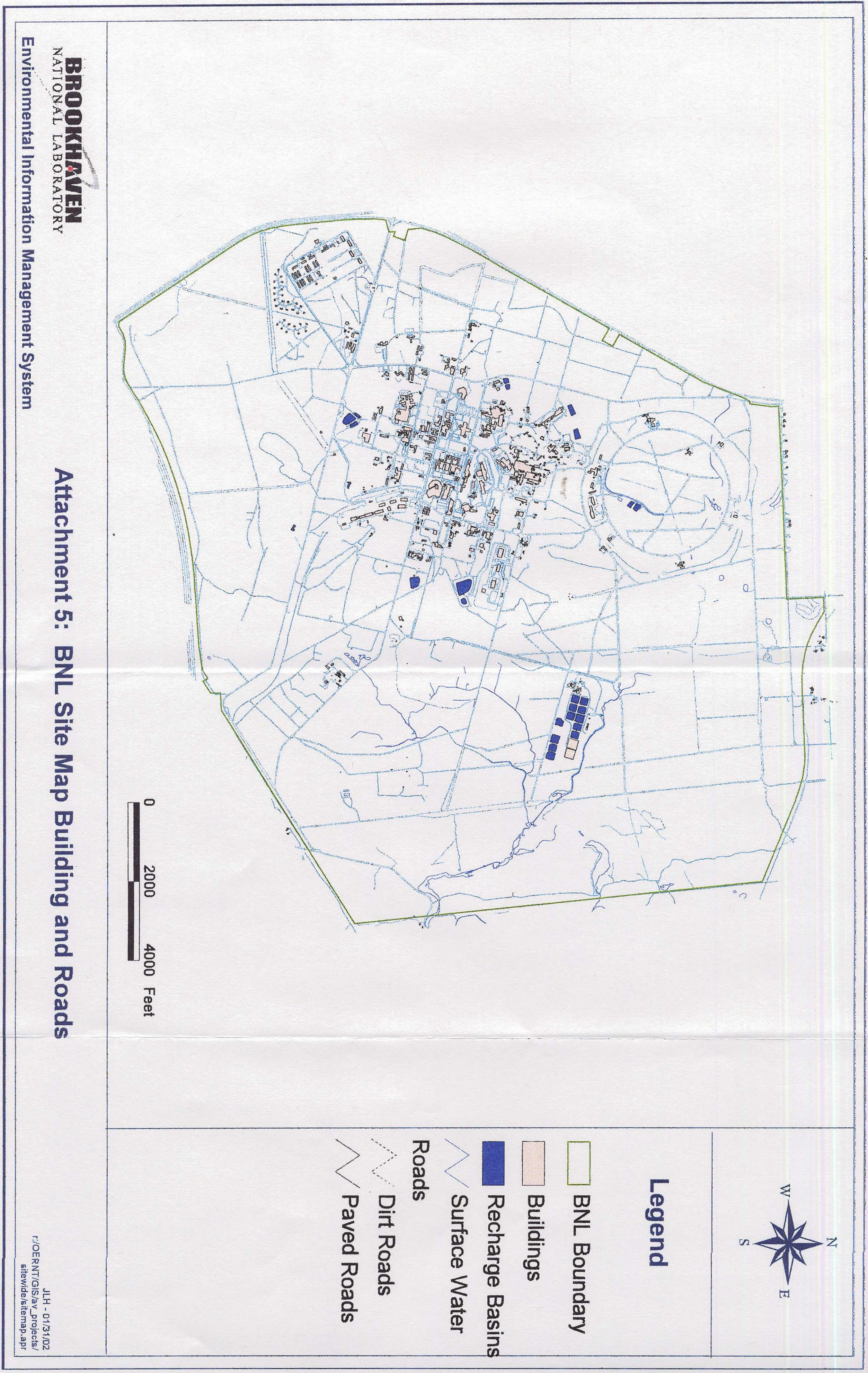




\section{Attachment 6 \\ Planned Ground Disturbing Activities \\ For 2005 and later years \\ (March 2005)}

New Construction Actions:

Research Support Center: Construction start - 2005

Center for Functional Nanomaterials: Construction start -- 2005

User Research Building: Construction start -- undefịned

Cyclotron Isotope Research Center: Construction start -- undefined

Energy Science Building: Construction start -- undefined

3rd Party Housing: Construction start -- undefined

NSLS II: Construction start -- undefined

RHIC II - upgrades to RHIC: Construction start -- undefined

eRHIC: Construction start - - undefined

Building Demolitions:

Warehouse buildings 206, 207, 208, 209, 86, 87

Buildings 193, 457, 458, 527, 650A

Environmental Restoration:

Peconic River Cleanup - Nearing completion

Old Hazardous Waste Management Facility - Nearing completion

Waste Concentration Facility - In Progress

Facility \& Ultilities Maintenance:

RHIC Alcove 9C Electronic Equipment Modular Structure

Connect Building 815 to CCWF

Storm Outfall 002 Improvements

Removal/Replacement of Underground \#2 Fuel Tanks

Asphalt Paving of RHIC Areas 


\begin{tabular}{|c|c|c|c|c|c|c|}
\hline$B N L C R I D$ & Type & Period & Name & Description & NRHP & Comments \\
\hline BNL-CR-01 & site & Historic & Weeks Campbell Site & Late 19 th - early 20 th century site & $\mathbf{L}$ & $\begin{array}{l}\text { Reference CRM Project \# CRP. } \\
2004-2\end{array}$ \\
\hline BNL-CR-02 & site \& objects & Historic & Wheel \& Hub & Steel wheel \& hub assembly & $\mathbf{u}$ & Artifacts identified in 2002 \\
\hline BNL-CR-03 & objects & Historic & Camp Upton Collection & $\begin{array}{l}\text { Collection of WWI \& WWII artifacts \& } \\
\text { donated items : }\end{array}$ & $\mathbf{u}$ & $\begin{array}{l}\text { Other database lists Cu Collection } \\
\text { items }\end{array}$ \\
\hline BNL-CR-04 & sites & Historic & WWI Training Trenches & $\begin{array}{l}10 \text { networks of trench warfare training } \\
\text { earthworks }\end{array}$ & $\mathbf{Y}$ & $\begin{array}{l}\text { Reference CRP \#CRP-2002-02 for } \\
\text { detail }\end{array}$ \\
\hline BNL-CR-05 & sites & Historic & WWI foundations \& structures & $\begin{array}{l}\text { Areas of Camp Upton building foundations } \\
\& \text { other structures }\end{array}$ & $\mathbf{L}$ & $\begin{array}{l}\text { Reference CRP \#CRP-2002-02 for } \\
\text { detail }\end{array}$ \\
\hline BNL-CR-06 & building & Historic & Grain silo bases & $\begin{array}{l}\text { Concrete bases from } 2 \text { WWI Camp Upton } \\
\text { silos }\end{array}$ & $\mathbf{u}$ & Building 482 \\
\hline BNL-CR-07 & building & Historic & Brick building (Bldg 455) & Brick structure circa WWI Camp Upton. & $\mathbf{U}$ & Substantial modifications \\
\hline BNE-CR-08 & building & Historic & White Pines & Stands of white pine trees planted by $\mathrm{CCC}$ & $u$ & \\
\hline BNL-CR-09 & building & Historic & Building 30 & $\begin{array}{l}\text { Building extant to CCC \& WWII Camp } \\
\text { Upton }\end{array}$ & $\mathbf{N}$ & \\
\hline BNL-CR-10 & building & Historic & Building 120 & Barracks building WWII CU & $\mathbf{N}$ & Minimal exterior renovations \\
\hline BNL-CR-11 & complex & Scientif & $\begin{array}{l}\text { Graphite Reactor (BGRR) } \\
\text { Complex }\end{array}$ & $\begin{array}{l}7 \text { buildings assoc. with first non-weapons } \\
\text { research reactor }\end{array}$ & $\mathbf{Y}$ & Determined NRHP eligible in 2000 . \\
\hline BNL-CR-12 & complex & Scientif & $\begin{array}{l}\text { High Flux Beam Reactor } \\
\text { (HFBR) Complex }\end{array}$ & $\begin{array}{l}6 \text { buildings assoc. with BNL's 2nd } \\
\text { aeneration reserch reactor }\end{array}$ & $\mathbf{Y}$ & Determined NRHP eligible in 2001 \\
\hline
\end{tabular}




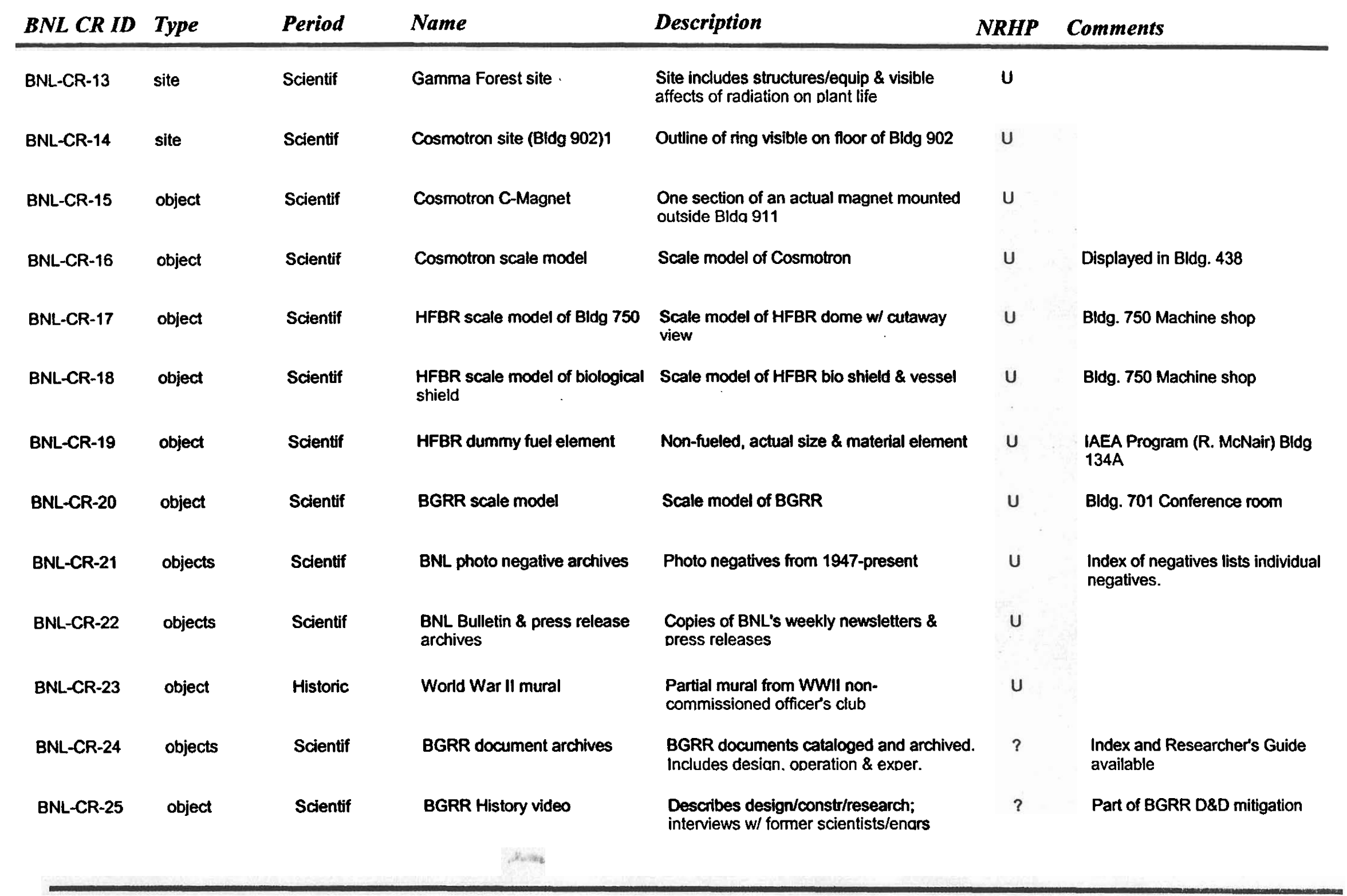




\begin{tabular}{|c|c|c|c|c|c|c|}
\hline$B N L C R I D$ & Type & Period & Name & Description & $\boldsymbol{N R H P}$ & Comments \\
\hline BNL-CR-26 & building & Historic & W. J. Weeks house site & Circa 1850 's house site & $L$ & $\begin{array}{l}\text { Reference CRM Project \# CRP- } \\
2004-2\end{array}$ \\
\hline BNL-CR-27 & object & Scientif & $X X$-inch bubble chamber & & $\mathbf{u}$ & Stored outside near BIdg 438 \\
\hline BNL-CR-28 & object & Scientif & HFBR CNF H9 beam plug & HFBR Cold Neutron Facility beam plug & $\mathbf{u}$ & Stored outside near Bldg 438 \\
\hline BNL-CR-29 & object & Scientif & Bubble Chamber glass window & & $\mathbf{u}$ & Stored outside near Bldg 438 \\
\hline BNL-CR-30 & object & Scientific & T. Goldhabers model & 3D model of isomer éxcited states & $\mathbf{u}$ & Mounted on wall of Bldg. 510 lobby \\
\hline BNL-CR-31 & object & Scientific & Tandem van der Graff model & Scale model of Tandem van der Graff & $\mathbf{U}$ & $\begin{array}{l}\text { Utilized for tours in BIdg 901E. (C. } \\
\text { Carlson) }\end{array}$ \\
\hline BNL-CR-32 & object & Scientific & Graphite Block & $-6^{*} \times 12^{*}$ example of BGRR graphite & $\mathbf{N}$ & $\begin{array}{l}\text { IAEA Program (R. McNair) Bldg } \\
\text { 134A }\end{array}$ \\
\hline BNL-CR-33 & object & Scientific & $\begin{array}{l}\text { BGRR Control Room } \\
\text { Instrument panels mockups }\end{array}$ & $\begin{array}{l}3 \text { sections of control rm instrument } \\
\text { panels: with actual instruments }\end{array}$ & $\mathbf{N}$ & $\begin{array}{l}\text { BGRR Artifact, Bldg } 703 \text { west } \\
\text { basement }\end{array}$ \\
\hline BNL-CR-34 & object & Scientific & $\begin{array}{l}\text { BGRR Control rod Position } \\
\text { Indicator panels }\end{array}$ & $\begin{array}{l}\text { Actual instruments from BGRR control } \\
\text { room }\end{array}$ & $\mathbf{N}$ & $\begin{array}{l}\text { BGRR Artifact, Bldg } 703 \text { west } \\
\text { basement }\end{array}$ \\
\hline BNL-CR-35 & object & Scientific & $\begin{array}{l}\text { BGRR dummy fuel element - } \\
11 \mathrm{ft} \text { long }\end{array}$ & Aluminum, actual size & $\mathbf{N}$ & $\begin{array}{l}\text { BGRR Artifact, BIdg } 703 \text { west } \\
\text { basement }\end{array}$ \\
\hline BNL-CR-36 & object & Scientific & $\begin{array}{l}\text { BGRR fuel element sections } \\
\text { (2) }-1 \mathrm{ft} \text { long }\end{array}$ & $\begin{array}{l}2 \text { types of elements, mounted on wood } \\
\text { plaque }\end{array}$ & $\mathbf{N}$ & $\begin{array}{l}\text { IAEA Program (R. McNair) Bldg } \\
\text { 134A }\end{array}$ \\
\hline BNL-CR-37 & object & Scientific & BGRR sample tubes (rabbits) & $\begin{array}{l}\text { Aluminum tubes for sample irradiation - } 1 \\
\text { case of } X X\end{array}$ & $N$ & BGRR Artifact \\
\hline \multirow[t]{2}{*}{ BNL-CR-38 } & object & Scientific & BGRR status blackboard (2) & $\begin{array}{l}\text { 2, slate blackboards used for } \\
\text { communicatina facilitv operatina status }\end{array}$ & $\mathbf{N}$ & $\begin{array}{l}\text { BGRR Artifact; located in NE \& SW } \\
\text { sides of } 702\end{array}$ \\
\hline & & & 's & & & \\
\hline
\end{tabular}




\begin{tabular}{|c|c|c|c|c|c|c|}
\hline$B N L C R I D$ & Type & Period & Name & Description & $N R H P$ & Comments \\
\hline BNL.CR-39 & object & Scientific & Atoms For Peace mural & Loated on central staircase of 703 Lobby & $N$ & BGRR Artifact \\
\hline BNL-CR-40 & Building & Architectural & Chemistry Building & $\begin{array}{l}\text { Designed by renouned architect Marcel } \\
\text { Breuer }\end{array}$ & $\mathbf{L}$ & Reference CRP-2004-1 \\
\hline BNL-CR-41 & Building & Architectural & Berkner Hall & $\begin{array}{l}\text { Designed by renouned architect Max } 0 \text {. } \\
\text { Urbahn }\end{array}$ & $\mathbf{L}$ & Reference CRP-2004-1 \\
\hline BNL-CR-42 & object & Scientific & Ceremonial Flask & $\begin{array}{l}\text { Flask/plaque from Medical Research } \\
\text { Center qround breakina }\end{array}$ & $N$ & Medical Dept possession \\
\hline$B N L-C R-43$ & object & Scientific & $\begin{array}{l}\text { BGRR On-shift staff status } \\
\text { board }\end{array}$ & Wood status board w/ name tags & $u$ & $\begin{array}{l}\text { BGRR Artifact, Bldg } 703 \text { west } \\
\text { basement }\end{array}$ \\
\hline BNL-CR-44 & object & Scientific & HFBR NSS Instrument chassis & Nuclear Safety System Instrument & $\mathbf{u}$ & $\begin{array}{l}\text { HFBR Artifact, IAEA Program (R. } \\
\text { MCNair) Bidg 134A }\end{array}$ \\
\hline BNL-CR-45 & object & Scientific & PET scan device & PET scan device, encased in plexiglass & $\mathbf{u}$ & Displayed in Chemistry Bldg lobby \\
\hline BNL-CR-46 & object & Scientific & BMRR scale model & Medical Reactor scale model & $\mathbf{u}$ & Stored in BMRR Treatment Room \\
\hline
\end{tabular}




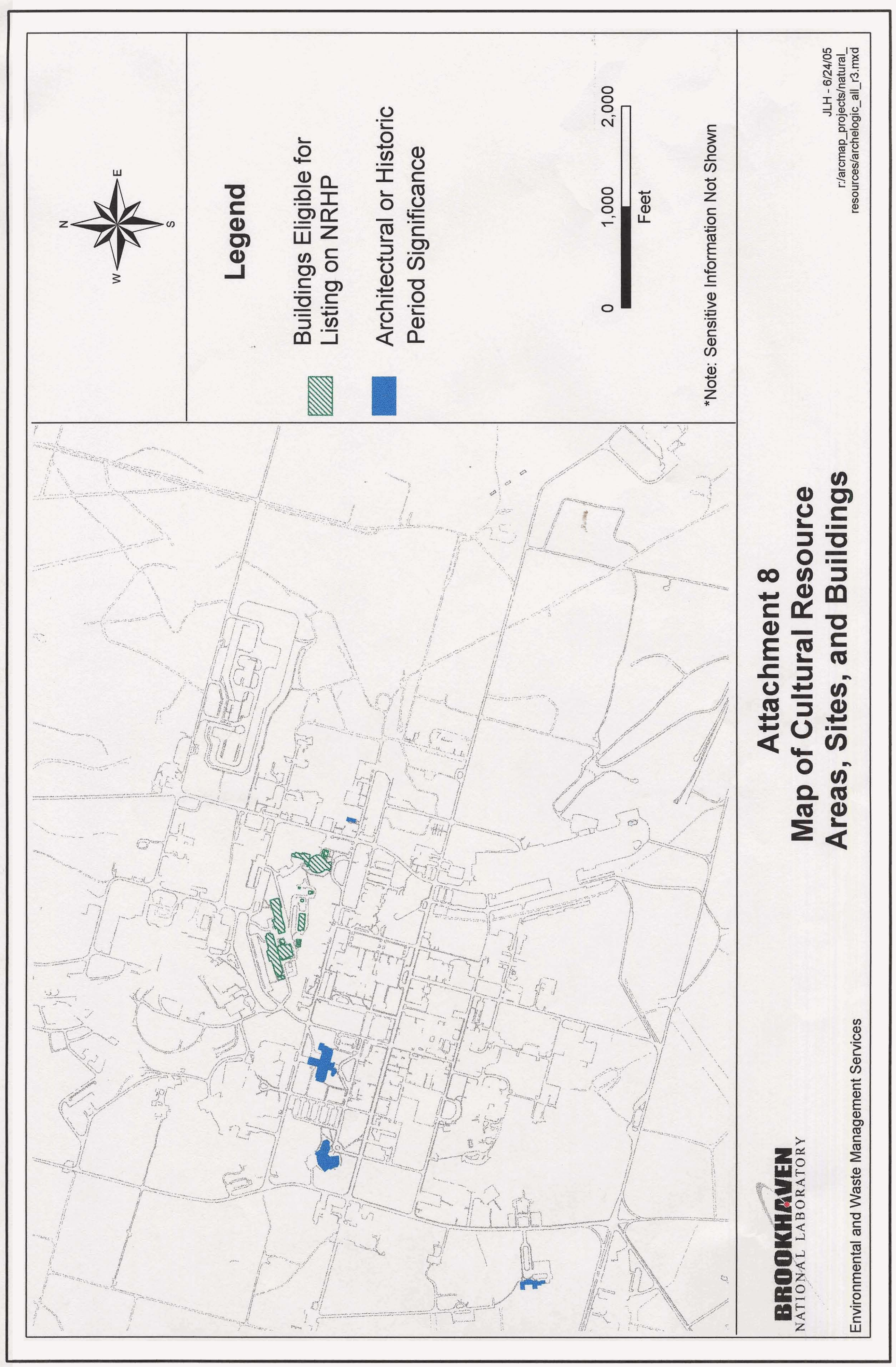




\section{Cultural Resource Projects}

\section{Attachment 9}

\begin{tabular}{|c|c|c|c|c|}
\hline$C R P I D \#$ & Name & Description & Performed By & Comments \\
\hline CRP-1999-01 & $\begin{array}{l}\text { Cultural Resource } \\
\text { Programmatic } \\
\text { Agreement }\end{array}$ & $\begin{array}{l}\text { Develop draft PA between } \\
\text { DOE and Advisory Counsil on } \\
\text { Historic Preservation }\end{array}$ & C. Kielusiak & $\begin{array}{l}\text { PA Drafted but not finalized; } \\
\text { DOE decided to develop } \\
\text { CRMP. }\end{array}$ \\
\hline CRP-2000-01 & $\begin{array}{l}\text { BNL Architectural } \\
\text { Inventory }\end{array}$ & $\begin{array}{l}\text { Evaluated BNL buildings and } \\
\text { structures for NRHP eligibility } \\
\text { potential IAW NHPA Section } \\
110\end{array}$ & ILIA & $\begin{array}{l}\text { Produced the Architectural } \\
\text { Inventory of the Brookhaven } \\
\text { National Laboratory }\end{array}$ \\
\hline CRP-2000-02 & $\begin{array}{l}\text { BGRR Document } \\
\text { Inventory }\end{array}$ & $\begin{array}{l}\text { Inventory all BGRR } \\
\text { documents, appraise to SAA } \\
\text { stds and NARAVOE } \\
\text { retentions; catalog in a } \\
\text { searchable database; develop } \\
\text { desriptions; prep documents } \\
\text { for transfer to BNL RHA }\end{array}$ & S. Kalamaris & $\begin{array}{l}\text { Ref. Webreq } 40605 ; \text { produced } \\
\text { final report dated } 12 / 2001\end{array}$ \\
\hline CRP-2000-03 & $\begin{array}{l}\text { BGRR History } \\
\text { Video }\end{array}$ & $\begin{array}{l}\text { R. Crease interviews BGRR } \\
\text { designers/engineers/scientists } \\
+ \text { historic photos }\end{array}$ & BNL & Distributed in 2003 \\
\hline CRP-2000-04 & $\begin{array}{l}\text { Historic Film Reel } \\
\text { Conversion }\end{array}$ & $\begin{array}{l}\text { Converted historic 16-mm film } \\
\text { reel footage to high quality } \\
\text { tape \& developed database } \\
\text { listing }\end{array}$ & Adwar Video & $\begin{array}{l}\text { Listing of } 19 \text { tapes placed on } \\
\text { Cultural Resources website }\end{array}$ \\
\hline CRP-2001-01 & $\begin{array}{l}\text { Historic Context \& } \\
\text { Archelogical } \\
\text { Sensitivity }\end{array}$ & $\begin{array}{l}\text { Developed historic contexts for } \\
\text { BNL and assessed potential for } \\
\text { arch. finds. }\end{array}$ & ILIA & $\begin{array}{l}\text { Cultural Resources Inventory } \\
\text { of BNL, including Archival } \\
\text { Search, Prehistoric and } \\
\text { Historic period Contexts, and } \\
\text { Archeological Sensitivity } \\
\text { Assessment }\end{array}$ \\
\hline CRP-2002-01 & $\begin{array}{l}\text { Evaluation of WWI } \\
\text { Features }\end{array}$ & $\begin{array}{l}\text { Mapped trenches, foundations } \\
\text { \& other features; Determined } \\
\text { NRHP eligibility;recommended } \\
\text { preservation and restoration } \\
\text { concepts }\end{array}$ & ILIA & \\
\hline CRP-2002-02 & $\begin{array}{l}\text { Camp Upton } \\
\text { Collection Catalog } \\
\text { \& Inventory }\end{array}$ & $\begin{array}{l}\text { Cataloged \& labeled } 2040+ \\
\text { items; organized and stored } \\
\text { items in museum std materials; } \\
\text { Est. database w/ accession. } \\
\text { collection \& photo tables; } \\
\text { digitally photographed ea item }\end{array}$ & C-S-V Assoc. & \\
\hline CRP-2003-01 & $\begin{array}{l}\text { CR Management } \\
\text { Methods and } \\
\text { Procedures } \\
\text { Assessment }\end{array}$ & $\begin{array}{l}\text { Identified requirements \& } \\
\text { recommended methods for } \\
\text { compliance with CRM laws \& } \\
\text { regulations }\end{array}$ & ILIA & \\
\hline CRP-2003-02 & $\begin{array}{l}\text { Archeological Field } \\
\text { Survey } \\
\text { Requirements } \\
\text { Asssessmnt }\end{array}$ & $\begin{array}{l}\text { Identified need and scope of } \\
\text { archeol. surveys and areas } \\
\text { where surveys are } \\
\text { recommended. }\end{array}$ & ILIA & \\
\hline CRP-2003-03 & $\begin{array}{l}\text { Protection of W.J. } \\
\text { Weeks House Site }\end{array}$ & $\begin{array}{l}\text { Erected fencing and posted } \\
\text { warning signed around } 0.4 \\
\text { acre site. }\end{array}$ & BNL/contractor & \\
\hline
\end{tabular}




\begin{tabular}{lllll} 
CRP ID\# & Name & Description & Performed By & Comments \\
\hline CRP-2004-01 & $\begin{array}{l}\text { Architectural Eval - } \\
\text { Chemistry Bldg; } \\
\text { Berkner Hal }\end{array}$ & $\begin{array}{l}\text { Performed architectual survey } \\
\text { \& NRHP evaluation of Bldgs } \\
555 \text { \& 488; Assisted w/ } \\
\text { developing mgmt strategies for } \\
\text { other CR buildings }\end{array}$ & PAL & $\begin{array}{l}\text { (PAL) Public Archeology } \\
\text { Associates, of Rhode Island }\end{array}$ \\
CRP-2004-02 & $\begin{array}{l}\text { Archeological } \\
\text { Evals of 1800s } \\
\text { House Sites }\end{array}$ & $\begin{array}{l}\text { Performed archeaological } \\
\text { evaluation of W.J. Weeks } \\
\text { House site and Weeks } \\
\text { Campbell Site }\end{array}$ & ILIA \\
CRP-2004-03 & Protective Fencing & $\begin{array}{l}\text { Installed protective fencing \& } \\
\text { warning signs around W.J. } \\
\text { Weeks House site }\end{array}$ & BNL &
\end{tabular}




\section{Attachment 10}

NHPA Section 106 Reviews

Performed after 2005

-- Placeholder -- 


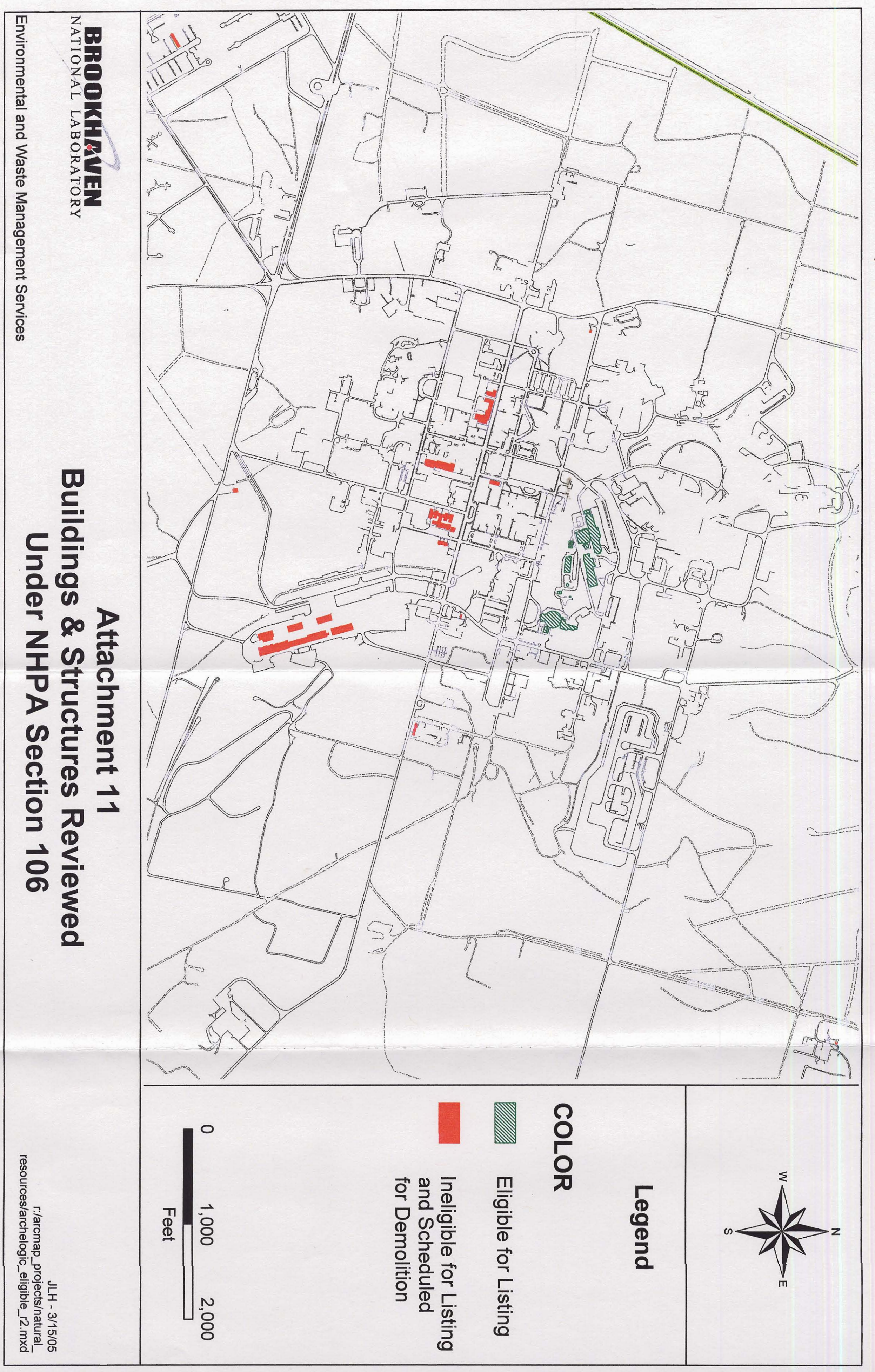




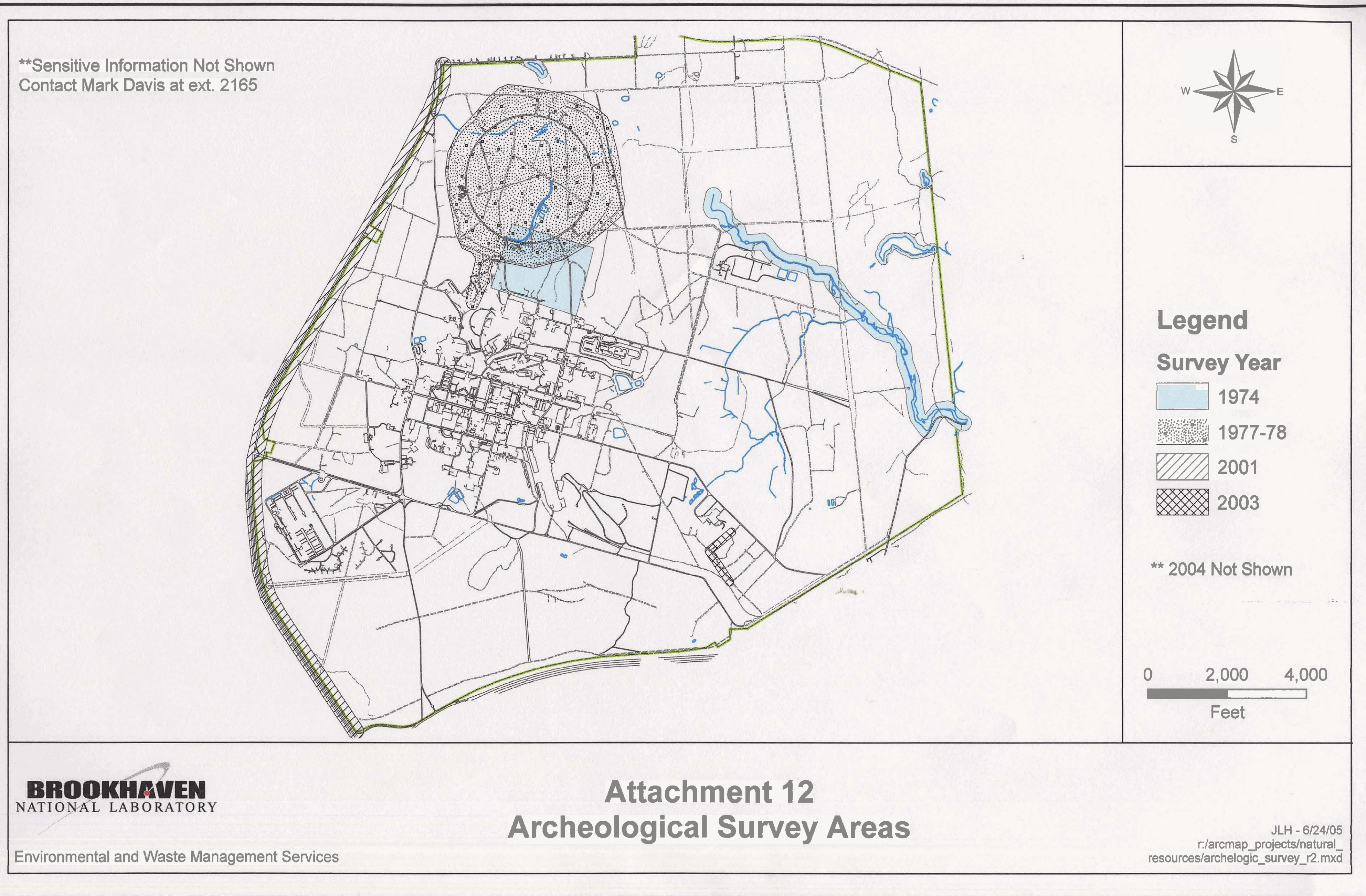




\section{Cultural Resource Outreach Activities Attachment 13}

\begin{tabular}{|c|c|c|c|}
\hline Date & Event Description & Internal/External & External Organization(s) \\
\hline $9 / 1 / 2001$ & $\begin{array}{l}\text { CU Display at Longwood } \\
\text { Country Fair }\end{array}$ & External & Sponsor - Brookhaven Town \\
\hline $10 / 1 / 2001$ & Camp Upton Presentation & External & Manorville Historical Society \\
\hline $5 / 1 / 2002$ & $\begin{array}{l}\text { Display at Wading River Duck } \\
\text { Pond Day }\end{array}$ & External & GeneralPublic \\
\hline $7 / 1 / 2002$ & Camp Upton Presentation & External & Rocky Point Historical Society \\
\hline $9 / 1 / 2002$ & $\begin{array}{l}\text { CU Display at Longwood } \\
\text { Country Fair }\end{array}$ & External & Sponsor - Brookhaven Town \\
\hline $10 / 1 / 2002$ & CU Display & External & $\begin{array}{l}\text { "Golden Gathering" at Suffolk } \\
\text { Cnty Comm College }\end{array}$ \\
\hline $10 / 1 / 2002$ & Camp Upton Presentation & External & Yaphank Historical Society \\
\hline $11 / 1 / 2002$ & Camp Upton Presentation & External & Saville Historical Society \\
\hline $3 / 1 / 2003$ & Camp Upton Presentation & External & $\begin{array}{l}\text { Greater Patchogue Historical } \\
\text { Society }\end{array}$ \\
\hline $5 / 25 / 2003$ & $\begin{array}{l}\text { CU Presentation to Onsite tour } \\
\text { Group }\end{array}$ & Extemal & $\begin{array}{l}\text { Great Neck Adult Education } \\
\text { group }\end{array}$ \\
\hline $7 / 1 / 2003$ & Summer Sundays Exhibit & Both & General Public \\
\hline $7 / 1 / 2003$ & Camp Upton Presentation & External & E. Islip Historical Society \\
\hline $9 / 6 / 2003$ & Longwood Country Fair & External & $\begin{array}{l}\text { Sponsor - Brookhaven Town; } \\
\text { General public }\end{array}$ \\
\hline $7 / 1 / 2004$ & Summer Sundays Exhibit & Both & $\begin{array}{l}\text { General Public - displayed July } \\
\text { \& August }\end{array}$ \\
\hline $9 / 6 / 2004$ & Longwood Country Fair & External & $\begin{array}{l}\text { Sponsor - Brookhaven Town: } \\
\text { General public }\end{array}$ \\
\hline
\end{tabular}




\section{Attachment 14 \\ Cultural Resource \\ Management Strategy Form}

Building/Site Name:

BNL Bldg. \#:

Grid \#:

Site \#:

Date of construction or period of use:

Historic Significance Category: $\square$ I or $\square$ II or $\square$ N/A

Historic Role(s):

Current Significant Feature(s): (Examples: exterior architecture; extant location; associated w/important personage; scientific achievement [e.g.; Nobel Prize]; unique facility; etc.)

Plans for Bldg or Site:

Treatment and/or Mitigation Plans:

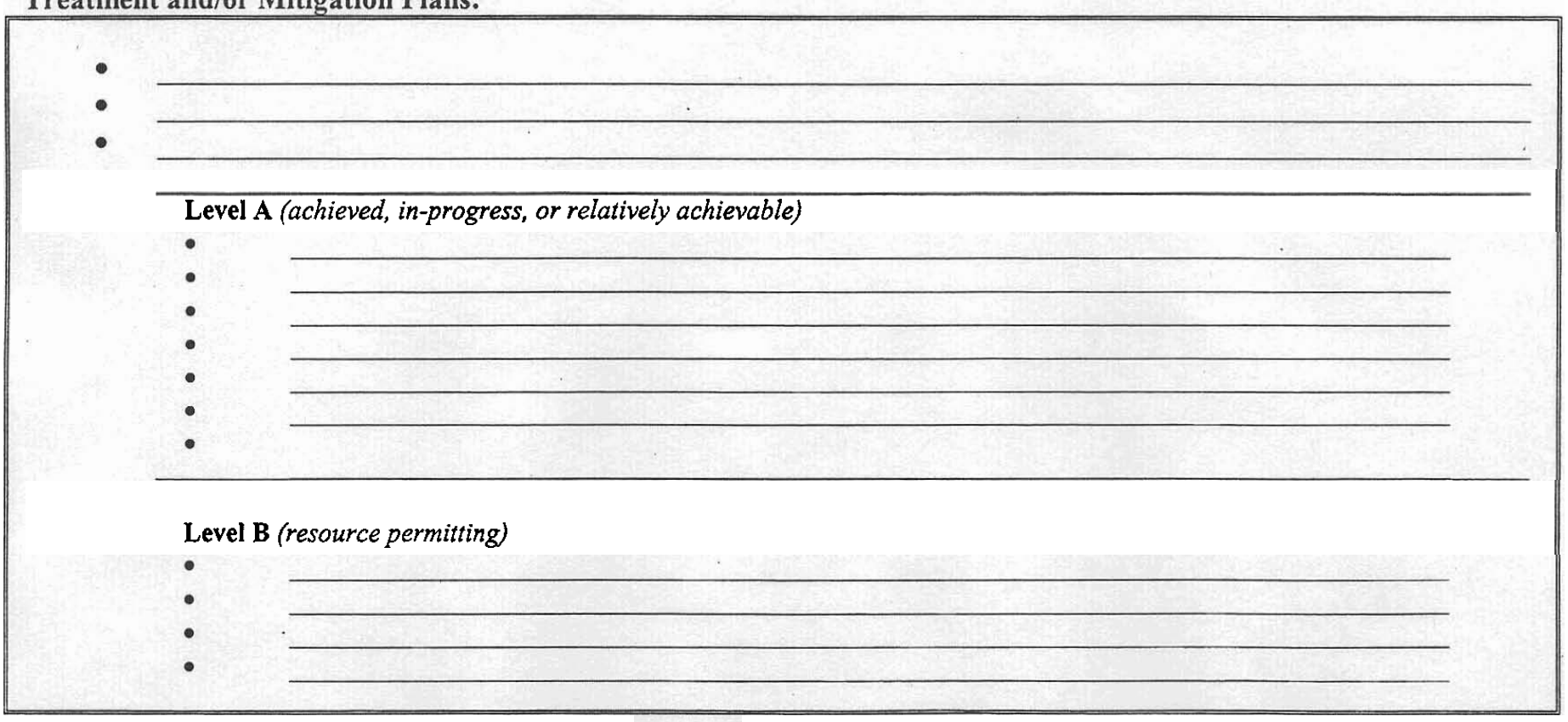




\section{Attachment 15}

\section{Cultural Resource Management Strategy Groups}

Historic \& Unique Sites:

World War I Features* (Trenches \& Foundations)

Circa 1850s home sites (2)

Gamma Forest site

Scientific Achievement \& Engineering Design:

BGRR Complex*

AGS Complex

HFBR Complex*

BMRR

Medical Research Center/Program Cosmotron

Architecturally Significant:

Chemistry Building, 555: Designed by Marcel Breuer Berkner Hall, 488: Designed by Max O. Urbahn

Period Representation:

Building 30: "The Center", CCC (1930's) era structure

Building 120: WWII barracks style building w/ minimal renovations 


\title{
Attachment 16
}

\author{
Archeological Site Numbers
}

NOTE: The following site numbers were assigned through the New York Sate Historic Preservation Officer

A103.02.0474.0015 Camp Upton World War I training trenches (SB20-SB33) identified during the ISABELLE project survey (Johannemann and Shroeder 1977).

A103.02.002283 Camp Upton, BNL features 01/01A (depression with brick pile), Feature 02 (latrine/shower facility), Feature 03 (WW I dump). Identified during the Eastern Long Island Extension Pipeline survey (Maymon et al. 2003). 


\section{NEW YORK STATE PREHISTORIC ARCHAEOLOGICAL SITE INVENTORY FORM}

For Office Use Only--Site Identifier

Project Identifier

Your Name

Address

Zip

Organization (if any)

1. Site Identifier(s)

2. County

One of following: City

Township

Incorporated Village

Unincorporated Village or Hamlet

3. Present Owner

Address

Zip

4. Site Description (check all appropriate categories): Structure/site

Site

$\begin{array}{ll}\text { - Stray find } & \text { Cave/Rockshelter } \\ \text { - Pictograph } & \text { - Quarry } \\ \text { - Burial } & \text { - Shell midden } \\ \text { - Surface evidence } & \text { - Camp } \\ \text { - Material below plow zone } & \text { - Buried evidence } \\ \text { - Single component } & \text { - Evidence of features } \\ \text { Multicomponent } & \end{array}$

$$
\begin{aligned}
& \text { - Workshop } \\
& \text { - Mound } \\
& \text { - Village } \\
& \text { - Material in plow zone } \\
& \text { - Intact occupation floor } \\
& \text { - Stratified }
\end{aligned}
$$

Location

Under cultivation
_ Pastureland
_Upland

$$
\begin{aligned}
& \text { Never cultivated } \\
& \text { - Woodland } \\
& \text { - Sustaining erosion }
\end{aligned}
$$$$
\begin{aligned}
& \text { Previously cultivated } \\
& \text { - Floodplain } \\
& \text { - Residential lawn }
\end{aligned}
$$

Soil Drainage: excellent_ good

Slope: flat_ gentle _ moderate fair__ poor

Distance to nearest water from site (approx.)

Elevation:

5. Site Investigation (append additional sheets, if necessary):

Surface--date(s)

Site Map (Submit with form)

Collection

Subsurface--date(s)

Testing: shovel

Excavation: unit size coring other unit size no. of units no. of units

Investigator

Manuscript or published report(s)(reference fully): 
6. Component (s)(cultural affiliation/dates):

7. List of material remains (be as specific as possible in identifying object and material):

If historic materials are evident, check here and fill out historic site form.

8. Map References: Map or maps showing exact location and extent of site must accompany this form and must be identified by source and date. Keep this submission to $8.5 \times 11$ " if possible.

USGS 7.5' Minute Series Quad. Name

For Office Use Only--UTM Coordinates

9. Photography (optional for environmental impact survey):

Please submit a 5x7" black and white print(s) showing the current state of the site. Provide a label for the print(s) on a separate sheet.

10. Eligibility Discussion

A.__ Property appears NR/SR eligible.

Identify relevant theme:

Existence of relevant context:__yes _ no

Discuss:

B. Specific Criteria for Eligibility:

Criteria A. Associated with events that have made a significant contribution to the broad patterns of our history.

Criteria B. Associated with the lives of persons significant in our past.

Criteria C. - Embodies the distinct characteristics of a type, period, or method of construction; or represents a significant and distinguishable entity whose components may lack individual distinction; or

Criteria D. _ Have yielded, or may be likely to yield, information important in prehistory or history.

C. Discussion (Provide a brief paragraph summarizing site) 


\section{NEW YORK STATE HISTORIC ARCHAEOLOGICAL SITE INVENTORY FORM}

For Office Use Only--Site Identifier

Project Identifier

Date

Your Name

Address

Zip

Organization (if any)

1. Site Identifier(s)

2. County

One of following: City

Township

Incorporated Village

Unincorporated Village or Hamlet

3. Present Owner
Address
Zip

Phone

4. Site Description (check all appropriate categories): Structure/site Superstructure: complete_ partial_ collapsed__ not evident Foundation: above_ below__ (ground level) not evident Structural subdivisions apparent: Only surface traces visible___ Buried traces detected

List construction materials (be as specific as possible):

Grounds: Under cultivation__ Sustaining erosion__ Woodland__ Upland Never cultivated__Previously cultivated Floodplain Pastureland Soil Drainage: excellent__ good___ fair___ poor Slope: flat_ gentle__ moderate __ steep Distance to nearest water from structure (approx.) Elevation:

5. Site Investigation (append additional sheets, if necessary):

Surface--date(s)

Site Map (Submit with form)

Collection

Subsurface--date(s)

Testing: shovel coring other unit size no. of units

Excavation: unit size no. of units Investigator

Manuscript or published report(s)(reference fully):

Present repository of materials 
6. Site inventory:

a. date constructed or occupation period

b. previous owners, if known

c. modifications, if known:

7. Site documentation (append additional sheets, if necessary):

a. Historic maps

1) Name Present location of original, if known

2) Name Date Source

Present location of original, if known

3) Name

Date

Present location of original, if known Source

b. Representation in existing photography

1) Photo date Where located

c. Primary and secondary source documentation (reference fully):

d. Persons with memory of site:

8. List of material remains other than those used in construction (be as specific as possible in identifying object and material):

If prehistoric materials are evident, check here and fill out prehistoric site form.

9. Map References: Map or maps showing exact location and extent of site must accompany this form and must be identified by source and date.

USGS 7.5' Minute Series Quad. Name

For Office Use Only--UTM Coordinates

10. Photography (optional for environmental impact survey): see report

11. Eligibility Discussion

A._Property appears NR/SR eligible.

Identify relevant theme:

Existence of relevant context:__yes _ no

Discuss:

B. Specific Criteria for Eligibility:

Criteria A. Associated with events that have made a significant contribution to the broad patterns of our history.

Criteria B. Associated with the lives of persons significant in our past.

Criteria C. _ Embodies the distinct characteristics of a type, period, or method of construction; or represents a significant and distinguishable entity whose components may lack individual distinction; or

Criteria D. _ Have yielded, or may be likely to yield, information important in prehistory or history.

C. Discussion (Provide a brief paragraph summarizing site) 
BROOKHAVEN NATIONAL LABORATORY

TRENCH FEATURE INVENTORY FORM

Trench ID number:

Data collected by:

Date:

USGS 7.5' quadrangle:

Photo number:

BNL map grid:

View of:

Description:

Trench type:

Adjacent trench number(s):

Associated cultural material:

Average dimensions (see attached):

length:

width: depth:

Coordinates (UTM Zone 18N)

\begin{tabular}{|l|l|l|}
\hline Point & Easting & Northing \\
\hline & & \\
& & \\
\hline
\end{tabular}


J

7 


\section{BROOKHAVEN NATIONAL LABORATORY FOUNDATION FEATURE INVENTORY FORM}

Foundation Area

Data collected by:

USGS 7.5' quadrangle:

Photo number:

Date:

BNL map grid:

View of:

Description:

Types of features:

Complex Dimensions:

East-West:

North-South:

Coordinates (UTM Zone $18 \mathrm{~N}$ )

\begin{tabular}{|l|l|l|}
\hline Point & Easting & Northing \\
\hline & & \\
& & \\
& & \\
\hline
\end{tabular}




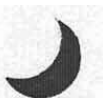

7 


\section{Cultural Resource Property Accession Receiving Report}

$\overline{\text { Accession }} \overline{\text { date }}$

Number of items in collection

(year-month-day)

Use this form to document the receipt of artifacts and/or records and to collect pertinent information on the item(s). If additional space is needed, attach a separate sheet. Use ink or type.

1. Name of Item(s):

2. Name and address of Source of Accession:

Phone:

E-mail:

3. Give brief description, identification and history of the collection. Note locality collected or purchased, give site names and numbers if appropriate. Use page 2 to list individual items in collection. This information is provided by the Source of Accession only.

4. Remarks:

5. Objects and/or Specimens Received by:

Print Name and Title of BNL Employee

Date:

at: 
Page 2 of 2

\section{ACCESSION RECEIVING REPORT LIST OF OBJECTS AND/OR RECORDS}

\section{BNL Office}

Accession Date

Use this form to provide a list of the objects and/or specimens and their condition. This form is used only as an attachment to the Accession Receiving Report.

\begin{tabular}{|c|c|c|c|}
\hline Quantity & Object or Specimen Name & Description & Condition \\
\hline & & & \\
\hline & & & \\
\hline & & & \\
\hline & & & \\
\hline & & & \\
\hline & & & \\
\hline & & & \\
\hline & & & \\
\hline & & & \\
\hline & & & \\
\hline & & & \\
\hline & & & \\
\hline & & & \\
\hline & & & \\
\hline & & & \\
\hline & & & \\
\hline & & & \\
\hline & & & \\
\hline & & & \\
\hline & & & \\
\hline & & & \\
\hline & & & \\
\hline & & & \\
\hline
\end{tabular}




\section{Camp Upton Historic Collection}

\section{Accession Records Work Sheet}

\section{Accession Number:}

Title:

First Name:

Last Name:

Street:

Street:

City:

State:

Zip

Day Phone:

Evening Phone:

Donation Date:

Acquistion Type:

Donation For:

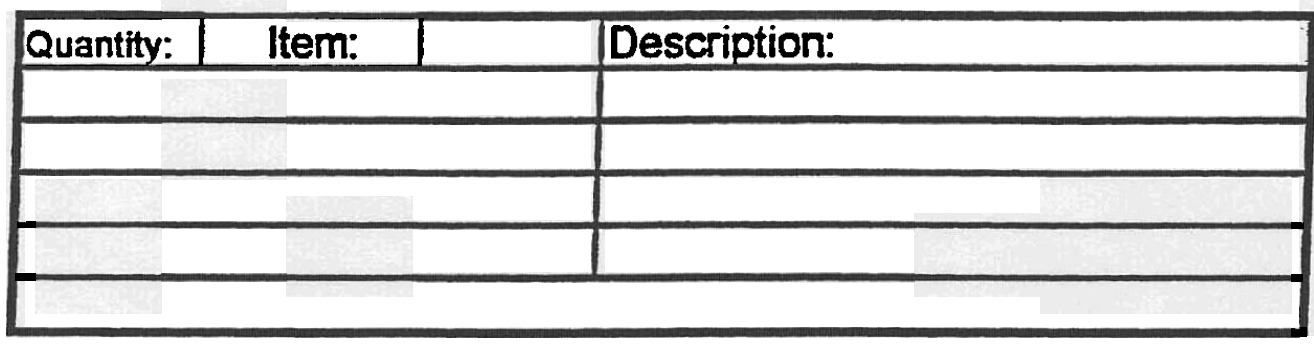

Comments and More Items (if necessary):

Signature of Donor.

Reply 
J

7

)

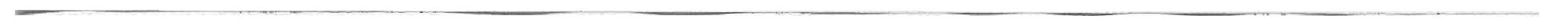


Camp Upton Historic Collections Cataloging Worksheet

Class2

BNL Negative No.
Accession No:
Object Name:

Accession No:
Object Name:

Object Location:

Description:
Attachment 23

Catalog No CU-
Photo Info.

Circle:

Object Date:

Artist/Author:

Maker/Publisher.

Maker Address:

Cultural Identity:

Association:

Eminent Figures:

Significance:

Dimension

Materials

Condition:

Condition Descript.:

Maintenance Cycle:

Cataloger Name:

Catalog Folder:

Photo Taken:

ontified By:

smo:

\begin{tabular}{llllll} 
Horizontal & BNW & Studio & Indoors & Glossy & \\
\hline Vertical .. & Color & Candid & Outdoors & Matte & Panoramic
\end{tabular}

Count:

Parts:

Object Status:

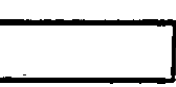


$J$

7

7 


\section{Attachment 24}

\section{Shovel Test Pit Record}

Project

Date

Crew

Unit
\begin{tabular}{|l|l|l|l|l|l|l||}
\hline \hline level & open & close & horizon & color/texture & cultural material & comments \\
\hline & & & & & & \\
\hline & & & & & & \\
\hline & & & & & & \\
\hline & & & & & & \\
\hline & & & & & & \\
\hline
\end{tabular}

Unit

\begin{tabular}{||l|l|l|l|l|l|l||}
\hline level & open & close & horizon & color/texture & cultural material & comments \\
\hline & & & & & & \\
\hline & & & & & & \\
\hline & & & & & & \\
\hline & & & & & & \\
\hline & & & & & & \\
\hline
\end{tabular}

Unit

\begin{tabular}{|l|l|l|l|l|l|l||}
\hline \hline level & open & close & horizon & color/texture & cultural material & comr \\
\hline & & & & & & \\
\hline & & & & & & \\
\hline & & & & & & \\
\hline & & & & & & \\
\hline & & & & & & \\
\hline
\end{tabular}




\section{Attachment 25}

\section{Excavation Record Form}

Project

Site/Area

Excavators

Date

ground surface or opening depths:

closing depth:

level \#__: (open) - (close)

stratum:

lot \#

cultural material:
Unit (SW corner)

Unit size

SW/SE/NW/NE quad of

Vertical datum

soil:

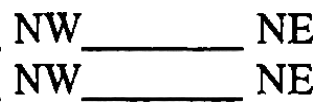

SW SE $\mathrm{NE}$

\# bags of artifacts:

comments:

check all that apply: feature color print photo color slide b\&w photo plan view profile drawing soil sample $\mathrm{C}^{14}$ sample other

closing depth:

SW NW $\mathrm{NE}$ level \# - (close)

stratum: : (open) SE NE

lot \# soil: material: comments:

check all that apply: feature color print photo color slide b\&w photo plan view profile drawing soil sample $\mathrm{C}^{14}$ sample other

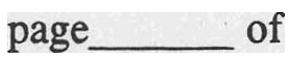




\section{Attachment 26}

\section{Feature Record Form}

Project

Site/Area

Excavators

Date

lot \# top depth below datum or ground surface:

description:

stratigraphic context:

feature matrix description:

dimensions: length width depth
Feature \#

Unit (SW corner)

Unit size

Vertical datum

associated cultural material/\# bags:

excavation methods (sectioning, screening, etc.):

photographs/drawings/samples (check all taken): color print photo color slide plan view drawing profile drawing b\&w photo $\mathrm{C}^{14}$ sample other 


\section{Attachment 27}

\section{BNL SBMS Subject Area}

\section{National Environmental Policy Act (NEPA) and Cultural Resource Reviews}




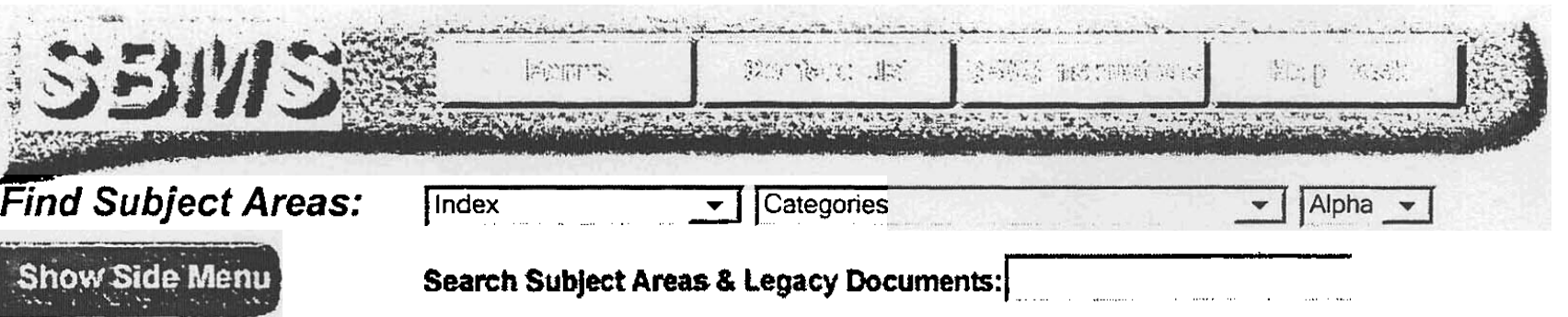

\section{Contents: National Environmental Policy Act (NEPA) and Cultural Resources Evaluations}

Effective Date: March 1999

Point of Contact: Environmental Subject Matter Expert for NEPA

\section{Section}

Introduction

1. Conducting National Environmental Policy Act (NEPA) and Cultural Resources Evaluations

Definitions

\section{Exhibits}

Flow Diagram of the NEPA Process

\section{Forms}

NEPA Environmental Evaluation Form
- Determine if reviews are required based on given criteria.

- Send specified information to the NEPA SME.

- NEPA SME either issues a memorandum that the NEPA process has been completed (via an existing approval) or provides PI with an EENF for completion.

- Complete EENF and forward to Manager of DOE-BAO.

- Follow appropriate procedure based on DOEBAO response.

\section{Training Requirements and Reporting Obligations}

This subject area does not contain training requirements.

This subject area contains reporting obligations. See the section Conducting National Environmental Policy Act (NEPA) and Cultural Resources Evaluations. 
National Environmental Policy Act (NEPA) and Cultural Resources Evaluations - Contents Page 2 of 2

\section{References}

None

\section{Standards of Performance}

All staff shall comply with applicable Laboratory policies, standards, and procedures, unless a formal variance is obtained.

Managers shall analyze work for hazards, authorize work to proceed, and ensure that work is performed within established controls.

Managers shall ensure that work is planned to prevent pollution, minimize waste, and conserve resources, and that work is conducted in a cost-effective manner that eliminates or minimizes environmental impact.

BNL shall actively seek and consider the public's input on the Laboratory's decisions that affect the community and the general public.

\section{Management System}

This subject area belongs to the Environmental Management System management system.

\section{Back to Top}

The only official copy of this file is the one online in SBMS. Before using a printed copy, verify that it is the most current version by checking the document effective date on the BNL SBMS website.

\section{2-092003/standard/09/0900t011.htm}

Send a question or comment to the SBMS Help Desk

Disclaimer 


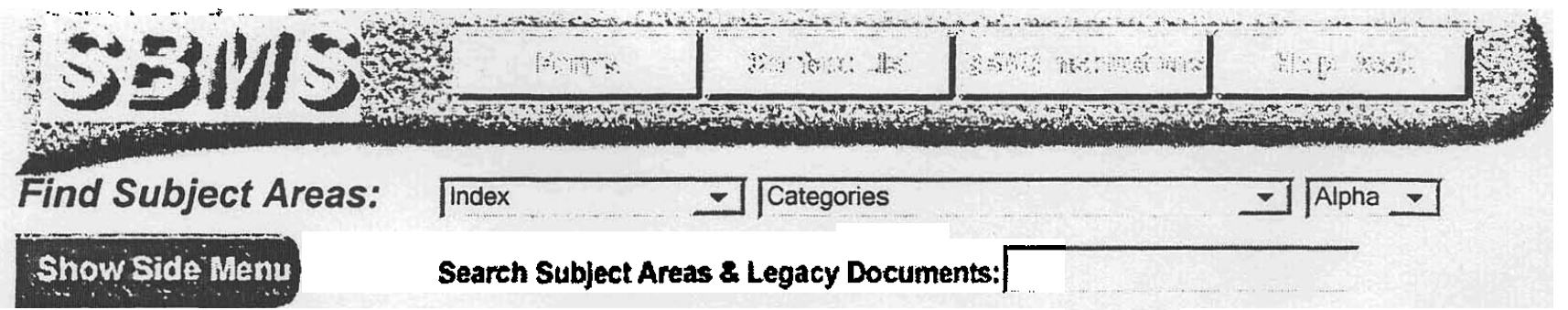

\section{Introduction: National Environmental Policy Act (NEPA) and Cultural Resources Evaluations}

Effective Date: March 1999

Point of Contact: Environmental Subject Matter Expert for NEPA

Staff involved in projects, activities, or facility modifications that involve either federal funding, or use of federal facilities, federal lands, or capital equipment must ensure that a NEPAVCultural Resources review is performed before initiating work.

Back to Top

The only official copy of this file is the one online in SBMS. Before using a printed copy, verify that it is the most current version by checking the document effective date on the BNL SBMS website.

\section{2-092003/standard/09/09001011.htm/standard/09/0900i011.htm}

Send a question or comment to the SBMS Help Desk Disclaimer 


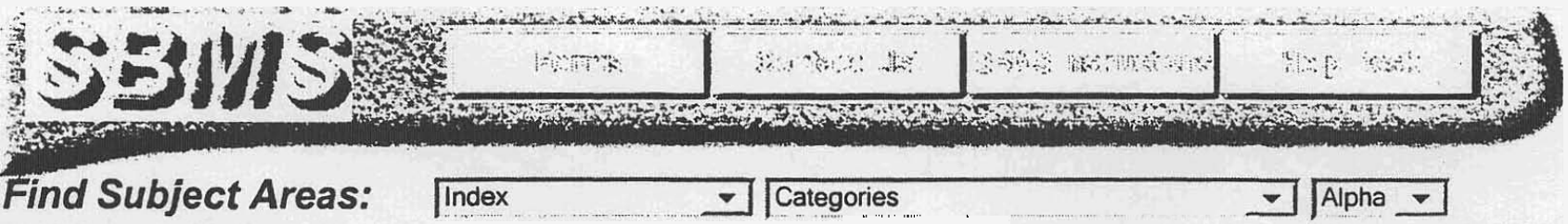

\section{Conducting National Environmental Policy Act (NEPA) and Cultural Resources Evaluations}

\section{Applicability}

This information applies to Project Managers/Principal Investigators responsible for projects, activities, or facility modifications that involve either federal funding or use of federal facilities, federal lands, or capital equipment.

\section{Required Procedure}

Staff involved in projects, activities, or facility modifications that involve either federal funding, or use of federal facilities, federal lands, or capital equipment must ensure that a NEPA/Cultural Resources review is performed before initiating work.

Note: Any work performed by Brookhaven Science Associates for other national laboratories must comply with DOE NEPA requirements, even if the work does not involve the Brookhaven National Laboratory site, Department of Energy-Chicago (DOE-CH) facilities, or other federal resources. The Laboratory that is requesting funds from DOE is responsible for completion of the NEPA process.

Note: If the proposed activity does not involve federal funding, but uses DOE-owned or leased property, capital equipment, or federal lands, the activity must be reviewed by the Environmental Subject Matter Expert for NEPA or Environmental Compliance Representative to determine the level of NEPA documentation required.

Note: If the proposed activity does not involve federal funding or the use of federal facilities, lands, or capital equipment, NEPA does not apply.

Note: Certain activities may be allowed prior to NEPA approval. Contact the Environmental Subject Matter Expert for NEPA for additional information.

The following actions must be taken to initiate a NEPAVCultural Resources review. 


\begin{tabular}{|c|c|}
\hline Step 1 & $\begin{array}{l}\text { Project Managers/Principal Investigators involved in projects, activities, or facility } \\
\text { modifications that involve either federal funding or use of a federal facility, federal } \\
\text { lands, or capital equipment determine if NEPA and Cultural Resources reviews } \\
\text { are required. NEPACultural Resources reviews are required for the following } \\
\text { types of projects: } \\
\text { - a project that involves a research paper investigation } \\
\text { - a project that involves experimental work } \\
\text { - a project where the scope, location, or probable environmental impact has } \\
\text { changed since an earlier NEPA review } \\
\text { - a project that involves facility or structural construction, installation, or } \\
\text { modifications } \\
\text { - a project that involves outdoor field work such as excavation, } \\
\text { environmental monitoring, characterization, or research } \\
\text { - an activity that involves a capital procurement over } \$ 25,000 \text {. } \\
\text { Questions regarding the applicability of NEPACultural Resources Review should } \\
\text { be directed to the Environmental Subject Matter Expert for NEPA. }\end{array}$ \\
\hline Step 2 & $\begin{array}{l}\text { Provide the Environmental Subject Matter Expert for NEPA with a project title, } \\
\text { project description, total estimated project cost, and source of funding. }\end{array}$ \\
\hline & $\begin{array}{l}\text { If the action is an authorized Categorically Excluded activity, or is included in a } \\
\text { Finding of No Significant Impact or a Record of Decision previously issued to the } \\
\text { Laboratory, the Environmental Subject Matter Expert for NEPA issues a } \\
\text { memorandum that the NEPA process has been completed. Maintain this record } \\
\text { and proceed with work if funding is available. }\end{array}$ \\
\hline Step 4 & $\begin{array}{l}\text { If the action requires a decision by a DOE NEPA Compliance Officer, the } \\
\text { Environmental Subject Matter Expert for NEPA will direct you to submit a NEPA } \\
\text { Environmental Evaluation Notification Form. Complete sections I through III. In } \\
\text { section V, provide an explanation for each item marked "yes" in Section III. } \\
\text { Forward the form to the Environmental Subject Matter Expert for NEPA, who will } \\
\text { review, sign, and return the form. Review the form for accuracy, sign it, and } \\
\text { forward it to the Manager, Department of Energy Brookhaven Area Office (DOE- } \\
\text { BAO) under the subject "Request for NEPA Evaluation." }\end{array}$ \\
\hline Step 5 & $\begin{array}{l}\text { If DOE's response to the "Request for NEPA Evaluation" is a written } \\
\text { determination that the action is consistent with DOE-established Categorically } \\
\text { Excluded actions, the NEPA process has been completed. If the project has the } \\
\text { potential to impact a known or possibly unknown cultural resource, additional } \\
\text { instructions on compliance will be provided by the Environmental Subject Matter } \\
\text { Expert for NEPA. Maintain this record and proceed with work if funding is } \\
\text { available. }\end{array}$ \\
\hline Step 6 & $\begin{array}{l}\text { If DOE's response to the "Request for NEPA Evaluation" is a request to prepare } \\
\text { an Environmental Assessment, work with the Environmental Subject Matter } \\
\text { Expert for NEPA to complete one. A cultural resource review will be included as } \\
\text { part of this document. Review the document with the Environmental Subject } \\
\text { Matter Expert for NEPA, and then submit the Environmental Assessment to the }\end{array}$ \\
\hline
\end{tabular}


National Environmental Policy Act (NEPA) and Cultural Resources Evaluations - 1. Con... Page 3 of 3

\begin{tabular}{||l||l|l||} 
& $\begin{array}{l}\text { NEPA process has been completed. Maintain this record and proceed with work } \\
\text { if funding is available. }\end{array}$ \\
\hline Step 7 & $\begin{array}{l}\text { If DOE's response to the "Request for NEPA Evaluation" or completed } \\
\text { Environmental Assessment is that an Environmental Impact Statement (EIS) is } \\
\text { required, the DOE and its contracted designee works with the Project } \\
\text { Manager/Principal Investigator to gather information on the proposed action, } \\
\text { possible alternatives, and anticipated impacts. A cultural resources review will be } \\
\text { included as part of the EIS. Should DOE issue a Record of Decision, the NEPA } \\
\text { process has been completed. Maintain this record and proceed with work if } \\
\text { funding is available. Should the Record of Decision incorporate a Mitigation } \\
\text { Action Plan, requirements must be incorporated into the planned work. }\end{array}$ \\
\hline
\end{tabular}

\section{Guidelines}

If the proposed activity is funded by a federal agency other than DOE and does not involve the use of DOE-owned or leased facilities, capital equipment, or federal lands, the Project Manager/Principal Investigator should notify the client that compliance with the requirements of NEPA is the responsibility of that agency.

\section{Back to Top}

\section{The only official copy of this file is the one online in SBMS. Before using a printed copy, verify that it is the most current} version by checking the document effective date on the BNL SBMS website.

\section{2-092003/standard/09/0901d011.htm}

Send a question or comment to the SBMS Help Desk

Disclaimer 
National Environmental policy Act (NEPA) ENVIRONMENTAL EVALUATION NOTIFICATION FORM

Grantee/Contractor Laboratory: BROOKHAVEN NATIONAI LABORATORY Project/Activity Title:

CH NEPA Tracking No. : Type of Funding:

$B \& R$ Code: Total Estimated Cost:

DOE Cognizant secretarial officer (CSO): James F. Decker, SC-I

Contractor Project Manager: Signature:

Date :

Contractor NEPA Reviewer: T. Green Signature:

Date:

I. Description of Proposed Action:

II. Description of Affected Environment: 
NEPA Environmental Evaluation Notification Form (continued)

III. Potential Environmental Effects: (Attach explanation for each "yes" response and "no" response if additional information is available and could be significant in the decision making process.)

A. Sensitive Resources: Will the proposed action result in changes and/or disturbances to any of the following resources?

$\underline{\text { Yes/NO }}$

1. Threatened/Endangered Species and/or Critical Habitats

2. Other Protected Species (e.g., Burros, Migratory Birds)

3. Wetlands

4. Archaeological/Historic Resources

5. Prime, Unique or Important Farmland

6. Non-Attainment Areas

7. Class I Air Quality Control Region

8. Special Sources of Groundwater (e.g., Sole Source Aquifer)

9. Navigable Air space

10. Coastal Zones (e.g., National Forests, Parks, Trails)

11. Areas w/Special National Designation (e.g., National Forests, Parks, Trails)

12. Floodplain

B. Regulated Substances/Activities: Will the proposed action involve any of the following regulated substances or activities?

13. Clearing or Excavation (indicate if greater than 5 acres)

14. Dredge or Fill (under Clean water Act section 404; indicate if greater than 10 acres)

15. Noise (in excess of regulations)

16. Asbestos Removal

17. PCBs

18. Import, Manufacture or Processing of Toxic Substances

19. Chemical storage/Use

20. Pesticide Use

21. Hazardous, Toxic, or Criteria Pollutant Air Emissions

22. Liquid Effluent

23. Underground Injection

24. Hazardous Waste

25. Underground storage Tanks

26. Radioactive (AEA) Mixed Waste

27. Radioactive Waste

28. Radiation Exposures

C. Other Relevant Disclosures. Will the proposed action involve the following?

29. A threatened violation of ES\&H regulations/permit requirements

30. Siting/Construction/Major Modification of Waste Recovery or TSD Facilities

31. Disturbance of Pre-existing Contamination

32. New or Modified Federal/state Permits

33. Public controversy (e.g., Environmental Justice Executive Order 12898 consideration and other related public issues)

34. Action/involvement of Another Federal Agency (e.g., license, funding, approval) 
NEPA Environmental Evaluation Notification Form (continued)

35. Action of a state Agency in a state with NEPA-type law.

(Does the state Environmental Quality Review Act Apply?)

36. Public Utilities/Services

37. Depletion of a Non-Renewable Resource 
IV. Section D Determination: Is the project/activity appropriate for a determination by the OM under subpart $D$ of the DOE NEPA Regulations for compliance with NEPA?

\section{A. DOE-CH NEPA Coordinator Review:}

DOE-CH NEPA CoOrdinator Reviewer:

Signature:

Date:

B. DOE CH NCO NEPA Review:

NCO Concurrence with Proposed Class of Action Recommended

$\begin{array}{lll}\text { CX } & \text { EA }\end{array}$

Category

DOE CH NCO Reviewer:

Signature:

Date :

DOE Recommendation Approvals:

CH NCO:

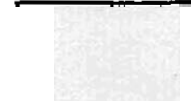

CH GLD :

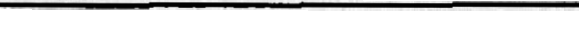

CH ESHD:

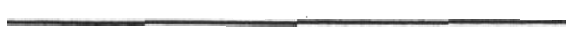

CH AMST:

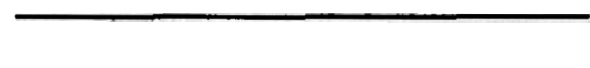

CH Office Mgr.:

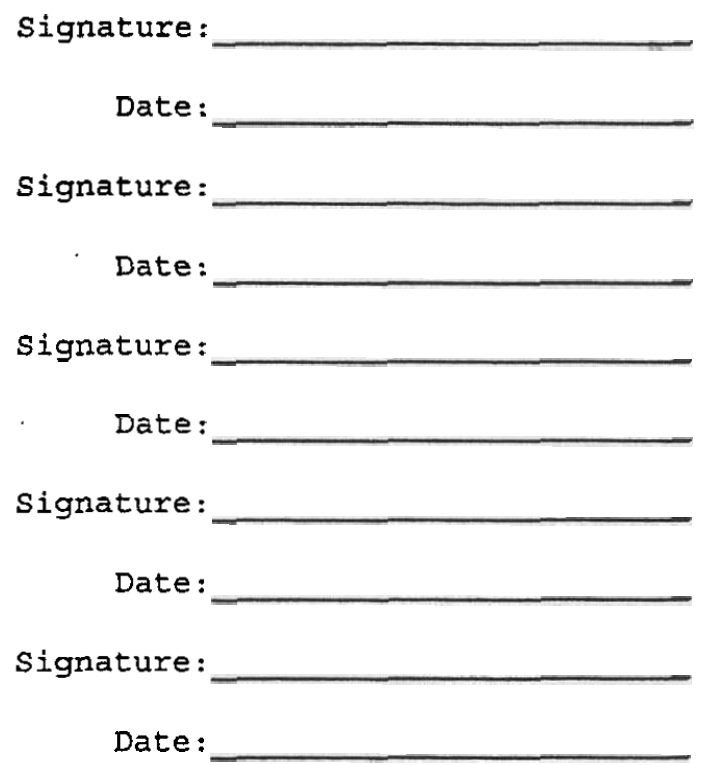


NEPA Environmental Evaluation Notification Form (continued)

v. Additional Information 


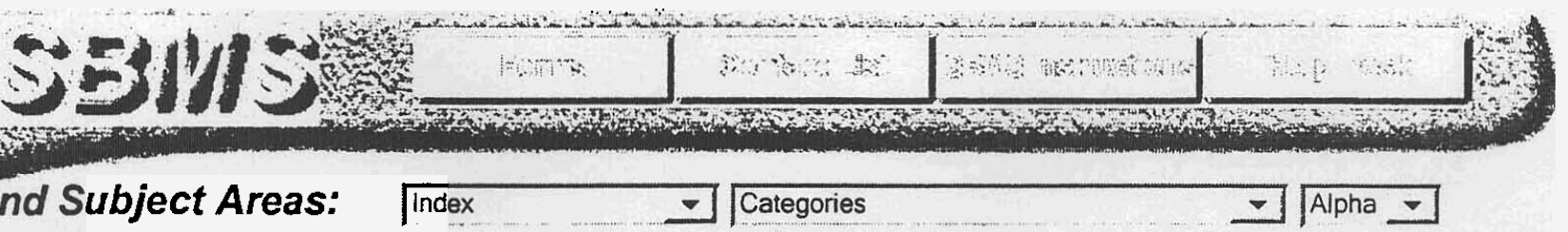

\section{Definitions: National Environmental Policy Act (NEPA) and Cultural Resources Evaluations}

Effective Date: March 1999

Point of Contact: Environmental Subject Matter Expert for NEPA

\begin{tabular}{|c|c|}
\hline Term & Definition \\
\hline action & $\begin{array}{l}\text { A project, program, plan, or policy that is subject to DOE's control } \\
\text { and responsibility. Actions which DOE is directed to conduct without } \\
\text { discretion, such as congressionally mandated actions, are not } \\
\text { included. }\end{array}$ \\
\hline $\begin{array}{l}\text { categorical } \\
\text { exclusion (CX) }\end{array}$ & $\begin{array}{l}\text { Through previous experience and documentation, DOE has } \\
\text { identified actions that have no significant environmental impact and } \\
\text { do not require the preparation of an Environmental Assessment or } \\
\text { Environmental Impact Statement. These actions are Categorically } \\
\text { Excluded from NEPA. }\end{array}$ \\
\hline cultural resources & $\begin{array}{l}\text { Historic or prehistoric sites, artifacts, or other items of cultural } \\
\text { importance; standing structures that are over } 50 \text { years of age, or } \\
\text { represent a major historical theme or era; recent structures, } \\
\text { facilities, equipment, and apparatuses that have historical scientific } \\
\text { significance. (Contact the Environmental Subject Matter Expert for } \\
\text { Cultural Resources for questions on specific items or potential } \\
\text { resources). }\end{array}$ \\
\hline $\begin{array}{l}\text { environmental } \\
\text { assessment (EA) }\end{array}$ & $\begin{array}{l}\text { A public document that provides sufficient evidence to support the } \\
\text { preparation of an Environmental Impact Statement or a Finding of } \\
\text { No Significant Impact. The EA includes brief discussions of the } \\
\text { need for the proposal; alternatives to the proposal; environmental } \\
\text { impacts associated with the proposal and alternatives considered; } \\
\text { and a listing of agencies and persons consulted. DOE is responsible } \\
\text { for this document. }\end{array}$ \\
\hline $\begin{array}{l}\text { environmental } \\
\text { impact statement } \\
\text { (EIS) }\end{array}$ & $\begin{array}{l}\text { A public document which provides sufficient evidence to support the } \\
\text { preparation of a Record of Decision. The EIS includes brief } \\
\text { discussions of the need for the proposal; alternatives to the } \\
\text { proposal; environmental impacts associated with the proposal and } \\
\text { alternatives considered; and a listing of agencies and persons } \\
\text { consulted. Document review is conducted through a prescribed }\end{array}$ \\
\hline
\end{tabular}


National Environmental Policy Act (NEPA) and Cultural Resources Evaluations - Definit... Page 2 of 2

\begin{tabular}{|c|c|}
\hline & $\begin{array}{l}\text { |process or pubic participation and inivoivermemt. LUE is resporisidie } \\
\text { for this document. }\end{array}$ \\
\hline $\begin{array}{l}\text { Environmental } \\
\text { evaluation } \\
\text { notification form } \\
\text { (EENF) }\end{array}$ & $\begin{array}{l}\text { This form includes a preliminary evaluation of the potential } \\
\text { environmental impacts associated with a proposed action, in order } \\
\text { to determine the appropriate level of NEPA documentation required. } \\
\text { It is completed by the Environmental Subject Matter Expert for } \\
\text { NEPA and the PI/PM and is reviewed and approved by the DOE- } \\
\text { Chicago (DOE-CH) NEPA Compliance Officer. }\end{array}$ \\
\hline $\begin{array}{l}\text { finding of no } \\
\text { significant impact } \\
\text { (FONSI) }\end{array}$ & $\begin{array}{l}\text { A determination by DOE that the proposal will not produce any } \\
\text { significant impact to the environment, based on a review of the } \\
\text { proposed action and alternatives. }\end{array}$ \\
\hline $\begin{array}{l}\text { mitigation action } \\
\text { plan (MAP) }\end{array}$ & $\begin{array}{l}\text { A plan that establishes measures to be conducted in conjunction } \\
\text { with a proposed action in order to minimize impacts to the } \\
\text { environment. The measures established by a MAP are considered } \\
\text { enforceable requirements for project completion, and must be } \\
\text { tracked and reported based on an established schedule. }\end{array}$ \\
\hline $\begin{array}{l}\text { record of decision } \\
\text { (ROD) }\end{array}$ & $\begin{array}{l}\text { A decision rendered by the Secretary of Energy based on } \\
\text { information provided in an EIS. It includes the selection of } \\
\text { alternatives and potential mitigating measures that have been } \\
\text { incorporated through a MAP. }\end{array}$ \\
\hline
\end{tabular}

\section{Back to Top}

The only official copy of this file is the one online in SBMS. Before using a printed copy, verify that it is the most current version by checking the document effective date on the BNL SBMS website.

\section{2-092003/standard/09/09001011.htm}

Send a question or comment to the SBMS Help Desk Disclaimer 


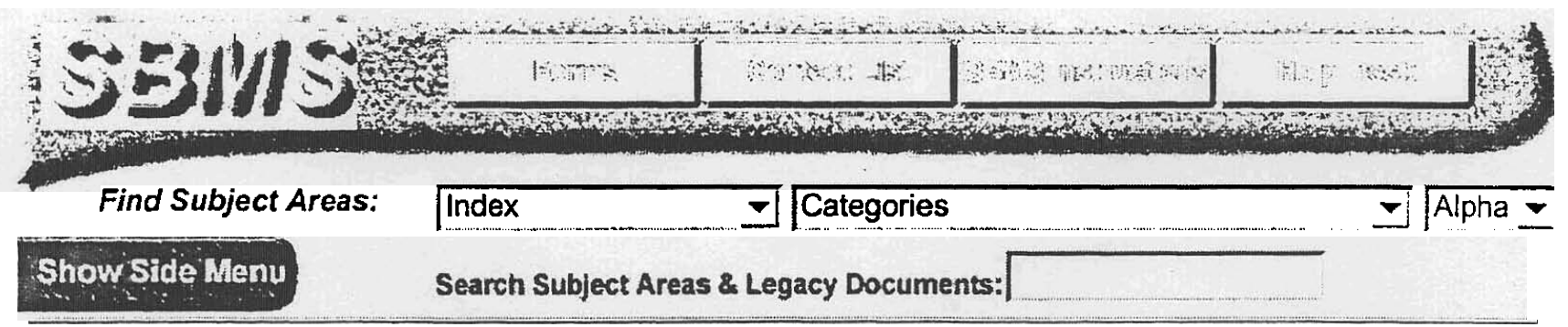

Subject Area: National Environmental Policy Act (NEPA) and Cultural Resources Evaluations

Revision History: National Environmental Policy Act (NEPA) and Cultural Resources Evaluations

Point of Contact: Environmental Subject Matter Expert for NEPA

\section{Revision History of this Subject Area}

\begin{tabular}{|l|l|l||}
\hline \hline Date & Description & Management System \\
\hline \hline March 1999 & $\begin{array}{l}\text { This subject area replaces ES\&H Standard/SEAPPM } \\
\text { 6.1.1. }\end{array}$ & $\begin{array}{l}\text { Environmental Management } \\
\text { System }\end{array}$ \\
\hline
\end{tabular}

The only official copy of this file is the one online in SBMS. Before using a printed copy, verify that it is the most current version by checking the document effective date on the BNL SBMS website.

\section{1-022000/standard/09/0900a011.htm}

Send a question or comment to the SBMS Help Desk

Disclaimer 
J

) 


\section{ENVIRONMENT, SAFETY, HEALTH AND QUALITY} DIRECTORATE

\section{BROOKHA VEN NATIONAL LABORATORY}

REGULATORY COMPLIANCE PROCEDURE

\section{Project Reviews For Potential Impact to Cultural Resources}

1.0 PURPOSE/SCOPE .

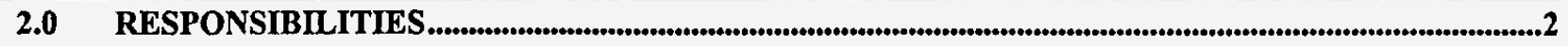

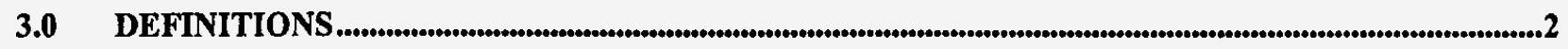

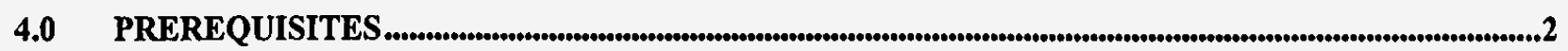

5.0 PRECAUTIONS

6.0 PROCEDURE

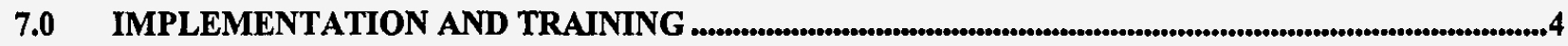

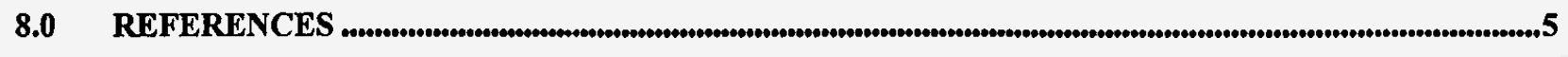

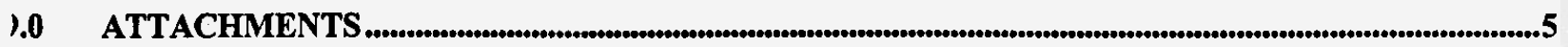

\begin{tabular}{|c|c|c|}
\hline $\begin{array}{l}\text { PREPARED BY: } \\
\text { /s/ M. Davis/12/15/03 }\end{array}$ & $\begin{array}{l}\text { REVIEWED BY: } \\
\text { /s/ T. Green/12/17/03 }\end{array}$ & $\begin{array}{l}\text { APPROVED BY: } \\
\text { /s/ G. Goode/12/22/03 } \\
\end{array}$ \\
\hline \multirow{3}{*}{$\begin{array}{l}\text { Author Date } \\
\text { Filing Code: EC45ER.03 }\end{array}$} & $\begin{array}{l}\text { Natural \& Cultural Resource } \\
\text { Manager/Date } \\
\text { /s/ R. Lee/12/17/03 }\end{array}$ & $\begin{array}{l}\text { EFFECTIVE DATE: } \\
\text { Dec. } 22,2003\end{array}$ \\
\hline & $\begin{array}{l}\text { EWMSD Deputy Manager for } \\
\text { Environmental Programs/Date } \\
\text { /s/ S. Stein/12/16/03 }\end{array}$ & REVIEW CYCLE: 3 years \\
\hline & QR/Date & \\
\hline
\end{tabular}




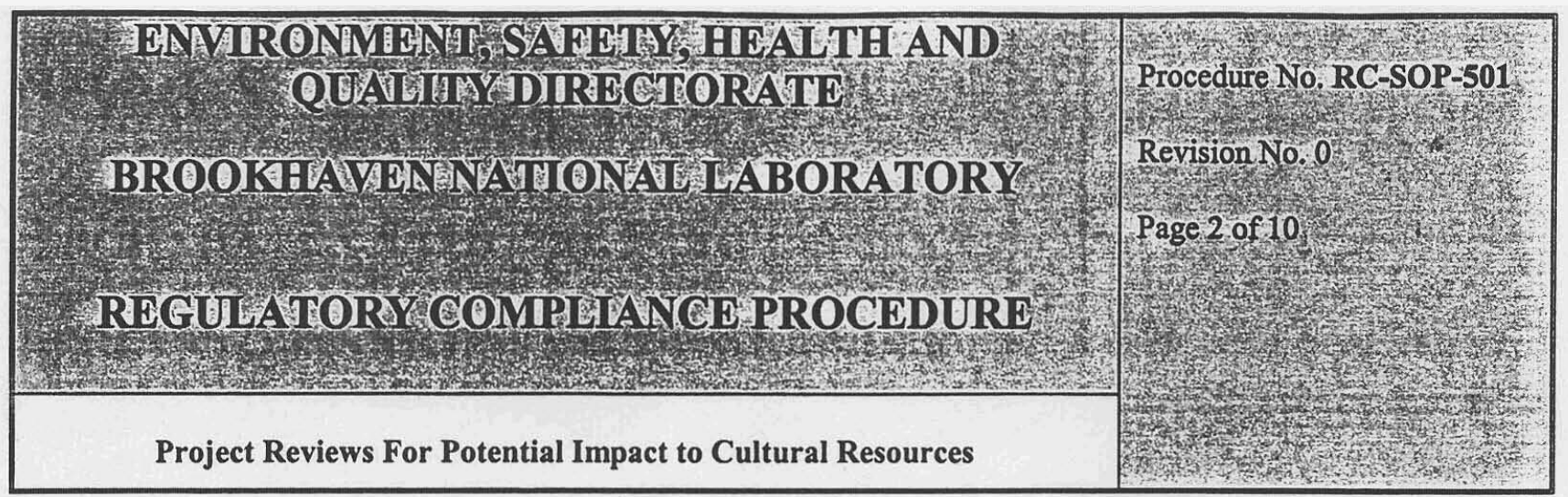

\subsection{PURPOSE AND SCOPE}

This procedure describes the process followed to review BNL projects in order to assess their potential to impact onsite cultural resources. The scope includes descriptions of how reviews are initiated; cultural resource aspects to be considered; and management tools used to assist these evaluations.

\subsection{RESPONSIBILITIES}

2.1 Cultural Resource Coordinator (CRC) - responsible for: reviewing project information (proposals, descriptions, work permits, digging permits, etc.) to determine the potential effects on BNL cultural resources; ensuring mitigating actions are performed in accordance with the BNL Cultural Resource Management Plan (CRMP).

2.2 Division Manager - responsible for reviewing, signing and ensuring distribution of formal documents $t$ DOE.

2.3 Natural \& Cultural Resources Manager - responsible for reviewing draft and final documents generated by the CRC.

2.4 Environmental Subject Matter Expert (SME) - Environmental SMEs with designated authority to review project documents and sign Digging Permits are responsible to consider the impact on cultural resources in their review.

\subsection{DEFINITIONS}

3.1 Cultural Resources: Historic or prehistoric sites, artifacts, or other items of cultural importance; Standing structures over 50 years of age, or that are important because they represent a major historical theme or era. Recent structures, facilities, equipment and apparatus that have scientific significance, or that are determined to be supporting assets. Note: This definition was paraphrased from the definition found in Reference 8.1.

4.0 PREREQUISITES

None

\subsection{PRECAUTIONS}

None 


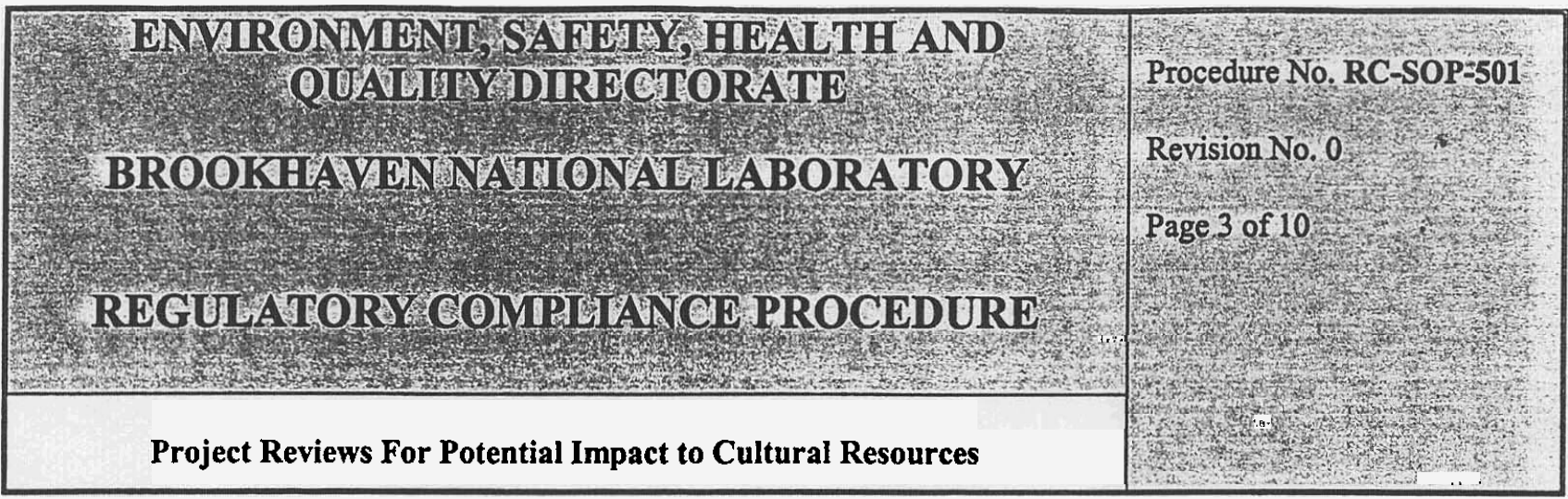

Section 6.1 identifies mechanisms that initiate a CR review. Sections 6.2 through 6.4 identify the culturally significant resources and aspects that shall be considered during the review. Project reviews shall consider both direct and indirect impacts to these resources

6.1 Project Review Initiation - Cultural resource reviews are initiated through the following mechanisms:

6.1.1 NEPA Reviews: A NEPA review is required to be conducted for the majority of projects performed onsite including construction, modification, renovation, scientific experiments and studies, etc. (Refer to reference 8.2 for a description of the NEPA process). Cultural resources are one of the environmental aspects evaluated as part of a NEPA review. This procedure will serve as a guide identifying the various cultural resources to be considered during a project review.

6.1.2 Digging Permits: The Plant Engineering Digging Permit program requires issuance of a Digging Permit for "any excavations in any areas", including CERCLA related projects. The Digging Permit form is reviewed by an environmental program Subject Matter Expert (SME) and contains a signature review line. The SME is to consider potential impacts to cultural resources, along with endangered species, and other environmental aspect.

6.1.3 CERCLA Projects: CERCLA projects are reviewed by environmental Subject Matter Experts (SME). If a project has the potential to impact a cultural resource(s) or the SME is not certain, the project information shall be forwarded to the CRC for review.

\subsubsection{Building Maintenance: To Be Developed}

\subsubsection{Site Maintenance: To Be Developed}

\subsection{Buildings}

6.2.1 Buildings over 50 years of age: Any major undertaking (major modification, demolition, relocation) associated with a building over 50 years of age requires that a National Historic Preservation Act (NHPA) Section 106 Review be performed, unless otherwise addressed in the approved BNL Cultural Resource Management Plan. The Section 106 review must be based on the requirements of 36 CFR Part 800.4. Previous BNL Section 106 Review packages may be used as template examples.

6.2.2 Cultural Significance Categories: Attachment 1 'Cultural Significance Category Descriptions' describes the categories that establish discrete levels of historical significance, and identify specific buildings within each level. If the action to be performed is associated with a Category I or II building, then refer to the Cultural Resource Management Strategy Form associated with that structure or associated group, for details on the specific features considered historically significant. The Strategy 


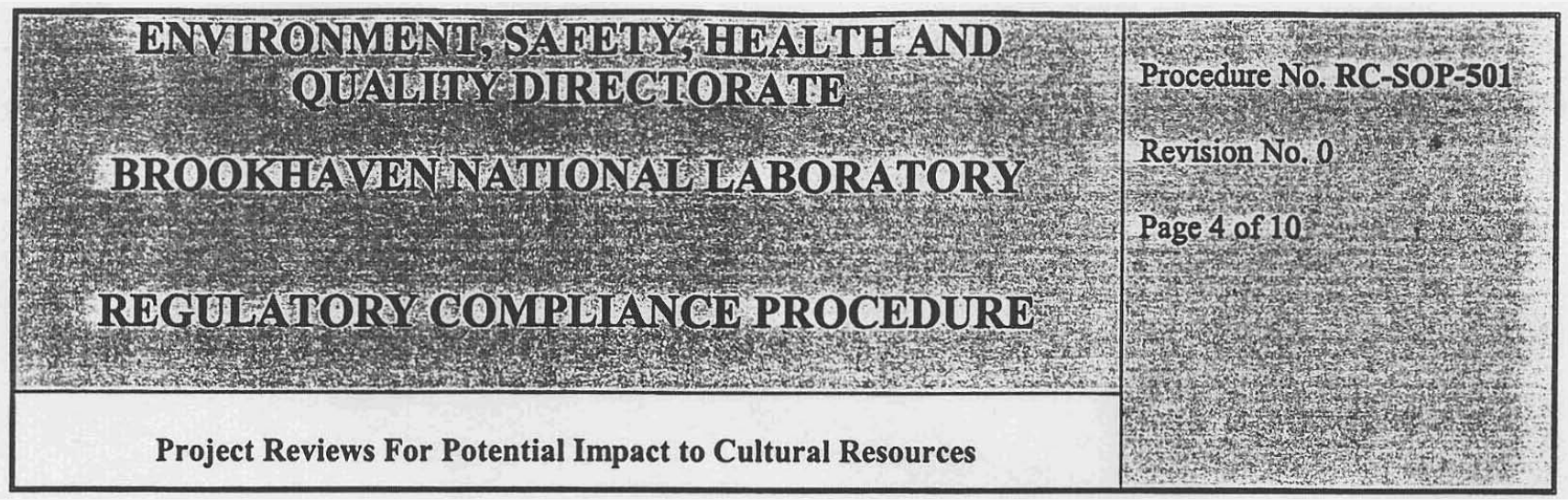

Forms may also identify specific strategies developed for certain types of actions. Note: Cultural Resource Management Strategy Forms are available in the Cultural Resource Management Plan.

6.3 Cultural Resource Areas \& Sites

6.3.1 Areas considered culturally significant or sensitive include:

6.3.1.1 World War I training trenches

6.3.1.2 World War I Camp Upton foundations \& structures

6.3.1.3 Gamma Forest site

6.3.1.4 $19^{\text {th }}$ century home sites

6.3.2 The following tools may be utilized to identify the location of these onsite areas.

6.3.2.1 Sensitive Cultural Resources map: This map is produced by the CRC, and is considered for Limited Distribution due to sensitive information related to the location and protection of cultural resources.

\subsubsection{Cultural resource site files and project files.}

6.4 Archeological Surveys: Based on the high degree of previous disturbance in the developed portion of the BNL site, archeological surveys do not need to be performed in these areas identified on Attachment 2. If grounddisturbing activities are planned for the following areas, archeological surveys are recommended prior to initiating excavation actions (Reference attachment 3 ):

6.4.1 Fresh Water Sources - Areas in the immediate vicinity of fresh water sources at BNL (property within or adjacent to wetlands and other fresh water sources (especially near the Peconic River).

6.4.2 Culturally Sensitive Areas - Areas within the footprint of World War I era Camp Upton, the Civilian Conservation Corps period, and World War II era Camp Upton, that have not had major disturbance.

6.4.3 $19^{\text {th }}$ Century house sites - Within 100 feet surrounding these sensitive areas.

\subsection{IMPLEMENTATION AND TRAINING}

7.1 The Cultural Resource Coordinator is responsible to coordinate with departments/divisions to identify the appropriate project planning mechanisms in which cultural resource issues should be integrated.

7.2 The CRC is responsible to identify and brief personnel involved in project planning and work control programs that have the potential to affect cultural resources. 


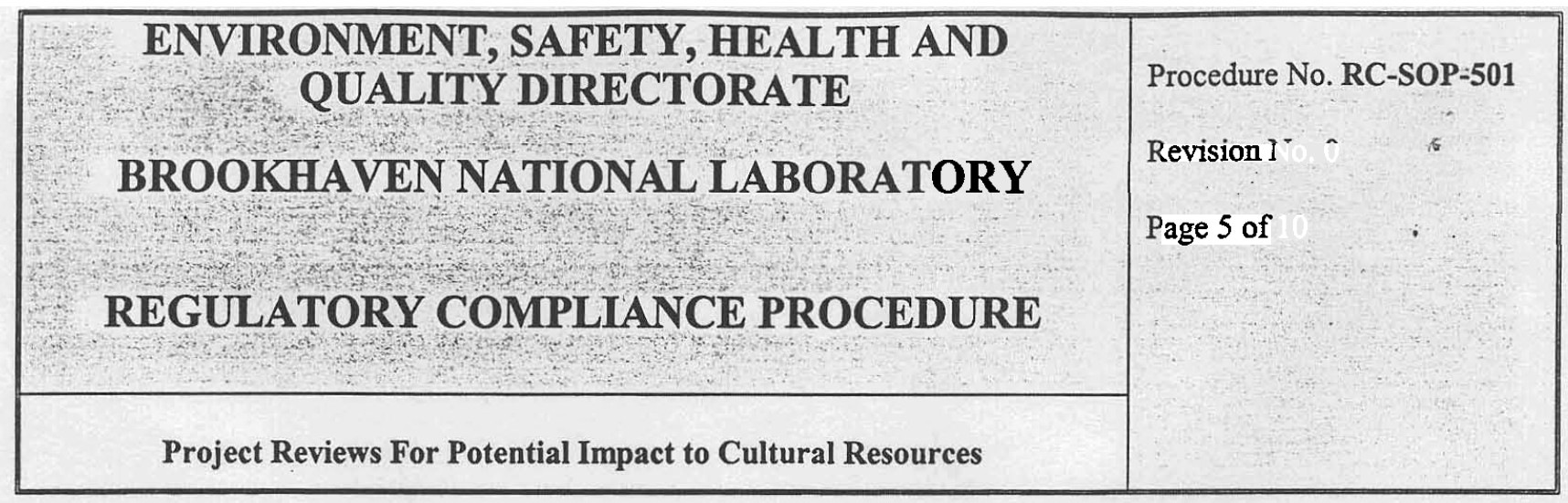

\subsection{REFERENCES}

8.1 Environmental Guidelines for Development of Cultural Resource Management Plans (DOE/EH-0501).

8.2 SBMS subject area National Environmental Policy Act (NEPA) and Cultural Resource Reviews

\subsection{WWI Camp Upton - BNL Site Overlay Map}

8.4 Cultural Resource Management Plan for Brookhaven National Laboratory (Draft)

\subsection{ATTACHMENTS}

9.1 Attachment 1 "Cultural Significance Category Descriptions"

9.2 Attachment 2 "Areas of Substantial Ground Disturbance"

9.3 Attachment 3 "Archeologically Sensitive Areas" 


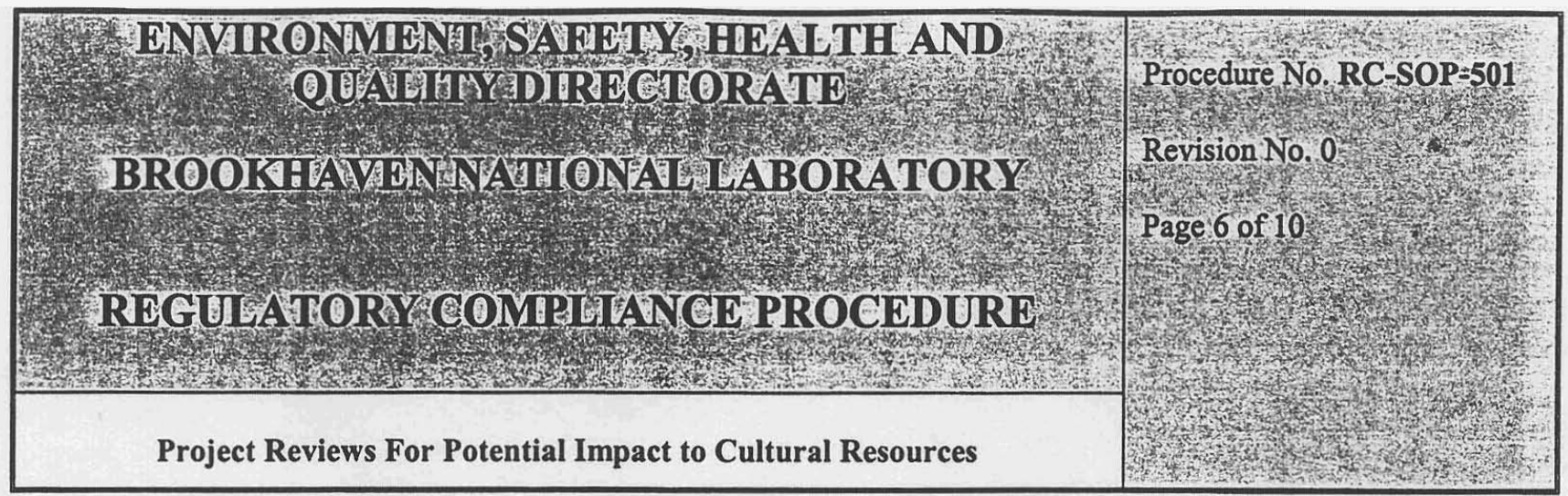

\section{Attachment 1}

\section{Cultural Significance Categories Table}

Category I: A building, site or program determined to be historically significant due to: historic context; architecture; engineering \& design; direct association with important personages; or scientific achievement. The resource(s) may be individually eligible for listing on the National Register, however, eligibility is not a requirement.

Treatment and/or mitigation: Some degree of treatment and/or mitigation is necessary to ensure cultural significance is retained and available for interpretation. Examples include, but are not limited to:

- Specific treatment or architectural management plan, if architecturally significant;

- Documentation of engineering \& design, and scientific achievements (photos, scale- models, document archives, etc.)

- Development of a Researcher's Guide

- Preservation/display of associated equipment

\begin{tabular}{|c|c|c|c|c|c|}
\hline Grid \# & Bldg \# & Building/Site Name & Date & $\begin{array}{c}\text { NRHP } \\
\text { Eligible }\end{array}$ & Category \\
\hline & & & & & \\
\hline Multi & N/A & World War I Training Trenches & 1917 & Yes & I \\
\hline $70 / 80$ & N/A & 1800's Home Sites & 1850 's & U & I \\
\hline & 701, & Brookhaven Graphite Research Reactor & & & \\
65 & 702 & BGRR & 1949 & Yes & I \\
\hline 65 & 703 & BGRR Office \& Laboratories & 1949 & Note 1 & I \\
\hline 64 & 902 & Cosmotron & 1949 & U & I \\
\hline 64 & 913 & Alternating Gradient Synchrotron & 1957 & U, C & I \\
\hline 84 & 490 & Medical Research Center/Program & 1958 & U & I \\
\hline 84 & 491 & Medical Research Reactor & 1958 & U & I \\
\hline 75 & 750 & High Flux Beam Reactor & 1964 & Yes & I \\
\hline 74 & 555 & Chemistry & 1966 & U, A & I \\
\hline 74 & 488 & Berkner Hall & 1968 & U, A & I \\
\hline
\end{tabular}

Category II: A building, facility or site that directly supported a significant BNL program, or uniquely represents a specific period in the evolution of BNL's site history and has had little alteration.

Treatment and/or mitigation: 


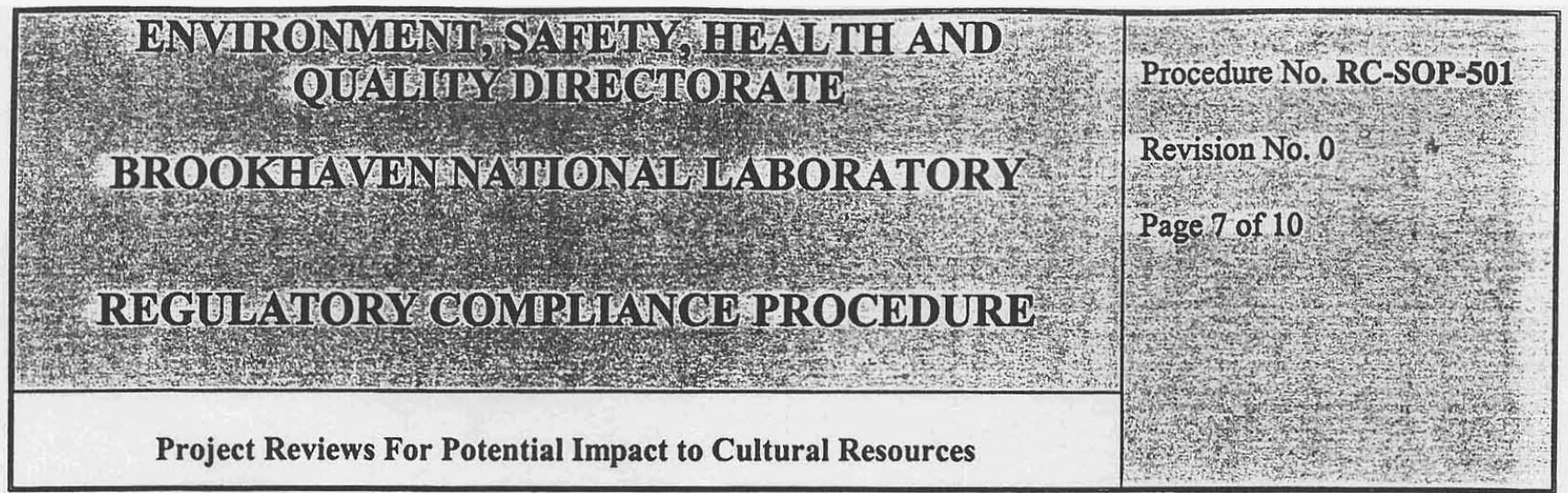

For support buildings: As-built drawings and photos; documented description of structure's role (may be included in existing facility description documents).

For period structures: Treatment plans to minimize further alteration of specifically identified aspects (implementation is funding dependent). Mitigation would entail documentation of as-built drawings and photos.

BGRR, HFBR, AGS \& other Support buildings:

\begin{tabular}{|c|c|c|c|c|c|}
\hline Grid \# & Bldg \# & Building name & Date & $\begin{array}{c}\text { NRHP } \\
\text { Eligible }\end{array}$ & Category \\
\hline 75 & 704 & Fan House & 1949 & Note 1,2 & II \\
\hline 65 & 705 & Reactor Stack & 1949 & Note 1,2 & II \\
\hline 75 & 707 & Pump House & 1949 & Note 1,2 & II \\
\hline 75 & 708 & Instrument House & 1949 & Note 1 & II \\
\hline 75 & 751 & Cold Neutron Facility & 1970 & Note 2 & II \\
\hline 65 & 801 & Isotope Research and Processing & 1950 & Note 1 & II \\
\hline 65 & 802 & Fan House & 1950 & Note 1 & II \\
\hline 64 & 911 & Collider Accelerator Building & 1956 & U, C & II \\
\hline 55 & 912 & AGS Experimental Hall & 1958 & U, C & II \\
\hline $21 / 29$ & N/A & Gamma Forest Site & 1961 & U & II \\
\hline 75 & 901 & Isochronous Cyclotrons & 1968 & U & II \\
\hline 75 & $901 \mathrm{~A}$ & Tandem Van de Graaff Accelerator & & U \\
\hline
\end{tabular}

Representative Period Buildings

\begin{tabular}{|c|c|c|c|c|c|}
\hline 93 & 30 & Brookhaven Center & 1934 & No & II \\
\hline 75 & 120 & Building 120 & 1942 & No & II \\
\hline
\end{tabular}

Note 1: Eligible as part of the BGRR Complex

Note 2: Eligible as part of the HFBR Complexes

Note 3: Resources with the following designations have not been formally evaluated for National Register eligibility (i.e., eligibility is undetermined): $A=$ Architecturally significant; $U=$ Undetermined; $C=$ Part of a complex.

Category III: Buildings or structures that supported lab-wide programs and may be representative of the evolution of government use of the site.

Buildings in this category include the World War II era buildings. During a site visit (January 3, 2003), SHPO has agreed that these structures would not be considered eligible for the National Register. However, since these types of structures do represent a distinct period in the site and BNL history, the following means may be used to document the association.

Mitigation: Document the development and evolution of the site by archiving engineering and plan drawings of site layout, building plans and photos for select structures, and aerial photos. 


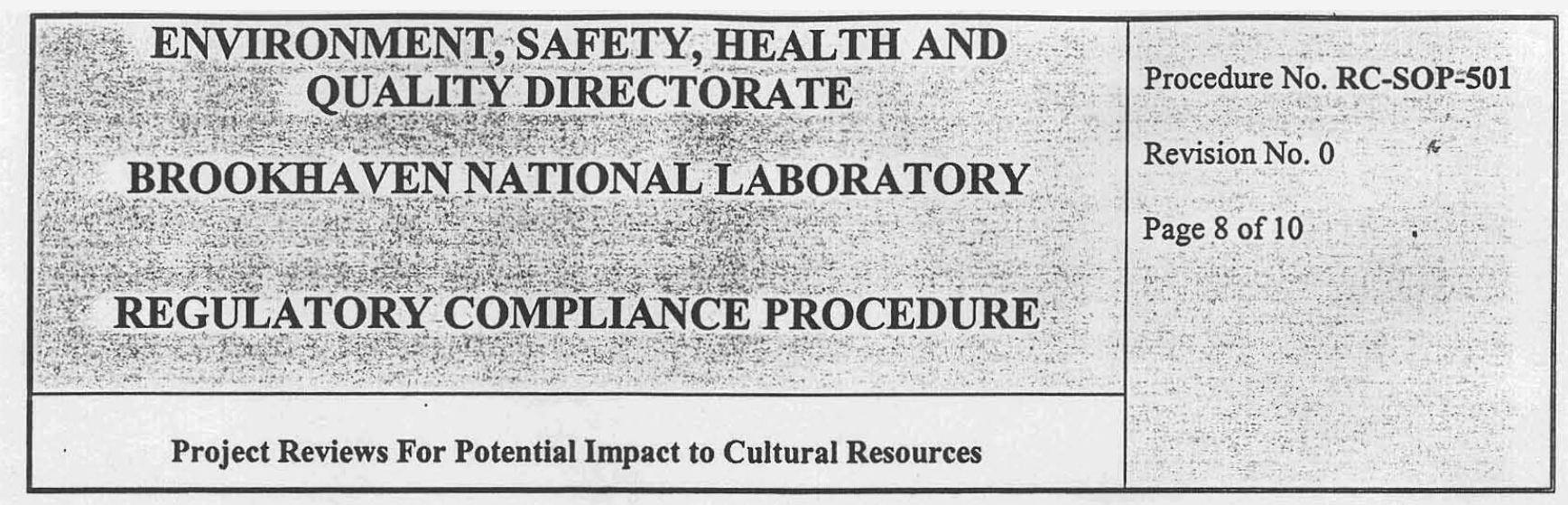

\section{Attachment 2}

\section{Areas of Substantial Ground Disturbance}

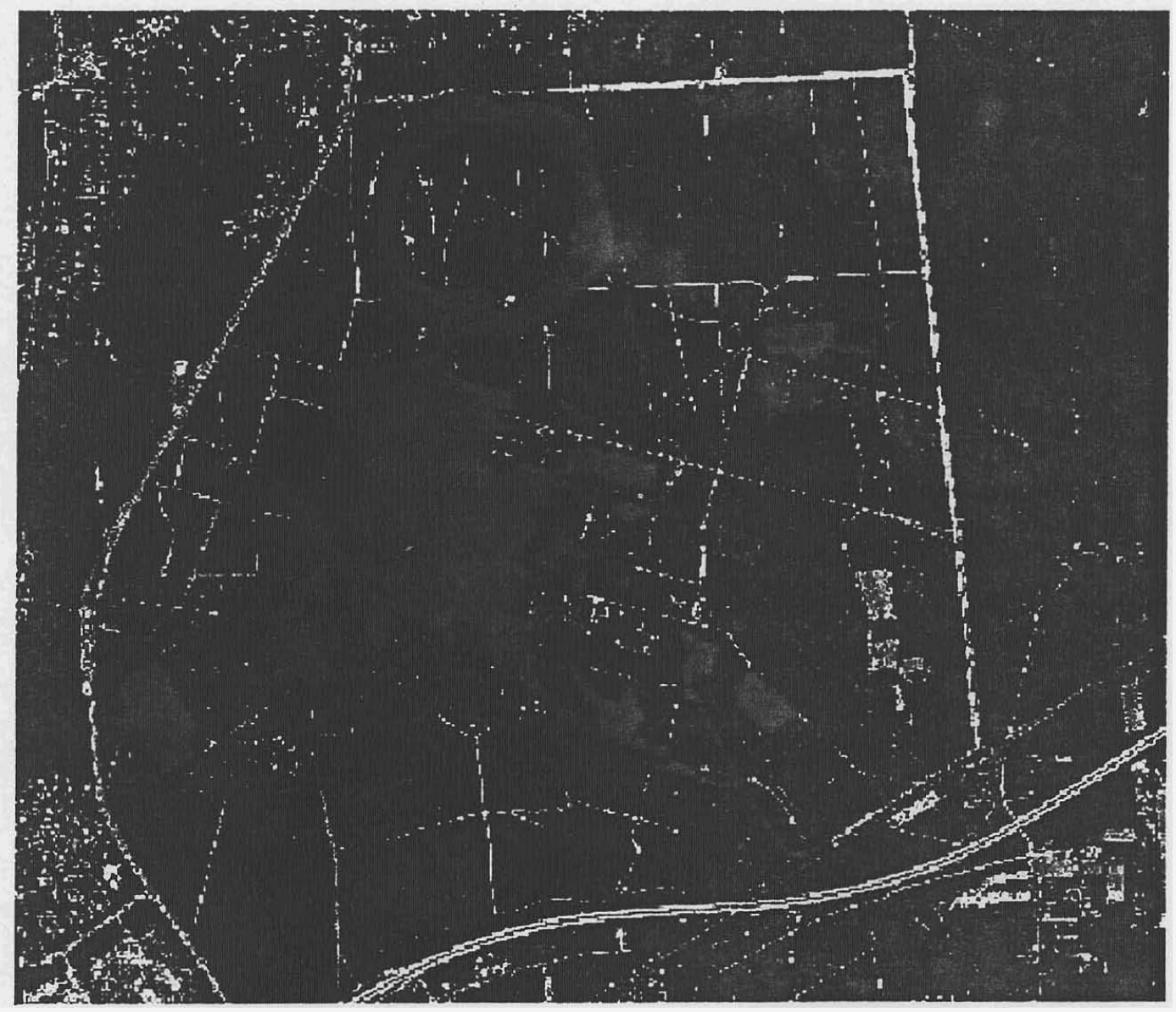




\begin{tabular}{|c|l|}
\hline $\begin{array}{c}\text { ENVIRONMENT, SAFETY, HEALTH AND } \\
\text { QUALITY DIRECTORATE }\end{array}$ & Procedure No. RC-SOP-501 \\
BROOKHAVEN NATIONAL LABORATORY & Revision No. 0 \\
REGULATORY COMPLIANCE PROCEDURE 9 of 9 \\
\hline Project Reviews For Potential Impact to Cultural Resources & \\
\hline
\end{tabular}

\section{Attachment 3}

\section{Archeologically Sensitive Areas}

Prehistoric Period -:Archeologically Sensitive Areas diagram is intentionally not shown

Contact BNL Cultural Resources Coordinator (x2165) for additional information

Prehistoric Period - Archeologically Sensitive Areas

The Historic Period - Archeologically Sensitive Areas diagram is intentionally not shown Contact BNL Cultural Resources Coordinator (x2165) for additional information 
ENVIRONMENT, SAFETY, HEALTH AND QUALITY DIRECTORATE

BROOKHAVEN NATIONAL. LABORATORY

REGULATORY COMPLIANCE PROCEDURE
Procedure No. RC.SOP-500

Revision No. 0

Page 1 of 6

\section{BNL Historical Resource Identification Tag Program}

1.0 PURPOSE/SCOPE 2

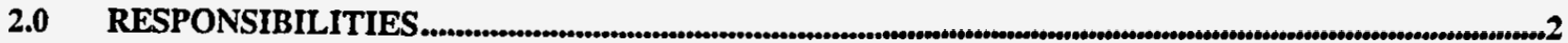

3.0 DEFINITIONS.

4.0 PREREQUISITES.....

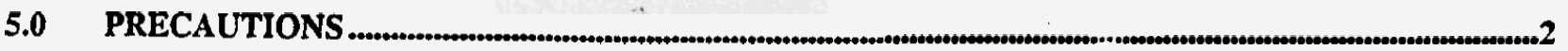

6.0 PROCEDURE...

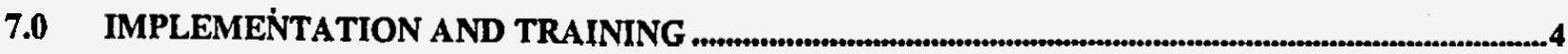

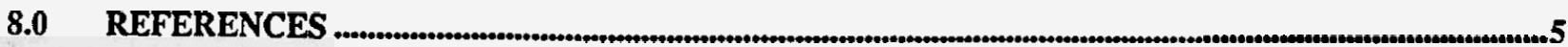

9.0 ATTACHMENTS .

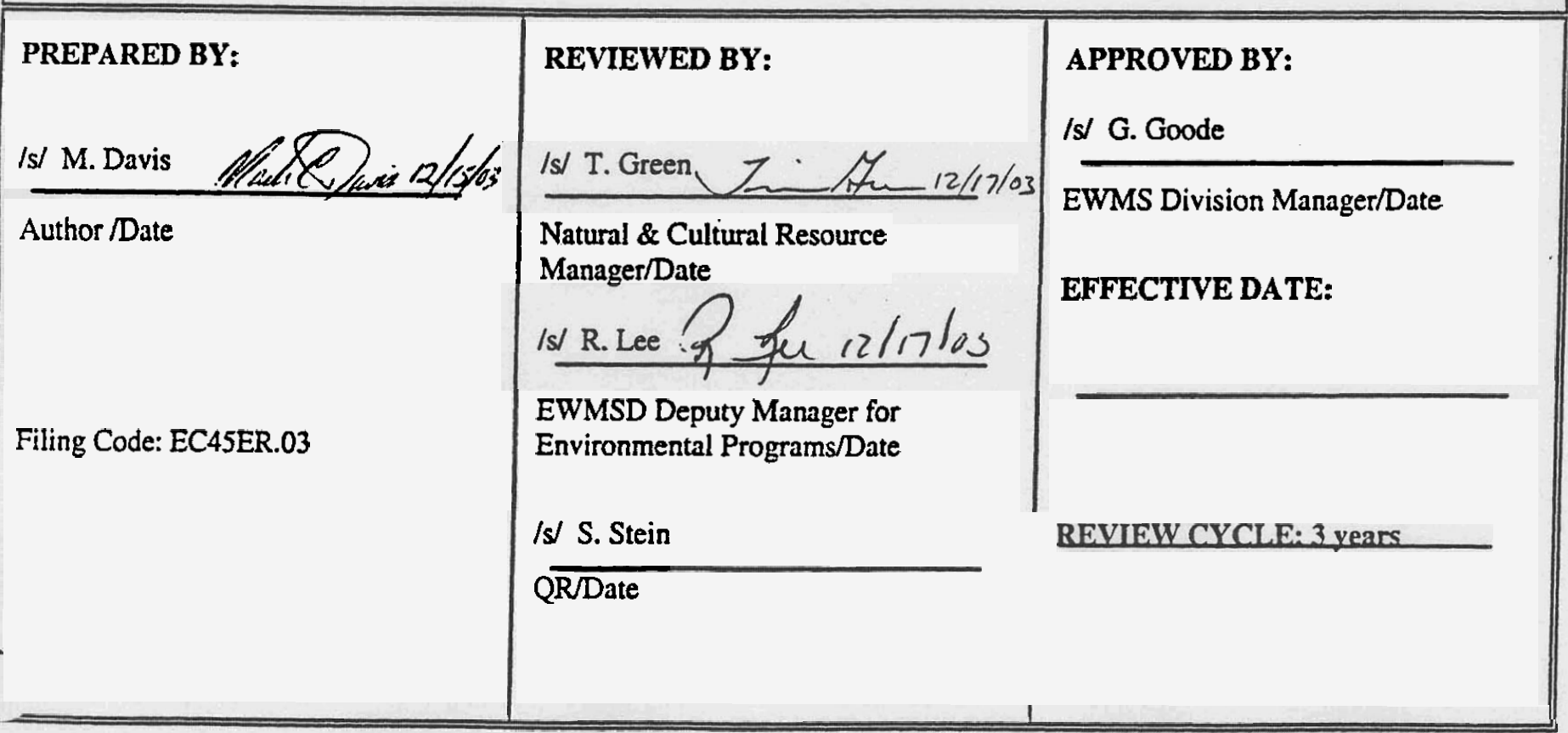




\section{REGULATORY COMPLIANCE PROCEDURE}

BNL Historical Resource Identification Tag Program

\subsection{PURPOSE AND SCOPE}

This procedure describes implementation of the BNL Historical Resource Identification Tag system. The scope includes identification, application, tracking, and expectations associated with the program.

Historical resources encompassed by this tagging program primarily include those items that could be relocated. Very large items, buildings, and sites may be tracked through other means identified in the BNL Cultural Resource Management Plan, including listing within the Plan.

The primary purpose for tagging these items is to identify them as significant or supporting resources, acknowledge responsibility, and to prevent inadvertent loss or disposal.

Items in the Camp Upton Historical Collection are not included within the scope of the program.

\subsection{RESPONSIBILITIES}

2.1 Cultural Resource Coordinator (CRC): Responsible for: administration of all aspects associated with this tagging program.

2.2 Natural \& Cultural Resources Manager: Responsible for reviewing draft and final documents generated by the CRC.

2.3 Department Contact: Responsible to ensure items identified as BNL historical resources are maintained under appropriate care and control including: notifying the $\mathrm{CRC}$ of a planned change in item's disposition (e.g., relocation; planned modification, disposal, etc.); obtain appropriate authorization regarding issues that may adversely affect the identified item; inform the CRC of a change in status as the department contact.

\subsection{DEFINITIONS}

3.1 Cultural Resources (aka, Historical Resources): Historic or prehistoric sites, artifacts, or other items of cultural importance; Standing structures over 50 years of age, or those important because they represent a major historical theme or era. Recent structures, facilities, equipment and apparatus that have scientific significance or that are determined to be supporting assets. Note: This definition was paraphrased from the definition found in Reference 8.1. 


\begin{tabular}{|c|l|}
\hline $\begin{array}{c}\text { ENVIRONMENT, SAFETY, HEALTH AND } \\
\text { QUALITY DIRECTORATE }\end{array}$ & Procedure No. RC-SOP-500 \\
BROOKHAVEN NATIONAL LABORATORY & Revision No. 0 \\
Rage 3 of 3 \\
BEGLATORY COMPLIANCE PROCEDURE & \\
\hline BNL Historical Resource Identification Tag Program & \\
\hline
\end{tabular}

3.2 Department Contact: Individual identified on the Historical Resources tag, within the BNL department/division that maintains ownership and responsibility for the identified historical resource.

\subsection{PREREQUISITES}

None

\subsection{PRECAUTIONS}

None

\subsection{PROCEDURE,}

Across BNL, items have been identified as BNL Historical Resources. These items have been determined to be unique to BNL, or DOE, and may represent a significant facility, program, site or event. These resources become increasingly significant as facilities are decommissioned or renovated, and knowledgeable individuals retire. Key components to the BNL Cultural Resource Management Program include: preserving the knowledge of BNL's historic and unique programs so that it is available for interpretation; outreach to inform others of BNL history; mitigating the effects of demolition actions. Ensuring identified resources remain accessible will help to ensure BNL's history is preserved. Identification tags are to be attached to these items in order to ensure that they are properly managed, tracked, and that inadvertent modification or disposal does not occur resulting in the loss of a valuable asset.

\subsection{Resource Identification}

6.1.1 Items that may be considered BNL Historical Resources include, but are not limited to:

- Equipment associated with a major or unique BNL facility or program (Examples: bubble chambers, BGRR tools)

- Scale models of buildings, facilities or equipment (Examples: Cosmotron model; HFBR \& BGRR models, mock fuel elements)

- Photographs or other visual displays that may be unique, with regard to enlargement, mounting, etc., or would require significant resources or costs to replicate. 


\begin{tabular}{|c|l|}
\hline $\begin{array}{c}\text { ENVIRONMENT, SAFETY, HEALTH AND } \\
\text { QUALITY DIRECTORATE }\end{array}$ & Procedure No. RC-SOP-500 \\
BROOKHAVEN NATIONAL LABORATORY & Revision No. 0 \\
REge 4 of 4 \\
\cline { 1 - 2 } BNL Historical Resource Identification Tag Program & \\
\hline
\end{tabular}

6.1.2 Items determined to be potential resources may be tagged in order to prevent future loss.

6.1.3 Individuals or departments are encouraged to nominate items for consideration as historical resources.

\subsection{Tagging Process - reference Figure 1 "BNL Historical Resource Identification Tag".}

6.2.1 The BNL CRC completes the information on the tag. The information may be handwritten or typed onto the tag. The tag should be printed on colored, heavy grade paper whenever possible. The size of the tag may be adapted to the object on which it is to be fastened. NOTE: A more permanent or weather resistant material may be used for outdoor items.

6.2.2 Paper tags must be laminated in order to minimize wear and degradation.

6.2.3 Attach tag to the item, in an indiscrete location", using non-permanent, nondestručtive means such as the those identified below, or a combination there of:

- Thumb tack

- Wire

- String

- Taped in a non-prominent location (back or bottom), that would not damage or deface the item when the adhesive is removed.

*Note: Tags should be located so that they are not easily visible from the object's normal viewing angle, but would be noticed if the object were moved.

6.2.4 Tags should be replaced if the information becomes obsolete, or the tag is missing or damaged.

\subsection{Tracking \& Documentation}

6.3.1 Each item is assigned a unique identification number, which is entered into a database managed by the BNL Cultural Resource Coordinator.

6.3.2 The CRC should periodically assess the status of items currently in the database. 


\begin{tabular}{|c|l|}
\hline $\begin{array}{c}\text { ENVIRONMENT, SAFETY, HEALTH AND } \\
\text { QUALITY DIRECTORATE }\end{array}$ & Procedure No. RC-SOP-500 \\
BROOKHAVEN NATIONAL LABORATORY & Revision No. 0 \\
Page 5 of 5 \\
REGULATORY COMPLIANCE PROCEDURE & \\
\cline { 1 - 2 } BNL Historical Resource Identification Tag Program & \\
\hline
\end{tabular}

6.4 Department Contact

6.4.1 The CRC will identify a specific individual within the department in order to:

- Acknowledge departmental ownership of the item

- Communicate responsibilities, identified in section 2.3 above.

6.4.2 The CRC shall provide the department contact with documentation of the resource identification and tagging (Example: email, memo, photocopy of tag, etc.)

\subsection{IMPLEMENTATION AND TRAINING}

7.1 The CRC shall brief affected personnel on the purpose, process and responsibilities associated with this procedure.

7.2 Consideration should be given to informing the lab-wide population via informal means such as inclusion in general training information, Bulletin article and/or website link.

\subsection{REFERENCES}

8.1 Environmental Guidelines for Development of Cultural Resource Management Plans (DOE/EH-0501).

\subsection{ATTACHMENTS}

9.1 Figure 1 "BNL Historical Resource Identification Tag" 


\section{ENVIRONMENT, SAFETY, HEALTH AND}

QUALITY DIRECTORATE

BROOKHAVEN NATIONAL LABORATORY

\section{REGULATORY COMPLIANCE PROCEDURE}

Revision No. 0

Page 6 of 6

BNL Historical Resource Identification Tag Program

Figure 1

BNL HISTORICAL RESOURCE

IDENTIFICATIONTAG

This item has been identified as a unique resource associated with BNL history.

Before relocating, modifying, disposing or destruction contact:

BNL Cultural Resource Program

Coordinator: $x$

Dept. Contact:

Item:

ID \#__ Date 
Received:

Sent for Review:

Sontrol No.:

\title{
UNITED STATES DEPARTMENT OF THE INTERIOR
}

\author{
APPLICATION for a FEDERAL PERMIT under \\ THE ARCHAEOLOGICAL RESOURCES PROTECTION ACT \\ approved October 31, 1979 \\ (P.L. 96-95; 93 Stat. 721; 16 U.S.C. 470aa-mm; 43 CFR 7) \\ or \\ THE ANTIQUITIES ACT \\ approved June 8, 1906 \\ (P.L. 59-209; 34 Stat. 225; 16 U.S.C. 431-433; 43 CFR 3)
}

Instructions: Complete and return two copies of this application form and attachments to each state or regional office of the land managing agencies involved. All information requested must be completed before the application will be considered. Use separate sheets of paper if more space is needed to complete a section.

1. Name of Institution:

2. Address: (include zip code, phone number, email)

Type of permit requested: (check appropriate box)

a. Surveys, limited testing and/or limited collections on lands identified in No. 4.

b. Excavation, collection and intensive study of specific sites described below in No. 4 .

4. Lands of the United States for which a permit is requested:

a. Description: Specify State and land managing agency(ies) including regions or districts. If on surveyed lands, descriptions must be by subdivisions of the Public Land Surveys. If on unsurveyed lands, description must be by metes and bounds with ties to some topographic feature.

b. Attach a readable copy of a map or plan showing specific sites or areas for which permit is desired.

5. Nature and extent of the work proposed, including how and why it is proposed to be conducted: (include research design, methods, curation) 
6. Name, address and institutional affiliation, if any, of persons in " $a$ " and " $b$ " below:

a. Individual(s) proposed to be responsible for conducting the work (i.e., in direct charge of field work): Include evide, of qualifications (vitae) in accordance-with Section 7.8 of the Final Uniform Regulation (43 CFR'7).

b Individual(s) proposed to be responsible for carrying out the terms and conditions of the permit (i.e., in general charge):

7. Proposed date project will begin:

8. Proposed date project will be completed:

9. University, museum or other scientific or educational institution in which the applicant proposes to store all collections and copies of records, data, photographs and other documents derived from the proposed work: (The application must include a written certification, signed by an authorized official of the institution, of willingness to assume curatorial responsibility, and to safeguard and preserve these materials as property of the United States or, in the case of an application on Indian lands, in the event the Indian owners do not wish to take custody.)

10. Proposed outlet for public written dissemination of the results:

11. Evidence of the applicant's ability to initiate, conduct and complete the proposed work, including evidence of logistical support and laboratory facilities:

12. Signature of individual in general charge:

13. Date of application:

Paperwork Reduction Act and Estimated Burden Statement: This information is being collected, pursuant to 16 U.S.C. 470mm, to provide the necessary information needed to complete the Secretary's Report to Congress on Federal Archeology Programs, and will be used to allow the National Park Service to evaluate Federal archeological protection programs and assess compliance with the Archaeological Resources Protection Act of 1979 (16 U.S.C. 470).A federal agency may not conduct or sponsor, and a person is not required to respond to a collection of information unless it displays a valid. OMB control number. Public reporting for this collection of information is estimated to average one hour per response, including the time for reviewi! instructions, searching existing data sources, gathering and maintaining the date needed, and completing and reviewing the collection of information. Send comments regarding this burden estimate or any other aspect of this collection of information, inciuding suggestions for reducing this burden to the Departmental Consulting Archeologist; Archeology and Ethnography Program, NC210; National Park Service; 1849 C Street, NW; Washington, DC 20240. 


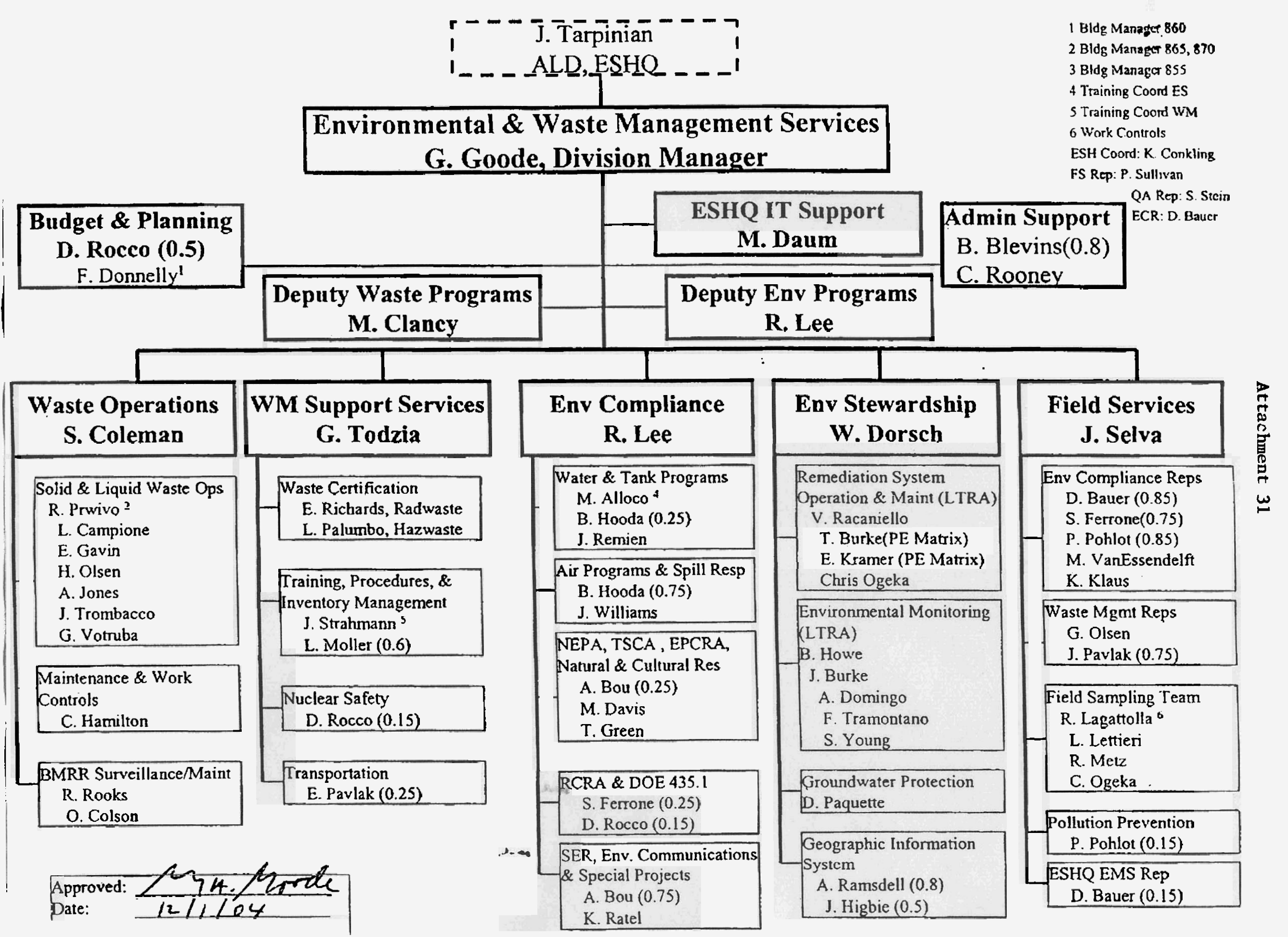





\title{
Attachment 32
}

\author{
Resume
}

\section{Cultural Resources Manager}

(7 pages) 


\section{Attachment 32}

\section{Résumé}

Name Deleted

W: (631) 344-3091

Education:

Ph.D., Zoology, Texas A\&M University, August 1993. Specialization in freshwater aquatic invertebrate distributions of desert mountain streams, taxonomy, and stream ecology and management.

M.S., Zoology, Texas A\&M University, May 1986. Specialization in invertebrate biology, decapod crustacean taxonomy, and sandy beach ecology.

B.S., Biology, West Texas State University, May 1983.

Specialization in wildlife science and vertebrate ecology.

\section{Experience:}

Sep. 1999 Project Engineer I - Cultural and Natural Resource Manager with Brookhaven To Present Science Associates, Brookhaven National Laboratory. Responsible for all aspects of managing the Cultural and Natural Resources associated with the 5,265-acre site of BNL. Responsibilities include coordination of natural resource stewardship between the Department of Energy, BSA, the U.S. Fish \& Wildlife Service, Long Island Pine Barrens Commission, and New York State Department of Environmental Conservation. Responsibilities also involve maintaining a fauna and floral monitoring program to document effects of BNL's operations on the environment.

Sep. 1998 Sectional Scientist with Mason \& Hanger Corp. Pantex Plant, Amarillo, Texas.

to Sep. 1999 Coordinate scientific monitoring and characterization activities associated with playa management, plan and implement terrestrial invertebrate surveys, coordinate GIS/GPS needs for natural resources, plan and implement algae-eating fish experiments, serve as lead scientist for special permits, manage contracts, and act as section manager in abscence of section manager.

Feb. 1998 Section Manager over Pantex Plant's Water Program. This function 
Attachment 32

Sep. 1998 provides technical support services, project reviews, and operations interface for water compliance issues. This includes communicating with Plant personnel on discharge limits, coordinating reporting of water effluents, ensuring the accuracy of water-related data, evaluating data to determine compliance status, assisting in preparing permit applications, providing subject matter expert review and interpretation of environmental regulatory and permitting requirements, input to environmental policy, procedures and guidance, and establishing requirements for sampling and monitoring systems necessary to comply with water requirements.

Jun. 1995

Feb. 1998

Jan. 1995

May 1995

Senior Project Scientist (Scientist IV) with Battelle Memorial Institute, Pantex Plant, Amarillo, Texas. Development and implementation of natural resource management plans concerning natural resources on 10,000 acres of Department of Energy owned land, National Environmental Policy Act compliance, Environmental Restoration support, coordination of outside contracts concerning biological research at Pantex Plant. Participation in the Playa Lakes Joint Venture. Management emphasis on Southern High Plains ecosystem and maintenance of local biodiversity.

Aug. 1994 Acting Refuge Manager (GS-11) at Cibola National Wildlife Refuge, AZ. Jun. 1995 Develop and submit annual budgets, oversee and coordinate all operations of the refuge including public use, biological, operations and maintenance. Insure operations fall within budget. Coordinate with outside agencies, local, private and governmental bodies in operation of Refuge. Coordinate operation of Refuge within Ecosystem Management directives and within goals of Comprehensive Management Plan for Lower Colorado River Refuges Complex.

Oct. 1994 Refuge Operations Specialist (GS-11) at Cibola National Wildlife Refuge, AZ. Jun. 1995 Plan and maintain schedules for refuge operations and maintenance. Develop, plan major projects. Responsible for environmental assessments and permitting. Responsible for day to day operation of Refuge.

Aug. 1994

Biology Instructor, Arizona Western College, La Paz Center, Parker, AZ.

Dec. 1994 Work involved preparation, teaching, and testing students for basic knowledge of biological concepts and principles in Introduction to Biology.

Apr. 1994

Biologist (GS-11) at Cibola National Wildlife Refuge, Arizona. Develop and Oct. 1994 manage biological program for refuge. Emphasis on endangered species, migratory waterfowl, neotropical migrant birds, and riparian habitat biodiversity. 


\section{Attachment 32}

Dec. 1992 Outdoor Recreation Planner (GS-9) at Cibola National Wildlife Refuge,

Apr. 1994 Arizona. Manage and implement outdoor public use of the refuge in addition to development of both biological and broad based land management plans.

1988-1993 Completion of dissertation work. Collection and analysis of field samples of freshwater invertebrates from McKittrick Canyon of the Guadalupe Mountains National Park, Texas for a distributional analysis of the invertebrate population of McKittrick Creek.

1989-1992 Instructor at El Paso Community College, Valle Verde Campus, teaching freshman biology lecture and lab, anatomy and physiology lecture and lab.

1988-89 Media Technician at the El Paso Independent School District Planetarium. Designed and built exhibits. Maintained planetarium equipment. Presented Planetarium Lessons.

1985-88 Teaching Assistant, Invertebrate Zoology and Marine Biology, Texas A\&M University, Department of Biology. Maintained teaching collection of zoological specimens and organized field biology research.

Fall 1987 Teaching Assistant, Cell Biology, Texas A\&M University, Department of Biology.

1984-86 Teaching Assistant, Freshman Biology and Invertebrate Zoology, Texas A\&M University, Department of Biology.

Fall 1983 Teaching Assistant, Industrial Microbiology, Texas A\&M University, Department of Biology.

1981-83 Undergraduate Teaching Assistant, Zoology, West Texas State University, Department of Biology.

Fall 1982 Undergraduate Teaching Assistant, Botany, West Texas State University, Department of Biology.

1982 Ecology Director, Camp M.K. Brown, B.S.A., Mobeetie, Texas. Developed and maintained nature trail, directed ecology program for the camp.

1981 Assistant Ecology Director, Camp M.K. Brown, B.S.A., Mobeetie, Texas. 


\section{Attachment 32}

Honors:

2002 Department of Energy Outstanding Mentor Award from the Office of Science Undergraduate Research Programs

1998 Battelle Key Contributor Award for work on Algae-Eating Fish Research Project.

1995 Special Achievement Award, U.S. Fish and Wildlife Service.

1985-86 President Biology Graduate Students Association, Texas

A\&M University.

May 1983 Graduate with Honors, West Texas State University.

1981 Beta Beta Beta, Biology Honor Society, West Texas State University.

1981 Vigil Honor Order of the Arrow, Boy Scouts of America.

$1977 \quad$ Eagle Scout, Boy Scouts of America.

Professional Societies:

1985-2000 Biological Society of Washington.

2000-Present Natural Areas Association

1987-92 Texas Academy of Science.

1995 -Present The Wildlife Society, Currently Chapter Secretary for the NY Chapter TWS

Professional Interests:

Freshwater ecology, invertebrate ecology, biogeography, crustacean taxonomy, marine biology, commensalisms, vertebrate ecology, wildlife management, soil science, astronomy, geology, archaeology, and use of computers in science education.

Consulting:

XXXX 2000. Use of Algae Eating Fish for Control of Suspended Solids in a Sewage Treatment Lagoon, Pantex Plant, Amarillo, TX. 


\section{Attachment 32}

XXXX 1985. The affects of rotenone on aquatic invertebrates: recommendations for use in McKittrick Creeks of the Guadalupe Mountains National Park, Texas. June, 1989.

Peterson, J.P. and XXXXX An introduction to astronomy: A teacher's workshop. El Paso Independent School District. June, 1989.

Professional Training:

Feb. 1993 USFWS Region 2 Biological Workshop for Refuge Biologists in Region 2. Workshop held in Albuquerque, NM.

June 1993 Interpretive Training. Course presented for Region 2 - USFWS Outdoor Recreation Planners. Course developed by USNPS and adapted for use in the USFWS. $40 \mathrm{hr}$. course gave training in specialized interpretive development to be implemented on refuges. It included publications, brochures, associations, wayside displays, visitor center interpretive displays and design of displays. Training held at Albuquerque, NM.

Oct. 1993 Office of Training and Education - USFWS developed course on Visitor Center Development and Design. $40 \mathrm{hr}$. course dealing with the development, design, funding, contracting, and construction of visitor centers that fall in the cost range of $\$ 3-\$ 12$ million. Training occurred in Minneapolis, MN.

Feb.- Mar. National Advance Resource and Technology Center course on Fire in Ecosystem 1994 Management. $60 \mathrm{hr}$. course teaching the history, use, implementation, and control of fire in ecosystems. Course developed the concept of the use of fire as a management tool for maintaining fire dependent ecosystems. Course held at NARTC facilities at Marana, AZ.

Mar. 1995 RCRA Waste Management Regulations Training. Conducted by Intermountain Technical Solutions, Inc., Colorado School of Mines. Albuquerque, NM.

Dec. 199540 hour OSHA, Hazardous Waste Operator Training. Amarillo College, Amarillo, Texas. Annual refreshers Dec. 1996 - Dec. 1998.

May 1996 National Environmental Compliance Act Compliance Course course presented by Pacific Western Technologies, LTD and Franklin Quest.

Oct. 1998 Clean Water Compliance Institute. Training on compliance with the Clean Water Act including safe drinking water and National Pollutant Discharge Elimination System regulations. 


\section{Attachment 32}

Nov. 1998 Management Principles and Effective Leadership Training. Amarillo College Adult Vocational Education Workforce Development Divison.

April 2000 National Historic Preservation Act, Section 106 Compliance training. Council on Historic Preservation. Merrietta, GA.

Oct. 2001 Perfomance Based Planning for Natural Resource Management, Performance Management Institute, Arlington, VA.

Aug. 2002 Project Leadership (Advanced Course), PCI Global, Inc.

Publications \& Presented Papers:

XXXX 1983: Distribution of Fish in Deaf Smith and Swisher Counties of the Texas Panhandle. Honor's Thesis. Department of Biology, West Texas State University.

XXXX 1985. Pinnotheres jamesi synonymized with $\underline{P}$. reticulatus (Decapoda: Brachyura). Proceedings of the Biological Society of Washington 98(3): 611-614.

XXXX 1986. The relationship between Pinnixa chacei Wass and Callianassa islegrande Schmitt in the sandy beach community on Mustang Island, Texas. Master's Thesis. Texas A\&M University.

XXXX 1987. The relationship between Pinnixa chacei Wass and

Callichirus islegrande Schmitt in the sandy beach community of Mustang Island, Texas. Paper presented at the 90th Annual Meeting of the Texas Academy of Science. Huntsville, Texas.

XXXX 1989. Notes on recent research in the Guadalupe Mountains National Park, Texas. Paper presented at the 92nd Annual Meeting of the Texas Academy of Science. Lamar University, Beaumont, Texas.

XXXX 1992. Pinnaxodes gigas, a new species of pinnotherid crab from the Gulf of California (Decapoda: Brachyura: Pinnotheridae). Proceedings of the Biological Society of Washington 105(4): 775-779.

XXXX 1993. A Distributional Analysis of Aquatic Invertebrates in McKittrick Creek of the Guadalupe Mountains National Park, Texas. Ph.D. Dissertation, Texas A\&M University, College Station, TX.

XXXX 1998. Distribution of Aquatic Invertebrate in McKittrick Creek. Paper presented at the Guadalupe Mountains Research and Resource Management Symposium. April 22-25. 


\section{Attachment 32}

XXXX 2000. Use of Algae-Eating Fish To Control Phytoplankton Blooms and Total Suspended Solids at the Pantex Plant Wastewater Treatment Facility. Mason \& Hanger Corporation, Pantex Plant, Amarillo, TX. Report prepared for the Department of Energy.

XXXX 2003, The Upton Ecological and Research Reserve, Partnerships for Understanding the Long Island Pine Barrens Ecosystem. Paper presented at the $59^{\text {th }}$ Annual Northeast Fish and Wildlife Conference. Newport, Rhode Island.

XXXX 1999. Vegetation Differences In and Out of Prairie Dog Towns at Pantex Plant. Paper Presented at the Annual meeting of the Texas State Chapter, TWS.

XXXX 1987.A Quantitative Study of Sandy Beach Organisms at Padre Island National Seashore. Cooperative Park Studies Unit, Department of Recreation and Parks, Texas A\&M University. Technical Report No. 7.

\section{$\underline{\text { References }}$}

Available upon request. 


\section{NAME DELETED}

Home - Not Shown

Work - (631) 344-2165

Email: Not Shown

\begin{tabular}{|l||l|}
\hline EDUCATION: & $\begin{array}{l}\text { Master of Business Administration, Dowling College, Oakdale, Long Island, NY } \\
(1985-1988) . \text { Concentration: Management. GPA: 3.85/4.0. } \\
\text { Bachelor of Science, Petroleum Engineering, West Virginia University, } \\
\text { Morgantown, WV } \\
(1979-1983) . \text { GPA: } 3.25 / 4.0 .\end{array}$ \\
\hline \begin{tabular}{l|l} 
PROFESSIONAL \\
EXPERIENCE:
\end{tabular} & Brookhaven National Laboratory, Upton, NY \\
\hline 2000 - present & $\begin{array}{l}\text { BNL Environmental Compliance Engineer, Environmental Services Division-ESD } \\
\text { Responsible for Laboratory wide implementation of the National Environmental } \\
\text { Policy Act (NEPA), the National Historic Preservation Act, and polychlorinated } \\
\text { biphenyl (PCB) regulations. }\end{array}$ \\
\hline
\end{tabular}

- Interpreting and implementing federal, state and local regulatory requirements.

- Preparation of NEPA environmental assessments and associated documents.

- Development of BNL Cultural Resources Management Plan.

- Serve as Self-Assessment Coordinator for the ES Division.

- Serve as the BNL Cultural Resources Coordinator; NEPA Program Coordinator and PCB Subject Matter Expert.

$1997-2000$

\section{HFBR Operations Manager, Reactor Division}

Responsible for direct oversight of the Operations Section in maintaining safe and efficient operation of the High Flux Beam Reactor.

- Management of 25 reactor supervisors, operators, engineers, and technical/administrative personnel for this Department of Energy multiprogram facility that conducts research in the materials, bio-medical and physics disciplines.

- Directly responsible for all aspects of plant operations and regulatory compliance, including implementation of programs, policies and procedures for improvement of operations.

- Approve and direct installation of facility system design changes. Management of multiple facility upgrade projects utilizing team building and goal oriented approach.

- Hiring, promotion, career development and performance management of Operations Section personnel.

- Facility Systems Closure and Lay-Up Project Manager - Identified scope, developed WBS, allocated resources and implemented project on schedule \& within budget. Developed and implemented formal controlled process and procedure for Lay-up Management of facility systems. 


\begin{tabular}{|c|c|}
\hline & $\begin{array}{l}\text { In conjunction with Operations Manager, responsible for direct oversight of the } \\
\text { Operations Section in maintaining safe and efficient operation of the High Flux } \\
\text { Beam Reactor. } \\
\text { - Planning, scheduling, procedure development and coordination of all plant } \\
\text { maintenance and operating modes. } \\
\text { - Development and administration of rotating shift schedules. } \\
\text { - Investigative oversight; including root cause analysis, development and } \\
\text { evaluation of special test procedures. }\end{array}$ \\
\hline $1991-1994$ & $\begin{array}{l}\text { Work Controls Group Leader, Reactor Division } \\
\text { - Facilitated development and implementation of Maintenance Management } \\
\text { Program which significantly improved multi-group communication capabilities, } \\
\text { coordination, scheduling and overall efficiency of resource management. } \\
\text { - Managed development and implementation of the Work Controls Group from } \\
\text { an initial concept to an effective asset, including personnel hiring, training and } \\
\text { procedure development. } \\
\text { - Establishing priority, plant conditions, post work testing, permit requirements, } \\
\text { and technical specifications of facility corrective maintenance activities. } \\
\text { Development of schedules to support plant outages, restarts and facility } \\
\text { upgrade projects. }\end{array}$ \\
\hline $1986-1991$ & $\begin{array}{l}\text { Reactor Supervisor, Reactor Division } \\
\text { Certified Shift Supervisor of High Flux Beam Reactor. Directly responsible for } \\
\text { safe and efficient operation of nuclear research reactor. } \\
\text { - Directing and coordinating work efforts of reactor operators, electricians, and } \\
\text { mechanical, instrumentation and health physics technicians. } \\
\text { - Assessing emergency situations and performing appropriate corrective action. }\end{array}$ \\
\hline $1984-1985$ & $\begin{array}{l}\text { Staff Engineer, Isotopes \& Special Nuclear Materials Group } \\
\text { Involved interaction with scientific, administrative and engineering personnel in } \\
\text { the management, control, and accountability of nuclear materials. Responsibilities } \\
\text { included: } \\
\text { - Implementation of U.S. DOE, DOT and NRC regulations. } \\
\text { - Coordination of reactor fuel reprocessing shipments with city, state and federal } \\
\text { agencies. }\end{array}$ \\
\hline $\begin{array}{l}\text { PROFESSIONAL } \\
\text { ACHIEVEMENTS: }\end{array}$ & $\begin{array}{l}\text { - Developed and presented the paper Implementation of NEPA at BNL at the } \\
\text { National Association of Environmental Professionals Conference (June 2003) } \\
\text { - Project Management Professional (PMP) Certification - May } 2002 \\
\text { - Co-Authored article published in Radiation Protection Management Vol.17, } \\
\text { No. } 15 \text { Sept./Oct. 2000, Draining Heavy Water Form a Research Reactor } \\
\text { Vessel. } \\
\text { - Appointed by the BNL Deputy Director for Operations, to the following } \\
\text { Accelerator Readiness Review (ARR) Teams: } \\
\text { - Chairman for commissioning of the Source Development Lab } \\
\text { - Commissioning of the Ebco Cyclotron (2003) } \\
\text { - Commissioning of the NASA Space Radiation Laboratory (2002-2003) } \\
\text { - Commissioning of the Relativistic Heavy Ion Collider (RHIC) (1999 - 2000). } \\
\text { - Appointed by the BNL Deputy Director for Operations to be a member of the } \\
\text { Reactor Division Review of Operations Committee (ROC) }\end{array}$ \\
\hline
\end{tabular}




\begin{tabular}{|c|c|}
\hline $\begin{array}{l}\text { ACHIEVEMENTS: } \\
\text { - CONTINUED - }\end{array}$ & $\begin{array}{l}\text { Reactor Division Review of Operations Committee (ROC). } \\
\text { - Selected as a member of the } 1997 \text { Annual BNL Reactor Safety Ad Hoc } \\
\text { Committee to review and assess programs and procedures at the Brookhaven } \\
\text { Medical Research Reactor. } \\
\text { - Co-Authored Program For Improved Facility Management; From Concept } \\
\text { through Implementation, and presented paper at the 5th Asian Symposium on } \\
\text { Research Reactors in Taejon Korea, April } 1996 \text {. } \\
\text { - Selected as participant on US DOE Argonne National Laboratory West } \\
\text { Investigative Team for the Experimental. Breeder Reactor II Technical } \\
\text { Specification Violation - Dec. 1993. Team comprised of personnel from } 4 \\
\text { different DOE national laboratories was tasked with identifying root cause and } \\
\text { contributing causes to procedural violation. Methods utilized included } \\
\text { personnel interviews, documentation reviews and field observation. } \\
\text { - Selected as a member of the BNL Employee Relations Committee (3 year term } \\
\text { 1992-1994), which serves as a conflict resolution mechanism available to the } \\
\text { professional and technical employees. } \\
\text { - Chairman of HFBR Contamination Control Review Committee (Dec.-Jan. } \\
\text { 1992). Committee was tasked with conducting a facility wide review of } \\
\text { radiological work practices and recommending programmatic, procedural and } \\
\text { engineering solutions to minimize personnel contaminations. } \\
\text { - Project leader for Reactor Vessel Level Instrument In-Vessel Tubing } \\
\text { Replacement, and Operations Coordinator for Replacement of In-Vessel } \\
\text { Thimble V-13. } \\
\text { - Project leader for In-Vessel Thimbles V15 \& V16 Upper Clamp Replacement. }\end{array}$ \\
\hline $\begin{array}{l}\text { PROFESSIONAL } \\
\text { TRAINING: }\end{array}$ & $\begin{array}{l}\text { - Conservation Basics - Fraser Spafford Ricci Art \& Archival Conservation, Inc. } \\
\text { - ISO } 14000 \text { Environmental Management System - Lead Auditor Training } \\
\text { - } \text { (September 2002) } \\
\text { - Martified Project Management Professional, (PCI Global), May 2002.. } \\
\text { - NHPA Section } 106 \text { Review, } 2000 \\
\text { - ISO14001 Environmental Management System Implementation Training, } 1998 . \\
\text { - Community Relations Communication Skills, Exec/Comm. Inc., March } 1997 . \\
\text { - Project Management \& Advanced Project Management, Project Management } \\
\text { Associates, November and May 1988. } \\
\text { - Technical Writing, Dr. James Paradis, Massachusetts Institute of Technology, } \\
\text { January } 1989 \text {. } \\
\text { - Basic Instructor Training, DOE Professional Instructor Training Program, } \\
\text { November 1989. } \\
\text { - Management and Disposal of Radioactive Wastes, Harvard School of Public } \\
\text { Health, July 1991 } \\
\text { - Introduction to R:Base, BNL Computing and Communication Division, March } \\
\text { 1993. } \\
\text { - DOE Maintenance Implementation Plan Workshop, March - April 1993. } \\
\text { - DOE Configuration Management Workshop, May 1994. } \\
\text { - Hazardous Materials, First Responder - Operations Level and Hazmat } \\
\text { Specialist Training, Hazmat Training, Information and Services, Inc. } \\
\text { - Rutgers Supervisory Management Development Program, Rutgers Univ. } 1987 . \\
\text { - All courses required for BNL Supervisory personnel. }\end{array}$ \\
\hline
\end{tabular}




\section{ATTACHMENT 32}

R2A2 - Natural and Cultural Resources Manager:

Role:

- Serves as Laboratory Cultural and Natural Resources Manager.

- Ensures that high quality, timely regulatory guidance to the Line in areas of NEPA, cultural and historic resources, and natural resources, as well as to ensure compliance with requirements and protection of the environment.

- Provides subject matter expertise on Cultural and Natural Resources environmental compliance requirements.

- Conduct/manage special projects/activities as assigned by the Division Manager.

Responsibilities:

- Ensures that environmental evaluation notification forms, environmental assessments, and other documentation associated with NEPA determinations are prepared correctly to ensure compliance with NEPA requirements.

- Review and maintain as current NEPA and cultural/historic resources subject areas and associated guidance within Standards Based Management System.

- Liaison with other National Laboratory and Department of Energy (DOE) NEPA counterparts to exchange information on projects, practices, and methodologies.

- Ensure the development and maintenance of a cultural resources management system for site wide application, including an inventory, programmatic agreements, cultural resources management plan, and documentation packages for any resources submitted for inclusion on the National Register of Historic Places.

- Provide technical support to the Line in the interpretation and application of NEPA, cultural/historic resources, and natural resource to facilitate operations that meet requirements.

- Develop, implement, evaluate, and maintain a comprehensive Natural Resources Management Plan for the Lab.

- Assist Division Manager to communicate responsibilities under the self-assessment program to line managers.

- Act as Education Coordinator for the division making ES personnel aware of opportunities to provide education to students.

- Provide research and educational opportunities for interns as appropriate.

- Develop and manage career goals.

- Keep capabilities and qualifications current, including completing required training for assigned tasks and work location.

- Maintain awareness of environmental impact of work, and apply pollution prevention and waste minimization techniques.

- Ensure work permits and other worker requirements for safe working conditions are prepared for research programs, student programs, and work related to the Upton Reserve.

- Identify potential hazards, environmental concerns, and unsafe conditions or practices in work or at work site, and implement or suggest controls to minimize risk.

Accountabilities:

- To Laboratory customers for quality and timeliness of NEPA, cultural and historic resource review completion, project reviews, digging permits, and natural resource impact assessments as needed.

- To Line managers, guidance and status updates on self-assessment program performance.

- To the Line organization for the delivery of high quality, efficient, effective, and timely services that are consistent with their needs while ensuring environmental compliance and stewardship. 
ATTACHMENT 32

- To the ES manager and Environmental Management System for providing information pertaining to changing environmental legislation, programmatic improvements needed, performance measure status, and pending regulatory issues critical to continued Laboratory operations.

- To DOE for providing timely, high quality response to inquiries and regulatory requirements.

- To Supervisor, or any other authorized manager, for quality, quantity, and timeliness of work, and ideas on improvement opportunities.

- To fellow staff, for effective communication and safe and professional conduct.

\section{Authorities:}

- Identify program vulnerabilities or potential liabilities to supervisors.

- Notify affected line organization of financial needs to complete NEPA evaluations of proposals.

- Notify Laboratory Management (Line and Level N, DOE and regulatory agencies of nonconformances.

- Act as necessary to ensure safe and effective operations.

- Provide input to personal employee performance appraisal.

- Seek supervisory feedback on own performance.

- Identify training, information, equipment, and facility needs to perform work.

- Cease work activity and/or issue a Stop Work Order, if an imminent ESH danger exists.

- Use available Laboratory programs to address concerns and employment issues. 
R2A2 - Cultural Resources Coordinator:

Role:

- Serves as Laboratory National Environmental Policy Act (NEPA) and Cultural Resources Coordinator.

- Provides high quality, timely regulatory guidance to the Line in areas of NEPA and cultural and historic resources to ensure compliance with requirements and protection of the environment.

Responsibilities:

- Prepare environmental evaluation notification forms, environmental assessments, and other documentation associated with NEPA determinations to ensure compliance with NEPA requirements.

- Develop and maintain as current NEPA and cultural/historic resources subject areas and associated guidance within Standards Based Management System.

- Liaison with other National Laboratory and Department of Energy (DOE) NEPA counterparts to exchange information on projects, practices, and methodologies.

- Develop and maintain cultural resources management system for site wide application, including an inventory, programmatic agreements, cultural resources management plan, and documentation packages for any resources submitted for inclusion on the National Register of Historic Places.

- Provide technical support to the Line in the interpretation and application of NEPA and cultural/historic resources to facilitate operations that meet requirements.

- Systematically analyze programs under purview for enhancements, and ensure continual improvement of these programs.

Accountabilities:

- To Laboratory customers for quality and timeliness of NEPA, cultural and historic resource reviews.

- To the Line organization for the delivery of high quality, efficient, effective, and timely services that are consistent with their needs while ensuring environmental compliance and stewardship.

- To the manager and Environmental Management System for providing information pertaining to changing environmental legislation, programmatic improvements needed, performance measure status, and pending

- To DOE for providing timely, high quality response to inquiries and regulatory requirements.

- To Supervisor, or any other authorized manager, for quality, quantity, and timeliness of work, and ideas on improvement opportunities.

- To fellow staff, for effective communication and safe and professional conduct.

Authorities:

- Identify program vulnerabilities or potential liabilities to supervisors.

- Notify affected line organization of financial needs to complete NEPA evaluations of proposals.

- Notify Laboratory Management (Line and Level 1), DOE and regulatory agencies of nonconformances.

- Act as necessary to ensure safe and effective operations.

- Identify training, information, equipment, and facility needs to perform work. 


\section{Archeologically Sensitive Areas}

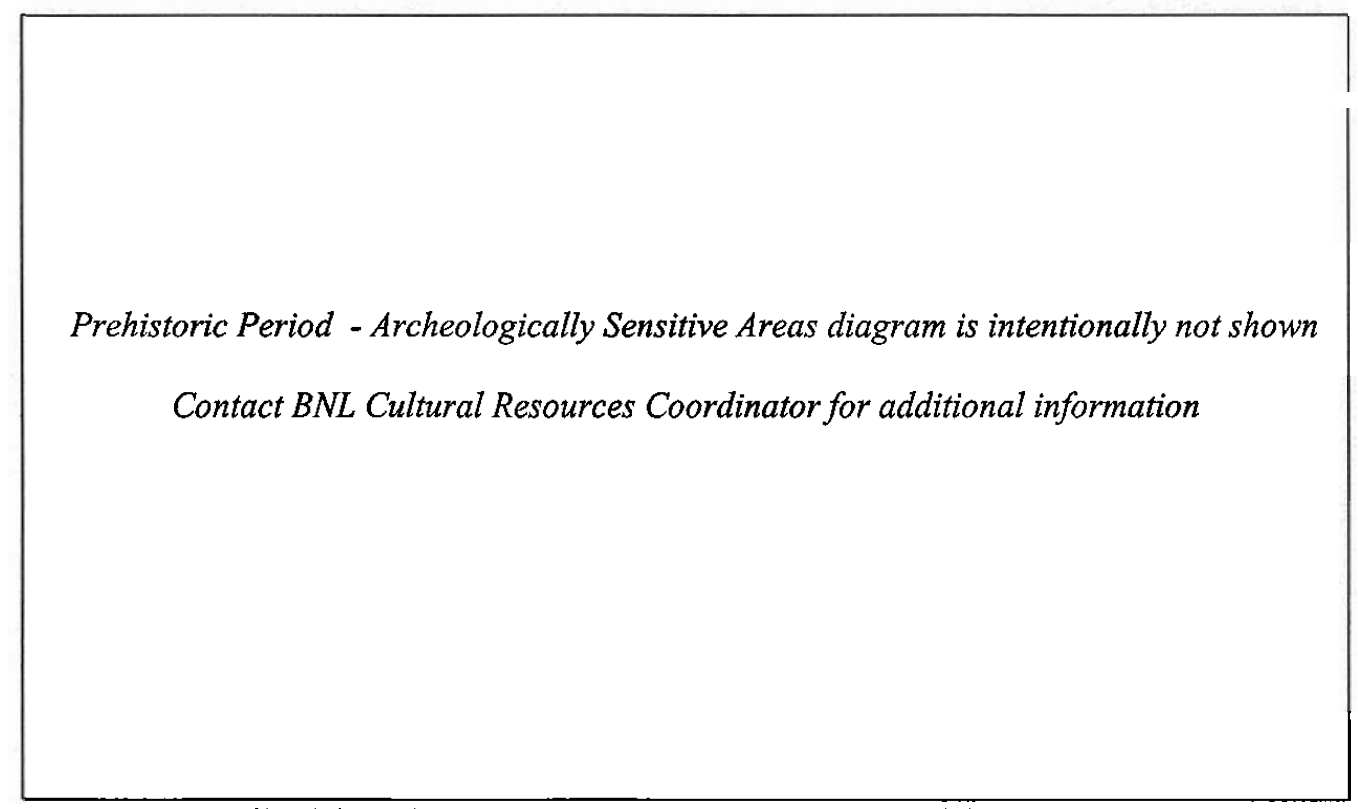

Prehistoric Period - Archeologically Sensitive Areas

Historic Period - Archeologically Sensitive Areas diagram is intentionally not shown

Contact BNL Cultural Resources Coordinator for additional information

Historic Period - Archeologically Sensitive Areas 



\section{ATTACHMENT 35}

\section{BNL ORAL HISTORY INTERVIEWS}

\begin{tabular}{|c|c|c|c|c|c|c|}
\hline INDIVIDUAL & TOPIC & DATE & INTERVIEWER & TAPE \# & COMMENTS & FORMAT \\
\hline $\begin{array}{l}\text { Borst (3/4 } \\
\text { masters) }\end{array}$ & BNL History & 6/26/1986 & & 1196 & & \\
\hline \begin{tabular}{|l|} 
Borst \\
\end{tabular} & BNL History & $6 / 26 / 1986$ & & $1197-1201$ & & \\
\hline Plotkin & BNL History & $3 / 13 / 1986$ & & $1202-1204$ & & \\
\hline Blewett & BNL History & $3 / 17 / 1986$ & & $1205-1214$ & & \\
\hline Long & BNL History & $6 / 24 / 1986$ & & $1215-1221$ & & \\
\hline $\begin{array}{l}\text { Collins }(3 / 4 \\
\text { masters) }\end{array}$ & BNL History & $11 / 3 / 1983$ & & 1222 & & \\
\hline \begin{tabular}{|l|} 
Collins \\
\end{tabular} & BNL History & $11 / 3 / 1983$ & & $1223-1226$ & & \\
\hline Morse & BNL History & $1 / 26 / 1983$ & & $1227-1232$ & & \\
\hline Courant & BNL History & $4 / 3 / 1986$ & & 1233-1236 & & \\
\hline Sweet & BNL History & $2 / 18 / 1983$ & & $1237-1241$ & & \\
\hline Goldhaber & BNL History & $3 / 25 / 1986$ & & $1242-1245$ & & \\
\hline Powell & BNL History & $3 / 3 / 1986$ & & $1246-1250$ & & \\
\hline Manowitz & BNL History & $5 / 8 / 1986$ & & 1251-1253 & & \\
\hline Mallory & BNL History & 10/1/1982 & & $1254-1258$ & & \\
\hline Nichols & BNL History & $8 / 4 / 1983$ & & $1259-1263$ & & \\
\hline Rabi & BNL History & 9/29/1982 & & $1264-1268$ & & \\
\hline Smyth & BNL History & $6 / 15 / 1983$ & & $1269-1272$ & & \\
\hline Vineyard & BNL History & $3 / 20 / 1986$ & & $1273-1275$ & & \\
\hline Bacher & BNL History & 10/1/1982 & & $1276-1280$ & & \\
\hline Livingston & BNL History & 10/1/1982 & & $1281-1286$ & & \\
\hline Anderson & BNL History & $3 / 14 / 1986$ & & $1287-1290$ & & \\
\hline Gurinsky & BNL History & $4 / 18 / 1986$ & & $1291-1299$ & & $t$ \\
\hline Glasoe & BNL History & 10/1/1982 & & $1300-1303$ & & 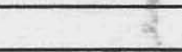 \\
\hline Fitch & BNL History & 6/16/1983 & & $1304-1307$ & & \\
\hline Kouts & BNL History & $5 / 15 / 1986$ & & $1308-1312$ & & \\
\hline Higinbotham & BNL History & $5 / 6 / 1986$ & & $1313-1316$ & & \\
\hline Love & BNL History & $4 / 4 / 1986$ & & $1317-1319$ & & \\
\hline Mrs. Kupers & BNL History & 3/11/1986 & & $1320-1322$ & & \\
\hline Mr. Kupers & BNL History & $3 / 11 / 1986$ & & $1323-1325$ & & \\
\hline Zacharias & BNL History & $1 / 27 / 1983$ & & $1326-1329$ & & \\
\hline Rabi & BNL History & $6 / 29 / 1983$ & & $1330-1332$ & & \\
\hline Tape & BNL History & $3 / 9 / 1983$ & & $1333-1341$ & & \\
\hline Ramsey & BNL History & $7 / 15 / 1982$ & & $1342-1347$ & & \\
\hline DuBridge & BNL History & $12 / 1 / 1982$ & & $1348-1351$ & & \\
\hline Boerst, Lyle & BGRR History & $8 / 1 / 2000$ & R. Crease & & & \\
\hline Chrien, Robert & BGRR History & $8 / 1 / 2000$ & R. Crease & & & \\
\hline $\begin{array}{l}\text { Goldhaver, } \\
\text { Maurice }\end{array}$ & BGRR History & $8 / 1 / 2000$ & R. Crease & & & \\
\hline $\begin{array}{l}\text { Harbottle, } \\
\text { Garman }\end{array}$ & BGRR History & $8 / 1 / 2000$ & R. Crease & & & \\
\hline Hastings, Julius & BGRR History & $8 / 1 / 2000$ & R. Crease & & & \\
\hline Hendrie, Joseph & BGRR History & $8 / 1 / 2000$ & R. Crease & & & \\
\hline & & & & & (Continued & ext page) \\
\hline
\end{tabular}




\begin{tabular}{|c|c|c|c|c|c|c|}
\hline \multicolumn{2}{|c|}{$\frac{\text { INDIVIDUAL }}{\text { (Continued from previous page) }} \frac{\text { TOPIC }}{\underline{\text { fous }}}$} & DATE & INTERVIEWER & TAPE \# & COMMENTS & FORMAT \\
\hline Kouts, Herbert & BGRR History & $8 / 1 / 2000$ & R. Crease & & & \\
\hline $\begin{array}{l}\text { Manowitz, } \\
\text { Bernard }\end{array}$ & BGRR History & $8 / 1 / 2000$ & R. Crease & & & \\
\hline $\begin{array}{l}\text { Marburger, John } \\
\text { H. }\end{array}$ & BGRR History & $8 / 1 / 2000$ & R. Crease & & & \\
\hline $\begin{array}{l}\text { Passell, } \\
\text { Lawrence }\end{array}$ & BGRR History & $8 / 1 / 2000$ & R. Crease & & & \\
\hline Philips, Jack & BGRR History & $8 / 1 / 2000$ & R. Crease & & & \\
\hline Powell, Robert & BGRR History & $8 / 1 / 2000$ & R. Crease & & & \\
\hline Rorer, David & BGRR History & $8 / 1 / 2000$ & R. Crease & & & \\
\hline Frei, Haskel & BGRR History & $8 / 1 / 2000$ & R. Crease & & & \\
\hline Schweller, David & BGRR History & $8 / 1 / 2000$ & R. Crease & & & \\
\hline Davis, Raymond & Neutrinos & & R. Crease & & & \\
\hline Lee, T. D. & Cosmotron & & R. Crease & & & \\
\hline Polk, Irving (Irv) & Cosmotron & & R. Crease & & & \\
\hline Courant, Ernest & Cosmotron & & R. Crease & & & \\
\hline Alberger, David & Cosmotron & & R. Crease & & & \\
\hline $\begin{array}{l}\text { Watson, Richard } \\
\text { (Dick) }\end{array}$ & NSLS/Physics & $7 / 20 / 2004$ & R. Crease & & & \begin{tabular}{|l} 
DVC-PRO \& \\
DVD backup \\
\end{tabular} \\
\hline Blume, Martin & NSLS/Physics & $7 / 21 / 2004$ & R. Crease & & & \begin{tabular}{|l|} 
DVC-PRO \& \\
DVD backup \\
\end{tabular} \\
\hline Friedlander, Gerhs & Chemistry & $7 / 29 / 2004$ & R. Crease & & & $\begin{array}{l}\text { DVC-PRO \& } \\
\text { DVD backup }\end{array}$ \\
\hline Krinsky, Samuel & NSLS & $8 / 5 / 2004$ & R. Crease & & & $\begin{array}{l}\text { DVC-PRO \& } \\
\text { DVD backup }\end{array}$ \\
\hline
\end{tabular}

CR - Oral

Histories -

Excel - 1/3/05 


\section{Attachment 36}

BNL Oral History Program - Overview \& Planning Document

Overview: The purpose of this document is to establish a process for developing a formal oral. history $(\mathrm{OH})$ program at $\mathrm{BNL}$. The scope of the program will include identification and tracking of existing video and audio interviews, process development, program roles and responsibilities.

The BNL Cultural Resource Management Program (part of the EWMS Division) assumes responsibility for this program, working in close coordination with the Community Relations \& Public Affairs Directorate, and BNL Science Historian, Robert Crease. Development of this process is expected to evolve and build upon early experiences.

I. General

A. The BNL Oral History Program will, to the extent practical, follow the guidelines presented in the draft document "Handbook for Oral History in the National Park Service", June 2004 by Janet A. McDonnell, available at the National Park Service (NPS) website.

B. Interviews associated with the oral history program should be coordinated through the BNL Cultural Resources Coordinator.

II. Interview Topics

A. Topics and individuals to be interviewed may be determined by various means including, but not limited to:

i. Established $\mathrm{OH}$ program priority

ii. Departmental recommendations

iii. Special projects

iv. Thematic programs

B. The $\mathrm{OH}$ program will strive to develop a "routine" schedule or priority for interviews. However, a special theme or project series may also be conducted.

III. Background/Research

Ideally, research should be conducted into the background of the individual, in order to ensure a thorough and smooth interview.

A. Departmental Questionnaire: Attachment 1 presents an example of a questionnaire that may be forwarded to departments in order to develop background information.

B. All background materials and resource lists shall become part of the "interview documentation package".

IV. Interviews

A. Interviews may be conducted by the following personnel:

- R. Crease

- M. Davis

- Other (or other designated CEGPA representative) 


\section{Attachment 36}

B. Interviews may be conducted with assistance from an individual associated with the interviewee's department/program, in order to have subject matter expertise and/or familiarization with the individual's background.

V. Process

A. Identify Individual(s) to be interviewed

i. If warranted - Distribute memo to department(s) soliciting recommendations

ii. Potential prioritization

1. Age/Health

2. Scientific achievement/program association

3. Duration of BNL employment

B. Conduct background research using one or more of the following resources

i. Distribute questionnaire to department(s)

ii. Talk with coworkers and others knowledgeable

iii. Utilize Public Affairs resources

iv. Conduct audio interviews prior to video to identify focus/avoidance topics. (Crease's method)

C. Develop interview topics \& questions (note: include in "interview document package").

D. Schedule \& conduct interview,

E. Revise $\mathrm{OH}$ database and file "interview document package", containing:

Background information/notes, reference list, interview questions/topics, etc. .

F. Video reviewed and edited per Community Relations Group recommendations.

VI. Documentation

A. Develop a listing/database of existing video and audio interviews

B. Identify current storage location(s) and responsible individuals

i. Evaluate potential to centralize storage/responsibility

C. Develop/distribute annual memo acknowledging existence, location and responsibility - if determined necessary.

D. Establish preferred medium(s)

E. Establish consistent marking/archive system

VII. Video Use

A. Develop protocols for permitting access to interviews/documents; consider addressing the following aspects:

i. Notification of availability: Mentioned with other CR information/ websites CR \& BNL history/Bulletin articles 


\section{Attachment 36}

ii. Raw interview tapes, database lists, database identification of related files (research files)

iii. CRC to contact other DOE facilities \& Pantex for their process

iv. Must submit request via phone, email, letter

v. Develop form to request access

vi. View at $\mathrm{BNL}$ video

B. Evaluate other potential uses, such as:

i. Website - Video clips linked with text (Similar to SLAC website?)

7/28/04 (revised 2/3/05) 



\section{Attachment 37 \\ MEMORANDUM OF AGREEMENT}

\section{BROOKHAVEN GRAPHITE RESEARCH REACTOR,}

WHEREAS, the U.S. Department of Energy, Brookhaven Group (DOE) has determined that the Brookhaven Graphite Research Reactor (BGRR) Complex at the Brookhaven National Laboratory (BNL) is eligible for inclusion in the National Register of Historic Places, and that decommissioning would have an adverse effect on this property, and has consulted with the New York State Historic Preservation Officer (SHPO) pursuant to 36 CFR 800, regulations implementing Section 106 of the National Historic Preservation Act (16 USC 470f); and

WHEREAS, Federal agencies are required to seek ways to avoid, minimize, or mitigate adverse effects on historic properties under the provisions of 36 CFR 800.6; and

WHEREAS, recordation of historic properties is required of Federal agencies by Section 110(b) of the National Historic Preservation Act whenever an agency action may substantially alter or demolish an historic property; and

WHEREAS, the Advisory Council on Historic Preservation (ACHP) has promoted the use of innovative mitigation measures that place the resource and its value before the public.

NOW THEREFORE, DOE and the SHPO agree that the undertaking shall be implemented in accordance with the following in order to take into account the effects of the undertaking on this historic property.

Upon execution of this agreement, DOE will ensure that the following measures are carried out, subject to the availability of appropriated funds:

\section{A. Documentation, Interpretation, Curation}

Mitigation measures for the Brookhaven Graphite Research Reactor Complex are:

1. Create a "Researcher's Guide" to the BGRR. In creating this guide, DOE will locate and curate documents, drawings, manuals, oral histories, photographs, and video or movie footage pertaining to BGRR and the primary operational support facilities to be impacted through decommissioning [i.e., the Fan House (Bldg. 704), the Instrument House (Bldg. 708), the Canal House (Bldg. 709) and the Water Treatment House (Bldg. 709A)]. DOE will seek to assemble information that depicts BGRR at various stages of use over its operational lifetime. In creating the Researcher's Guide, DOE will utilize both published materials as well as records and documents retained in the BNL archives.

2. Using best efforts, DOE will develop a visual record of the operational history of BGRR derived from information and individuals located and/or identified in creating the Researcher's Guide. The format will be a "virtual tour" of the facilities conducted by both researchers and support staff who worked within BGRR over its lifetime. Their accounts will illustrate and personalize the significance of the work conducted. These will include:

a. A video documentary - the video will be a minimum of $1 / 2$ hour in length, and will be produced to broadcast standards. The video would walk the "visitor" through the facility and interpret its operation through historic documentation and on-camera or recorded inteviews with former researchers and staff. The video will be made available through the BNL Research Library and BNL Science Museum for individual viewing or presentations at public forums, through local media outlets, and, potentially, through national release either independently or as part of a DOEcomplex-wide documentary. 
b. An interactive $C D-t \quad 2 D$, compiled from the video and supplen ... ted with current and historic documentation, will be produced in a format compatible for use with personal computers. The $C D$ is intended for release to on-site, local, regional, and national museums, schools, and libraries. Users would have the ability to select subjects of interest and scan the disk for appropriate text, photos, or video clips.

At their discretion, the SHPO will participate in the review and selection of materials to be used in the production of the video and $C D$. Upon completion, draft copies of the video and $C D$ will be provided to the SHPO for review.

3. Final products, together with original drawings, photographs, negatives, or interviews created in support of this MOA, will be deposited at the BNL Research Library. Copies of the final products will be filed with the SHPO and other repositories as determined appropriate.

4. Prior to decommissioning, DOE will assess the contents of BGRR and its operational support facilities to determine whether items with educational or interpretive potential for use in local, state, regional, or national museums are present. Collections made in support of this MOA will be curated with DOE and will be available for public interpretation through loan or assignment.

B. Administrative Conditions

1. Should the SHPO object within thirty (30) days after receipt to any plans, specifications, contracts, or other documents provided for review pursuant to this agreement, or to the manner in which this agreement is being implemented, DOE shall consult with the SHPO to resolve the objection. If DOE determines that the objection cannot be resolved, DOE shall forward all documentation relevant to the dispute to the Advisory Council on Historic Preservation in accordance with 36 CFR 800.7(a)(1). Within forty-five (45) days after receipt of all pertinent documentation, the Council will either:

(a) provide DOE with recommendations, which DOE will take into account in reaching a final decision regarding the dispute; or

(b) notify DOE that it will comment pursuant to $36 \mathrm{CFR} 800.7$ (c) and proceed to comment. Any Council comment provided in response to such a request will be taken into account by DOE in accordance with 36 CFR 800.7 (c)(4).

Execution of this Memorandum of Agreement by DOE and the New York SHPO and implementation of its terms are evidence that DOE has afforded the Council an opportunity to comment on the impact that decommissioning has on the BGRR Complex, and that DOE has taken into account the effects of the undertaking on this property.

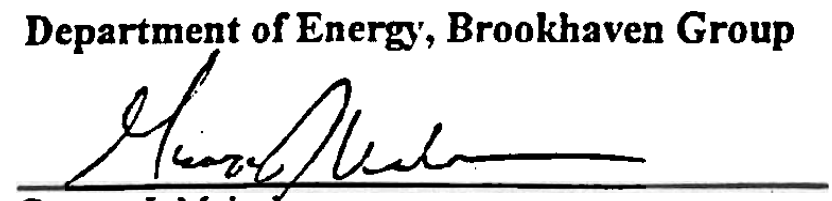

George J. Malosh

Brookhaven Group Manager

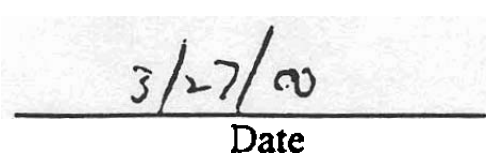

New York State Historic Preservation Officer

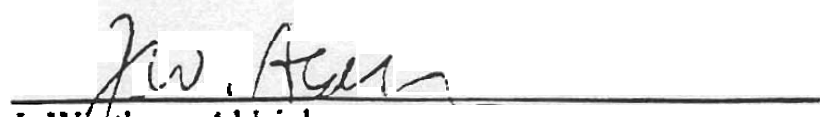

J. Wonthrop Aldrich,

Deputy Commissioner for

Historic Preservation

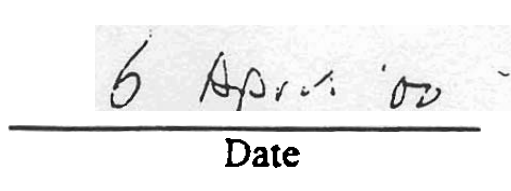




\subsection{APPENDICES}

Appendices include complete documents providing primary or supporting information and are considered integral parts of the management plan.

Appendix A The Cultural Resources Inventory Including Archival Search, Prehistoric and Historic Period Contexts, and Archeology Sensitivity Assessment of the Brookhaven National Laboratory. (Bernstein 2001b)

Appendix B Cultural Significance Categories Table

Appendix C Cultural Resource Management Strategy Forms

Appendix D Cultural Resources Management Plan - Action Items 
Appendix A

\section{The Cultural Resources Inventory of the \\ Brookhaven National Laboratory}

(Including Archival Search, Prehistoric and Historic Period Contexts, and Archeology Sensitivity Assessment) 


\section{CULTURAL RESOURCES INVENTORY}

INCLUDING ARCHIVAL SEARCH, PREHISTORIC and HISTORIC PERIOD CONTEXTS, and ARCHAEOLOGICAL SENSITIVITY ASSESSMENT

of the

BROOKHAVEN NATIONAL LABORATORY

UPTON, TOWN OF BROOKHAVEN

SUFFOLK COUNTY, NEW YORK

PREPARED BY:

David J. Bernstein, Ph.D.

Daria E. Merwin, M.A.

The Institute for Long Island Archaeology Department of Anthropology

State University of New York at Stony Brook

Stony Brook, New York 11794-4364 


\begin{abstract}
This report is a cultural resources inventory of the United States Department of Energy facility at Brookhaven National Laboratory (BNL). The facility is located in Upton, Town of Brookhaven, Suffolk County, New York, and consists of approximately 1,420 hectares $(3,500$ acres) situated east of William Floyd Parkway and south of New York State Route 25. The purpose of the cultural resources inventory is to document the prehistoric and historic period contexts for the property, and to determine the probability of the presence of previously unknown cultural resources.

Based on the results of the archaeological site file searches and a consideration of environmental features, portions of the BNL property have a high sensitivity for the presence of archaeological remains. For prehistoric resources, these include areas of the property within or adjacent to wetlands and other fresh water sources. If prehistoric materials are present, they are most likely small manifestations that may represent hunting or specialized collecting which occurred away from larger interior camps. Sections of the BNL property which are not adjacent to fresh water resources have a low to moderate potential for prehistoric archaeological sites. In addition, many portions of the BNL property have been thoroughly disturbed by twentieth century land use activities (e.g., road and building construction). Disturbed areas have a very low sensitivity for the presence of intact archaeological deposits.

The BNL property has an overall low sensitivity for the presence of historic period archaeological resources dating prior to the early twentieth century, but a moderate to high sensitivity for the presence of cultural material associated with Camp Upton. Expected historic period archaeological remains include early to mid-twentieth century deposits from World War I era Camp Upton (1917-1921, including training trenches and other earthworks potentially located throughout the entire BNL parcel), the Civilian Conservation Corps period (1934-1936), and World War II Camp Upton (1940-1946). Such early to mid-twentieth century archaeological resources would be potentially significant at local, State, and National levels.
\end{abstract}




\section{TABLE OF CONTENTS}

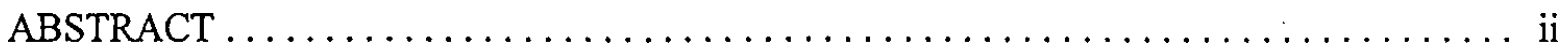

LIST OF FIGURES $\ldots \ldots \ldots \ldots \ldots \ldots \ldots \ldots \ldots \ldots \ldots \ldots \ldots \ldots \ldots$ iv

LIST OF TABLES $\ldots \ldots \ldots \ldots \ldots \ldots \ldots \ldots \ldots \ldots \ldots \ldots \ldots \ldots \ldots \ldots$

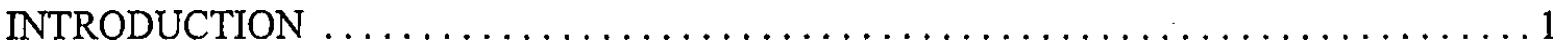

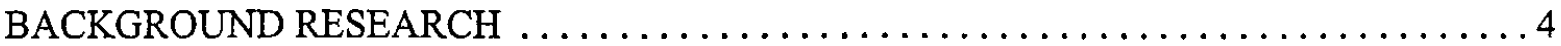

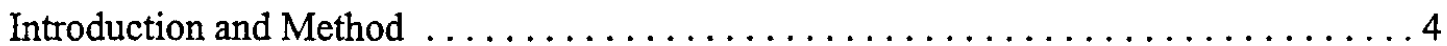

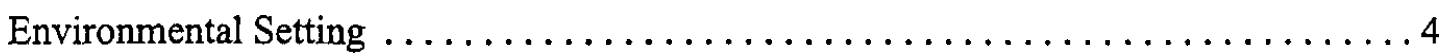

Site File Research $\ldots \ldots \ldots \ldots \ldots \ldots \ldots \ldots \ldots \ldots \ldots \ldots \ldots \ldots$

NATIVE AMERICAN CONTEXT $\ldots \ldots \ldots \ldots \ldots \ldots \ldots \ldots \ldots \ldots \ldots \ldots \ldots$

Overview of the Prehistoric Period in Southern New England $\ldots \ldots \ldots \ldots \ldots \ldots$.

Prehistoric Context: Central Suffolk County . . . . . . . . . . . . . . . . 11

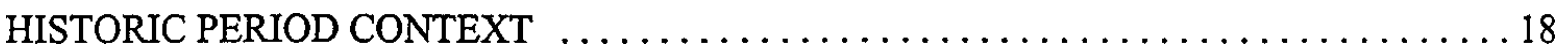

Pre-World War I . . . . . . . . . . . . . . . . . . . . 18

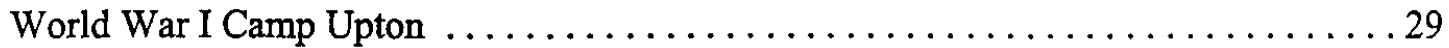

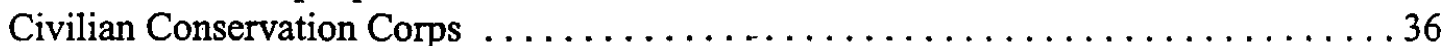

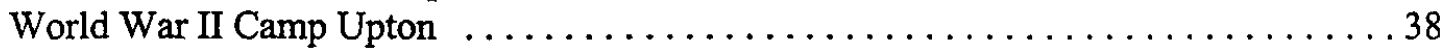

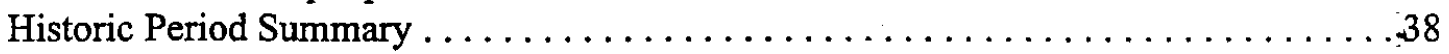

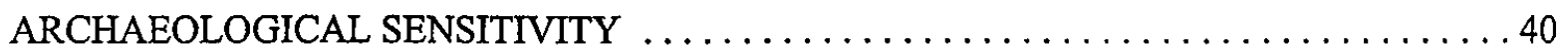

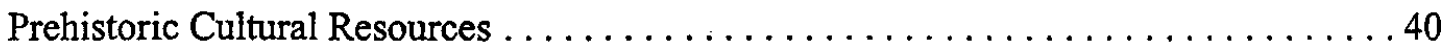

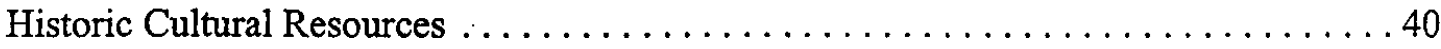

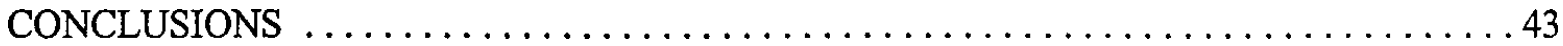

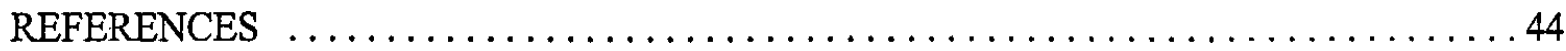

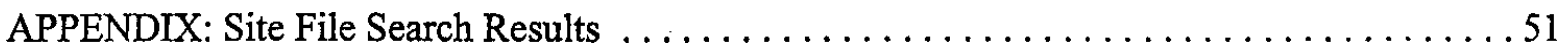




\section{LIST OF FIGURES}

Figure 1. Map of Long Island showing the location of Brookhaven National

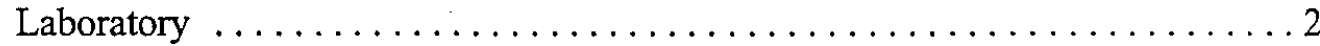

Figure 2. Mosaic of 1967 USGS topographic 7.5 minute series maps (scale $1: 24,000$ ) showing the location of Brookhaven National Laboratory $\ldots \ldots \ldots \ldots \ldots$

Figure 3. 1797 Hulse Survey of the Town of Brookhaven. The BNL property is shown as undeveloped land west of the headwaters of the "Peaconick River" ........23

Figure 4. 1838 United States Coastal Survey showing the BNL parcel as undeveloped

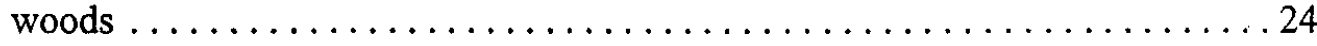

Figure 5. 1858 Chace Map of Suffolk County. The BNL property is depicted as

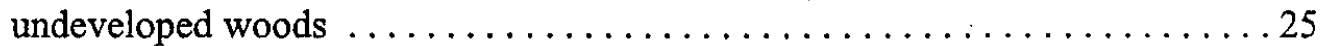

Figure 6. 1873 Beers Atlas of Long Island showing the location of the project area . . . 27

Figure 7. 1896 Hyde Atlas of Long Island showing the BNL property as open space . . . 28

Figure 8. 1904/1920 USGS topographic map of Moriches, New York showing the extent of World War I Camp Upton . . . . . . . . . . . . . . . . . . . 31

Figure 9. 1917 Hyde Atlas of a Part of Suffolk County illustrating the general location of the Army cantonment at Camp Upton ........................ 32

Figure 10. 1917 U.S. Army Quartermaster Corps map of Camp Upton and properties . . ... 33

Figure 11. 1917 postcard showing draftees arriving at the Camp Upton rail station . . . . 34

Figure 12. Postcard showing a typical view of barracks at Camp Upton . . . . . . . . 34

Figure 13. World War I Camp Upton command headquarters $\ldots \ldots \ldots \ldots \ldots \ldots$

Figure 14. Postcard showing soldier training at circa 1917 Camp Upton . . . . . . . . 35

Figure 15. 1930 Dolph and Stewart Atlas of Suffolk County showing the extent of "Upton National Forest" beyond the modern boundaries of BNL . . . . . . . . 37

Figure 16. 1944 U.S. Army Corps of Engineers Map showing the extent of World War II Camp Upton . . . . . . . . . . . . . . . . . . . . . . . . . . . 


\section{LIST OF TABLES}

Table 1. Known archaeological sites located within one mile of Brookhaven National

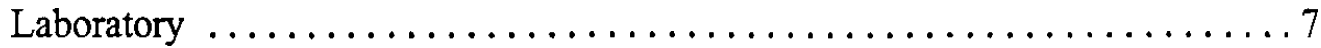

Table 2. Prehistoric chronology for the Long Island region $\ldots \ldots \ldots \ldots \ldots$ 


\section{INTRODUCTION}

This report presents the results of a cultural resources inventory of the United States Department of Energy facility at Brookhaven National Laboratory (BNL). The facility is located in Upton, Town of Brookhaven, Suffolk County, New York (Minor Civil Division 10302), and consists of approximately 1,420 hectares (3,500 acres) situated east of William Floyd Parkway and south of New York State Route 25. The study was conducted from July through September 2001 by the Institute for Long Island Archaeology, State University of New York at Stony Brook.

The purpose of the cultural resources inventory is to document the prehistoric and historic period contexts for the property, and to determine the probability of the presence of previously unknown cultural resources. 


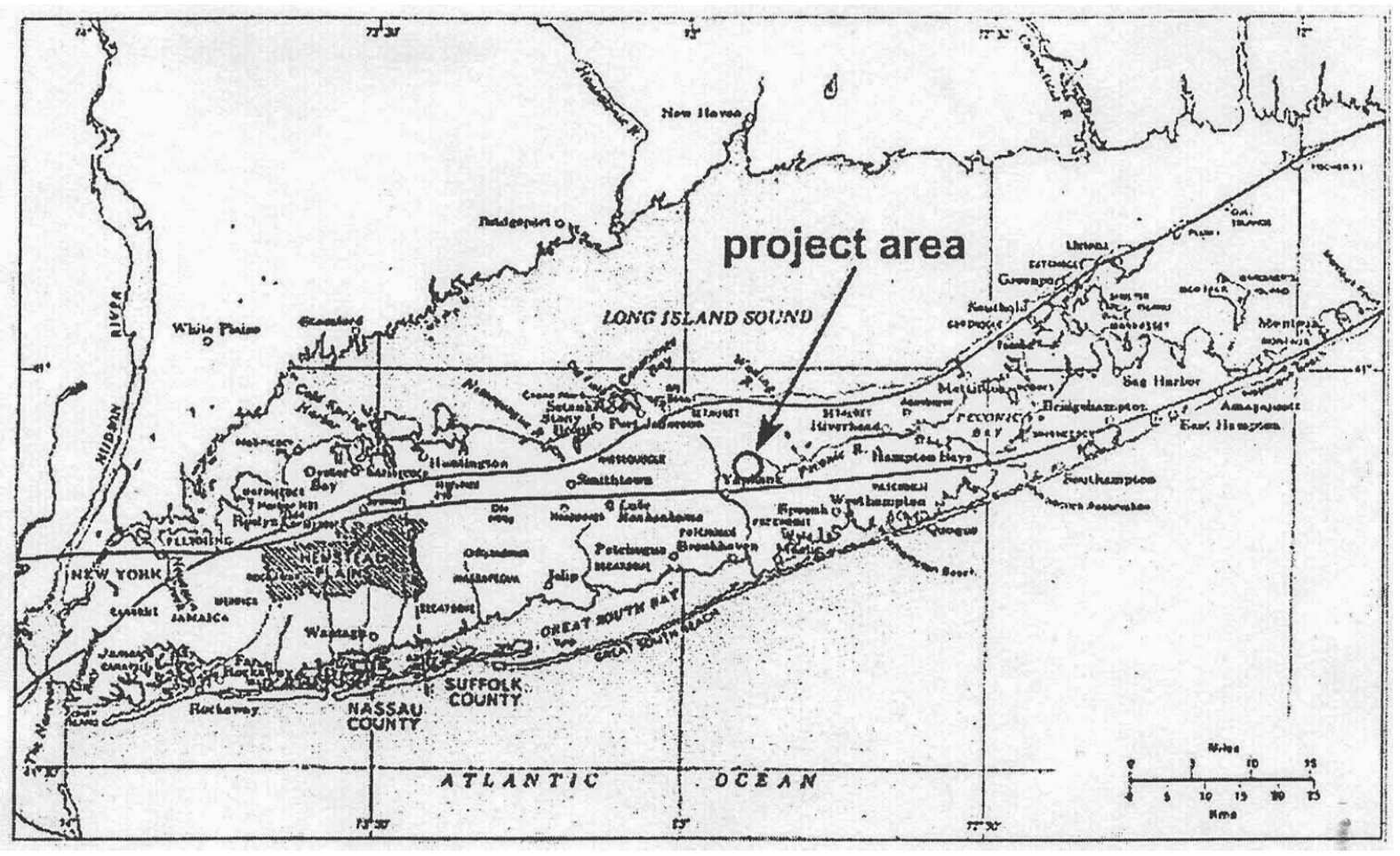

Figure 1. Map of Long Island showing the location of Brookhaven National Laboratory. 


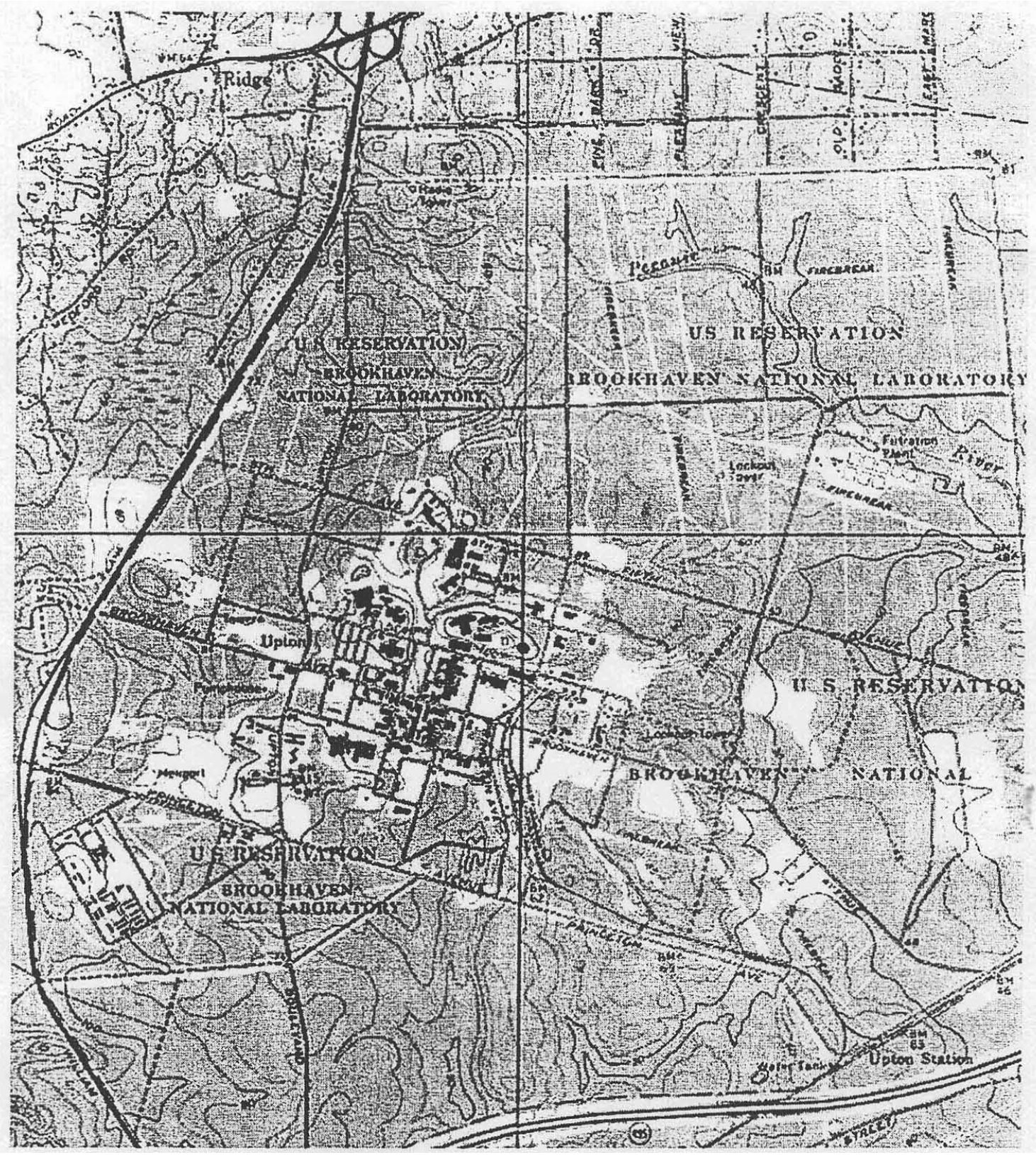

Figure 2. Mosaic of 1967 USGS topographic 7.5 minute series maps (Bellport, New York, Middle Island, New York, Moriches, New York, and Wading River, New York) (scale 1:24,000) showing the location of Brookhaven National Laboratory. 


\section{BACKGROUND RESEARCH}

\section{Introduction and Method}

An evaluation of the environmental and physical characteristics of an area is essential to understanding past land use, as well as the likelihood of encountering prehistoric or historic archaeological sites. Human groups locate their settlements in order to best take advantage of the characteristics of the natural and social landscape. Thus, knowledge of a region's environmental features, as well as its history, is important for reconstructing past behavior and assessing the probability of locating evidence of early activities.

A search of the available published records and unpublished site files (on Long Island and in Albany) of known archaeological and historic sites was undertaken to determine if any previous studies had documented archaeological remains in, or in the vicinity of, Brookhaven National Laboratory. Pertinent historical records such as maps, photographs, and descriptive histories were examined to obtain information on past activities in the study parcel and surrounding region.

\section{Environmental Setting}

Brookhaven National Laboratory is located near the center of Suffolk County, approximately 96 kilometers (60 miles) east of New York City (Figure 1). It is on the Terryville outwash plain, a feature created during the last glacial period over 15,000 years ago (Sirkin 1995). The Ronkonkoma terminal moraine is just to the south of BNL. The sandy outwash plain is cut by the Peconic River Valley; the headwaters of the river are located just over one kilometer north of the most densely-built portion of the BNL complex (Figure 2).

Topography is variable over the large expanse of the BNL facility. Elevations range from a high of 40 meters above mean sea level ("Rutherford Hill," the site of the Brookhaven Graphite Research Reactor near the center of the campus) to 14 meters on the eastern periphery. Soils are dominated by Riverhead sandy loam, graded Riverhead and Haven soils, and cut and fill land (Warner et al. 1975:Sheet 57). The Riverhead series consists of deep, well-drained, medium to 
coarse textured soils with low natural fertility (Warner et al. 1975:81-83).

Prior to the clearing of vegetation throughout much of the BNL property during construction of Camp Upton in 1917, the property was wooded with species typical of the central Long Island pine barrens. Large sections of the property were reforested with eastern white pine saplings by the Civilian Conservation Corps in the early 1930s. The extant woodlands surrounding the structures at BNL support a variety of wildlife.

\section{Site File Research}

The site files of the Suffolk County Archaeological Association (SCAA), the Institute for Long Island Archaeology (ILIA), New York State Museum (NYSM), and the New York State Office of Parks, Recreation, and Historic Preservation (SHPO) document five known prehistoric finds, one site with prehistoric and historic period components, and ten historic period sites within one mile (1.6 kilometers) of Brookhaven National Laboratory (Appendix). Archaeological sites are listed in Table 1.

There is one documented archaeological site on the grounds of BNL; SHPO A10302.000474, Camp Upton World War I training trenches. The site files show two general locations for these trenches, which have been determined to be eligible for the National Register of Historic Places. The remainder of the archaeological sites listed in Table 1 have been inventoried by SHPO, but these sites are either not eligible for the National Register or have not yet been evaluated.

During the mid-1970s, cultural resource investigations were performed on a part of the BNL project area (Johannemann and Schroeder 1977, 1978). The investigations were conducted at the site of the proposed Intersecting Storage Accelerator (ISABELLE), north of the existing Alternating Gradient Synchrotron (AGS) near the northwestern corner of the BNL property. In addition, Johannemann performed a surface survey near the headwaters of the Peconic River in 1974, with negative results (Johannemann and Schroeder 1977:7).

No prehistoric archaeological sites were encountered during the 1970s surveys, but twenty loci of twentieth century activity associated with World War I and II Camp Upton were identified. These features include training trenches, circular depressions for camp sites and other 
military training functions, a pistol range sided by earthen berms, a mound of construction debris, and other features (Johannemann and Schroeder 1977, 1978). Some of the World War I era trenches documented by Johannemann and Schroeder appear to be those which have been determined to be National Register eligible (site A10302.000474). 
Table 1. Known archaeological sites located within one mile (1.6 kilometer) of Brookhaven National Laboratory.

\begin{tabular}{|c|c|c|c|}
\hline Site Identifier & Site Name & $\begin{array}{l}\text { Age/Cultural } \\
\text { Affiliation } \\
\end{array}$ & Comments \\
\hline A 10302.000470 & Lake Panamoka & prehistoric & $\begin{array}{l}\text { surface finds of lithic artifacts, including Wading } \\
\text { River and Orient fishtail points }\end{array}$ \\
\hline $\mathrm{A} 10302.000471$ & Tarkill Pond & prehistoric & no information provided: possibly Late Woodland \\
\hline $\mathrm{A} 10306.000724$ & & prehistoric & stray find of one quartz flake \\
\hline A 10302,000473 & & prehistoric & $\begin{array}{l}\text { finds from surface and one test pit include } 14 \text { lithic } \\
\text { flakes, } 34 \text { fire-cracked rocks, and charcoal }\end{array}$ \\
\hline A 10306.000725 & & historic, $18^{\text {th }}-19^{\text {th }} c$. & $\begin{array}{l}\text { field stone foundation and well; artifacts include } \\
\text { stoneware, whiteware, bottle glass, and nails }\end{array}$ \\
\hline A 10306.000726 & & prehistoric & stray find of one quartz tool \\
\hline $\mathrm{A} 10306.000727$ & & historic, late $19^{\text {th }} \mathrm{c}$. & brick foundation and scattered refuse \\
\hline A.10302,001834 & Ridgeco & $\begin{array}{l}\text { prehistoric and } \\
\text { historic (late } 19^{\text {th }} \text { - } \\
\text { early } 20^{\text {th }} \mathrm{c} \text {.) }\end{array}$ & $\begin{array}{l}\text { prehistoric artifacts include possible quartz debitage, } \\
\text { cores, hammerstones, and scraper; historic period } \\
\text { remains include field stone and concrete foundations } \\
\text { and bottle glass }\end{array}$ \\
\hline A 10302,000474 & $\begin{array}{l}\text { Camp Upton } \\
\text { trenches }\end{array}$ & historic, ca. 1917 & $\begin{array}{l}\text { NRE, two areas of trenches dug at WWI Camp } \\
\text { Upton; it is likely that other unmapped trenches are } \\
\text { present }\end{array}$ \\
\hline A 10302.000549 & $\begin{array}{l}\text { Camp Upton } \\
\text { trenches and } \\
\text { bunkers }\end{array}$ & historic, $20^{\text {th }} \mathrm{c}$. & $\begin{array}{l}\text { training trenches from WWI activity at Camp Upton } \\
\text { observed near rifle range at Brookhaven State Părk; } \\
\text { recommended that remainder of park be surveyed for } \\
\text { additional WWI and WWII resources }\end{array}$ \\
\hline A 10306.000278 & $\begin{array}{l}\text { Hom Tavern } \\
\text { Farm }\end{array}$ & historic, $18^{\text {th }} \mathrm{c}$. & $\begin{array}{l}\text { site of Colonial period tavern; no visible evidence of } \\
\text { structure }\end{array}$ \\
\hline A 10302.000536 & & $\begin{array}{l}\text { historic, late } 19^{\text {th }} \text { - } \\
\text { mid- } 20^{\text {th }} \mathrm{c} \text {. }\end{array}$ & $\begin{array}{l}\text { farm complex; brick foundation, barnyard artifacts } \\
\text { and household refuse midden }\end{array}$ \\
\hline $\mathrm{A} 10302.000472$ & & historic & bottle glass, oyster and clam shell \\
\hline A 10302.000465 & $\begin{array}{l}\text { Weeks Octagonal } \\
\text { House }\end{array}$ & historic, mid- $19^{\text {th }} \mathrm{c}$. & site of William Weeks' house \\
\hline A10302.000469 & & historic, mid- $19^{\text {th }} \mathrm{c}$. & $\begin{array}{l}\text { house and outbuilding site; field stone house } \\
\text { foundation }\end{array}$ \\
\hline A10302.000523 & Homan mill dam & historic & early $19^{\text {th }}$ century earthen dam \\
\hline
\end{tabular}




\section{NATIVE AMERICAN CONTEXT}

\section{Overview of the Prehistoric Period in Southern New England}

Eastern Long Island has been occupied for at least ten thousand years by ancestors of modern and historically known Algonquian speaking Native Americans. The archaeology of this portion of southem New England and southeastern New York is well-developed and has a history dating back into the last century. This work has involved cultural resource management studies, avocational excavations, and traditional "academic" endeavors. Broad regional overviews are provided in Ritchie (1980), Salwen (1978), Snow (1980), and Dincauze (1990). A recent synthesis of the relevant ethnohistoric sources is found in Grumet (1995). The historian John Strong (1997) has written a lengthy popular overview of the archaeology and history (to A.D. 1700) of Long Island Native Americans.

Archaeologists working on Long Island and elsewhere in the northeastern United States usually employ a system of three periods (Paleoindian, Archaic, and Woodland) to divide the span of time between the first settlement of the region by Native peoples and the arrival of the European explorers and colonists in the sixteenth century (for alternative temporal frameworks see Snow 1980 and Dincauze 1990). This chronological scheme is shown in Table 2.

Although much fieldwork has taken place on Long Island (especially the north shore), many questions regarding the region's prehistory remain. Interpretation has been hindered by a lack of radiocarbon dates from prehistoric Native American sites. This means that in many cases, sites and components of sites have been dated solely on the basis of artifact (especially projectile point) styles. In the Northeast, projectile points are typically classified based on considerations of form, and the contexts from which they were recovered are then assigned the absolute dates that have been obtained for similar materials in the region (Table 2). The resolution available with typological cross-dating is generally very broad and therefore not always adequate for sorting out remains into contemporary components or making comparisons among sites. It is also the case the various point types do not represent discrete temporal periods (Filios 1989) and that many of the types were used for extremely long (thousands of years) 
periods of time. This is especially the case for some of the Late Archaic point types. Despite these drawbacks, artifact typologies are indispensable tools for ordering the prehistoric past, and they are used to organize the discussion that follows, except in those cases where specific radiocarbon dates are mentioned.

Since the retreat of the Late Pleistocene glaciers (circa 18,000 B.P.), the coastlines of southern New England and New York have been progressively inundated. Significant for the study of Native American archaeology is the fact that many early (pre-5000 B.P.) coastal sites are now under water. Although sea-level continues to rise today, most shorelines attained their approximate modern positions by 3000 B.P. During the last three to five thousand years of the prehistoric era (and possibly earlier), the mouths of estuaries were particularly attractive to hunter-gatherer-fishers, and many of the larger sites dating to the Late Holocene have been identified in these settings.

Table 2. Prehistoric chronology for the Long Island region.

\begin{tabular}{||l|l|l||}
\hline Period & Dates & Trends \\
\hline \hline Late Woodland & A.D. $1000-1500$ & Agriculture in mainland river valleys. \\
\hline Middle Woodland & A.D. $0-1000$ & \\
\hline Early Woodland & 700 B.C. - A.D. 0 & Pottery; intensive use of coastal resources. \\
\hline Terminal Archaic & $1000-700$ B.C. & Elaborate burial ritual. \\
\hline Late Archaic & $4000-1000$ B.C. & $\begin{array}{l}\text { Increase in number of archaeological sites; } \\
\text { consumption of shellfish. }\end{array}$ \\
\hline Middle Archaic & $6000-4000$ B.C. & Modern flora and fauna. \\
\hline Early Archaic & $8000-6000$ B.C. & \\
\hline Paleoindian & $10,500-8000$ B.C. & Fluted projectile points. \\
\hline \hline
\end{tabular}


The Paleoindian period (Table 2) dates from the first arrival of humans into the region until around 8000 B.C. Settlement here, like all of the Americas, took place at the end of the Pleistocene glacial epoch as human populations radiated out from Asia across the exposed Bering Sea land bridge and/or by boat across the northern Pacific (see Meltzer 1988 for a synthesis of data pertaining to the early peopling of eastern North America). As discussed further below, very few sites dating to this period are known from the Long Island region, although the presence of early peoples is implied from the occasional find (almost always on the surface) of characteristic fluted projectile points that were presumably used to hunt Late Pleistocene/Early Holocene fauna (Merwin 2000; Saxon 1973). The lack of early sites along the modern coast is to be expected. Even if the region was well-populated prior to 8000 B.C., most of the evidence for early human presence has been destroyed or hidden by a series of natural forces. Foremost among these forces is the post-glacial rise in sea-level. During the initial settlement of the region, sea-level was over one hundred meters lower than today, meaning that, for example, the south shore of Long Island was located as much as one hundred miles (160 kilometers) south of its present position (Sirkin 1995). What is now Long Island Sound was not a marine ecosystem, but rather a freshwater glacial lake that eventually burst through the moraine behind which it was dammed, and drained into the Atlantic Ocean. Thus the environment settled by the earliest inhabitants of Long Island Sound was not coastal in the modern sense.

After the retreat of the glacial ice sheet, tundra vegetation, similar to that found today in Alaska and northern Canada, colonized newly exposed Long Island (Sirkin 1996). Between nineteen and eleven thousand years ago, a spruce dominated forest was present, to be followed by a forest dominated by pine. Finally, by nine thousand years ago (probably during the Early Archaic period [Table 2]) hardwood forests, similar to those that characterize the Eastern Woodlands today, began to develop on Long Island.

The Archaic period is characterized by the gradual development of more-or-less modern environmental conditions. Humans adapted to the abundant resources provided by interior woodlands, ponds, and rivers, as well as coastal estuaries by exploiting a broad range of food (nuts, large and small game, seed-bearing plants, fish, etc.) and industrial products (stone for making tools and weapons, plants for baskets and textiles, bark for house construction, etc.). By 
5000 B.C. the region was heavily settled, with populations for the southern New England coast and offshore islands possibly numbering in the thousands. Archaeological evidence of this apparent population "explosion" is reflected in the enormous number of archaeological sites dating to this period, and by the size of the individual settlements, many of which exceed five hectares (12.4 acres). A number of these large Archaic settlements or villages have been discovered on the north shore of Suffolk County, approximately eight kilometers north of Brookhaven National Laboratory.

Archaeologically, little behavioral change is observable during the Woodland period on Long Island. Some artifact forms are altered (e.g., projectile point shape) and pottery seems to be increasingly important over time, but the long-established economic pattern of the exploitation of a broad range of natural resources continues. During the Late Woodland (circa A.D. 1000-1500) agriculture, especially the growing of corn and beans imported from the American tropics, becomes important in the economies of native groups living along the middle and upper reaches of the major river valleys (e.g., Hudson, Connecticut, Housatonic) in upstate New York and Connecticut. The importance of agriculture on the mainland coast and Long Island is still not well known, and is a topic much debated by archaeologists (Bendremer and Dewar 1994; Bernstein 1993; Ceci 1979, 1982; Lavin 1988; Silver 1981). Regardless of the importance of cultivated foods like com, beans, and squash in the diet, it is clear that Native peoples on the . coast continued to hunt, gather, and collect the abundant products of the natural environment. This strategic use of a diverse range of available resources characterized many native economies into the present century.

\section{Prehistoric Context: Central Suffolk County}

Eastern Long Island, including central Suffolk County and the region around Brookhaven National Laboratory, was probably first settled sometime prior to 10,000 years ago, after the retreat of the last Pleistocene glacier. Long Island was ice-free by 20,000 years ago (Sirkin 1995), however, the region was not suitable for human habitation until thousands of years later. The date of the first arrival is not known, and due to the dynamics of local geology will probably never be ascertained with any certainty. No sites dating to the Paleoindian period (Table 2) have 
been excavated on Long Island, but numerous characteristic fluted projectile points have been recovered (Gwynne 1982:39-40; Merwin 2000; Saxon 1973). Aside from these isolated surface finds and pieces that occasionally appear in private artifact collections, no substantial evidence of the earliest inhabitants of Long Island is present anywhere in the region.

Intensive occupation of Long Island by Native peoples began during Late Archaic times (roughly 4000-1000 B.C.). Sites dating to this period are often very large and contain dense and diverse quantities of artifactual materials. Further, they frequently contain great numbers of features such as pits, hearths, and post molds that also indicate a sizable Native American presence. Analysis of faunal materials suggest that populations were probably rather sedentary, living in fixed settlements for most of the year (Gwynne 1982). "Small-stemmed" projectile points (cf. Ritchie 1971), referred to as Wading River, Squibnocket, or Lamoka types are very common at Long Island sites dating to the traditionally-defined Late Archaic, although they are also sometimes found in association with ceramics.

On Long Island and elsewhere in the coastal Northeast, the Woodland period is typically identified by a single characteristic, ceramics. Coastal shell middens increase in frequency on Long Island during the Woodland period, and many of these have been studied in detail (Lightfoot 1988).

Site file listings at the New York State Office of Parks Recreation and Historic Preservation (SHPO), the New York State Museum (NYSM), and the Institute for Long Island Archaeology at SUNY Stony Brook indicate the presence of numerous Native American sites in the general vicinity of Brookhaven National Laboratory. Most of these are located near the Wading River estuary, approximately eight kilometers north of the project area, including the Wading River I and II localities (NYSM 5589 and SHPO A10302.000503), Shoreham I and II (NYSM 5592 and SHPO A10302.000506), Cusano (NYSM 5588), Split Rock (NYSM 5587), Riverview (NYSM 5591), and St. Joseph's Villa (NYSM 5593) locales on the western flanks of the Wading River marshlands (Ritchie 1959; Wyatt 1977).

Based on artifact typology, most of the Wading River sites appear to be multi-component (Late Archaic through Woodland periods). None of the sites seem to cover much more than an acre, and most contain shellfish remains (hard and soft clams, scallop, and oyster are the most 
common) along with pieces of bone from a variety of food species (e.g., deer, turtle, bird) and an occasional charred nut shell (e.g., hickory). In addition to the food refuse, the Late Archaic sites at Wading River yielded a broad array of lithic artifacts, most of which were made from locally abundant quartz cobbles. Numerous pit features (presumably used for cooking, storage, and/or refuse disposal) were excavated at Wading River, as were concentrations of fire-cracked rock and several hearths. This configuration of remains (bivalve shell, bone preserved in the shell matrix, pit features, concentrations of fire-cracked rock, tools and detritus from quartz cobble reduction) is typical of Late Archaic and Woodland sites on the north shore of Long Island.

The frequency of known sites deceases south of the Harbor Hill Moraine, but scattered loci of prehistoric activity have been encountered. The Kurovics Farm site, a light surface scatter of lithic material (SHPO A10302.000021; Billadello and Johannemann 1987) is located approximately six kilometers north of BNL. Although the landowner has reported finding artifacts on the property, no prehistoric materials were found during subsurface testing performed during a cultural resource management survey (Billadello and Johannemann 1987). The Lake Panamoka site (SHPO A10302.000470), nearly four kilometers north of BNL, is reportedly an extensive Late Woodland site on the western side of this large kettle pond. All over Long Island, kettle ponds such as Lake Panamoka were attractive settings to prehistoric peoples. Southwest of Lake Panamoka is the Tarkill Pond site (SHPO A10302.000471), on the grounds of Brookhaven State Park. The site (Table 1) possibly dates to the Late Woodland period.

Further to the south, "stray finds" are reported for sites A10306.000724 (one quartz flake) and A10306.000726 (one quartz tool) that were identified during a survey of Peconic River County Park (Johannemann and Schroeder 1980a)(Table 1). Both of these finds are located slightly less than two kilometers east of BNL.

The RidgeCo site (A10302.001834), a mixed historic and prehistoric site (with only lithics recovered), is located approximately 1.7 kilometers west of BNL, on the north side of Middle Country Road (Tracker 1996). Among the possible artifacts reported are quartz debitage (waste flakes produced during stone tool manufacture and/or resharpening) and cores, a scraper, an abrader, a mortar, and hammerstones. 
Four prehistoric sites (designated with the SHPO numbers A10302.000473 and A10302.000524 in the site files and as Sites 3-22, 3-18A, 3-18B, and 3-24 in the technical report) are reported along the Carmans River in Southaven County Park (Johannemann and Schroeder 1980b). One of these sites, A10302.000473, is located just over one kilometer southwest of BNL (Table 1).

Comparatively little is known about prehistoric settlement and subsistence patterns for the interior reaches of Long Island, as attention has traditionally focused on the island's coast (Lightfoot 1988). This bias may be seen in the Suffolk County Archaeological Association's Cultural Resources Inventory (Gonzalez and Rutsch 1979), where much of the interior portion of the county (including the project area) is characterized as an area "of low activity or insufficient data." The results of some preliminary studies suggest that many sites located away from the coast are "short duration camps or procurement stations" (Lightfoot 1988:38). These are sites where a limited ranges of activities were performed (such as hunting, nut collecting, or lithic raw material procurement), and their archaeological assemblages frequently contain a low diversity of artifactual remains.

The lack of attention given to small interior sites has serious implications for the understanding of regional patterns of settlement and resource use. In order to fully understand the nature of prehistoric settlement patterns on Long Island and other coastal areas, it is necessary to consider samples from a wide range of sites.

Archaeological research suggests that prehistoric hunter-gatherers on Long Island engaged in relatively low residential mobility (cf. Binford 1980); coastal habitation sites appear to have been occupied for months or even years before abandonment by the entire group. The frequency and importance of logistical mobility, where individuals or small task-specific groups made forays from the residential base to procure resources, is less clear. Part of the problem in understanding how the interior influenced coastal hunter-gatherer settlement, subsistence, and even social patterns, has been the perception that the interior of Long Island was lacking in useful natural resources.

Much of the central portion of eastern Long Island, including the BNL property, consists of pine barrens communities. These habitats range from oak-dominated oak-pitch pine forest, to 
pine-dominated pitch pine-oak forest, pitch pine-oak heath woodlands, dwarf pine plains, and pitch pine-scrub oak barrens (Reschke 1990). The plant communities within the pine barrens ecosystem thrive on sandy, dry, acidic, nutrient-poor soils, and typically can withstand drought and fire.

One problem with understanding prehistoric adaptation in the pine barrens concerns the origins of this ecosystem; specifically, whether or not the pine barrens of Long Island pre-date European arrival and occupation during the mid-seventeenth century (for details of this debate, see Hamilton 1998). Human activity can have a profound effect on the landscape. In the case of the pine barrens, fire is among the most important factors for determining the spatial extent of fire-favored pitch pine at the expense of deciduous trees.

Aboriginal use of fire for clearing and to create grazing areas is documented elsewhere in southern New England (Cronon 1983), but some researchers have suggested that Native American populations were too low on Long Island to have had any net effect (Turano 1983). Instead, they cite Euro-American exploitation (over-harvesting desirable hardwood species) and technology (the opening of railroad lines in the 1840s resulted in regular brush fires caused by sparks from passing trains) as responsible for the modern dominance of pine in this ecosystem (Turano 1983). However, early documents such as the 1734 New England Coasting Pilot clearly indicate the center of the island was "barren land" prior to significant Euro-American utilization. Pollen studies also support the interpretation that modern pine barrens are analogous to prehistoric pitch pine-oak forests that occupied the outwash plain in the center of Long Island since at least eight thousand years ago (Sirkin 1995).

The concept that the pine barrens are economically unproductive seems to reflect EuroAmerican values, where the usefulness of land is directly linked with its agricultural capability. Despite this perception, almost every type of patch in the pine barrens mosaic has useful natural resources (Villani 1997). Mammals including white-tailed deer, squirrel, raccoon, possum, fox, rabbit, and woodchuck, birds such as wild turkey and grouse, and reptiles like box turtle and black snake are abundant. Economically important plants found in large patches include blueberry, and nut-bearing trees such as oak and hickory. Of course, the presence of such resources does not necessarily mean that they were utilized by hunter-gatherers. However, 
analysis of coastal sites with good organic preservation suggests a broad subsistence base for Native peoples in this region.

Among the most productive settings in the pine barrens ecosystem are the kettle and coastal plain ponds that dot the eastern Long Island landscape. Besides potable water, these ponds offered a dense concentration of animal and edible plant species. The results of academic and cultural resource management studies indicate that, much like their coastal counterparts, the location of interior prehistoric sites appears to be heavily influenced by the close proximity of a freshwater source (Bernstein et al. 1996).

To date, only one large prehistoric site which resembles contemporary coastal residential bases has been identified in the pine barrens, the Twin Ponds site (Lightfoot 1988), located approximately six kilometers northwest of Brookhaven National Laboratory. Named for its location around two kettle ponds, this site contained pit features, concentrations of fire-cracked rock, and post-molds interpreted as house remains. Artifacts include projectile points and other bifacially-worked lithic tools, hammerstones, cores, lithic waste flakes, stone pestles, ceramics, and marine shell. Temporally-diagnostic stone tools are indicative of multiple occupations of the site over at least two thousand years.

Both the density and diversity of remains suggest that Twin Ponds was a residential camp from which families were able to readily exploit resources of the Long Island interior. Activities represented in this assemblage include house construction, cooking, stone tool production and maintenance, hunting, butchering, and plant processing.

The Twin Ponds site is markedly different from most other known sites in the pine barrens of eastern Long Island. More typical are comparatively small manifestations of prehistoric activity that are best interpreted as sites where a limited range of tasks were performed. This is reflected in archaeological assemblages which frequently contain a low diversity of artifactual remains. For example, a preliminary archaeological survey of the former Naval Weapons Industrial Reserve Plant in Calverton (approximately seven kilometers northeast of BNL) discovered two small prehistoric hunting stations located directly adjacent to fresh water ponds, while only one artifact was recovered from all test areas that were more than 100 meters from a pond or stream (Historical Perspectives 1996). Other regional surveys have identified 
very small manifestations of prehistoric activity distant from any fresh water source. These . manifestations, usually one to five artifacts, represent activities such as tool maintenance, loss, or discard that took place away from the main camps. These seemingly isolated finds are probably the most prevalent type of evidence of prehistoric activity found on Long Island (Bernstein and Lenardi 2001).

In summary, recent archaeological research suggests that the pine barrens of eastern Long Island were utilized by hunter-gatherers as part of a regional subsistence and settlement pattern. The foundation of this pattern is a broad subsistence base, encompassing diverse coastal and interior resources. The results of preliminary surveys suggest that a large number of sites located away from the coast are camps or stations that were used for short durations and for a limited range of activities, as reflected by frequently small assemblages with a low diversity of artifact types. Based on a consideration of environmental features, the results of site file searches, and previous archaeological research on eastern Long Island, Brookhaven National Laboratory, especially sections containing fresh water resources (e.g., the headwaters of the Peconic River), has a moderate to high sensitivity for the presence of prehistoric deposits. 


\section{HISTORIC PERIOD CONTEXT}

\section{Pre-World War I}

Permanent settlement by the English did not occur in central Suffolk County until the late seventeenth century. At the time of contact, the region was occupied by the Secatogue and Unquachog Indians, both speakers of the Mohegan-Pequot-Montauk Algonquian language (Salwen 1978). According to an early historian (Thompson 1839), the division between the deciduous forests on, and north of, the Ronkonkoma terminal moraine and the scrub oak and pitch pine barrens of the glacial outwash plain to the south also marked a cultural boundary between Native American groups (with the Secatogues to the north and the Unquachogs to the south).

By the time of European arrival there was little conflict as local Native Americans were already weakened by disease and from raids by the mainland Connecticut tribes. While there was constant fear of attack, there was little actual violence (Bayles 1874:4), and prime land and local power quickly passed to the white settlers. However, the Ryder Survey of 1670 refers to the southern two-thirds of present day Suffolk County only as "Sachem Land." This suggests that residual Native American groups may have continued to live throughout the region at least until the end of the seventeenth century.

The lands of present-day Town of Brookhaven were ceded from the Native Americans in a series of deeds dating from 1655 to 1677 (Hazelton 1925). A huge parcel in the interior of the Town of Brookhaven near its eastern border (including the BNL property) was purchased from representatives of the Secatogues by Colonel William Smith in 1691. However, there is no documentation of English occupation in the interior portion of Brookhaven until the eighteenth century. Instead, the earliest English settlements were generally located along the coastline of Long Island, at places such as Wading River, approximately eight kilometers north of the project area.

English settlement in the interior of Brookhaven township commenced in earnest after the division of lands along Middle Country Road (New York State Route 25, north of the main 
section of BNL) was voted upon in 1730 (Bailey 1949). The earliest recorded Euro-American settlement in the vicinity of BNL dates to 1728 , when Stephen Randall established a farm in the nearby hamlet of Ridge (Bayles 1874).

Several roads connecting coastal villages of the north and south shores of Suffolk County were established in the late seventeenth and eighteenth century (Bailey 1949). However, it was the advent of the railroad, and later the automobile, which irrevocably changed the nature of the interior reaches of the county. The railroad provided an economical means of transporting both people and bulk goods. By 1844, trains on the Brooklyn-Greenport line were running regularly near the southern edge of the BNL property. Settlement of the interior reaches of Suffolk was facilitated (as well as encouraged) by the railroad. In the early twentieth century, a spur from the main railroad line was built to facilitate the World War I era construction of Camp Upton (see below).

Little changed in the lifeways of the Euro-American colonists of Suffolk County until the American Revolution. Early in the conflict Long Island attracted British attention because of the island's proximity to the major port of New York Harbor, and also to Connecticut and Rhode Island. In addition, Long Island was used as a major resource for provisioning British troops, and the local agrarian economy was disrupted as the British stripped the region of food, timber, and herd animals (Luke and Venables 1976).

Industry and water-borne trade were interrupted with British occupation of Suffolk County, but life gradually returned to the earlier pattern after 1781 . Following the Revolution and into the mid-nineteenth century, the settlement of the interior regions of the Town of Brookhaven proceeded slowly and was concentrated along main thoroughfares such as Middle Country Road (New York State Route 25). Developing communities formed a linear farming district surrounded by forests, well-situated to utilize this important overland east-west stage route. Most early structures in Ridge were located on the north side of Middle Country Road, the southern boundary of the Colonial "Great Lots" which extended from Long Island Sound in the north to the middle of the island. By the 1870 s, Ridge was "a scattered settlement of a dozen houses... in the midst of woodland" (Hazelton 1925:818). 
Population growth continued slowly during the late nineteenth and early twentieth century, while the linear settlement pattern along Middle Country Road was maintained. Following World War II, housing developments were built as the population in eastern Brookhaven Town increased dramatically and farming diminished in economic importance.

Brookhaven National Laboratory is bounded on the north and west by the hamlet of Ridge, on the north by Brookhaven State Park, on the east by Peconic River County Park, and on the south by the hamlet of Yaphank. As mentioned above, the first recorded settlement at Ridge dates to 1728, when Stephen Randall established a farm on Whiskey Road (Bayles 1874). Stephen Randall gained local fame during the American Revolution when he organized a company of minutemen to defend area homesteads against the Crown. Ridge is identified on some early maps as "Randallville," since most early residents belonged to this family. The community was also known as Ridgeville or Ridgefield prior to the opening of the post office in 1949. The name Ridge is for the prominent geological feature on the north side of the hamlet (Newsday 1998:H95).

The site files contain information on one known historic period archaeological site in Ridge less than two kilometers from BNL. The RidgeCo site (SHPO A10302.001834) has a late nineteenth to early twentieth century component (mainly building foundation remains). In addition, the Randall House and Randall Cemetery (SHPO 10302.000940 and 10302.000941) are standing west of William Floyd Parkway on Whiskey Road, and the National Register listed eighteenth century Smith Estate "Longwood" is west of William Floyd Parkway on Longwood Road, both opposite BNL property.

Brookhaven State Park was originally part of Camp Upton and the Upton National Forest, as the large tract was known during the period between the world wars. The parcel became state parkland in 1971, but remains largely undeveloped except for a few roads and a rifle range. The park has been inventoried by the Office of Parks, Recreation, and Historic Preservation (SHPO 10302.001878), and found to be ineligible for the National Register. There is one documented historic period archaeological site in Brookhaven State Park, trenches possibly from World War I activity at Camp Upton observed near the modern rifle range in the park (SHPO A10302.0000549). The site inventory form indicates the high likelihood for the presence of 
additional Camp Upton resources within unsurveyed portions of Brookhaven State Park.

However, it is possible that the trenches in Brookhaven State Park may have served a function other than World War I Army training, as this tract is not shown as part of Camp Upton on pre1920 maps (see below).

The headwaters of the Peconic River originate near Peconic River County Park, and the availability of fresh water and associated wetlands resources undoubtedly attracted prehistoric hunter-gatherers as well as later Euro-Americans. The most significant historic period land use in the park was the cultivation of cranberries. During the late nineteenth century, Suffolk County was the third largest producer of cranberries in the country, and the coastal plain ponds of the Peconic headwaters provided an ideal growing environment. The cranberry industry in Suffolk County began to decline in the 1930s, when competition from larger bogs in Massachusetts and New Jersey lowered market prices, and fireworm infestations ruined the Long Island crops (Johannemann and Schroeder 1980c).

There are three historic period archaeological sites reported as being in or adjacent to Peconic River County Park. The Horn Tavern Farm site (SHPO A10306.000278) is known through documentary sources; there is no evidence of this Colonial period tavern building on the ground surface, and no subsurface testing has been conducted to investigate the integrity and research potential of the site. The other two sites both consist of late nineteenth through twentieth century brick foundations with associated domestic refuse (SHPO A10306.000727 and A10302.000536).

The small rural community of Yaphank was established in the mid-eighteenth century as Millville (the name was changed when the post office opened in 1845). Yaphank witnessed a local development mini-boom following the opening of the railroad. Several community structures were constructed in the early 1850 s. By the 1870 s, Yaphank was a thriving village with two grist mills, two lumber mills, two blacksmith shops, and two wheelwright shops, as well as a lumber yard, a printing office, an upholstery shop, and one general store. The village was also home to two doctors, a cobbler, a dressmaker, and a butcher (Bayles 1874).

Besides the milling industry, agriculture also played an important role in the early economy of Yaphank. The Suffolk County Poor Farm was established in 1870 to provide food 
and shelter for indigent residents of the county. The 170 acre tract of "excellent quality" level . land (Bayles 1874:257) located slightly less than two kilometers southwest of BNL is currently operated by the Cornell Cooperative Extension as the Suffolk County Farm and Education Center. The Suffolk County Poor Farm is significant as a social welfare institution, and also as a well-preserved rural landscape.

Yaphank's growth was slowed at the beginning of the twentieth century, when competition from inland grain producers and the introduction of electrically-powered mills rendered the hydro-powered mills of the village obsolete. Many local businesses closed, though houses and farms remained. The hamlet witnessed little growth during this century, resulting in the preservation of several early structures. Yaphank's Main Street was designated a Brookhaven Town historic district in 1985 (SHPO 10302.000029). The extension of the Long Island Expressway (I-495) to Exit 67 in Yaphank during the 1970s has had some impact upon the rural quality of the village.

The closest known historic period archaeological sites in Yaphank are clustered around the Carmans River, and consist of mid-nineteenth century house remains (SHPO A10302.000465 and A10302.000469), a refuse scatter of bottle glass and shell (SHPO A10302.000472), and the early nineteenth century Homan Mill earthen mill dam (SHPO A10302.000523).

A survey of late eighteenth through early twentieth century maps suggests that the Brookhaven National Laboratory property witnessed minimal use other than possible hunting, cordwood harvesting, and agriculture until the twentieth century. The 1797 Hulse Survey of the Town of Brookhaven (Figure 3) shows much of east-central Brookhaven as open space, "Barren Sruboak Land" west of the headwaters of the "Peaconick River." The dirt road illustrated between Wading River on the North Shore and the mills at Yaphank to the south approximates the courses (north to south) of modern Ridge Road, Raynor Road, Smith Road, and Longwood Road, all west of modern William Floyd Parkway. The closest structures to the project area on the 1797 map are the Randall House on Middle Country Road in what is now Ridge, Horn Tavern, a structure depicted at the north end of "Long Pond" (now Lake Panamoka), and mills along the Carmans River at Yaphank. 


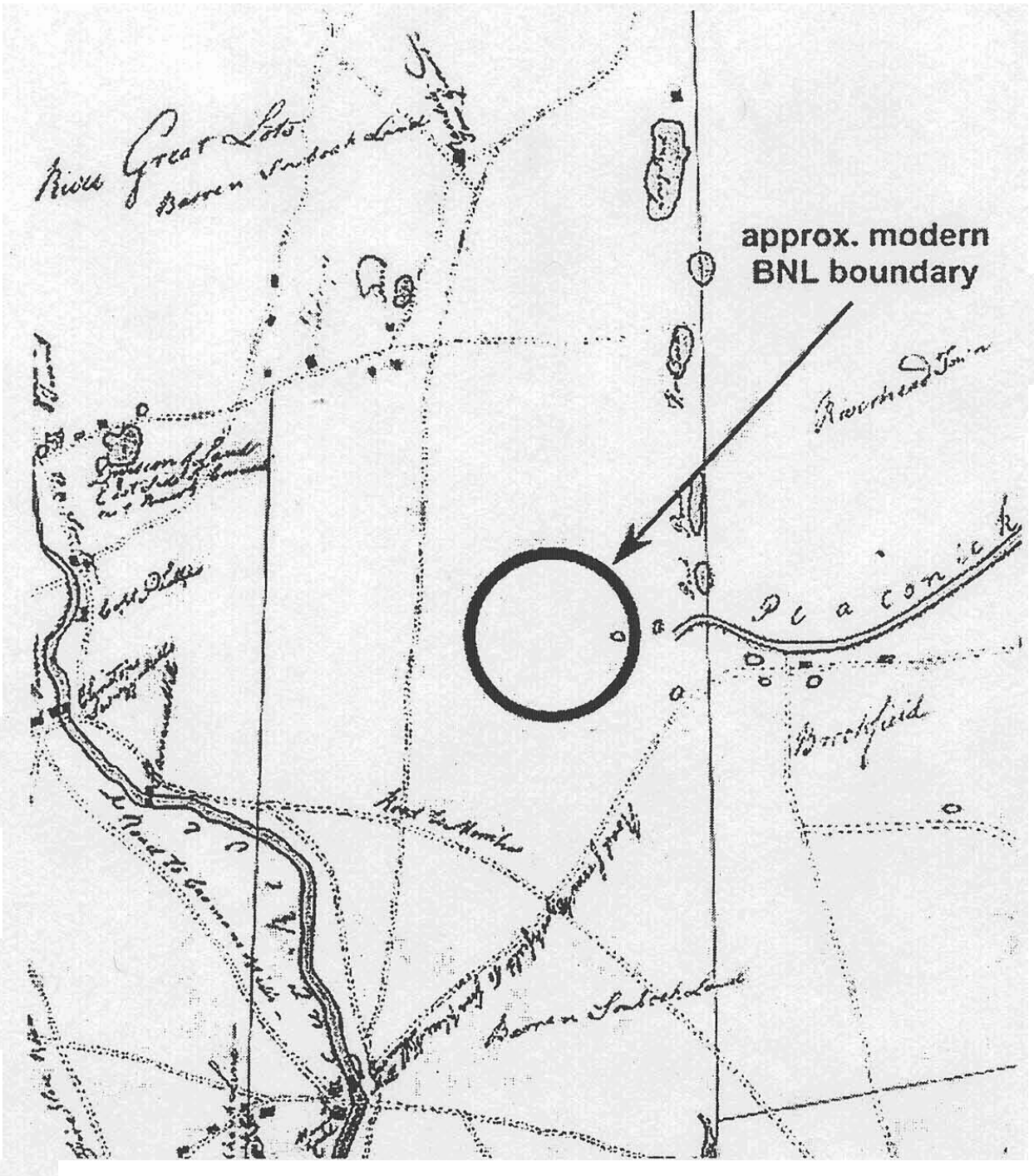

Figure 3. 1797 Hulse Survey of the Town of Brookhaven. The BNL property is shown as undeveloped land west of the headwaters of the "Peaconick River." 


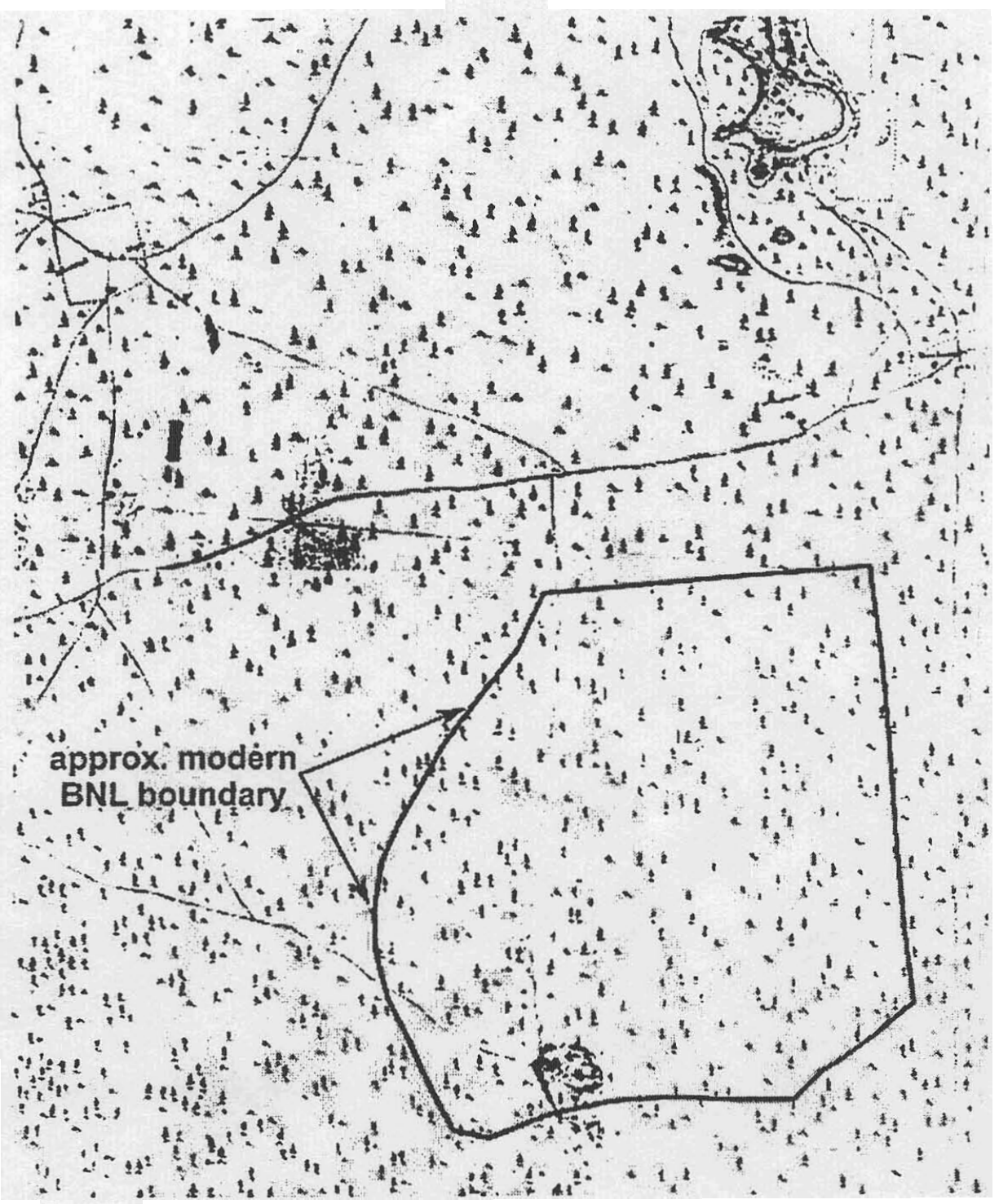

Figure 4. 1838 United States Coastal Survey showing the BNL parcel as undeveloped woods. 


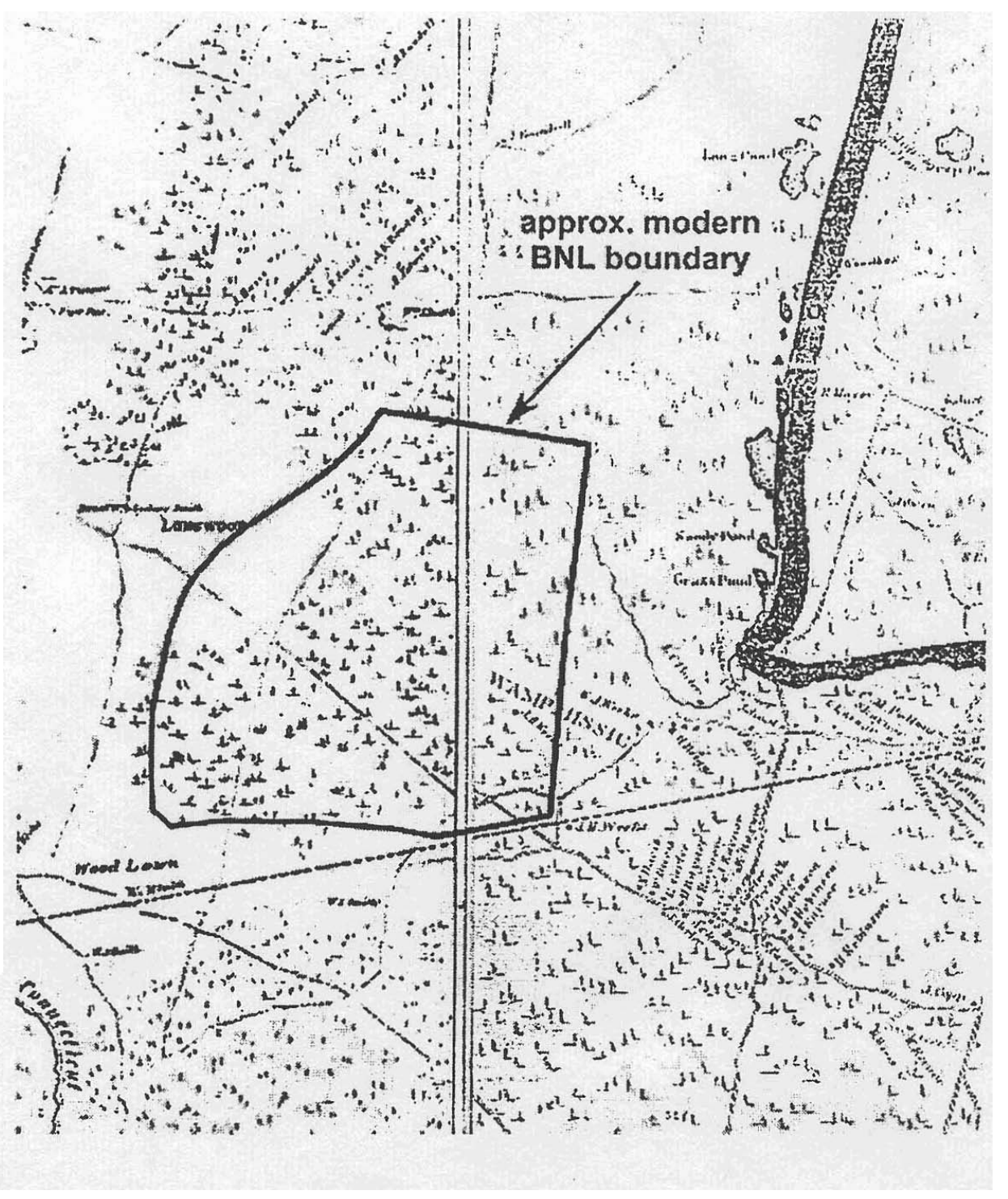

Figure 5. 1858 Chace Map of Suffolk County. The BNL property is depicted as undeveloped woods. The northwest-southeast road between the Longwood Estate and "Wampmissic" is on or near the modern course of Princeton Avenue within the project area. 
The 1838 United States Coastal Survey (Figure 4) is among the earliest maps showing detailed topographic and man-made features on the landscape of Long Island. Here, a small settlement at Wading River and another community on Carmans River in Yaphank are depicted, but nearly all of the land in between is illustrated as undeveloped woods crossed by a few dirt trails. A similar land use pattern is shown on the 1843 Mather and Smith Geological Map of Long and Staten Islands.

The 1858 Chace Map of Suffolk County (Figure 5) and 1873 Beers Atlas of Long Island (Figure 6) illustrate similar settlement patterns to earlier maps, although by this time the railroad had reached Brookhaven, and the extent of woodlands in central Brookhaven was greatly reduced. Settlement of interior regions of Suffolk County was facilitated by the railroad, as reflected by the growth of communities like "Wampmissic" and Manorville south and east of BNL. The location of the Weeks house shown in the extreme southeast corner of the project area on Figure 6 may have stood within or adjacent to the modem boundaries of BNL, but this structure does not appear on any twentieth century maps. Despite increasing population throughout the interior reaches of Brookhaven township, nearly all of the BNL property is depicted as undeveloped woods on the 1858 map, and as vacant land on the 1873 map. Similarly, the project area is shown as open space on the 1896 Hyde Atlas of Long Island (Figure 7). 


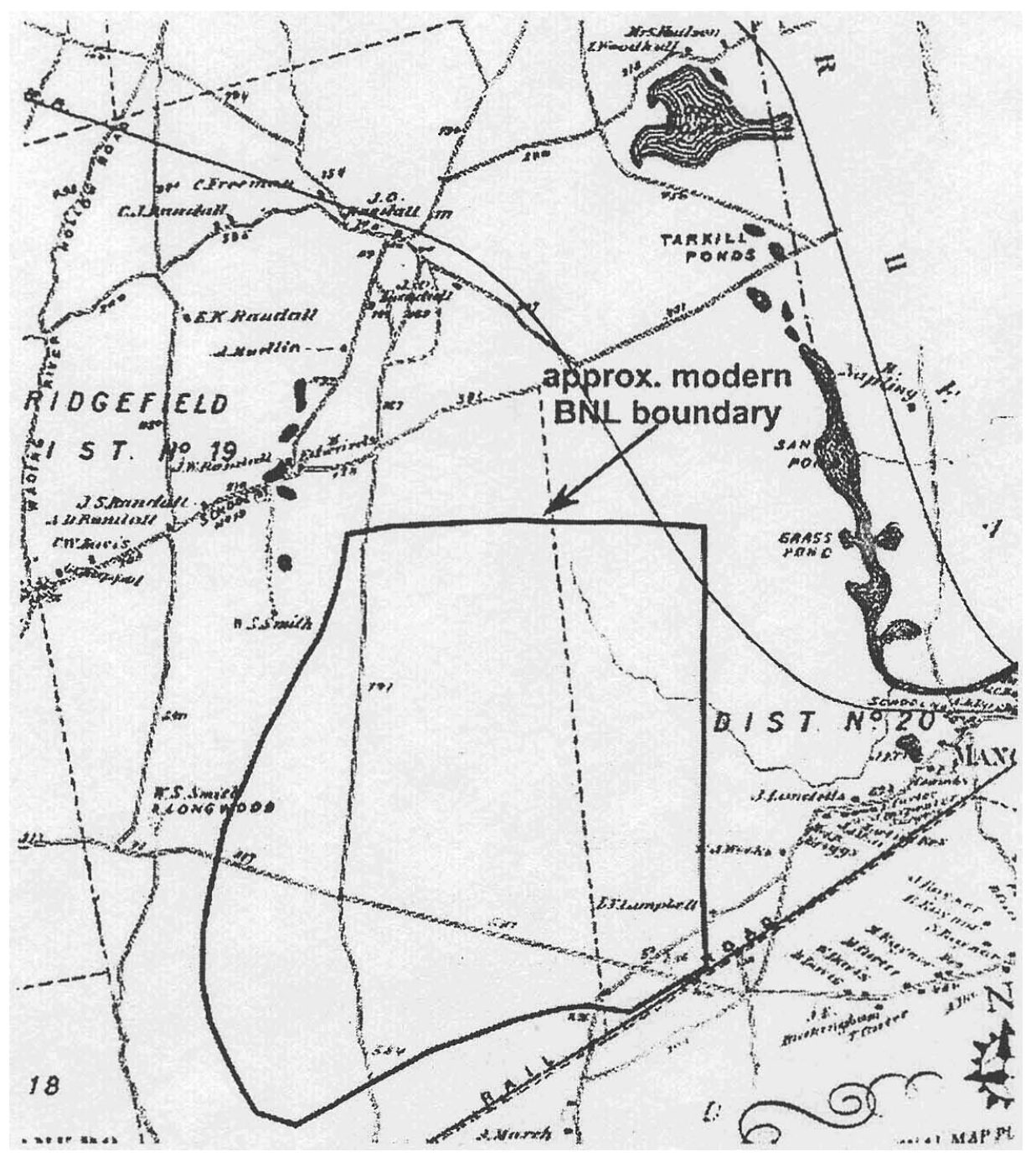

Figure 6. 1873 Beers Atlas of Long Island showing the location of the project area. The two roads illustrated within the BNL property are on or very near the modern courses of Upton Road (north-south) and Princeton Avenue (northwest-southeast).

Despite increasing population in central Brookhaven township, the project area remained open, undeveloped land. 


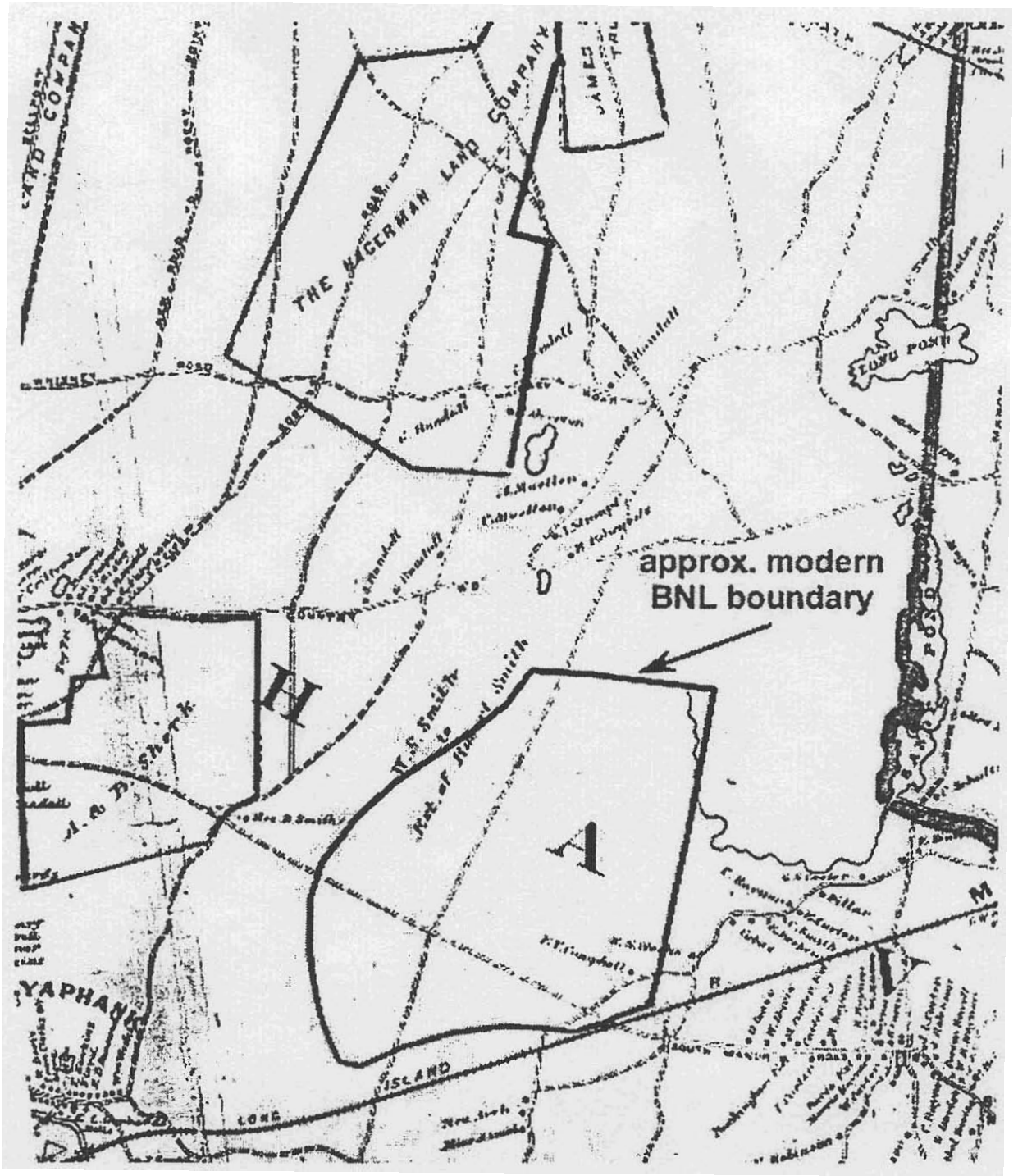

Figure 7. 1896 Hyde Atlas of Long Island showing the BNL property as open space. 


\section{World War I Camp Upton}

Shortly after the United States declared war against Germany in April 1917, mobilization for the war effort commenced and several training cantonments were built throughout the country. The site of Camp Upton was selected for one of these cantonments because of its proximity to New York City (the source of thousands of recruits), and access to water and electricity.

The Federal government acquired approximately 40 square kilometers ( 15 square miles) of central Long Island woodland in June 1917 (Figures 8 through 10), and construction of Camp Upton was contracted to the Thompson-Starrett Company of New York. Construction of the facility required the clearing of over 560 hectares ( 1400 acres) of pine barren forest. The main area of the camp was located near the center of the property (Figure 10), with drill grounds provided on all sides, taking care that the prevailing winds would not blow over the stables before reaching the barracks (Coyne 1919; Meyers 1918).

Camp Upton received its first draftees on September 10, 1917 (Figure 11), although the official completion of the facility was not until December of that year (Dwyer 1970a). A total of 1719 buildings was constructed, many of which were built assembly-line style (Figure 12), so that once the technique had been perfected, a 30 by 60 foot ( 9 by 18 meters) building could be raised in about five minutes (Donahue 1918). Barracks, stables, and warehouses were wood framed buildings set on wooden post foundations. Most of the lumber used was a low grade of unseasoned southern yellow pine (Meyers 1918).

Camp Upton (named after Civil War Major General Emery Upton) was active between September 1917 and October 1918, and served as the training camp of the Army $77^{\text {th }}$ Division under the leadership of Major General J. Franklin Bell (Figure 13). Most of the recruits were from the New York Metropolitan area, and were ethnically and racially diverse. AfricanAmerican men were segregated in separate barracks. By October 1917, 30,000 soldiers were being trained at Camp Upton (Dwyer 1962)(Figure 14). The $77^{\text {th }}$ Division was recognized for valor and skill during a major campaign in the Argonne Forest, France, in August of 1918.

A major component of training was instruction in trench warfare, a military technique which reached its peak during World War I. European officers instructed the Camp Upton 
recruits in the methods of trench construction, as well as "the technique of going over the top, throwing hand grenades, protecting themselves from... machine gun fire, and crawling through barbed wire entanglements" (Dwyer 1970b:55). An extensive network of training trenches was excavated throughout Camp Upton, sections of which are extant on the Brookhaven National Laboratory property. Sections of the remnant trenches previously have been determined to be eligible for the National Register of Historic Places (Tim Green, personal communication, 2000). Among the types of trenches identified during a mid-1970s cultural resource investigation of a portion of BNL (Johannemann and Schroeder 1977, 1978) are approach trenches, communication trenches, firing trenches, and local trenches. Each of these trench types served a particular function on the battlefield, as reflected by their design (U.S. Army Corps of Engineers 1917).

After Armistice Day in November 1918, Camp Upton became the demobilization center where the $77^{\text {th }}$ Division was discharged. This operation was completed in May 1919, and a government order closed Camp Upton the following year. Approximately 1,660 structures, utilities, and even livestock were sold at public auction in August 1921, and the entire camp was dismantled and cleared in three days (Bayles 1977). Only two structures remain in their original location from World War I era Camp Upton, Buildings 455 and 482 . Both are probably extant because they are masonry structures, which would have been difficult to remove from the site (Bernstein et al. 2001).

The 1904/1920 United States Geological Survey topographic map of Moriches, New York (15 minute series; Figure 8) outlines the extent of lands acquired by the Federal government for World War I Camp Upton. The parcel north of Middle Country Road (New York State Route 25), now Brookhaven State Park, is not included within the boundaries of Camp Upton as shown on the 1904/1920 map. Land north of Middle Country Road is identified as belonging to the North Shore Development company on the 1917 Hyde Atlas of a Part of Suffolk County. The 1917 Hyde Atlas (Figure 9) does not show the location of individual buildings or other manmade landscape features, but indicates that at the time the map was drawn "extensive improvements and buildings [were] now under construction." These improvements and the general layout of the cantonment are depicted on a U.S. Army Quartermaster Corps map of Camp Upton (Figure 10) dated October 1917. By the time of the 1930 Dolph and Stewart Atlas of 
Suffolk County (Figure 15), nearly all of the World War I era buildings had been removed from the site, and the Federal government landholdings (identified as the Upton National Forest) extended north of Middle Country Road, including what is now Brookhaven State Park.

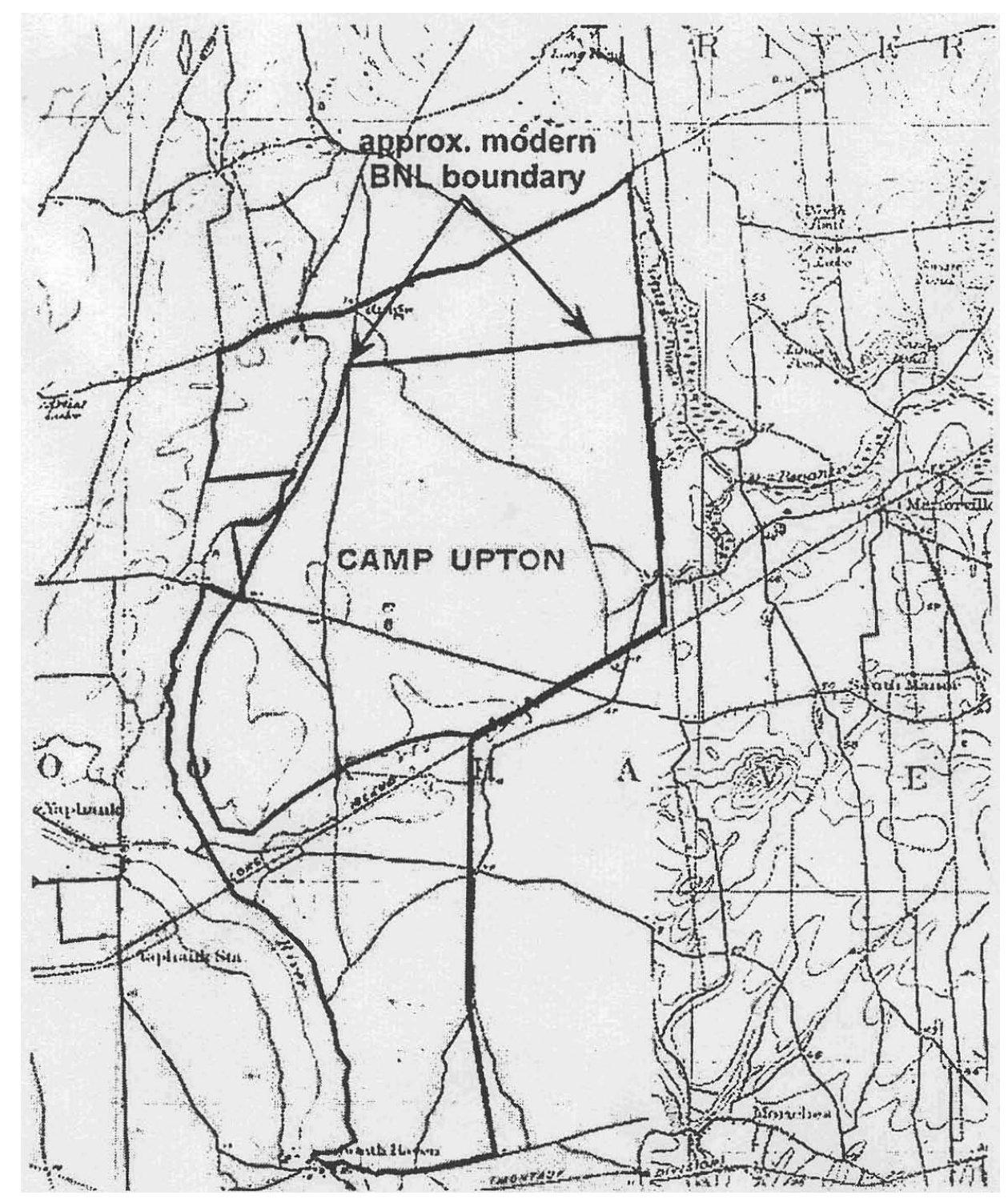

Figure 8. 1904/1920 USGS topographic map of Moriches, New York (15 minute series) showing the extent of World War I Camp Upton. 


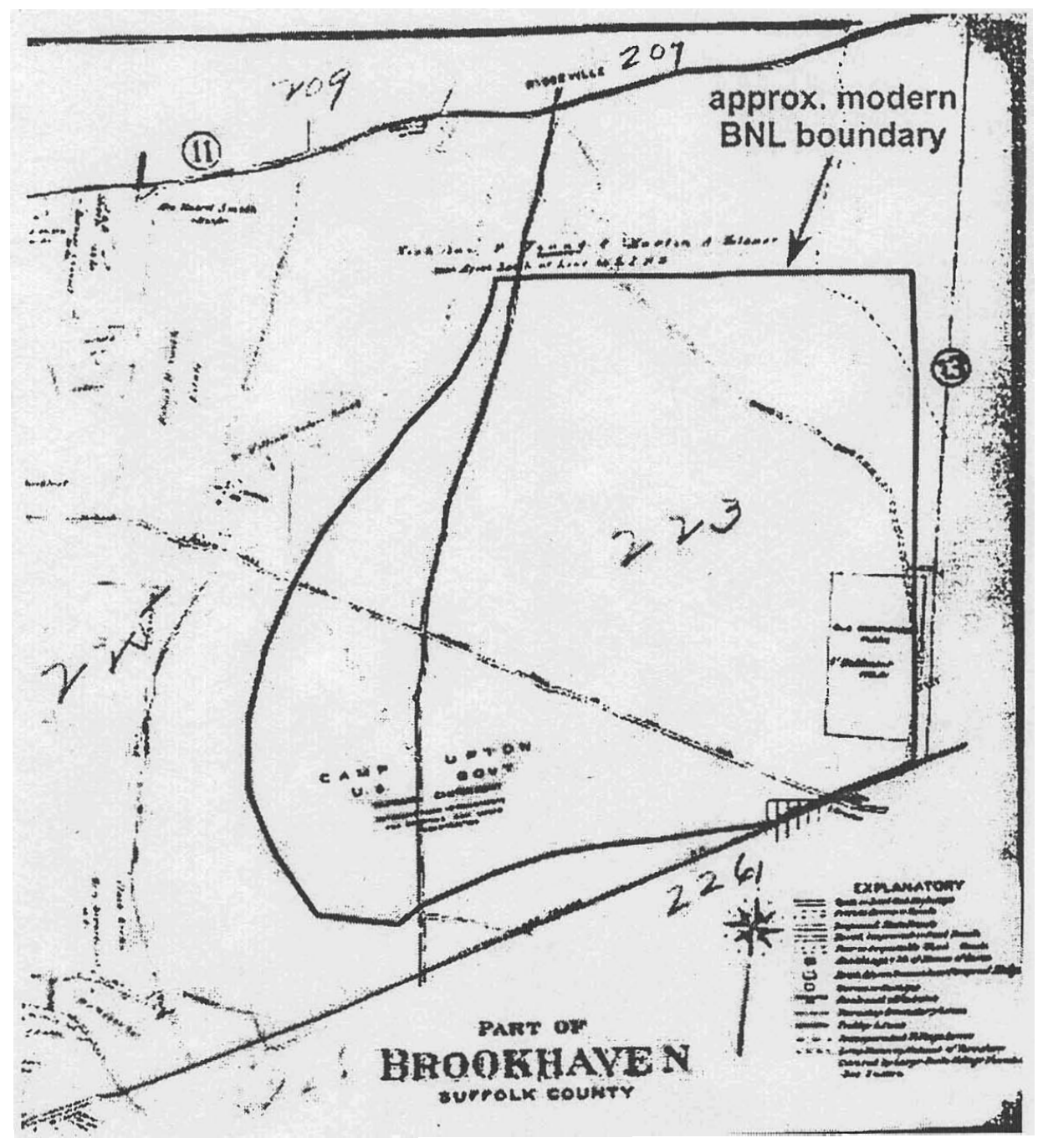

Figure 9. 1917 Hyde Atlas of a Part of Suffolk County illustrating the general location of the Army cantonment at Camp Upton. Land north of what is now BNL property is identified as belonging to Young and Metzner, while land on the north side of Middle Country Road in "Ridgeville" was identified as the holdings of the North Shore Development company. 


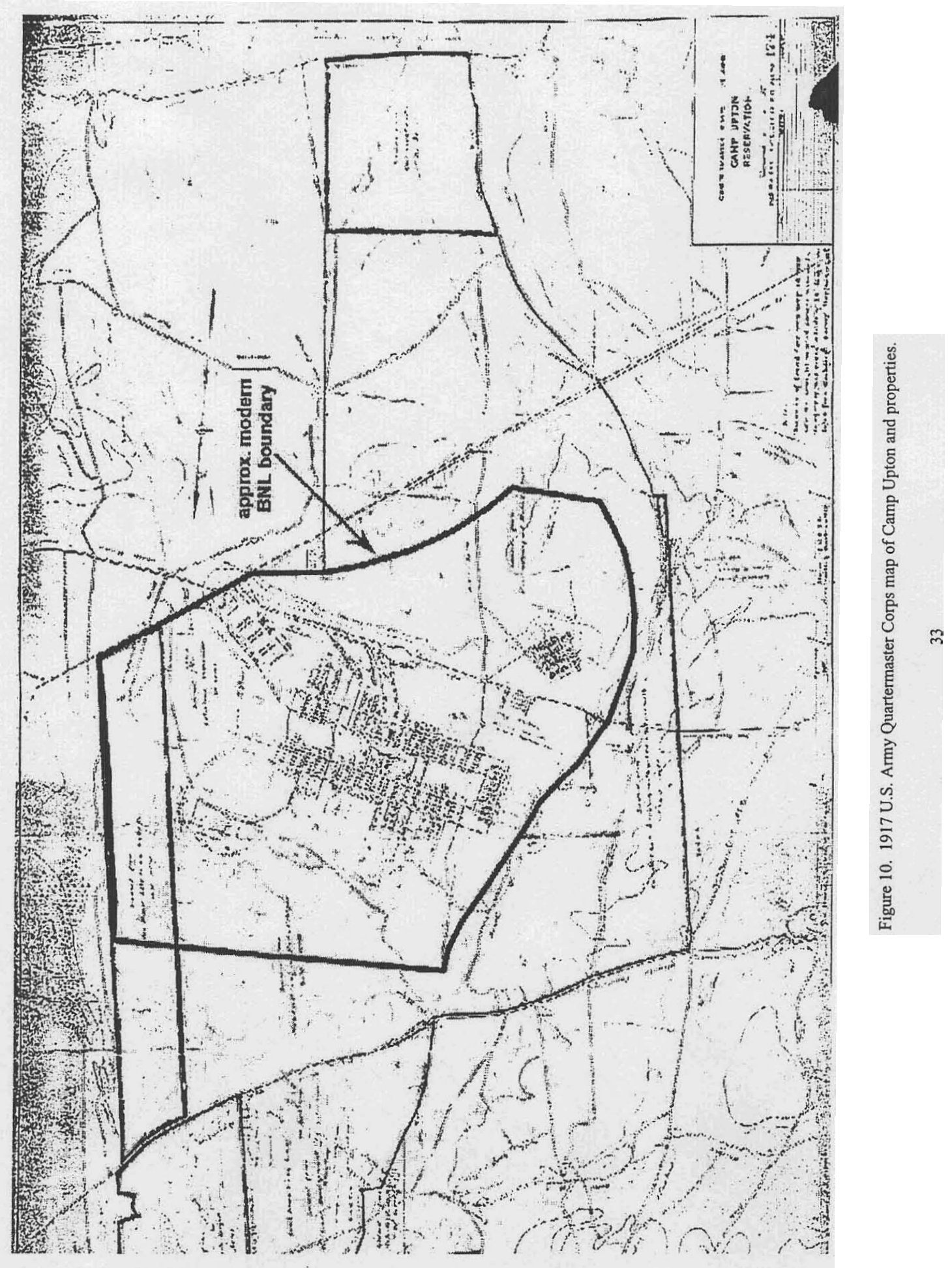




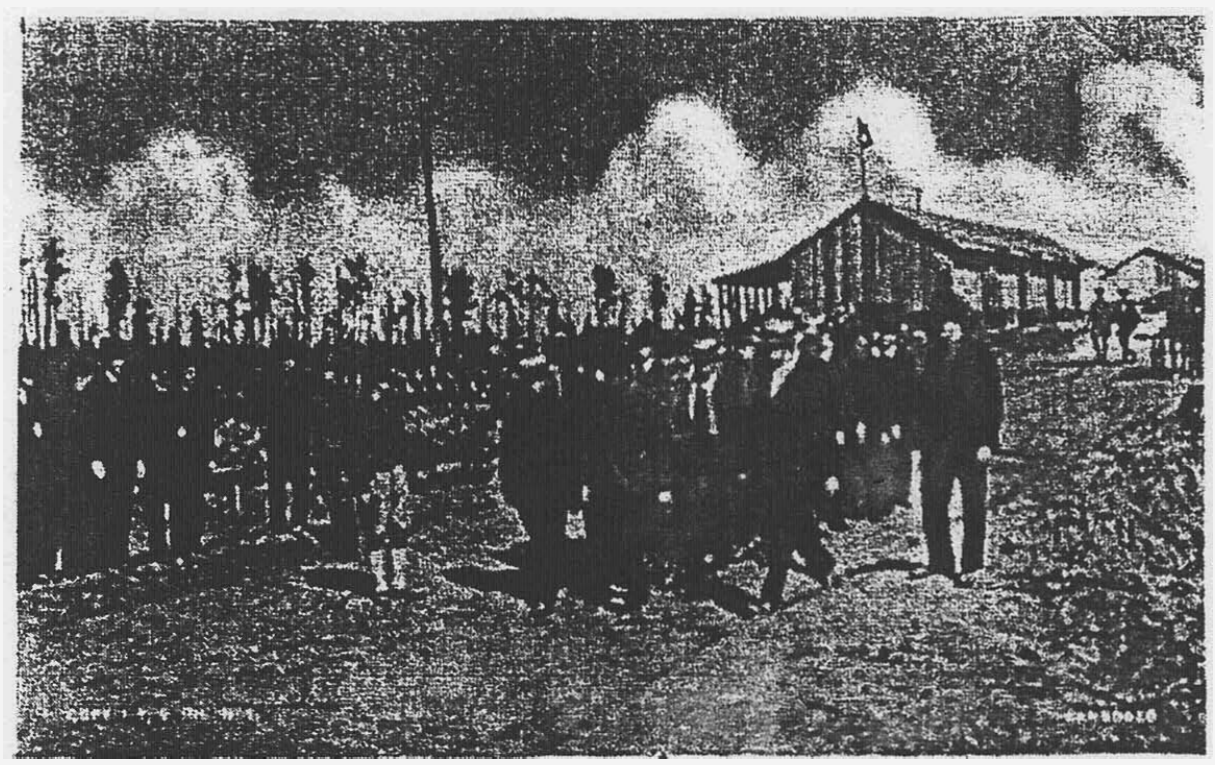

Figure 11. Circa 1917 postcard showing draftees arriving at the Camp Upton rail station.

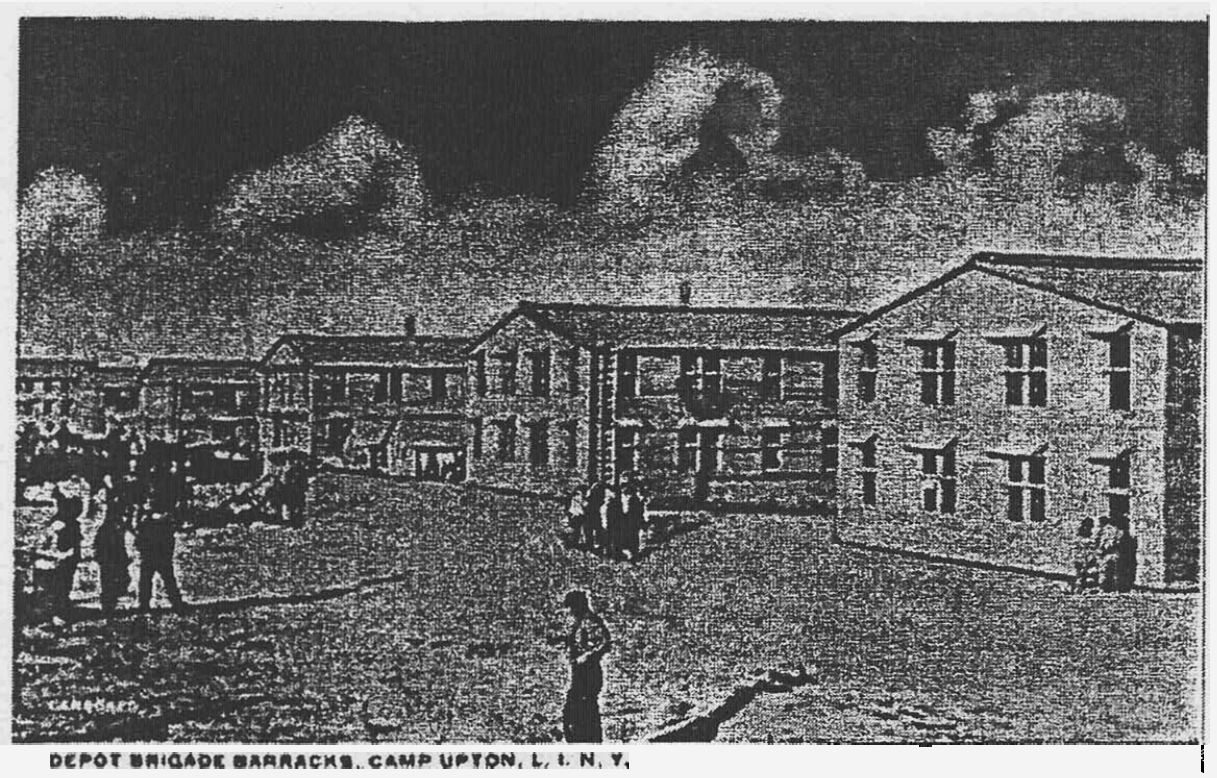

Figure 12. Postcard showing a typical view of barracks at Camp Upton during World War I. 


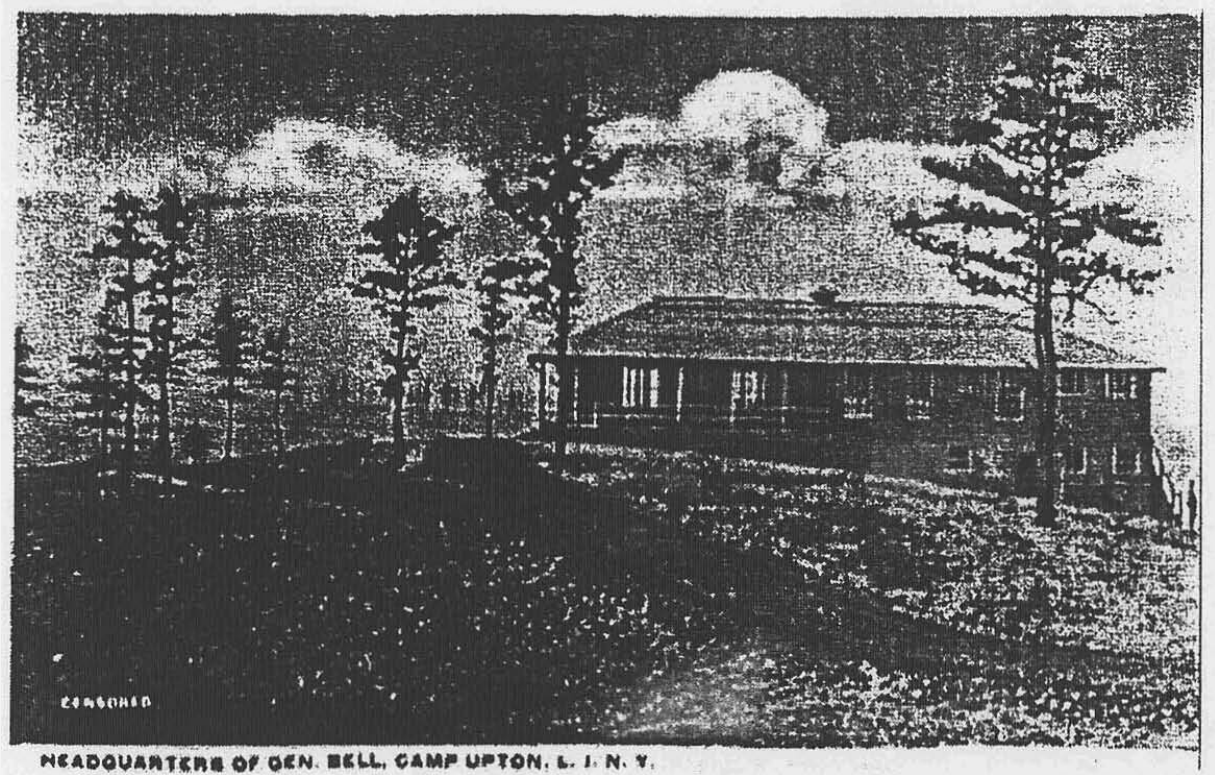

Figure 13. World War I Camp Upton command headquarters. Note sparse vegetation on the outwash plain in the background.

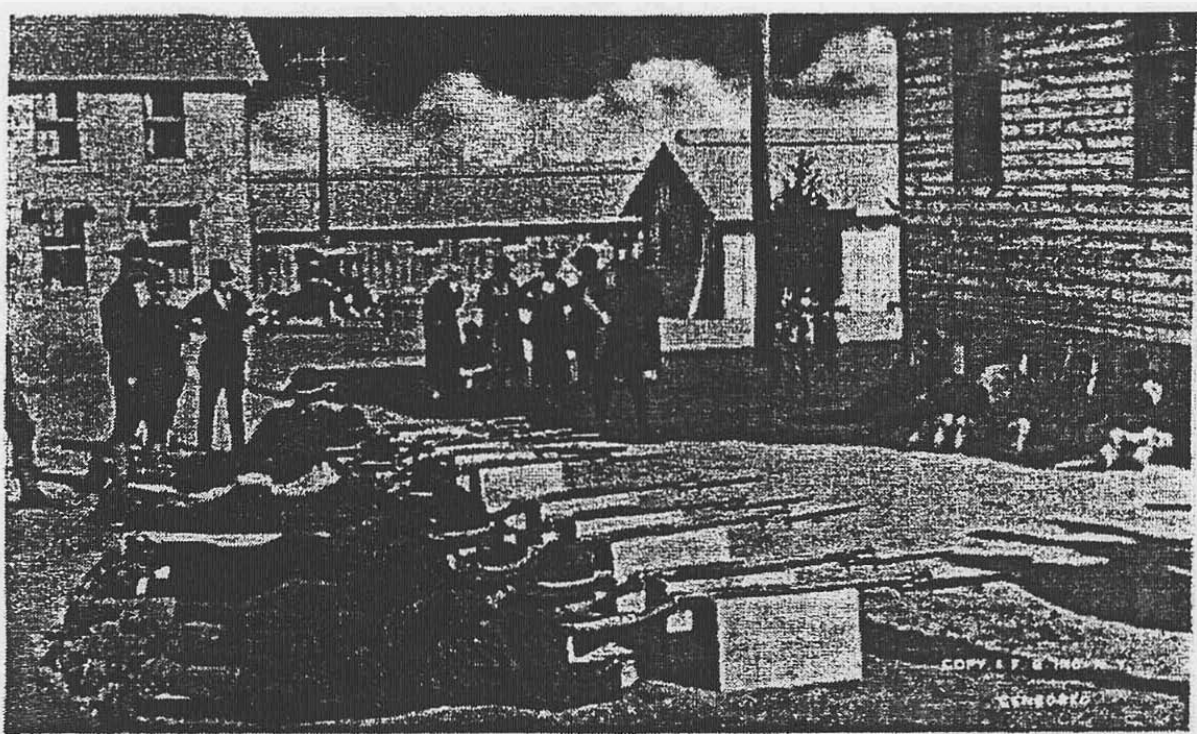

VIEW AT CAMP UPTON, L I:N $Y$

Figure 14. Postcard showing soldier training at circa 1917 Camp Upton. 


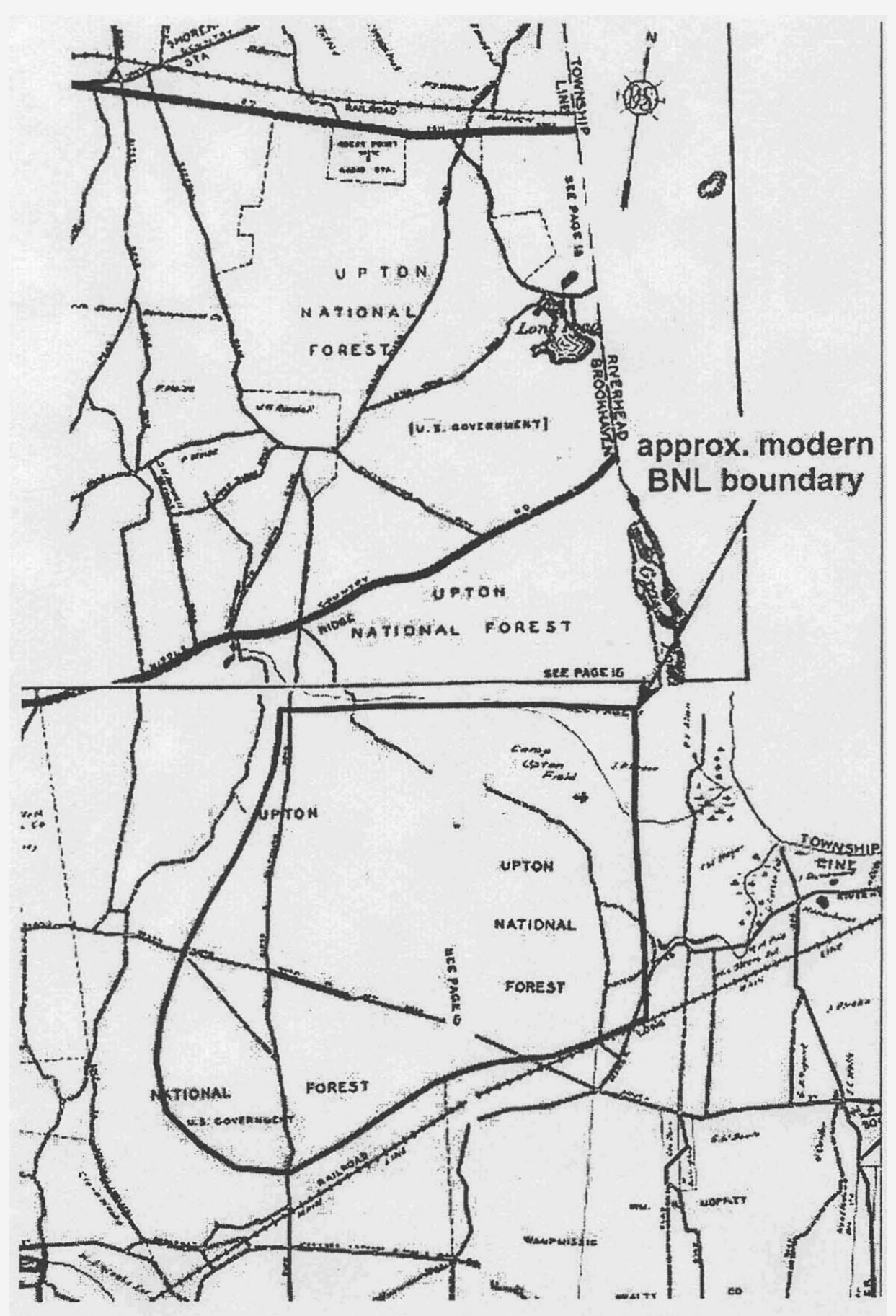

Figure 15. 1930 Dolph and Stewart Atlas of Suffolk County showing the extent of "Upton National Forest" beyond the modern boundaries of BNL. 


\section{Civilian Conservation Corps}

In 1933, President Franklin Roosevelt established a program known as the Emergency Conservation Work, later called the Civilian Conservation Corps (CCC), in an effort to provide income to otherwise unemployed men during the Great Depression. Laborers lived in group camps, and were active in soil conservation, disaster relief, and parks improvement throughout the country. By the time the program was terminated in 1942, the CCC had employed more than two million men at over 2,500 camps, making the CCC one of the most extensive and successful of the Depression era social programs (Salmond 1967).

During the mid-1930s, the CCC developed an 8,000 acre tract, including Camp Upton, as a state demonstration forest and game preserve. More than $800 \mathrm{CCC}$ workers cleared fire lanes, planted grains to attract wildlife, and reforested much of the cleared camp with approximately two million pine and locust saplings. In addition, because nearly all structures had been removed from the site of Camp Upton by 1921, CCC workers built their own barracks and other support structures.

There were four CCC work camps stationed at Camp Upton, or Upton National Forest as it was called in the 1930s (Figure 15). Each of the camps consisted of approximately two hundred men, and work began in 1934. Three of the companies were involved with constructing fire breaks and trails, digging water holes to aid in forest fire fighting, and with reforestation. The fourth company established a public shooting game preserve (now Brookhaven State Park)(Middle Island Mail 1935). By late 1935, two of the work camps were dismissed, followed shortly by the removal of a third camp in January 1936 (Middle Island Mail 1936).

The CCC occupied the BNL landscape for a relatively short period, resulting in few traces other than acres of propagated pine trees and the two extant buildings (Buildings 30 and 51)(Bernstein et al. 2001). However, between 1934 and 1936, more than 1,000 acres were planted with sapling trees, more than 700 acres were planted with grain, more than fifty miles of fire breaks and 26 miles of truck trails were constructed, nearly three miles of telephone line were laid, and several water holes were dug (Middle Island Mail 1936). 


\section{World War II Camp Upton}

Much of the CCC reforestation efforts were wasted when Camp Upton was rebuilt and reopened in 1940, as underbrush and saplings were cleared and roads and sewers improved. Camp Upton served primarily as an induction center for thousands of World War II Army draftees until the induction center was moved to Fort Dix, New Jersey in 1944. Camp Upton was then converted into a rehabilitation hospital for wounded soldiers. Recreational therapy for the returming convalescents required the construction of facilities such as a bowling alley, swimming pools, and tennis courts. In addition to providing services to returning American soldiers, Camp Upton briefly served as a prisoner-of-war camp for approximately 840 German men in 1945-1946 (Johannemann and Schroeder 1978:6-7). The general land area used during the World War II period at Camp Upton is shown in Figure 16.

After World War II, Camp Upton was transformed into the site of a new government laboratory. In July 1946, the property was transferred from the Army to the Associated Universities Incorporated in conjunction with the Atomic Energy Commission to form a peacetime (non-weapons) atomic research facility. The former Camp Upton site was selected as a compromise, as it was accessible to research institutions throughout the Northeast, several miles from heavily populated areas, and a large government parcel allowing for future growth. In addition, approximately 300 structures built for the World War II operation of Camp Upton were vacant and available for conversion into research laboratories and offices (Dwyer 1966:8). An active demolition and new construction program reduced the number of World War II era buildings (wood frame barracks and cement block structures) to about 140 by the mid-1960s.

\section{Historic Period Summary}

In summary, there is one documented historic period archaeological site within the BNL property, the World War I era trenches (two locations inventoried by SHPO as A10302.000474 [Appendix]). Other than the Weeks house (shown on the 1858 map, which may have stood within or adjacent to the southeast corner of the project area), there are no map documented structures within the project area prior to the twentieth century, and it is likely that the project area witnessed little use other than sporadic hunting and cordwood cutting before the parcel was 
acquired by the Federal government for Camp Upton. Twentieth century occupation of Camp Upton, especially during the World War I (1917-1921), CCC (1934-1936), and World War II (1940-1946) eras, has resulted in significant changes to the landscape, with activities ranging from clearing (along with removal of tree stumps by dynamite), cutting, filling, grading, excavation of World War I training trenches and CCC water holes, to road and building construction.

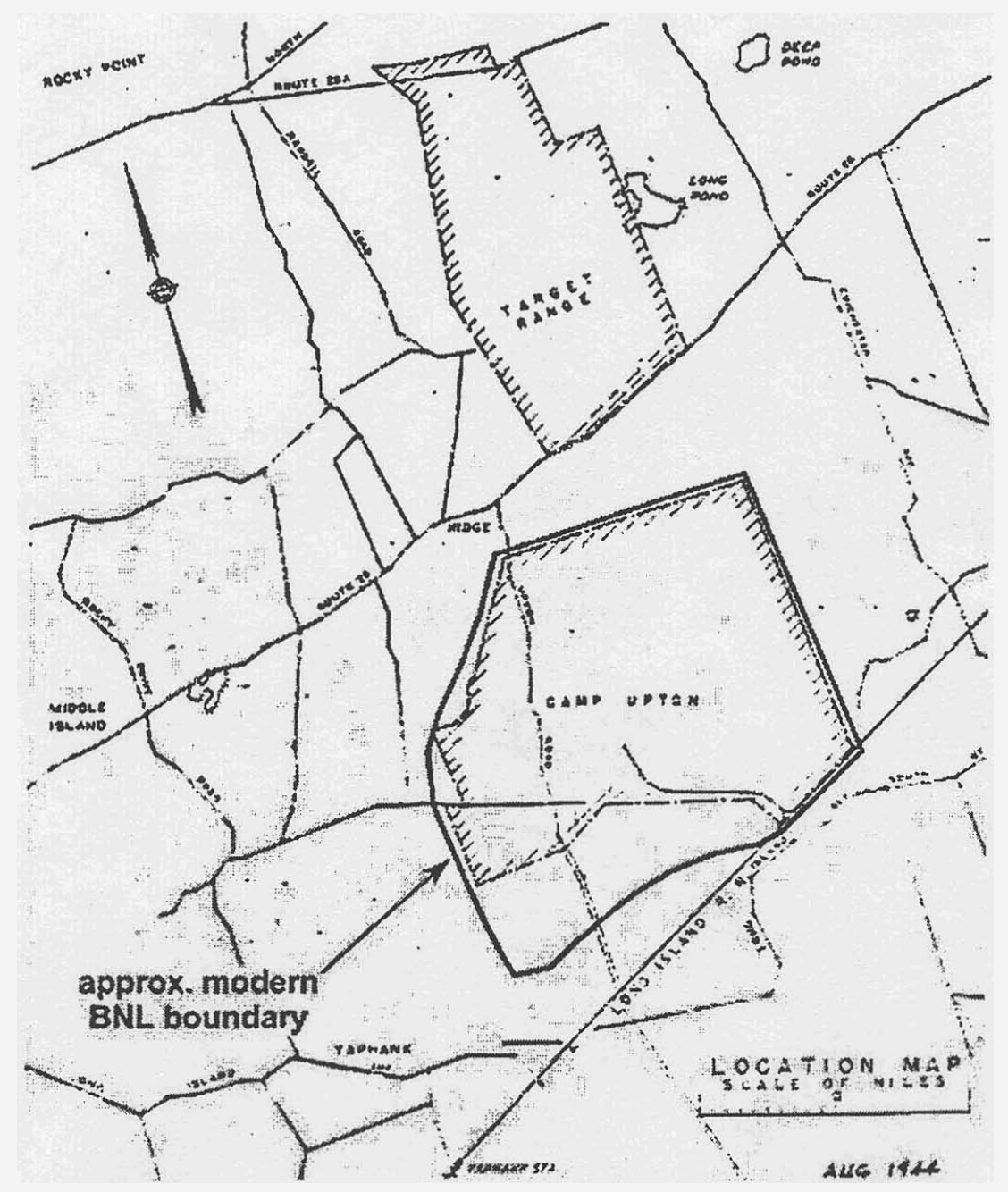

Figure 16. 1944 U.S. Army Corps of Engineers Map showing the extent of World War II Camp Upton. 


\section{ARCHAEOLOGICAL SENSITIVITY}

\section{Prehistoric Cultural Resources}

Based on the location of known prehistoric archaeological sites, as well as a consideration of environmental features, portions of the Brookhaven National Laboratory property have a high sensitivity for the presence of prehistoric deposits. These include areas of the property within or adjacent to wetlands and other fresh water sources, especially the Peconic River. These wetlands would have provided abundant natural resources attractive to Native American peoples, including waterfowl, small mammals, and a variety of edible and medicinal plants. The local paucity of suitable lithic raw material necessary for the manufacture of stone tools probably resulted in only seasonal or itinerant utilization of the region, with more permanent settlements located on the North Shore of Long Island (where both lithic and wetlands resources were available). If present, expected site types might include small manifestations of prehistoric activity (with a relatively low density and/or diversity of artifacts) that may represent specialized foraging activities or tool repair incidents which occurred away from the larger camps (Bernstein et al. 1996).

If prehistoric archaeological sites exist on the grounds of BNL, they could have significant research potential for understanding settlement and subsistence patterns for the interior regions of eastern Long Island.

Sections of the BNL property which are not adjacent to fresh water resources have a low to moderate potential for prehistoric archaeological sites. In addition, many portions of the BNL property have been thoroughly disturbed by twentieth century land use activities (e.g., road and building construction). Disturbed areas have a very low sensitivity for the presence of intact archaeological deposits.

\section{Historic Cultural Resources}

Based on the results of the site file search, survey of historic maps, and a consideration of local history and land use, the BNL property has an overall low sensitivity for the presence of 
historic period archaeological resources dating prior to the early twentieth century, but a moderate to high sensitivity for the presence of cultural material associated with Camp Upton. The potential for pre-World War I resources is the lowest, as the project area witnessed little discernable land use (possibly hunting, cord wood cutting, and other sporadic activities) prior to the early twentieth century when it was acquired by the Federal government for a military cantonment.

In terms of World War I era resources, there are probably unmapped remains of trenches, foundations, and other features associated with Camp Upton throughout the grounds of BNL, and nearby along William Floyd Parkway and New York State Route 25. Most of the moveable objects (including buildings and furnishings) on the site of World War I Camp Upton were sold at auction in 1921, so remaining archaeological deposits most likely would include trash middens created during the period of occupation and abandonment, as well as stray finds of ordnance around firing ranges and lost personal items around former barracks and drill grounds. Two sections of training trenches on the grounds of BNL have been previously identified as potentially eligible for inclusion on the National Register of Historic Places, and it is possible that additional archaeological resources from this period would have local, State, and National significance. In particular, trench warfare reached its peak of use worldwide during World War I, and the presence of preserved trenches and associated features on the grounds of BNL documenting their construction techniques and training methods is very significant for both American and international military history.

It is likely that CCC era archaeological resources exist on the BNL property, created both during the occupation by four work camps in 1934 and 1935, and during the relatively rapid abandonment of the camps in 1935 and 1936. Changes to the landscape made by CCC work crews, including trails, water holes, and planted forests, are present within and adjacent to the modern boundaries of BNL. Subsurface archaeological deposits associated with the CCC occupation could include refuse middens in the vicinity of the former location of barracks and the recreation building/mess hall (Building 30). More than 2,500 CCC camps were established throughout the United States by 1935, but few have been investigated for potential archaeological data (Smith 2001). If present, archaeological deposits associated with CCC activities within the 
project area could provide potentially significant information on temporary laborers' camp activity and behavior for this period in American history.

Many of the buildings from World War II Camp Upton are still standing, and retain historic integrity through original location and setting, some construction and design elements, and overall feeling and association. The above-ground World War II Camp Upton resources are significant for the study of military history and military architecture and planning (Bernstein et al. 2001). Any archaeological deposits from the World War II era on the BNL property are probably not significant individually, but could be considered contributing components to a potentially State and National Register eligible historic district. 


\section{CONCLUSIONS}

In summary, the Brookhaven National Laboratory property in Upton, Town of Brookhaven, Suffolk County, New York may contain significant archaeological resources. Based on the results of the archaeological site file searches and a consideration of environmental features, portions of the BNL property have a high sensitivity for the presence of archaeological remains. For prehistoric resources, these include areas of the property within or adjacent to wetlands and other fresh water sources. If prehistoric materials are present, they are most likely small manifestations that may represent hunting or specialized collecting which occurred away from larger interior camps. Sections of the BNL property which are not adjacent to fresh water resources have a low to moderate potential for prehistoric archaeological sites. In addition, many portions of the BNL property have been thoroughly disturbed by twentieth century land use activities (e.g., road and building construction). Disturbed areas have a very low sensitivity for the presence of intact archaeological deposits.

The BNL property has an overall low sensitivity for the presence of historic period archaeological resources dating prior to the early twentieth century, but a moderate to high sensitivity for the presence of cultural material associated with Camp Upton. Expected historic period archaeological remains include early to mid-twentieth century deposits from World War I era Camp Upton (1917-1921, including training trenches and other earthworks potentially located throughout the entire BNL parcel), the Civilian Conservation Corps period (1934-1936), and World War II Camp Upton (1940-1946). Such early to mid-twentieth century archaeological resources would be potentially significant at local, State, and National levels. 


\section{REFERENCES}

Bailey, Paul

1949 Long Island: A History of Two Great Counties, Nassau and Suffolk. Lewis Historical Publishing, New York.

Bayles, Richard $\mathrm{M}$.

1874 Historical and Descriptive Sketches of Suffolk County. Published by the author, Port Jefferson, New York.

Bayles, Thomas R.

1977 Camp Upton in World War I. Pamphlet published by the author, on file at the Institute for Long Island Archaeology, Department of Anthropology, State University of New York at Stony Brook.

Beers, F.W.

1873 Atlas of Long Island, New York. Beers, Comstock, and Cline, New York.

Bendremer, J. C. M., and Robert E. Dewar

1994 The Advent of Prehistoric Maize in New England. In Corn and Culture in the Prehistoric New World, edited by S. Johannessen and C. A. Hastorf, pp. 369-393. Westview Press, Boulder.

Bernstein, David J.

1993 Prehistoric Subsistence on the Southern New England Coast: The Record from Narragansett Bay. Academic Press, San Diego.

Bernstein, David J., Michael J. Lenardi, Daria Merwin, and Lynn Harvey-Cantone

1996 Prehistoric Use of Wetland Environments: A Case Study from the Interior of Long Island, New York. Northeast Anthropology 51:113-130.

Bernstein, David J. and Michael J. Lenardi

2001 The Use of Lithic Resources in a Coastal Environment: A Case Study from Long Island, New York. Presented at the Society for American Archaeology $66^{\text {th }}$ Annual Meeting. New Orleans, Louisiana, April 2001.

Bernstein, David J., Daria E. Merwin, and Sarah G. Schnepp 2001 Architectural Inventory of the Brookhaven National Laboratory, Upton, Town of Brookhaven, Suffolk County, New York. Report prepared for the United States Department of Energy by the Institute for Long Island Archaeology, Department of Anthropology, State University of New York at Stony Brook. 
Billadello, Laurie S. and Edward J. Johannemann

1987 Stage I Survey of Wading River Estates. Report prepared for Ashley Development Corporation.

Binford, Lewis

1980 Willow Smoke and Dogs' Tails: Hunter-Gatherer Settlement Systems and Archaeological Site Formation. American Antiquity 45:4-19.

Ceci, Lynn

1979 Maize Cultivation in Coastal New York: The Archaeological, Agronomical, and Documentary Evidence. North American Archaeologist 1 (1):45-74.

1982 Method and Theory in Coastal New York Archaeology: Paradigms of Settlement Pattern. North American Archaeologist 3:5-36.

Chace, J.

1858 Map of Suffolk County, Long Island, New York. John Duglass, Philadelphia.

Coyne, Albert

1919 Magic City for 40,000 Went Up in Five Months. In Trench and Camp Upton. National Was Work Council and Y.M.C.A., New York City.

Cronon, William

1983 Changes in the Land. Hill and Wang, New York.

Dincauze, Dena F.

1990 A Capsule Prehistory of Southern New England. In The Pequots in Southern New England, edited by L. M. Hauptman and J. D. Wherry, pp. 19-32. University of Oklahoma Press, Norman.

Dolph and Stewart

1930 Atlas of Suffolk County, New York. Dolph and Stewart, New York.

Donahue, Jämes J.

1918 The Building of Camp Upton. In Public Service Record Volume V, Number 2. The Public Service Commission, New York City.

Dwyer, Norval

1962 Yip Yip Yaphank. Long Island Forum 25:3-21.

1966 Brookhaven National Laboratory. Pamphlet published by the Long Island Forum, on file at the Institute for Long Island Archaeology, Department of Anthropology, State University of New York at Stony Brook.

1970a The Camp Upton Story, 1917-1921, Part 1. Long Island Forum 33:31-34.

$1970 \mathrm{~b}$ The Camp Upton Story, 1917-1921, Part 2. Long Island Forum 33:54-57. 
Filios, Elena L.

1989 The End of the Beginning or the Beginning of the End: The Third Millennium B.P. in Southern New England. Man in the Northeast 38:79-93.

Gonzalez and Rutch

1979 Suffolk County Cultural Resource Inventory. Published by the Suffolk County Archaeological Association, Stony Brook, New York.

Grumet, Robert S.

1995 Historic Contact: Indian People and Colonists in Today's Northeastern United States in the Sixteenth Through Eighteenth Centuries. University of Oklahoma Press, Norman.

Gwynne, Gretchen A.

1982 The Late Archaic Archaeology of Mount Sinai Harbor, New York: Human Ecology, Economy, and Residence Pattern on the Southern New England Coast. Unpublished Ph.D. dissertation, Department of Anthropology, State University of New York at Stony Brook.

Hamilton, Marsha

1998 "Barren and Waste Land": Long Islanders and the Pine Barrens. Long Island Historical Journal 10:207-221.

Hazelton, Henry 1.

1925 The Boroughs of Brooklyn and Queens, Counties of Nassau and Suffolk, Long Island, New York 1609-1924, Volume II. Lewis Historical Publishing Company, New York.

Historical Perspectives Incorporated

1996 Cultural Resources Survey, Naval Weapons Industrial Reserve Plant, Calverton, New York. Report prepared for the Department of the Navy by Historical Perspectives, Westport, Connecticut.

Hulse, Isaac

1797 Survey of the Town of Brookhaven. Copy on file, Map Library, State University of New York at Stony Brook.

Hyde, E. Belcher

1896 Atlas of Long Island, New York. E. Belcher Hyde, Brooklyn, New York.

1917 Atlas of a Part of Suffolk County, Long Island, New York: North Side, Sound Shore. E. Belcher Hyde, Brooklyn, New York. 
Johannemann, Edward J. and Laurie Schroeder

1977 Cultural Resource Inventory, Part I, Brookhaven National Laboratory, Upton, New York. Report prepared for the United States Department of Energy by the Long Island Archaeological Project, State University of New York at Stony Brook.

1978 Cultural Resource Inventory, Part II, Brookhaven National Laboratory, Upton, New York. Report prepared for the United States Department of Energy by the Long Island Archaeological Project, State University of New York at Stony Brook.

1980a Phase I Cultural Resource Survey Report for Peconic River County Park. Report prepared for the Suffolk County Department of Parks, Recreation and Conservation and the N.Y. State Division for Historic Preservation.

1980b Phase I Cultural Resource Survey Report for Southaven County Park. Report prepared for the Suffolk County Department of Parks, Recreation and Conservation and the N.Y. State Division for Historic Preservation.

1980c Phase II Cultural Resource Survey Report for Peconic River County Park. Report prepared for the Suffolk County Department of Parks, Recreation, and Conservation and the N. Y. State Division for Historic Preservation by the Long Island Archaeological Project, Department of Anthropology, State University of New York at Stony Brook.

Lavin, Lucianne

1988 Coastal Adaptations in Southern New England and Southern New York. Archaeology of Eastern North America 16:101-120.

Lightfoot, Kent G.

1988 Archaeological Investigations of Prehistoric Sites on Eastern Long Island. Pages 31-44 in Evoking a Sense of Place, edited by Joanne Krieg. Heart of the Lakes Publishing, Interlaken, New York.

Luke, Myron H. and Robert W. Venables

1976 Long Island in the American Revolution. New York State American Revolution Bicentennial Commission, Albany.

Mather, W.W. and J. Calvin Smith

1843 Geological Map of Long and Staten Islands with the Environs of New York. In The Natural History of New York by W.W. Mather, Endicott, New York.

Meltzer, David J.

1988 Late Pleistocene Human Adaptations in Eastern North America. Journal of World Prehistory 2:1-52. 
Merwin, Daria E.

2000 Environment and Prehistoric Adaptations in Eastern Long Island, New York. Paper presented at $40^{\text {th }}$ Annual Meeting of the Northeastern Anthropological Association, New York.

Meyers, O'K.

1918 Report of the Construction, Camp Upton, New York. Pamphlet on file, Longwood Public Library, Middle Island, New York.

Middle Island Mail

1935 Four Companies in C.C.C. Camp Now at Yaphank. 18 September.

1936 Review of C.C.C. Work is Reduced by State Dept. 15 January.

National Park Service

1991 National Register Bulletin 15: How to Apply the National Register Criteria for Evaluation. United States Department of the Interior, National Park Service Interagency Resources Division, Washington D.C.

Newsday

1998 Ridge: Minutemen Organized to Defend a Family. Our Towns Special Section, 22 February:H95.

Reschke, Carol

1990 Ecological Communities of New York State. Department of Environmental Conservation, New York Natural Heritage Program, Latham,-New York.

Ritchie, William A.

1959 The Stony Brook Site and its Relation to Archaic and Transitional Cultures on Long Island. New York State Museum and Science Service Bulletin 372. State University of New York, Albany.

1971 A Typology and Nomenclature for New York Projectile Points. Revised edition. New York State Museum Bulletin 384. The University of the State of New York, Albany.

1980 The Archaeology of New York State. Revised edition. Harbor Hill Books, Harrison, New York.

Salmond, John A.

1967 The Civilian Conservation Corps, 1933-1942: A New Deal Case Study. Duke University Press, Durham, North Carolina.

Salwen, Bert

1978 Indians of Southern New England and Long Island: Early Period. In Handbook of North American Indians, Volume 15, edited by Bruce Trigger, pp. 160-176. Smithsonian Institution, Washington D.C. 
Saxon, Walter

1973 The Paleo-Indian on Long Island. New York State Archaeological Association Bulletin $57: 1-11$.

Silver, Annette L.

1981 Comment of Maize Cultivation in Coastal New York. North American Archaeologist 2:117-130.

Sirkin, Les

1995 Eastern Long Island Geology with Field Trips. The Book and Tackle Shop, Watch Hill, Rhode Island.

Smith, Monica L.

2001 The Archaeology of a "Destroyed" Site: Surface Survey and Historical Documents at the Civilian Conservation Corps Camp, Bandelier National Monument, New Mexico.

Historical Archaeology 35:31-40.

Snow, Dean R.

1980 The Archaeology of New England. Academic Press, New York.

Strong, John A.

1997 The Algonquian Peoples of Long Island from Earliest Times to 1700. Empire State Books, Interlaken, New York.

Tracker Archaeology Services

1996 Phase I and II Archaeological Investigations for the Proposed Ridge Corporation Subdivision, Ridge, Town of Brookhaven, Suffolk County, New York. Report prepared.for the Ridge Corporation.

Turano, Frank

1983 Long Island Forests: A Historical Perspective. Ms. on file, Department of Anthropology, State University of New York at Stony Brook.

United States Army Corps of Engineers

1917 Engineer Field Manual. Government Printing Office, Washington, D.C.

1944 Location Map, Camp Upton. Copy on file, Department of Anthropology, State University of New York at Stony Brook.

United States Army Quartermaster Corps

1917 Map of Camp Upton Reservation. Copy on file, Brookhaven National Laboratory. 


\section{United States Coastal Survey}

1838 Survey of the Coast of Long Island, New York. Copy on file, Map Library, State University of New York at Stony Brook.

United States Geological Survey

1904/1920 Moriches, New York. 15 minute series, Topographic Surveys, Washington, D.C. 1967 Bellport, New York. 7.5 minute series, Department of the Interior, Washington, D.C.

1967 Middle Island, New York. 7.5 minute series, Department of the Interior, Washington, D.C.

1967 Moriches, New York. 7.5 minute series, Department of the Interior, Washington, D.C.

1967 Wading River, New York. 7.5 minute series, Department of the Interior, Washington, D.C.

Villani, Robert

1997 Long Island, A Natural History. Harry N. Abrams, New York.

Warner, J. W. Jr., W. E. Hanna, R. J. Landry, J. P. Wulforst, J. A. Neely, R. L. Holmes and C. E. Rice

1975 Soil Survey of Suffolk County, New York. U.S. Department of Agriculture, Soil Conservation Service, Washington, D.C.

Wyatt, Ronald J.

1977 The Archaic of Long Island. In Amerinds and Their Paleoenvironments in Northeastern North America. Annals of the New York Academy of Sciences 288:400-410. 
APPENDIX: SITE FILE SEARCH RESULTS 


\section{Appendix B}

\section{Cultural Significance Categories Table}

\begin{tabular}{|c|c|c|c|c|c|}
\hline $\begin{array}{c}\text { Grid } \\
\#\end{array}$ & $\begin{array}{c}\text { Bldg } \\
\#\end{array}$ & Building/site Name & Date & $\begin{array}{c}\text { NRHP } \\
\text { Eligible }\end{array}$ & Category \\
\hline Multi & $\mathrm{N} / \mathrm{A}$ & World War I Training Trenches & 1917 & Yes & I \\
\hline $70 / 80$ & $\mathrm{~N} / \mathrm{A}$ & $1800^{\prime} \mathrm{s}$ Home Sites & $1850 \prime s$ & $\mathrm{U}$ & $I$ \\
\hline 65 & $\begin{array}{l}701 \\
702\end{array}$ & $\begin{array}{c}\text { Brookhaven Graphite Research Reactor } \\
\text { BGRR }\end{array}$ & 1949 & Yes & $\underline{I}$ \\
\hline 65 & 703 & BGRR Office \& Laboratories & 1949 & Note 1 & $I$ \\
\hline 64 & 902 & Cosmotron & 1949 & $\mathbf{U}$ & $I$ \\
\hline 64 & 913 & Alternating Gradient Synchrotron & 1957 & U, C & $\underline{I}$ \\
\hline 84 & 490 & Medical Research Center/Program & 1958 & $\mathbf{U}$ & $I$ \\
\hline 84 & 491 & Medical Research Reactor & 1958 & $\mathbf{U}$ & $I$ \\
\hline 75 & 750 & High Flux Beam Reactor & 1964 & Yes & $\underline{I}$ \\
\hline 74 & 555 & Chemistry & 1966 & U, A & $I$ \\
\hline 74 & 488 & Berkner Hall & 1968 & $\mathrm{U}, \mathbf{A}$ & $\mathbf{I}$ \\
\hline
\end{tabular}

BGRR, HFBR, AGS \& other Support buildings:

\begin{tabular}{|c|c|c|c|c|c|}
\hline Grid \# & Bldg \# & Building name & Date & $\begin{array}{c}\text { NRHP } \\
\text { Eligible }\end{array}$ & Category \\
\hline 75 & 704 & Fan House & 1949 & Note 1,2 & II \\
\hline 65 & 705 & Reactor Stack & 1949 & Note 1,2 & II \\
\hline 75 & 707 & Pump House & 1949 & Note 1,2 & II \\
\hline 75 & 708 & Instrument House & 1949 & Note 1 & II \\
\hline 75 & 751 & Cold Neutron Facility & 1970 & Note 2 & II \\
\hline 65 & 801 & Isotope Research and Processing & 1950 & Note 1 & II \\
\hline 65 & 802 & Fan House & 1950 & Note 1 & II \\
\hline 64 & 911 & Collider Accelerator Building & 1956 & U, C & II \\
\hline 55 & 912 & AGS Experimental Hall & 1958 & U, C & II \\
\hline $21 / 29$ & N/A & Gamma Forest Site & 1961 & U & II \\
\hline 75 & 901 & Isochronous Cyclotrons & 1949 & U & II \\
\hline 75 & $901 \mathrm{~A}$ & Tandem Van de Graaff Accelerator & 1968 & U & II \\
\hline
\end{tabular}

Representative Period Buildings

\begin{tabular}{|c|c|c|c|c|c|}
\hline 93 & 30 & Brookhaven Center & 1934 & No & II \\
\hline 75 & 120 & Building 120 & 1942 & No & I \\
\hline
\end{tabular}

Note 1: Eligible as part of the BGRR Complex

Note 2: Eligible as part of the HFBR Complexes

Note 3: Resources with the following designations have not been formally evaluated for National Register eligibility (i.e., eligibility is undetermined): $A=$ Architecturally significant; $U=$ Undetermined; $C=$ Part of a complex.

(Descriptions of each category are presented on the following page) 


\section{Appendix B}

Category I: A building, site or program determined to be historically significant due to: historic context; architecture; engineering \& design; direct association with important personages; or scientific achievement. The resource(s) may be individually eligible for listing on National Register, however, eligibility is not a requirement.

Treatment and/or mitigation: Some degree of treatment and/or mitigation is necessary to ensure cultural significance is retained and available for interpretation. Examples include, but are not limited to:

- Specific treatment or architectural management plan, if architecturally significant;

- Documentation of engineering \& design, and scientific achievements (photos, scale- models, document archives, etc.)

- Development of a Researcher's Guide

- Preservation/display of associated equipment

Category II: A building, facility or site that directly supported a significant BNL program, or uniquely represents a specific period in the evolution of BNL's site history and has had little alteration.

Treatment and/or mitigation:

For support buildings: As-built drawings and photos; documented description of structure's role (may be included in existing facility description documents).

For period structures: Treatment plans to minimize further alteration of specifically identified aspects (implementation is funding dependent). Mitigation would entail documentation of as-built drawings and photos.

Category III: Buildings or structures that supported lab-wide programs and may be representative of the evolution of government use of the site.

Buildings in this category include the World War II era buildings. During a site visit (January 3, 2003), SHPO has agreed that these structures would not be considered eligible for the National Register.

However, since these types of structures do represent a distinct period in the site and BNL history, the following means may be used to document the association.

Mitigation: Document the development and evolution of the site by archiving engineering and plan drawings of site layout, building plans and photos for select structures, and aerial photos. 


\title{
APPENDIX C
}

\section{Cultural Resource Management Strategy Forms}

This appendix to the Cultural Resource Management Plan contains the management strategy forms associated with each specific resource. Refer to Section 4.4.1 of this plan for additional details. These forms may be revised as necessary, but must have BNL management and DOE/BHSO concurrence and be submitted by DOE-BHSO to the New York State Historic Preservation Officer for a 30-day review and comment period. Each form contains a revision number and date.

The following Cultural Resource Management Strategy Forms (listed alphabetically) have been developed to date:

\author{
Alternating Gradient Synchrotron (AGS) \\ Brookhaven Graphite Research Reactor Complex \\ Brookhaven Medical Research Reactor \\ Building 30, Brookhaven Center \\ Building 120, Former Barracks Building \\ Cosmotron \\ Gamma Forest \\ High Flux Beam Reactor Complex \\ Hot Laboratory \\ Medical Research Center (Program) \\ Weeks Campbell Site \\ W.J. Weeks House Site \\ World War I Foundation Features \\ World War I Training Trenches
}




\section{Cultural Resource \\ Management Strategy Form}

Building/Site Name: $\quad$ Alternating Gradient Synchrotron (AGS) Complex

BNL BIdg. \#: $\quad 911,912,913$ \& support buildings _ Grid \#: $\quad 55 \& 64 \quad$ Site \#: $\quad 10302.002559$

Date of construction or period of use: $\quad$ Construction: 1956-58 (Operating history: 1960 - present)

Historic Significance Category: $\bigotimes$ I or $\square$ II or $\square$ N/A

Historic Role(s): Engineering \& Design; BNL's development history; scientific achievements

- Engineering \& design -- The world's highest energy accelerator from 1960-1968

- $\quad$ Facility housed sites of research leading to three Nobel prizes $(1976,1980,1988)$

Current Significant Feature(s): (Examples: exterior architecture; extant location; associated w/important personage; scientific achievement [e.g.; Nobel Prize]; unique facility; etc.)

-- Association with Nobel Prize experiments.

-- Extant structure \& site consist of the tunnel (Bldg 913) housing the ring magnets and associated equipment, steel framed sheet metal sided \& roofed Experimental Hall (Bldg. 912), the administrative support building (BIdg. 911), and miscellaneous support buildings. Note: AGS buildings are not the significant feature of this resource.

Plans for Bldg or Site:

- The buildings and machine continue to function in the original design as a particle accelerator for physics experiments. Upgrades to the machine are planned in order to increase its intensity.

- The buildings/structures should not be the focus of this cultural resource.

\section{Treatment and/or Mitigation Plans:}

- Concentrate efforts on preserving information related to the engineering \& design of the AGS, and associated scientific achievements. Identifv and emphasize items representative of experiments or machine equipment (Ex. Bubble chambers, magnets, etc.)

- Identify significant buildings, systems, and experiments for focus of documentation treatment.

Level A (achieved, in-progress, or relatively achievable)

- Emphasize equipment artifacts:

Bubble chambers (30-inch \& 7-foot) saved - require permanent staging \& preservation

Bubble chamber windows - requires permanent mounting

- Identify \& evaluate other equipment artifacts

- Scale model of magnet line

- Identify and retain historic photos

- Display information on Nobel Prizes

Level B (resource permitting)

- $\quad$ Conduct 'Living History' interviews

- Records search \& archive

- $\quad$ Develop Researcher's Guide to AGS Complex Facilities \& Scientific Research 


\section{Cultural Resource \\ Management Strategy Form}

Building/Site Name:

Brookhaven Graphite Research Reactor (BGRR) Complex

BNL Bldg. \#: $\quad 701,702,703,704,705,708,709,709 A, 801 \quad$ Grid \#: $65 \quad$ Site \#: 10302.001608

Date of construction or period of use: $\quad$ Construction: 1949 (Operating history: 1949-1969)

Historic Significance Category: $\bigotimes$ I or $\square$ II or $\square$ N/A

Historic Role(s): $\quad$ Scientific achievement, Engineering/design

- Laboratory's first big machine and the first U.S. peace-time reactor

- Development of radioisotope technetium- $99 \mathrm{~m}$, radiography of archeological artifacts; materials studies; etc.

- $\quad$ Determined eligible for listing on the National Register of Historic Places in 1999

Current Signiffcant Feature(s): (Examples: exterior architecture; extant location; associated w/important personage; scientific achievement [e.g.; Nobel Prize]; unique facility; etc.)

-- Scientific achievements: Development of radiotracer Tc-99m, other studies.

- $\quad$ Extant building(s) remains in place - pending finalization and implementation of decommissioning plan.

- The significance of BGRR complex buildings is their association with the BGRR and operations/support functions.

Plans for Bldg or Site:

- A decommissioning plan is being developed for this facility. End state of structure will not be known until

D\&D plan is finalized \& funded - Assume total removal due to radiological contamination issues.

Treatment and/or Mitigation Plans:

- $\quad$ Assuming total D\&D, an MOA between SHPO \& DOE was signed to address mitigation of D\&D and includes development of a History Video, BGRR Researcher's Guide, etc.

- If structures remain after D\&D - acknowledge site in CRMP, CR tours, etc.; develop signage, displays, etc.

- Building 701, 703,801 and other BGRR complex buildings are considered mitigated through the activities identified in the MOA. Future architectural revisions (renovations/additions/removals) would be planned in order to minimize the impact to the visual lines of the buildings and other features directly linked to BGRR. For example:

- Additions would follow existing architectural lines and similar colors, or be sufficiently distinct in order to differentiate original structure from new.

Level A (achieved, in-progress, or relatively achievable)

- Create mitigation package for Stack (Building 705)- refer to HFBR strategy form for details

- BGRR History Video (includes living history interviews) - completed

- Records (including photos \& drawings) inventoried by professional archivist-completed

- BGRR Researchers Guide - $70 \%$ complete

- Retain scale model(s) \& mock fuel element(s)

- Develop architectural mgmt plan(s) to identify specific features and treatments assessment completed in 2004

- Website description-completed

- Identify tools \& equipment for potential display/preservation - identification completed; storage and documentation to be performed

Level B (resource permitting)

- Develop CD ROM version of Researcher's Guide 


\section{Cultural Resource \\ Management Strategy Form}

Building/Site Name: Brookhaven Medical Research Reactor (BMRR)

BNL Bldg. \#: $\quad 491$

Grid \#: 84

Site \#: $\quad 10302.002412$

Date of construction or period of use:

Construction: 1959 (Operating history: $1959-2000$ )

Historic Significance Category: $\bigotimes$ I or $\square$ II or $\square$ N/A

Historic Role(s): $\quad$ Scientific achievement, Engineering/design

- First reactor in the nation to be constructed specifically for medical research

- Boron neutron capture therapy development

Current Significant Feature(s): (Examples: exterior architecture; extant location; associated w/important personage;

scientific achievement [e.g.; Nobel Prize]; unique facility; etc.)

- Scientific achievements:

-- Extant building \& equipment are still in place - pending development and initiation of decommissioning plan.

Plans for Bldg or Site:

- A decommissioning plan is scheduled to be developed for this facility.

Treatment and/or Mitigation Plans:

- End state of structure will not be known until D\&D plan is developed \& funded - Assume total removal due to radiological contamination issues.

- Focus attention on identifying \& preserving information related to engineering/design and scientific achievements of the medical research program - not the building.

Level A (achieved, in-progress, or relatively achievable)

- Video building and facility prior to major D\&D effort

- $\quad$ Research \& compile information regarding significance of medical research

- $\quad$ Retain scale model, photos \& drawings

- Website description

Level B (resource permitting)

- $\quad$ Conduct 'Living History' interviews

- Records search \& archive 


\section{Cultural Resource \\ Management Strategy Form}

Building/Site Name: $\quad$ Brookhaven Center - Building 30

BNL BIdg. \#: $\quad 30 \quad$ Grid \#: 93

Site \#: $\quad 10302.002295$

Date of construction or period of use: $\quad$ Construction: 1934 (1934-present)

Historic Significance Category: $\square$ I or $\bigotimes$ II or $\square$ N/A

Historic Role(s): $\quad$ Original Civilian Conservation Corp (CCC) Structure

- Extant CCC building.

- Functioned as an Officer's Club during WWII Camp Upton.

Current Significant Feature(s): (Examples: exterior architecture; extant location; associated w/important personage; scientific achievement [e.g.; Nobel Prize]; unique facility; etc.)

- Exterior architecture.

-- Extant location.

Plans for Bldg or Site:

- The building is still in use as a club, including ballrooms, with portions also used as support division office space.

\section{Treatment and/or Mitigation Plans:}

- Resources permitting, BNL will seek to minimize further alteration to the exterior visual lines or architectural style of the 1930 s portions of the building.

- Have architectural evaluation performed - Completed in 2004

Develop architectural management plan, Examples:

- Replacement windows would be of similar style, whenever possible.

- Similar materials would be used in any maintenance or renovation action

- As long as the structure remains in place, it will be acknowledged in the CRMP, CR tours, etc.

- Should the building be scheduled for demolition - a mitigation package would be developed that includes original building plans, photos, etc

Level A (achieved, in-progress, or relatively achievable)

- Treatment plan identified above (including architectural mgt. plan).

- $\quad$ Retain early photos \& plan drawings.

Level B (resource permitting)

- None planned. 


\section{Cultural Resource \\ Management Strategy Form}

Building/Site Name:

Building 120 - Former WWII Barracks Building

BNL Bldg. \#: $\quad 120$

Grid \#: 75

Site \#: $\quad 10302.002310$

Date of construction or period of use:

Construction: 1942 (1942-present)

Historic Significance Category: $\square$ I or $\bigotimes I I$ or $\square$ N/A

Historic Role(s): $\quad$ Original World War II Barracks Structure

The building was originally located in another part of the BNL site, and was relocated in the early BNL years.

Current Significant Feature(s): (Examples: exterior architecture; extant location; associated w/important personage; scientific achievement [e.g.; Nobel Prize]; unique facility; etc.)

-- Exterior architecture. Two Story WW II barracks building with minimal exterior renovations. (e.g., no vinyl siding, double-hung $8 / 8$ windows remain); overhanging roof eaves with wood brackets are examples of architecture once prevalent during Camp Upton and early BNL years.

- Note: This form only applies to the original two-story portion of Building 120. Newer modular sections were added in the 1980 s

Plans for Bldg or Site:

- The building is still in use as office space for support divisions.

Treatment and/or Mitigation Plans:

- Resources permitting, BNL will seek to minimize further alteration to the exterior visual lines or architectural structure of the building. Examples:

- Replacement windows would be of similar style, whenever possible.

- Vinyl siding will not be installed.

- $\quad$ As long as the structure remains in place, it will be acknowledged in the CRMP, CR tours, etc.

- Should the building be scheduled for demolition - a mitigation package would be developed that includes original building plans, photos, etc.

Level A (achieved, in-progress, or relatively achievable)

- Have architectural evaluation performed to identify significant features \& treatments - completed

- Develop architectural management plan

- Retain early photos - completed

- Retain early pian drawings

Level B (resource permitting)

- None planned. 


\section{Cultural Resource \\ Management Strategy Form}

Building/Site Name: Cosmotron

BNL BIdg. \#: 902

Grid \#: 64

Site \#: $\quad 10302.002549$

Date of construction or period of use:

$1949(1952-1966)$

Historic Significance Category: $\bigotimes_{I}$ or $\square$ II or $\square$ N/A

Historic Role(s): $\quad$ Engineering \& Design; BNL's development history; scientific achievements

- First accelerator to achieve 1 billion electron volt ( $\mathrm{BeV}$ or $\mathrm{GeV})$ level $\&$ provide external particle beams for experiments

- Led to development of "Strong-Focusing Principle"

- $\quad$ BNL's second major facility - established BNL's leadership in physics community

- 1957 Nobel prize in physics awarded to T.D. Lee and C.N. Yang was associated with Cosmotron experiments

Current Significant Feature(s): (Examples: exterior architecture; extant location; associated w/important personage; scientific achievement [e.g.; Nobel Prize]; unique facility; etc.)

-- Extant structure \& site consist of the steel-framed, sheet metal sided \& roofed building and attached administrative support offices.

- The circular outline of the original machine remains visible by a slightly raised ring of concrete in the floor of building 902 where the machine was mounted. (Note: The building and ring area are currently in use for ongoing BNL project activities.)

-. 'C-Magnet' displayed outside building 911

- Scale models displayed in building 438

Plans for Bldg or Site:

- The area is currently used for assembling and testing superconducting magnets. The building is expected to remain in use as an industrial work area for BNL projects.

Treatment and/or Mitigation Plans:

- Focus attention on preserving information related to the Cosmotron's engineering \& design, and associated scientific achievements. Visible ring area and Bldg 902 will be noted in CRMP, but not emphasized as a significant site.

Level A (achieved, in-progress, or relatively achievable)

- $\quad$ C-magnet and plaque retained, maintained and displayed

- $\quad$ Scale model(s) and associated material retained, maintained and displayed

- $\quad$ Retain photos \& descriptive information files

- $\quad$ Website description

Level B (resource permitting)

- $\quad$ Conduct 'Living History' interviews - Initiated in 2003

- Records search \& archive 


\section{Cultural Resource \\ Management Strategy Form}

Building/Site Name:

Gamma Forest

BNL Bldg. \#: N/A

Grid \#: $21 \& 29$

Site \#:

Date of construction or period of use:

Construction: $1961(1961-1979)$

Historic Significance Category: $\square$ I or $\square$ II or $\square$ N/A

Historic Role(s): $\quad$ Unique site operated by Biology Dept. from $1961-1979$ to study effects of radiation on plants.

Current Significant Feature(s): (Examples: exterior architecture; extant location; associated w/important personage; scientific achievement [e.g.; Nobel Prize]; unique facility; etc.)

-. Extant structure \& site consist of the steel framed sheet metal operations shed; source storage pit (filled in); source tower (not standing); distance marking stakes.

- The effects of the radiation on vegetation remain clearly evident through the variation in regrowth pattems

Plans for Bldg or Site:

- The area is currently not in use, and remains in an "abandoned" state since the end of scientific project (1979).

Treatment and/or Mitigation Plans:

- Maintain site in its current state, and make available/accessible for cultural resource tours

- Minor enhancements such as housekeeping, fencing, gravel path, etc. would improve access

Level A (achieved, in-progress, or relatively achievable)

- Conduct supervised tours with site current state

- Documentation (research, photos, etc.) search for project information - Create reference file

- Develop interpretive signage for posting at site

- Develop specific management plan defining tasks, responsibilities, etc. for the site

- Develop information for CRM website

Level B (resource permitting)

- Improve accessibility (gravel pathway to minimize ticks) 


\section{Cultural Resource \\ Management Strategy Form}

Building/Site Name: $\quad$ High Flux Beam Reactor (HFBR) Complex

BNL Bldg. \#: $\quad 750,704,705,708,709$ A \& B, 751 Grid \#: $\quad 75 \quad$ Site \#: $\quad$ 10302:000989

Date of construction or period of use: $\quad$ Construction: 1964 (Operating history: 1965 - 1999)

Historic Significance Category: $\bigotimes$ I or $\square$ II or $\square$ N/A

Historic Role(s): $\quad$ Scientific achievement, Engineering/design

- Unique design resulting in neutron flux peaking outside core for beam line experiments

- $\quad$ Dome structure makes it one of the most recognizable buildings on the BNL site

- $\quad$ Most research reactors built since 1965 incorporate the design innovations, which first appeared in the HFBR.

- $\quad$ For over 30 years, the HFBR was one of the premier beam reactors in the world

- Determined eligible for listing on the National Register of Historic Places in 2001

Current Significant Feature(s): (Examples: exterior architecture; extant location; associated w/important personage; scientific achievement [e.g.; Nobel Prize]; unique facility; etc.)

-. Scientific achievements.

-- Extant building \& major equipment are still in place - pending development and initiation of decommissioning plan.

\section{Plans for Bldg or Site:}

- A decommissioning plan is being developed for this facility

\section{Treatment and/or Mitigation Plans:}

- End state of structure will not be known until D\&D plan is developed \& financed - Assume total removal due to radiological contamination issues. Focus attention on identifying \& preserving information related to engineering/design and scientific achievements - not the building.

- If building remains after D\&D - acknowledge site in CRMP, CR tours, etc.; develop signage \& displays

Level A (achieved, in-progress, or relatively achievable)

- Create a Mitigation Package specifically for the Stack, to include:

o Engineering Drawings and documentation

o Existing photos and videos (stack internals, etc.)

o Video stack from various vantage points (bay, roadways, etc.)

- Video building and facility prior to major D\&D effort.

- Retain two scale models \& mock fuel element.

- Retain photos \& plan drawings

- Website description - Completed

- Research \& compile information regarding significance of HFBR research

Level B (resource permitting)

- Records search/archive \& develop Researcher's Guide

- $\quad$ Conduct 'Living History' interviews 


\section{Cultural Resource \\ Management Strategy Form}

Building/Site Name: Hot Laboratory - Isotope Research and Processing

BNL Bldg. \#: $\quad 801$

Grid \#: 65

Site \#: $\quad 10302.002527$

Date of construction or period of use:

Construction: 1950 (Operating history: $1950-$ present)

Historic Significance Category: $\square$ I or $\bigotimes$ II or $\square$ N/A

Historic Role(s): $\quad$ Scientific achievement, Engineering/design

- Associated with BGRR and early BNL operations

- Development of radioisotopes

- Determined eligible for listing on the National Register of Historic Places in 1999 as part of the BGRR complex

Current Significant Feature(s): (Examples: exterior architecture; extant location; associated w/important personage; scientific achievement [e.g.; Nobel Prize]; unique facility; etc.)

- Extant building associated with BGRR complex.

\section{Plans for BIdg or Site:}

- The building continues to be utilized to support BNL program areas, including isotope processing. There are no plans to decommission this building at this time.

\section{Treatment and/or Mitigation Plans:}

- The mitigating actions identified in the BGRR MOA aiso encompass the Hot Laboratory. These actions include archiving documentation and building plan drawings.

- Acknowledge building in CRMP, CR tours, etc.

- Future architectural revisions (renovations/additions/removals) would be planned in order to minimize the impact to the building visual lines. For example:

- Additions would follow existing architectural lines and similar colors, or be sufficiently distinct in order to differentiate original structure from new.

Level A (achieved, in-progress, or relatively achievable)

- BGRR History Video (includes living history interviews) - complete

- $\quad$ Records inventoried by professional archivist (Retain photos \& drawings) - completed

- $\quad$ BGRR Researchers Guide - $70 \%$ complete

- Identify tools \& equipment for potential display/preservation

- Have architectural evaluation performed to identify specific features/treatments - completed 


\section{Cultural Resource \\ Management Strategy Form}

Building/Site Name: $\quad$ Medical Research Center/Program

BNL Bldg. \#: $\quad 490 \quad$ Grid \#:

Site \#: $\quad$ 10302:002411

Date of construction or period of use: $\quad$ Construction: 1958 (Operating history: 1958 - present)

Historic Significance Category: $\bigotimes_{\text {I }}$ or $\square$ II or $\square$ N/A

Historic Role(s): $\quad$ BNL's development history; scientific achievements

- Nuclear medical research program initiated in 1950. New facility (constructed in 1958) expanded program

Current Significant Feature(s): (Examples: exterior architecture; extant location; associated w/important personage; scientific achievement [e.g.; Nobel Prize]; unique facility; etc.)

-- Scientific achievements: Development of radioisotopes for medical applications; technetium-99m, L-dopa treatments, BNCT, thallium-201, tin-117m DPTA, positron emission tomography

Plans for Bldg or Site:

- Extant building is still in use in support of scientific programs as a center for research. Note: The building is not considered the significant feature of this

Treatment and/or Mitigation Plans:

- Identify \& preserve information related to the scientific achievements of the medical research program - not the building.

- Identify key pieces of equipment potentially representative of select experimental programs.

Level A (achieved, in-progress, or relatively achievable)

- Research \& develop information regarding significance of medical research.

- Identify \& evaluate potential equipment artifacts for future display - ceremonial groundbreaking flask/plaque identified.

- $\quad$ Retain MRI machine displayed in Chemistry Bldg lobby.

- $\quad$ Retain photos \& drawings.

Level B (resource permitting)

- $\quad$ Conduct 'Living History' interviews

- $\quad$ Records search \& archive 


\section{Cultural Resource \\ Management Strategy Form}

Note: Sensitive Information

- Not Shown -

Building/Site Name: Weeks Campbell Site

BNL BIdg. \#: None

Grid \#: $\quad$ XXXXX

Site \#:

Date of construction or period of use:

Late 1800 to early $1900 \mathrm{~s}$

Historic Significance Category: $\bigotimes$ I or $\square$ II or $\square$ N/A

Historic Role(s): $\quad$ Historical archeology site;

Current Significant Feature(s): (Examples: exterior architecture; extant location; associated w/important personage; scientific achievement [e.g.; Nobel Prize]; unique facility; etc.)

-- Above grades structures are no longer visible, however, stone foundation, brick walkway/patio remains. Site likely contains buried artifacts that provide evidence of rural life in the late $1800 \mathrm{~s}$.

-- Site has a relatively high degree of integrity, with several surface and subsurface features (agricultural landscape markers, the brick walkway, and most importantly, the foundation/cellar hole)

-- The site can speak to research questions regarding late nineteenth century rural domestic lifeways of what was likely an agrarian family; also, the site yielded evidence of military occupation, probably World War I era, so it might be important as a "satellite" site (even if not used for an official Army function) of Camp Upton

Plans for Bldg or Site:

- None; maintain and protect site for potential future research study

Treatment and/or Mitigation Plans:

- Conduct preliminary archeological survey/evaluation of potentially threatened site - completed 2004 .

-

Level A (achieved, in-progress, or relatively achievable)

- Research house site history - Completed as part of archeology evaluation.

- Develop \& implement monitoring plan for site, as determined necessary.

Level B

- :Development impinges on the area, a Phase III archeological data recovery project may need to be performed. 


\section{Cultural Resource \\ Management Strategy Form}

Building/Site Name: W. J. Weeks House Site

BNL BIdg. \#: None

Grid \#: $\quad$ XXXXX

Site \#:

Date of construction or period of use:

Mid 1800s

Historic Significance Category: $\bigotimes$ I or $\square$ II or $\square$ N/A

Historic Role(s): $\quad$ Historical archeology site;

Current Significant Feature(s): (Examples: exterior architecture; extant location; associated w/important personage; scientific achievement [e.g.; Nobel Prize]; unique facility; etc.)

-- Above grades structures are no longer visible, however, stone foundation (or partial) remains. Locust fence posts (3 to 4) remain. Site likely contains buried artifacts that provide evidence of life in the 1850 s.

-- Age, density and diversity of artifacts, along with intact subsurface features suggest high research potential research topics: lifeways of otherwise "undocumented" people, in this case, tenant woodchoppers; socio-economic issues of nonland holding lower class in nineteenth century rural setting.

Plans for Bldg or Site:

- None; maintain and protect site for potential future research study

Treatment and/or Mitigation Plans:

- $\quad$ Conduct preliminary archeological survey/evaluation of potentially threatened site - completed 2004.

- Implement protection plan for site to prevent unauthorized excavation - completed in 2004 (fencing \& signs)

Level A (achieved, in-progress, or relatively achievable)

- Research house site histories - Completed as part of archeology evaluation.

- Develop \& implement monitoring plan for site, as determined necessary.

Level B

- If development impinges on the area, a Phase III archeological data recovery project would need to be performed. 


\section{Cultural Resource \\ Management Strategy Form}

Building/Site Name: $\quad$ World War I Camp Upton Foundations \& Features

BNL Bldg. \#: None Grid \#: $\quad$ XXXXXXXX Site \#:

Date of construction or period of use:

$1917-1929$

Historic Significance Category: $\mathbf{I}_{\mathrm{I}}$ or $\square$ II or $\square$ N/A

Historic Role(s): Constructed in 1917-1918 as part of Camp Upton during WW I

- Likely to be eligible for listing on the National Register of Historic Places due to association with Camp Upton (based on contactor's evaluation)

- $\quad$ Associated with historic pattern of events - mobilization \& training of U.S. Army troop during WW I.

Current Significant Feature(s): (Examples: exterior architecture; extant location; associated w/important personage;

scientific achievement [e.g.; Nobel Prize]; unique facility; etc.)

- $\quad$ Four to five separate sites of foundations are extant.

-- These sites may be the only remaining examples of WWI Cantonment features remaining in the U.S. (None of the 16 WW I National Army Cantonments is currently listed on the National Register.)

-- High degree of integrity with respect to location, design, materials and association - offers a rare opportunity to study this aspect of military history.

Plans for Bldg or Site:

- Maintain sites in current state with surrounding wooded buffers.

Treatment and/or Mitigation Plans:

- Maintain areas in their current state; available for study/interpretation.

- If development threatens a specific site-perform archeological survey of impacted area.

Level A (achieved, in-progress, or relatively achievable)

- Survey and map foundation areas - completed $95 \%$ in 2002.

- Acknowledge and describe sites on CRM webpage.

Level B (resource permitting)

- Map newly identified features using GPS. 


\section{Cultural Resource \\ Management Strategy Form}

Building/Site Name: $\quad$ World War I Training Trenches

BNL Bldg. \#: $\quad$ None

Grid \#: $\quad$ XXXXXXXX

Site \#:

Date of construction or period of use:

$1917-1918$

Historic Significance Category: $\bigotimes$ I or $\square$ II or $\square$ N/A

Historic Role(s): Constructed in 1917-1918 as part of Camp Upton for trench warfare training

- $\quad$ Determined to be eligible for listing on the National Register of Historic Places

- $\quad$ Associated with historic pattern of events - mobilization \& training of U.S. Army troop during WW I.

State of preservation allows for documentation of construction techniques and training methods considered very significant for both U.S. and international military history

- $\quad$ Two sections of trenches identified in mid-1970s were assigned site no. A10302.000474

Current Significant Feature(s): (Examples: exterior architecture; extant location; associated w/important personage; scientific achievement [e.g.; Nobel Prize]; unique facility; etc.)

-- Ten separate sites of trench networks äre extant. (Complexity of each network varies from a single trench to intricate patterns similar to Army field manual diagrams)

-- These sites are likely the only remaining examples of WWI trench-works in the U.S.

-- High degree of integrity with respect to location, design, materials and association - offers a rare opportunity to study this aspect of military history.

Plans for Bldg or Site:

- Maintain sites in current state with surrounding wooded buffers.

- Develop tour program for a select site(s), with interpretive signage.

Treatment and/or Mitigation Plans:

- Maintain site in its current state, and make available/accessible for cultural resource tours.

- Develop management plan to include periodic assessment.

- If development threatens a specific site-perform archeological survey of impacted area.

- Submit nomination documents to have trenches listed on National Register

Level A (achieved, in-progress, or relatively achievable)

- Survey and map trench networks - completed in 2002.

- Select specific site(s) (1 or 2) for supervised Cultural Resource tours. Tours can be initiated with sites in current state (e.g. accessibility improvements \& signage not immediately necessary).

- Develop specific management plan that includes periodic physical assessment, security, etc.

Level B (resource permitting)

- Improve accessibility 


\section{Appendix D}

\section{Cultural Resource Management Plan - Action Items}

\begin{tabular}{|c|c|c|c|}
\hline Item \# & Action Item & Priority & Status/Action Taken \\
\hline 1 & Perform archeological evaluation of 1850's house sites & A & Performed in 2004 \\
\hline 2 & $\begin{array}{l}\text { Following archeological evaluation, implement protection of } \\
\text { 1850's house site(s), as determined necessary }\end{array}$ & A & $\begin{array}{l}\text { Fencing erected \& signs } \\
\text { posted in } 2004\end{array}$ \\
\hline 3 & $\begin{array}{l}\text { Develop a communications plan associated with the CRMP } \\
\text { (working with CEGPA) }\end{array}$ & A & \\
\hline 4 & Develop a Cultural Resources Management subject area. & A & \\
\hline 5 & $\begin{array}{l}\text { Coordinate with Plant Engineering and Environmental Restoration } \\
\text { personnel to identify appropriate CR review flags/checks and } \\
\text { incorporate them into existing programs and procedures such as } \\
\text { the ESH-500 form, Digging Permit, maintenance management } \\
\text { system, etc }\end{array}$ & A & \\
\hline 6 & $\begin{array}{l}\text { Develop cultural resource training; target specific groups such as } \\
\text { Plant Engineering supervisors and engineers, security, fire, EM } \\
\text { engineers, work control planners, etc }\end{array}$ & A & \\
\hline 7 & $\begin{array}{l}\text { Complete BGRR mitigation actions identified in the MOU as } \\
\text { resources permit (prepare a Researchers Guide and a list of tools } \\
\text { and equipment needed for evaluation or curation }\end{array}$ & A & $\begin{array}{l}\text { Equipment artifacts } \\
\text { Identified - Jan } 2005 .\end{array}$ \\
\hline 8 & $\begin{array}{l}\text { Nomination trenches for listing on National Register of Historic } \\
\text { Places }\end{array}$ & $A$ & Nomination form initiated \\
\hline 9 & $\begin{array}{l}\text { Evaluate architectural features of Chemistry Building, Berkner } \\
\text { Hall, and other identified structures (Buildings } 701,703,801,750 \text {, } \\
120 \text {, etc.) as appropriate (Pending available funding) }\end{array}$ & $\mathrm{B}$ & Performed in 2004 \\
\hline 10 & $\begin{array}{l}\text { Have an assessment performed to evaluate BNL's scientifically } \\
\text { significant facilities (Pending available funding). }\end{array}$ & B & \\
\hline 11 & $\begin{array}{l}\text { Continue developing georeferenced aerial photos and GIS map } \\
\text { layers of pre-BNL photos and maps }\end{array}$ & B & \\
\hline 12 & Implement Historic Resource Identification Tag program & $\mathrm{B}$ & Procedure developed \\
\hline 13 & $\begin{array}{l}\text { Develop a cultural resource tour program, including talking-points } \\
\text { script and visuals }\end{array}$ & B & In progress \\
\hline 14 & Develop CR presentation and display materials & $\mathrm{B}$ & \\
\hline 15 & $\begin{array}{l}\text { Evaluate the appropriate means of establishing a } \\
\text { catalog/accession/labeling/storage system for CR material and } \\
\text { records recovered during formal surveys, old "finds" retained by } \\
\text { individuals, and new discoveries }\end{array}$ & B & \\
\hline 16 & $\begin{array}{l}\text { Evaluate the need to establish a contract or MOA with a qualified } \\
\text { institution for curation of material, periodic assessment of curation } \\
\text { methods at BNL, or the value in becoming a designated } \\
\text { repository }\end{array}$ & B & \\
\hline 17 & $\begin{array}{l}\text { Contact organizations currently possessing materials and records } \\
\text { identified in section } 3.5 .5 \text { for a complete accounting and copies of } \\
\text { records, requesting that items be returned to BNL/DOE as } \\
\text { determined appropriate }\end{array}$ & B & \\
\hline 18 & $\begin{array}{l}\text { Obtain official site number for WW I Camp Upton Features from } \\
\text { NYSHPO }\end{array}$ & B & \\
\hline 19 & Complete site forms for other BNL CR sites & $\mathrm{B}$ & \\
\hline 20 & Identify location and content of the oral histories & $\mathrm{B}$ & \\
\hline 21 & $\begin{array}{l}\text { Develop a formal Collections Management Policy to guide future } \\
\text { decisions on the collection including how and what the collection } \\
\text { will contain, processes for accepting itemed into the collection, } \\
\text { loans, deaccessioning, etc. }\end{array}$ & B & \\
\hline
\end{tabular}




\begin{tabular}{|c|c|c|c|}
\hline Item \# & Action Item & Priority & Status/Action Taken \\
\hline 22 & $\begin{array}{l}\text { Develop architectural mgmt plan(s) to identify specific features } \\
\text { and treatments for BGRR complex structures }\end{array}$ & $\mathrm{B}$ & $\begin{array}{l}\text { Evaluation performed in } \\
2004\end{array}$ \\
\hline 23 & $\begin{array}{l}\text { Develop a program for periodic environmental monitoring and } \\
\text { inspection of Camp Upton collection and other CR collections. }\end{array}$ & B & \\
\hline 24 & $\begin{array}{l}\text { Develop evaluation/protection/maintenance plans for the } \\
\text { scientifically significant equipment on display }\end{array}$ & B & \\
\hline 25 & $\begin{array}{l}\text { Increase interactions with local historical societies, and other } \\
\text { internal/external outreach opportunities; offering presentations on } \\
\text { BNL History and the BNL CRMP }\end{array}$ & B & $\begin{array}{l}\text { Refer to outreach section } \\
\text { of CRMP }\end{array}$ \\
\hline 26 & $\begin{array}{l}\text { Develop procedure(s) for periodic monitoring and inspection of } \\
\text { cultural resources to identify potential damage due to natural, } \\
\text { unauthorized or illegal actions }\end{array}$ & B & \\
\hline 27 & $\begin{array}{l}\text { Develop architectural management plans for Bldg. } 120 \text { and Bldg. } \\
30\end{array}$ & B & $\begin{array}{l}\text { Evaluation performed in } \\
2004\end{array}$ \\
\hline 28 & $\begin{array}{l}\text { Evaluate the potential effects of wildland fires on cultural resource } \\
\text { areas and develop appropriate documentation (Section 106, } \\
\text { Procedure(s), MOA, etc.) to address issues identified in DOE G } \\
\text { 450-1.4 Wildland Fire Management Program }\end{array}$ & B & \\
\hline 29 & Map (using GPS) old roads \& trails & $\mathrm{B}$ & Initiated in 2004 \\
\hline 30 & $\begin{array}{l}\text { Document history of old roads/trails \& incorporate in CRM } \\
\text { program }\end{array}$ & B & \\
\hline 31 & $\begin{array}{l}\text { Include planning of pre and post cultural resource surveys in } \\
\text { prescribed fire areas }\end{array}$ & $\mathrm{C}$ & $\begin{array}{l}\text { Incorporated in draft } \\
\text { NRMP }\end{array}$ \\
\hline 32 & Research histories of 1800 s house sites - Create reference files & C & \\
\hline 33 & $\begin{array}{l}\text { Confirm that Smithsonian Institute has a 'C' - Magnet(s) in their } \\
\text { collection }\end{array}$ & C & \\
\hline 34 & $\begin{array}{l}\text { Develop a bibliography/searchable database of current BNL } \\
\text { cultural resources related documents }\end{array}$ & $\mathrm{C}$ & \\
\hline 35 & Continue expansion of the CR website & C & $\begin{array}{l}\text { Website features } \\
\text { expanded in } 2004\end{array}$ \\
\hline 36 & $\begin{array}{l}\text { Incorporate site forms and numbering system into an ESH\&Q } \\
\operatorname{SOP}(\mathrm{s})\end{array}$ & $\mathrm{C}$ & \\
\hline 37 & $\begin{array}{l}\text { Identify location and content of the significant document related } \\
\text { resources }\end{array}$ & $\mathrm{C}$ & \\
\hline 38 & $\begin{array}{l}\text { Develop methods to identify document resources as historic or } \\
\text { supporting resources, verify/assign responsible } \\
\text { personnel/organizations/points of contact and assure proper } \\
\text { storage/archiving }\end{array}$ & $\mathrm{C}$ & \\
\hline 39 & Map newly identified WW I foundations using GPS & $\mathrm{C}$ & \\
\hline 40 & $\begin{array}{l}\text { Evaluate options related to improving fire code related issues and } \\
\text { fire detection/suppression systems for CU Collection }\end{array}$ & $\mathrm{C}$ & \\
\hline 41 & $\begin{array}{l}\text { Evaluate the potential for establishing a more permanent area for } \\
\text { rotating display themes of Camp Upton Collection items }\end{array}$ & $\mathrm{C}$ & $\begin{array}{l}\text { Camp Upton items } \\
\text { displayed in Berkner Hall }\end{array}$ \\
\hline 42 & $\begin{array}{l}\text { Develop procedures to address the following topics: Collection } \\
\text { item loan/use approval process (Based on } 36 \text { CFR Part } 79 \\
\text { Appendix C) }\end{array}$ & $\mathrm{C}$ & \\
\hline 43 & $\begin{array}{l}\text { Evaluate the need for and extent of intrusion detection/deterrent } \\
\text { system and consider tightening building access in the collection } \\
\text { storage area(s). }\end{array}$ & $\mathrm{C}$ & \\
\hline 44 & $\begin{array}{l}\text { Evaluate the possibility of incorporating the BNL Historian's role } \\
\text { as part of the CRM program }\end{array}$ & C & $\begin{array}{l}\text { CR Coordinator is the } \\
\text { Tech Rep for Historian's } \\
\text { contract w/ BNL } \\
\text { Developed Oral History } \\
\text { program description }\end{array}$ \\
\hline
\end{tabular}




\begin{tabular}{|c|c|c|c|}
\hline Item \# & Action Item & Priority & Status/Action Taken \\
\hline 45 & Develop list of key figures in BNL's scientific history for interview & C & \\
\hline 6 & $\begin{array}{l}\text { Develop procedure for triggering and conducting oral histories of } \\
\text { employees retiring with XX years of service }\end{array}$ & $\mathrm{C}$ & \\
\hline 47 & $\begin{array}{l}\text { Incorporate site forms and numbering system into an ESH\&Q } \\
\text { SOP(s). }\end{array}$ & $\mathrm{C}$ & \\
\hline 48 & Develop a monitoring plan for the WW I trenches & $\mathrm{D}$ & \\
\hline 49 & $\begin{array}{l}\text { Formalize CU Collection catalog and storage system by } \\
\text { incorporating directly into a BNL procedure, or by reference }\end{array}$ & $\mathrm{D}$ & \\
\hline 50 & $\begin{array}{l}\text { Develop a system for acquiring, storing and accessing reports, } \\
\text { documents and other written materials dealing with BNL cultural } \\
\text { resources }\end{array}$ & $\mathrm{D}$ & \\
\hline 51 & $\begin{array}{l}\text { Evaluate the potential to have assessments performed by } \\
\text { qualified outside organizations via contract or cooperative } \\
\text { agreement }\end{array}$ & $\mathrm{D}$ & \\
\hline 52 & $\begin{array}{l}\text { Develop brief descriptions of the additional CR assets listed in } \\
\text { Attachment } 7 \text { and add to CRMP }\end{array}$ & $\mathrm{D}$ & \\
\hline 53 & $\begin{array}{l}\text { Develop Researcher's Guide to AGS Complex Facilities and } \\
\text { Scientific Research }\end{array}$ & $\mathrm{D}$ & \\
\hline 54 & AGS facility records search and archive & $\mathrm{D}$ & \\
\hline 55 & $\begin{array}{l}\text { Perform actions identified on BMRR CR management strategy } \\
\text { form }\end{array}$ & $D$ & \\
\hline 56 & $\begin{array}{l}\text { Perform actions identified on HFBR CR management strategy } \\
\text { form }\end{array}$ & $D$ & \\
\hline 57 & $\begin{array}{l}\text { Perform actions identified on Medical Center/Program CR } \\
\text { management strategy form }\end{array}$ & $D$ & \\
\hline 58 & Consider establishing a CR Advisory Group and/or Interest Group & $\mathrm{D}$ & \\
\hline 59 & $\begin{array}{l}\text { Develop map layer identifying location of equipment related to } \\
\text { programs/facilities of recent scientific significance }\end{array}$ & $\mathrm{D}$ & \\
\hline
\end{tabular}

